Gláucia Marconato

\title{
Análise Cladística de Charaxinae Guenée (Lepidoptera, Nymphalidae)
}
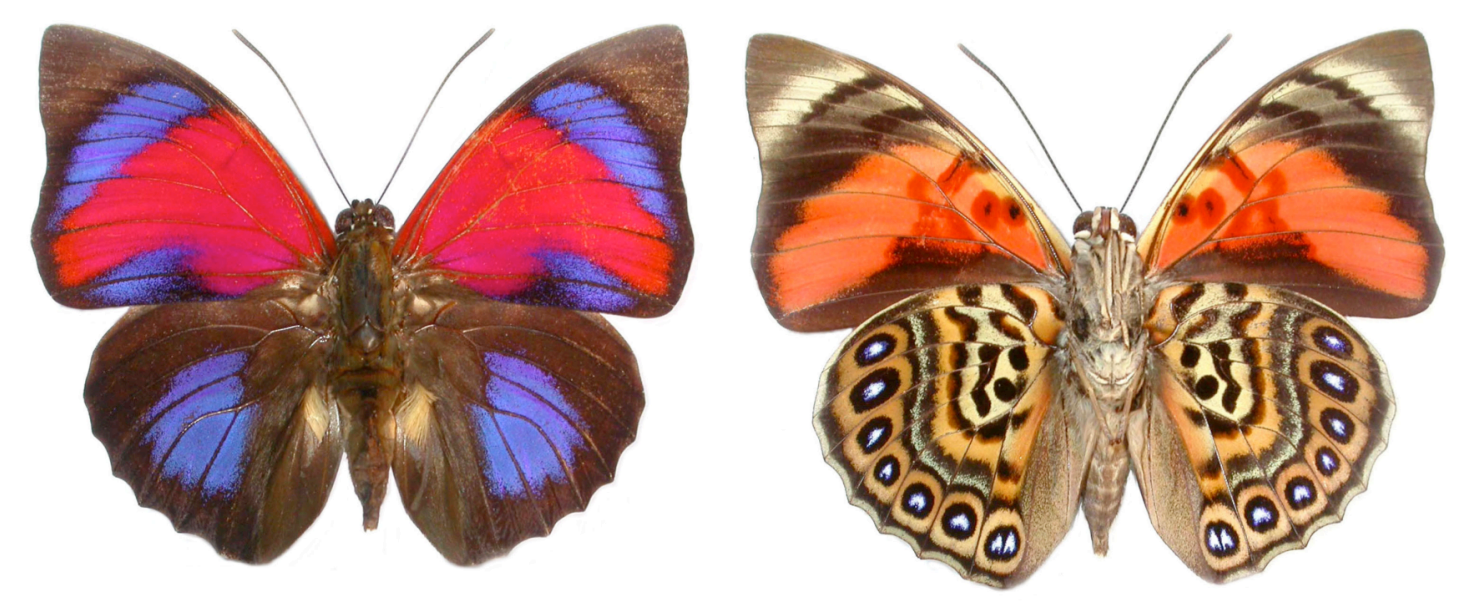

São Paulo

2008 


\section{Gláucia Marconato}

\section{Análise Cladística de Charaxinae Guenée (Lepidoptera, Nymphalidae)}

Tese apresentada ao Instituto de Biociências da Universidade de São Paulo, para a obtenção de Título de Doutor em Ciências, na Área de Zoologia.

Orientador: Dr. Marcelo Duarte

São Paulo

2008 


\section{Ficha Catalográfica}

Marconato, Gláucia

Análise Cladística de Charaxinae

Guenée (Lepidoptera, Nymphalidae)

xvii +180 páginas

Tese (Doutorado) - Instituto de Biociências da Universidade de São Paulo. Departamento de Zoologia.

1. Charaxinae 2. Filogenia 3. Sistemática de Lepidoptera I. Universidade de São Paulo. Instituto de Biociências. Departamento de Zoologia.

\section{Comissão Julgadora:}

Prof(a). Dr(a). $\quad$ Prof(a). Dr(a).

$\operatorname{Prof}(\mathrm{a}) . \operatorname{Dr}(\mathrm{a})$.

$\operatorname{Prof}(\mathrm{a}) . \operatorname{Dr}(\mathrm{a})$.

Prof. Dr. Marcelo Duarte

Orientador 
Aos meus pais, que são o meu começo e para quem dedico este fim, e tantos outros fins que ainda virão com algum mérito, que eles possam saber que assim como eu sempre fui parte deles, tudo o que eu realizar será também parte da obra deles. 
"L'évolution, quelle que soit sa marche, ne peut s'arrêter. La taxonomie devra suivre au mieux cette évolution, en fonction des progrès des systématiciens, qui n'oublieront jamais que lês lois de la nature ne peuvent être expliquées et classées par

les méthodes cartésiennes strictes. Elles ne sont ni simples, ni figées. Elles varient en fonction d'éléments divers et changeants, dans l'espace et dans le temps."

Jacques Plantrou, 1983 "Systematique biogeographie et évolution des Charaxe $s$ africans" (Lepidoptera, Nymphalidae)

"Dediquei especial atenção às borboletas por ter verificado que elas se prestam - mais do que qualquer outro grupo do reino animal ou vegetal - ao estudo das modificações que todas as espécies sofrem quando se alteram as condições de vida locais. [...] Podemos dizer, por conseguinte, que nessas membranas hipertrofiadas a Natureza escreve, como se numa lousa, a história das mutações da espécie, tal a precisão com que ficam registradas nelas as mudanças. Além do mais, uma mesma combinação de cores nas asas geralmente indica, com bastante regularidade, o grau de consangüinidade das espécies. Uma vez que as leis da Natureza devem ser as mesmas para todos os seres, as conclusões fornecidas por esse grupo de insetos hão de poder ser aplicadas a todo o mundo orgânico; por conseguinte, o estudo das borboletas - seres escolhidos para tipificar a inconstância e a frivolidade - ao invés de ser desprezado, ainda há de ser um dia considerado um dos mais importantes ramos da ciência biológica."

Henry Walter Bates, 1863 "Um Naturalista no Rio Amazonas" (Trad. Regina Regis Junqueira) 


\section{AGRADECIMENTOS}

Esta tese, e o desenvolvimento de seu projeto, somente puderam ser realizados com o apoio de muitas pessoas e instituições, às quais sou eternamente grata.

Ao Dr. Marcelo Duarte da Silva, pela orientação, infra-estrutura concedida e liberdade de trabalho. À Dra. Sônia Casari, pela oportunidade no ínício do doutorado, incentivo e compreensão.

Ao CNPq, pela concessão da bolsa de doutorado, e à CAPES pela bolsa de doutorado-sanduíche.

Ao Programa de Pós-graduação em Zoologia do IB/USP e ao Museu de Zoologia, onde realizei a maior parte do meu trabalho; a todos os alunos, funcionários e quadro docente.

Ao McGuire Center for Lepidoptera Research and Biodiversity e ao Florida Museum of Natural History por me receberem para o estágio de doutorado no exterior. Especialmente ao Dr. Keith Willmott que me orientou durante o estágio de doutorado sanduíche e me apoiou a levar adiante o projeto e a carreira; enfim, um grande mestre cujo exemplo de competência e humildade será sempre referência para minha vida e especialmente para minha carreira. Agradeço também ao Dr. Andrei Sourakov que durante o estágio tornou-se um segundo orientador, a quem eu recorria em qualquer emergência e com quem tive boas discussões sobre o meu trabalho, alguém com uma personalidade ímpar, que tinha o prazer de testar constantemente a minha atenção, inteligência e autocontrole. Espero não tê-lo decepcionado muito!

À Smithsonian Institution, particularmente aos Drs. Robert Robbins e Brian Harris, sempre muito atenciosos, pessoas realmente encantadoras. Ao American Museum of Natural History, particularmente aos Drs. David Grimaldi, Tam Nguyen, Suzanne Green e Jim Miller que tornaram a minha visita à coleção de Lepidoptera desse museu possível.

Ao Dr. Jorge Bizarro, pela inestimável colaboração com os dados de estágios imaturos. Aos Drs. Olaf Mielke e Mirna Casagrande por permitirem a minha visita à coleção do Departamento de Zoologia da UFPR. Agradeço também ao Dr. André V. L. Freitas, pela colaboração com dados de imaturos, e pelos conselhos valiosos. Ao Dr. Miguel Ângelo Monné Barrios do Museu Nacional do Rio de Janeiro e Alexandre Soares por permitirem e auxiliarem o estudo dos Charaxinae da coleção. Aos Drs. Luis Miguel 
Constantino e Julián Salazar pela contribuição, compartilhamento de informações, discussão e estímulo neste final do projeto.

A toda a minha família, pelo apoio e incentivo constantes, especialmente a meus pais Maria e Abílio (meu norte e meu sul), e meus irmãos, Cássia e Abílio Jr (meu leste e meu oeste), minha avó Ernesta, e às minhas borboletinhas prediletas, as minhas sobrinhas, Letícia e Lívia. À Gisele e Magda, de quem sempre recebi muito carinho sob a forma de uma sólida amizade, estas duas que circunstancialmente estiveram um pouco fora do contexto deste doutorado, mas nunca deixaram de me apoiar, principalmente no ínicio, quando as pernas fraquejavam em buscar nova vida em São Paulo.

Aos meus amigos aqui conquistados, pessoas adoráveis, invejáveis e honoráveis que fizeram parte da minha vida e do meu doutorado nestes quatro anos: Simone, Janice, Ilana, Rodrigo, Antônio, Liana, Carolina, Rogério, Bodo, Flávia, Eduardo, Peterson, Fernando, Guilherme, Maurício, Thiago e Gilcélia. Aos amigos e colegas de laboratório: Thaís, Maria Helena, Tábata, Luciane, Lívia, Simeão, Leonardo, Eduardo e Renato (meu presente de fim de tese), que sempre tornaram o dia-a-dia da rotina de laboratório mais leve e divertido. Agradeço especialmente à Simone, Rodrigo e Antônio pela revisão do texto, e Ilana pelas sugestões, discussão, ensinamentos cladísticos e muito carinho feito amizade. À Janice, minha consultora $24 \mathrm{~h}$ de assuntos diversos sobre tese, filogenia, ética, comportamento, atualidades e etc, uma grande amiga, a melhor sócia de apartamento que eu poderia ter garimpado nesta vida. À Tábata e Renato que me ajudaram na confecção de tabelas e revisão das referêcias na hora do desespero da ampulheta.

À Maria, que desde o primeiro dia do meu doutorado, até o último, esteve sempre presente, tornou-se uma amiga zelosa, companhia alegre dos memoráveis horários de almoço.

À Dra. Francisca do Val, que me salvou de muitos apuros, uma amiga, que sempre me fez dar boas risadas e sempre me colocou perto do adorável mundo da Arte.

À Dione, já não fosse pelo nome, seria ela mesma uma borboleta entre os livros, e também a todas as bibliotecárias do Museu, pela inestimável ajuda com as referências.

À Alzira, Maria José, Carlos, Ana, Joel, Benê e Ismael, pela amizade e apoio técnico. 
Aos meus amigos "de balada" do início do doutorado que tornaram a minha adaptação à vida em São Paulo e no Museu de Zoologia muito mais fácil: Lyncoln, Elias e Júlio.

Às pessoas com quem convivi no período de estágio nos Estados Unidos, Kole, Andrew e George. E à família Sourakov que me acolheu em Gainesville: Andrei, Sasha, Allie e Nika; e aos cães Sourakov, Pitzakay e Bijou, que me hospedaram em sua casa canina, foram companheiros fiéis e inseparáveis. Bijou, e Nika, meus melhores amigos em solo americano, serão sempre lembrados pelos momentos de pura diversão infantocanina.

A Vadim Kroutov, pela intensidade, elegância, e gentileza a mim dedicadas no tempo em que convivemos nos EUA, por acreditar em minhas potencialidades, quando eu mesma duvidava; obrigada pelo apoio, incentivo e conselhos muito acertados mesmo à distância.

Por fim, agradeço a todos, que participaram da minha vida positivamente, alegremente, que suavizaram os dias de aflição em alegres encontros nesses quatro anos. 


\section{RESUMO}

Os Charaxinae, subfamília de borboletas pertencente à família Nymphalidae, são objeto de estudo filogenético nesta tese. Com 20 gêneros válidos e cerca de 330 espécies distribuídos em 6 tribos, a subfamília tem distribuição panbiogeográfica e circuntropical. Neste estudo, foram selecionadas 70 espécies representando todos os gêneros como grupo interno incluído: Coenophlebia archidona, Consul electra, Consul fabius, Hypna clytemnestra, Polygrapha cyanea, Polygrapha suprema, Polygrapha tyrianthina, Polygrapha xenocrates, Siderone galanthis, Zaretis callidryas, Zaretis isidora, Anaea troglodyta, Fountainea nessus, Fountainea ryphea, Memphis appias, Memphis glauce, Memphis grandis, Memphis hirta, Memphis leonida, Memphis moruus, Memphis philumena, Memphis pithyusa, Memphis polycarmes, Memphis polyxo, Memphis verticordia, Anaeomorpha splendida, Noreppa chromus, Archaeoprepona amphimacus, Archaeoprepona chalciope, Archaeoprepona demophon, Archaeoprepona demophoon, Archaeoprepona licomedes, Prepona praeneste, Prepona laertes, Prepona pheridamas, Prepona pylene, Agrias amydon, Agrias claudina, Euxanthe eurinome, Euxanthe trajanus, Palla decius, Polyura athamas, Polyura delphis, Polyura gamma, Polyura pyrrhus, Polyura jalysus, Polyura schreiber, Charaxes varanes, Charaxes candiope, Charaxes cynthia, Charaxes lucretius, Charaxes jasius, Charaxes tiridates, Charaxes hadrianus, Charaxes nobilis, Charaxes zoolina, Charaxes eupale, Charaxes jahlusa, Charaxes pleione, Charaxes zingha, Charaxes etesipe, Charaxes etheocles, Charaxes nichetes, Charaxes laodice, Charaxes solon, Charaxes latona, Charaxes eurialus, Agatasa calydonia, Prothoe australis e Prothoe franck. Representando o grupo externo foram incluídas três espécies pertencentes a três sufamílias de Nymphalidae: Apatura iris (Apaturinae), Calinaga buddha (Calinaginae) e Amphidecta reynoldsi (Morphinae). Os 
objetivos deste trabalho são testar a hipótese de monofiletismo da subfamília e apresentar uma hipótese de parentesco para os níveis taxonômicos inferiores à subfamília. Os dados que geraram a matriz de caracteres são baseados em morfologia de adultos e estágios imaturos (quando disponíveis). A metodologia seguiu os princípios da parcimônia com polarização dos caracteres baseada no grupo externo. O monofiletismo da subfamília está corroborado na árvore de consenso por cinco sinapomorfias. Todas as tribos, exceto Preponini, são monofiléticas. Neste caso, Anaeomorpha splendida está mais próxima aos Anaeini, uma questão que necessitaria ainda mais investigações. $\mathrm{O}$ agrupamento de Prothoini com os Charaxinae neotropicais é outro resultado que emergiu da análise e muito provavelmente seu posicionamento é basal em relação ao grupo neotropical (Anaeini + Preponini) o que é indicado pela análise com pesagem sucessiva. Alguns gêneros resultaram como polifiléticos como é o caso de Charaxes, Archaeoprepona e Prepona e necessitam revisão taxonômica com base nesta filogenia. Assim, essa análise filogenética deve gerar futuramente revisões nas quais: Charaxes deve incluir as espécies do gênero Polyura, Archaeoprepona deve incluir o gênero monotípico Noreppa e Prepona deve incluir Agrias. 


\begin{abstract}
Charaxinae, a butterfly subfamily which belongs to the Nymphalidae, is the subject of this phylogenetic study. With 20 genera and about 330 species in 6 tribes, this subfamily is scattered all around the tropics of the world and is present in all the biogeographic regions. In this work, 70 species of all genera of the Charaxinae subfamily were chosen to represent the in-group: Coenophlebia archidona, Consul Electra, Consul fabius, Hypna clytemnestra, Polygrapha cyanea, Polygrapha suprema, Polygrapha tyrianthina, Polygrapha xenocrates, Siderone galanthis, Zaretis callidryas, Zaretis isidora, Anaea troglodyta, Fountainea nessus, Fountainea ryphea, Memphis appias, Memphis glauce, Memphis grandis, Memphis hirta, Memphis leonida, Memphis moruus, Memphis philumena, Memphis pithyusa, Memphis polycarmes, Memphis polyxo, Memphis verticordia, Anaeomorpha splendida, Noreppa chromus, Archaeoprepona amphimacus, Archaeoprepona chalciope, Archaeoprepona demophon, Archaeoprepona demophoon, Archaeoprepona licomedes, Prepona praeneste, Prepona laertes, Prepona pheridamas, Prepona pylene, Agrias amydon, Agrias claudina, Euxanthe eurinome, Euxanthe trajanus, Palla decius, Polyura athamas, Polyura delphis, Polyura gamma, Polyura pyrrhus, Polyura jalysus, Polyura schreiber, Charaxes varanes, Charaxes candiope, Charaxes cynthia, Charaxes lucretius, Charaxes jasius, Charaxes tiridates, Charaxes hadrianus, Charaxes nobilis, Charaxes zoolina, Charaxes eupale, Charaxes jahlusa, Charaxes pleione, Charaxes zingha, Charaxes etesipe, Charaxes etheocles, Charaxes nichetes, Charaxes laodice, Charaxes solon, Charaxes latona, Charaxes eurialus, Agatasa calydonia, Prothoe australis and Prothoe franck. The out-group consisted of three species from different subfamilies of Nymphalidae: Apatura iris (Apaturinae), Calinaga buddha (Calinaginae) and Amphidecta reynoldsi (Morphinae). The main goal of this work is to test
\end{abstract}


the monophyly hypothesis of the subfamily and to present a kinship hypothesis for the lower taxonomic levels. The matrix is composed with morphological data of adult and immature stages (when available). The methodology follows the Principles of Parsimony and the character polarization is based on out-group comparison. The monophyly of the subfamily was corroborated in the Consensus tree by four synapomorphies. All tribes are monophyletic, except for Preponini. In this case, Anaeomorpha splendida is placed with the Anaeini species, an issue that requires more scrutiny. The grouping of Prothoini and the Neotropical Charaxinae is another result derived from this analysis. It is probable that this grouping's place in the cladogram is a basal one relative to the Neotropical clade (Anaeini + Preponini). This supposition is supported by successive weighting analisys. Some genera proved to be polyphyletic, and Charaxes, Archaeoprepona and Prepona need taxonomic revision based on this phylogeny. Thus, Charaxes should include the Polyura species; Archaeoprepona should include the monotipic genus Noreppa; and Prepona should include Agrias in future taxonomic work. 


\section{ÍNDICE}

AGRADECIMENTOS

RESUMO

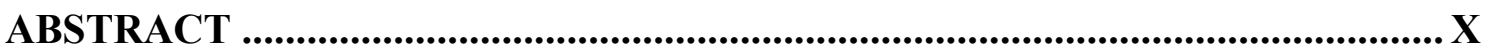

ÍNDICE

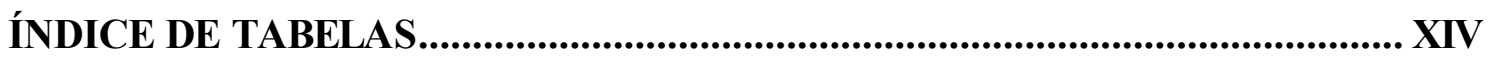

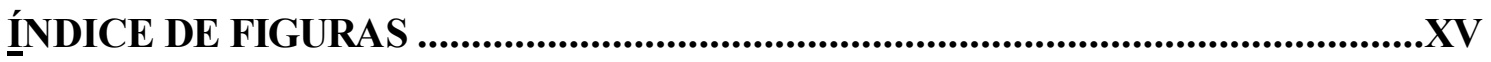

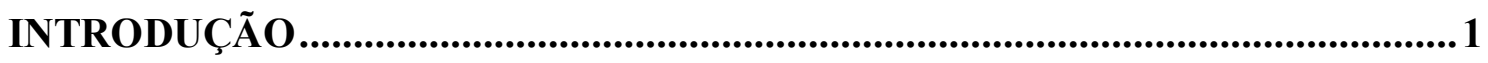

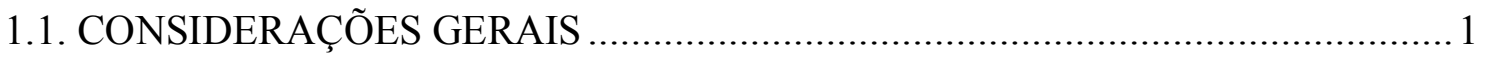

1.2. ASPECTOS BIOLÓGICOS DE CHARAXINAE .................................................

1.3. ASPECTOS SISTEMÁTICOS E BIOGEOGRÁFICOS .........................................

1.4. ESTADO DA ARTE E HISTÓRICO SISTEMÁTICO DE CHARAXINAE ........7

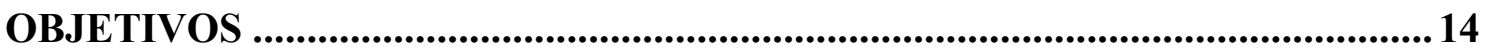

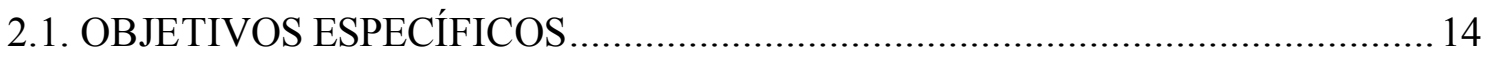

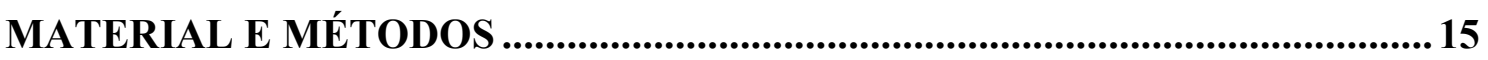

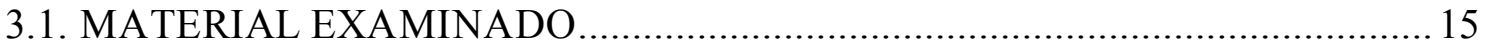

3.2. TERMINOLOGIA E PROCEDIMENTOS DE DISSECÇÃO...............................16

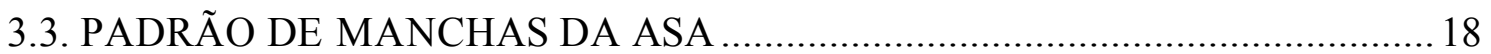

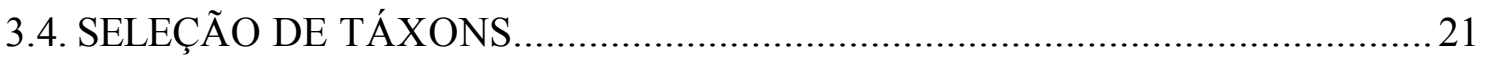

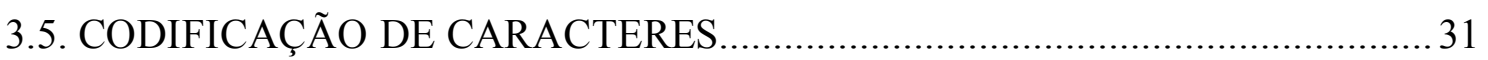

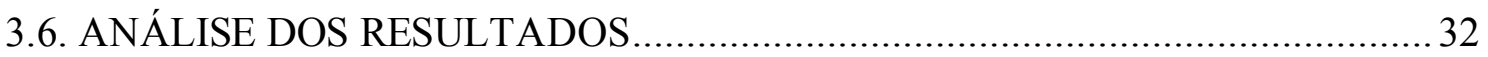

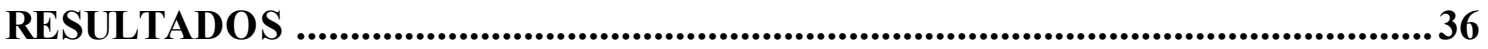




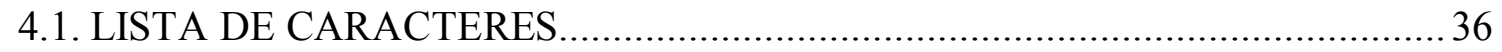

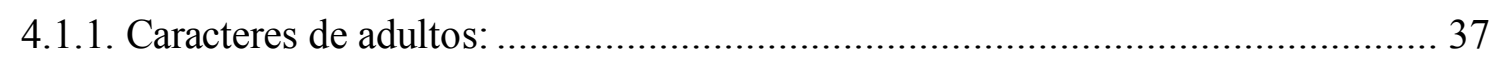

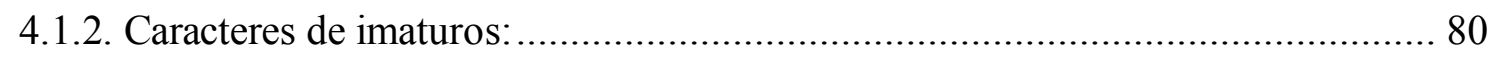

4.2. ANÁLISE E CLADOGRAMAS OBTIDOS …................................................. 102

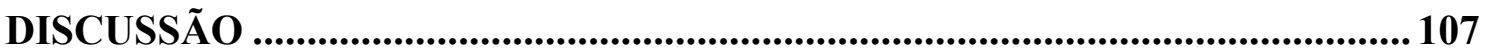

5.1. O MONOFILETISMO DE CHARAXINAE E SEU POSICIONAMENTO EM

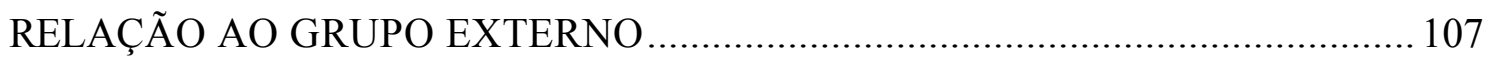

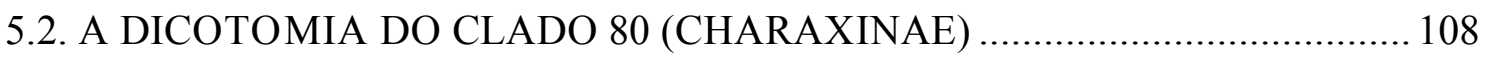

5.3. O CLADO 117 (PALLINI + (EUXANTHINI + CHARAXINI)) $\ldots \ldots \ldots \ldots \ldots \ldots \ldots \ldots . . . . . .110$

5.4. O CLADO 79 (PROTHOINI + (PREPONINI + ANAEINI)) .......................... 111

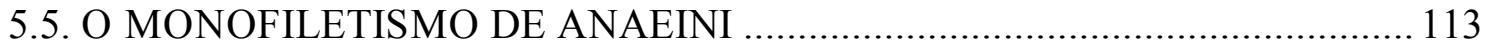

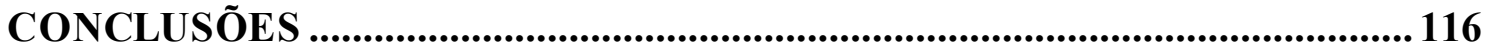

REFERÊNCIAS BIBLIOGRÁFICAS ..................................................................117

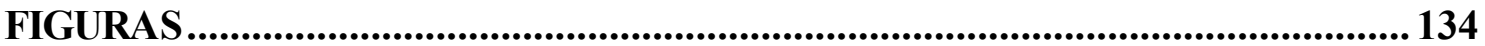

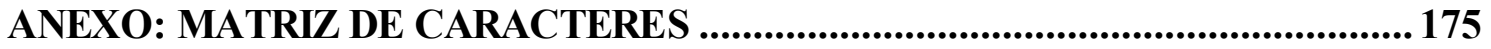




\section{ÍNDICE DE TABELAS}

Tabela I. Classificação atual de Charaxinae, espécies-tipo e número de espécies de cada gênero. 6

Tabela II. Lista dos táxons terminais e da procedência dos exemplares dissecados para estudo de genitália. 


\section{ÍNDICE DE FIGURAS}

Figura 1. Distribuição geográfica das tribos de Charaxinae.

Figura 2. Nomenclatura das estruturas de asa, genitália feminina e masculina. a. Charaxes jasius, b. Siderone galanthis, c. Charaxes varanes.

Figura 3. Modelo básico ninfalídeo contendo as letras que representam os elementos do padrão de asa. Modificado de NiJHOUT (1991).

Figura 4. Cladograma de consenso das hipóteses mais parcimoniosas para a subfamília Charaxinae com os valores de Bremer assinaladas para cada clado. 104

Figura 5. Cladograma resultante da ponderação sucessiva dos fits 5, 10, 15, 20, 25 e 30 .

Os números são identificadores de cada clado. IC: 0,319, IR: 0,785. 105

Figura 6: Transições dos estados no cladograma resultante da ponderação sucessiva dos fits $5,10,15,20,25$ e 30 . Os círculos escuros mostram as sinapomorfias exclusivas e os círculos abertos, as sinapomorfias homoplásticas. Os números acima indicam o caráter e abaixo o estado para qual a transição ocorreu. IC: 0,319, IR: 0,785. 106

Figura 7. Cabeça. Vista lateral. a. Agrias amydon, b. Noreppa chromus, c. Siderone galanthis, d. Memphis glauce. Escala $=1 \mathrm{~mm}$.

Figura 8. Cabeça. Vista lateral. a. Charaxes jasius,. b. Polygrapha cyanea. Vista frontal: c. Zaretis isidora, d. Memphis verticordia. Escala $=1 \mathrm{~mm}$. 136

Figura 9. Venação das asas. a. Archaeoprepona demophon, b. Prepona laertes, c. Agrias claudina, d. Anaeomorpha splendida. 137

Figura 10. Venação das asas. a. Coenophlebia archidona, b. Hypna clytemnestra. c. Zaretis isidora, d Siderone galanthis. 138

Figura 11. Venação das asas: a. Consul fabius, b. Polygrapha cyanea, c. Fountainea ryphea, d. Anaea troglodyta. 
Figura 12. Venação das asas, a. Charaxes jasius, b. Euxanthe eurinome, c. C. pleione, d. Prothoe franck, e. Calinaga buddha. 140

Figura 13. Venação das asas, a. Memphis hirta, b. M. philumena (modificado de Comstock, 1961). c, d. Costa serrilhada de Charaxes tiridates. c. vista ventral, d.vista dorsal. Escala $=0,5 \mathrm{~mm}$.

Figura 14. Genitália masculina. Vista lateral, a. Prothoe franck. b. Agatasa calydonia. Escala $=1 \mathrm{~mm}$ 142

Figura 15. Genitália masculina. Vista lateral, a. Archaeoprepona demophoon, c. A. chalciope. Vista dorsal, b. Archaeoprepona demophoon. Escala $=1 \mathrm{~mm}$ 143

Figura 16. Genitália masculina. Vista lateral. a. Archaeoprepona amphimacus, b. A. licomedes, c. Noreppa chromus. Escala $=1 \mathrm{~mm}$. 144

Figura 17. Genitália masculina. Vista lateral, a. Agrias claudina, b. Prepona pylene, c. P. pheridamas. Escala $=1 \mathrm{~mm}$. 145

Figura 18. Genitália masculina. Vista lateral, a. Coenophlebia archidona, b. Hypna clytemnestra, c. Consul fabius. Escala $=1 \mathrm{~mm}$. 146

Figura 19. Genitália masculina. Vista lateral, a. Siderone galanthis, b. Zaretis callidryas, Vista dorsal c. Zaretis callidryas. Escala $=1 \mathrm{~mm}$. 147

Figura 20. Genitália masculina. Vista lateral, a. Zaretis isidora, b. Polygrapha suprema. b. P. xenocrates. Escala $=1 \mathrm{~mm}$ 148

Figura 21. Genitália masculina. Vista lateral, a. Fountainea nessus, b. F. ryphea. c. Memphis verticordia. Escala $=1 \mathrm{~mm}$

Figura 22. Genitália masculina. Vista lateral. a. Memphis glauce, b. M. grandis, c. M. polyxo. Escala $=1 \mathrm{~mm}$. 150

Figura 23. Genitália masculina. Vista lateral. a. Memphis philumena, b. M. polycarmes, c. Palla decius. Vista dorsal. Palla decius. Escala $=1 \mathrm{~mm}$. 151 
Figura 24. Genitália masculina. Vista lateral, a. Euxanthe eurinome, b. Euxanthe trajanus, c. Charaxes varanes, Escala $=1 \mathrm{~mm}$. 152

Figura 25. Genitália masculina. Vista lateral, a. C. candiope, b. C. cynthia . Escala $=1 \mathrm{~mm}$.

Figura 26. Genitália masculina. Vista lateral, a. Charaxes hadrianus, b. C. laodice. Escala $=1 \mathrm{~mm}$. 154

Figura 27. Genitália masculina. Vista lateral. A. C. lucretius, b. C. nichetes. Escala $=1 \mathrm{~mm}$. 155

Figura 28. Genitália masculina. Vista lateral. a. Charaxes. nobilis, b. Charaxes zoolina. Escala $=1 \mathrm{~mm}$ 156

Figura 29. Genitália masculina. Vista lateral. a. C. etesipe, b. C. etheocles. Escala $=1 \mathrm{~mm}$.

Figura 30. Genitália masculina. Vista lateral. a. C. eupale, b. C. pleione.Escala $=1 \mathrm{~mm} . .158$

Figura 31. Genitália masculina. Vista lateral. C. zingha. Escala $=1 \mathrm{~mm}$.

Figura 32. Genitália masculina. Vista lateral. a. C. jasius, b. Polyura delphis. Escala = $1 \mathrm{~mm}$. 160

Figura 33. Genitália masculina. Vista lateral. a. Polyura schreiber, b. P. pyrrhus, Escala = $1 \mathrm{~mm}$. 161

Figura 34. Genitália feminina. Vista ventral. a. Archaeoprepona amphimacus, b. Prepona pylene, d. Polygrapha xenocrates. Vista lateral. c. Prepona laertes. Escala $=1 \mathrm{~mm}$. 162

Figura 35. Genitália feminina. Vista ventral. a. Siderone galanthis, b. Fountainea nessus, E. Memphis leonida, Vista lateral. B. Siderone galanthis. Escala $=1 \mathrm{~mm}$. 163

Figura 36. Genitália feminina. Vista ventral. a. M. philumena, b. M. pithyusa, c. Charaxes varanes, d. C. lucretius. Escala $=1 \mathrm{~mm}$. 164 
Figura 37. a. Androcônia em Agrias claudina, b. Cabeça de Agrias claudina. Detalhe do abdome em vista lateral: c. Archaeoprepona demophon, d. Prepona praeneste. Vista ventral: e.Prepona pylene, f. Noreppa chromus. 165

Figura 38. Vista ventral: a. Agrias claudina . b. Archaeoprepona demophon, b. Polygrapha cyanea c. Charaxes solon, d. Memphis grandis, e. detalhe da asa posterior de $M$. pithyusa, f. Detalhe da genitália feminina de Polygrapha cyanea em vista lateral...166

Figura 39. a. Detalhe da genitália masculina de Archaeoprepona demophon em vista dorsal, Detalhe da genitália feminina b. Palla decius em vista látero-frontal, c. Charaxes nobilis d. C. tiridates. e. Ovo. Archaeoprepona chalciope (foto: A.V. L. Freitas). f. Charaxes jasius (extraído de Woodhall, 2008). 167

Figura 40. Larva de quinto ínstar. a. A. demophon. b. A. demophoon (foto: D. H. Janzen). c. A. amphimacus UI (foto: G. B. Small), d. A. chalciope (foto: A.V.L. Freitas), e. Agrias amydon, (foto: D. H. Janzen), f. Prepona laertes, (foto: D. H. Janzen), g. Siderone galanthis (foto: G. B. Small), h. Zaretis itys. 168

Figura 41. Larva de último ínstar. a. Hypna clytemnestra (foto: G. B. Small), b Consul fabius (foto: A.V. L. Freitas), c. Fountainea ryphea (G. B. Small), d. M. moruus (A.V. L. Freitas), e,f. Memphis pithyusa (foto: D. H. Janzen), e. vista dorsal; f. Vista frontal, g. Abrigo da larva de Memphis moruus (foto: D. H. Janzen), h. Larva de ínstar inicial de A. demophon no suporte de excrementos (foto: D. H. Janzen), i. Larva de Noreppa chromus (foto: L. M. Constantino). 169

Figura 42. Pupas de Charaxinae. a. Archaeoprepona amphimacus (foto: G. B. Small), b Hypna clytemnestra (foto: A.V. L. Freitas), c. Zaretis isdora (foto: D. H. Janzen), d. Siderone galanthis (foto: G. B. Small), e. Consul electra (foto: D. H. Janzen), f. Consul fabius (foto: A.V. L. Freitas), g. Anaea troglodyta (foto: D. H. Janzen), h. Memphis pithyusa (foto: G. B. Small), i. M. moruus (foto: D. H. Janzen)..... 170 
Figura 43. Larvas e pupas de Charaxes: a. grupo varanes, b. grupo candiope, c, d. grupo cynthia, e, f. grupo lucretius, g, h. grupo jasius. (retirado de HENNING, 1988)..... 171

Figura 44. Larvas e pupas de Charaxes: a, b. grupo tiridates, c. grupo etesipe, d. grupo hadrianus, e. grupo jahlusa, f. grupo eupale g, h. grupo etheocles. (retirado de HENNING, 1988).

Figura 45. Larvas e pupas de Charaxes: a, b, c. grupo etheocles, d. grupo zoolina, e. grupo pleione, f. grupo nichetes. (retirado de HeNNING, 1988). 173

Figura 46. Larvas e pupas de de Palla ussheri. a, b. último ínstar; c, d. cápsula cefálica; e, f. pupa. (retirado de HENNING, 1988). 


\section{INTRODUÇÃO}

\subsection{CONSIDERAÇÕES GERAIS}

A ordem Lepidoptera forma a maior linhagem de organismos fitófagos terrestres, diferindo de seu grupo-irmão, Trichoptera, cujas larvas são aquáticas (GRIMALDI \& Engel, 2005). Além disso, os lepidópteros diferem dos tricópteros por possuírem cerdas escamiformes nas asas ao invés de cerdas piliformes. A proximidade filogenética de ambos é inegável e juntos constituem o grupo Amphiesmenoptera cujo ancestral comum é considerado um membro da família Necrotauliidae (KRISTENSEN, 1997; WheEler et al., 2001, GRIMALDI \& ENGEL, op. cit.).

Ainda que a referida família tenha seus primeiros registros no Triássico, estima-se que a ordem Lepidoptera tenha divergido deste ancestral comum apenas no início do Jurássico. Os registros fósseis de Lepidoptera são poucos e, em geral, encontram-se mal preservados devido à fragilidade destes organismos. Os melhores registros para a ordem são encontrados em âmbar e em minas de folhas fossilizadas. Estes datam do Cretáceo e início do Terciário, o que indica que este foi o período de maior diversificação da ordem, que coincide com o período de diversificação das angiospermas (as suas plantashospedeiras). Assim, Lepidoptera parece ser uma das ordens a irradiar mais recentemente entre os insetos (Kristensen, 1997; Grimaldi \& EnGEL, 2005). Dentro desse grupo, os Papilionoidea foram os últimos a divergirem (Paleoceno), sendo que a irradiação das famílias e subfamílias é ainda mais recente.

A ordem Lepidoptera, um dos maiores grupos de insetos do mundo, correspondendo a 16\% da fauna de Hexapoda, é representada pelas borboletas e mariposas. 
KRISTENSEN et al. (2007) mencionaram aproximadamente 160.000 espécies descritas para a fauna mundial. Entretanto, estima-se que este número tenha um acréscimo significativo com a soma de resultados de futuros trabalhos taxonômicos e de inventariamento faunístico. Seu papel ecológico é reconhecido como de grande importância, seja na fase de imago ou de estágios imaturos, por participarem de um conjunto de relações tri-tróficas nos ecossistemas, onde desempenham um caráter de interface entre o primeiro (produtores) e o terceiro nível trófico (parasitóides e predadores), incorrendo em sofisticadas relações de adaptação e coevolução relacionadas às estratégias de ataque e defesa. Sendo assim, borboletas e mariposas são organismos importantes na avaliação e monitoramento ambiental, e seu uso como bioindicadores tem sido intensificado nos últimos anos (veja Brown, 1991; Erhardt \& ThOMAs, 1991; Brown, 1996; Brown, 1997; Thomas et al., 1998; Brown \& Freitas, 2000; Brown, 2001; Brown \& Freitas, 2002).

As borboletas (sensu ACKERY et al., 1998) incluem as superfamílias Hedyloidea, Hesperioidea e Papilionoidea. Esta última soma 6\% da ordem, ou seja, cerca de 14.500 espécies válidas. A família Nymphalidae, à qual pertence a subfamília Charaxinae, com 7.222 espécies (HEPPNER, 1991), ocorre em todas as regiões biogeográficas do mundo e é a mais diversificada e rica das famílias de Papilionoidea. Borboletas muito coloridas, os ninfalídeos estão distribuídos em 12 subfamílias: Libytheinae, Danainae, Ithomiinae, Morphinae, Satyrinae, Charaxinae, Biblidinae, Apaturinae, Nymphalinae, Limenitidinae, Heliconiinae e Calinaginae (FreITAS \& BROWN, 2004; LAMAS, 2004).

Segundo LAMAS (2008), a família Nymphalidae é aquela que apresenta os maiores problemas de classificação e incógnitas filogenéticas entre as famílias de borboletas. As subfamílias Satyrinae e Morphinae carecem de sinapomorfias que as sustentem, contudo o clado formado por ambas tem grande sustentação e é apontado pelo trabalho de PEÑA et al. (2006) como grupo irmão de Charaxinae. 


\subsection{ASPECTOS BIOLÓGICOS DE CHARAXINAE}

De vôo rápido, os Charaxinae são borboletas coloridas e de tamanho médio a grande, freqüentemente com iridescência nas asas e corpo bastante robusto. Alguns gêneros exibem, na face ventral das asas, uma aparência críptica eficiente em assemelharse a folhas, permitindo-os serem confundidos com o folhiço pelos predadores, ao se alimentarem de frutos fermentados e excrementos no chão da floresta, ou quando em repouso.

A maioria dos Charaxinae adultos, machos e fêmeas, pode ser encontrada alimentando-se de frutas em fermentação, exsudatos e resinas de plantas, fezes de animais carnívoros e poças em solos úmidos. Alguns Charaxinae são especialmente atraídos por fezes de felinos (T. LARSEN, comunicação pessoal), outros como Charaxes lydiae Holland, 1917 nunca foram capturado em armadilhas de isca de qualquer espécie, sendo apenas possível capturá-los com o uso de rede entomológica (DARGE, 1983).

As larvas são fitófagas, à semelhança da maioria dos Lepidoptera, e têm preferências alimentares bastante específicas quanto às plantas hospedeiras. Um grande número de espécies se alimenta de Euphorbiaceae, especialmente do gênero Croton L., outras restringem-se às Lauraceae; há também o grupo que se alimenta de leguminosas, principalmente entre as espécies de Charaxes Ochsenheimer, 1816 africanos (HENNING, 1988). Com menor ocorrência, estão os grupos que se alimentam das famílias Piperaceae, Flacourtiaceae e Monimiaceae como plantas-hospedeiras para algumas espécies neotropicais de Charaxinae (BECCALONI et al., 2008); Sapindaceae, para algumas espécies de Polyura Billberg, 1820 australianas; e Annonaceae, para os Prothoini asiáticos (IGARASHI \& FUKUDA, 1996, 2000). 


\subsection{ASPECTOS SISTEMÁTICOS E BIOGEOGRÁFICOS}

A subfamília Charaxinae caracteriza-se pela parapatágia parcialmente ou inteiramente esclerotizada (membranosa em outras borboletas) (EHRLICH, 1958b), pelas nervuras $\mathrm{R}_{4}$ e $\mathrm{R}_{5}$ bifurcadas a partir de um tronco curto (RYDON, 1971), e pelo ovo esférico com ápice côncavo (FREITAS \& BROWN, 2004). Além desses caracteres morfológicos, o monofiletismo da subfamília tem sido corroborado em análises filogenéticas com base em dados moleculares (Brower, 2000; WAhlberg et al., 2003; PeÑA et al., 2006). Essas análises, bem como aquelas baseadas em dados morfológicos, apontam Calinaginae, Apaturinae ou Satyrinae, em diferentes hipóteses, como prováveis grupos-irmãos de Charaxinae.

Charaxinae está dividida em seis tribos: Charaxini, Euxanthini, Pallini, Prothoini, Preponini e Anaeini (Figura 1); inclui 20 gêneros (WAHLBERG et al., 2003; LAMAS, 2004, 2008) (Tabela I) e cerca de 400 espécies em todo mundo, distribuídas majoritariamente nas regiões tropicais e umas poucas espécies nas regiões temperadas como a América do Norte, Europa, China e )sudeste da Austrália (ACKERY et al., 1998).

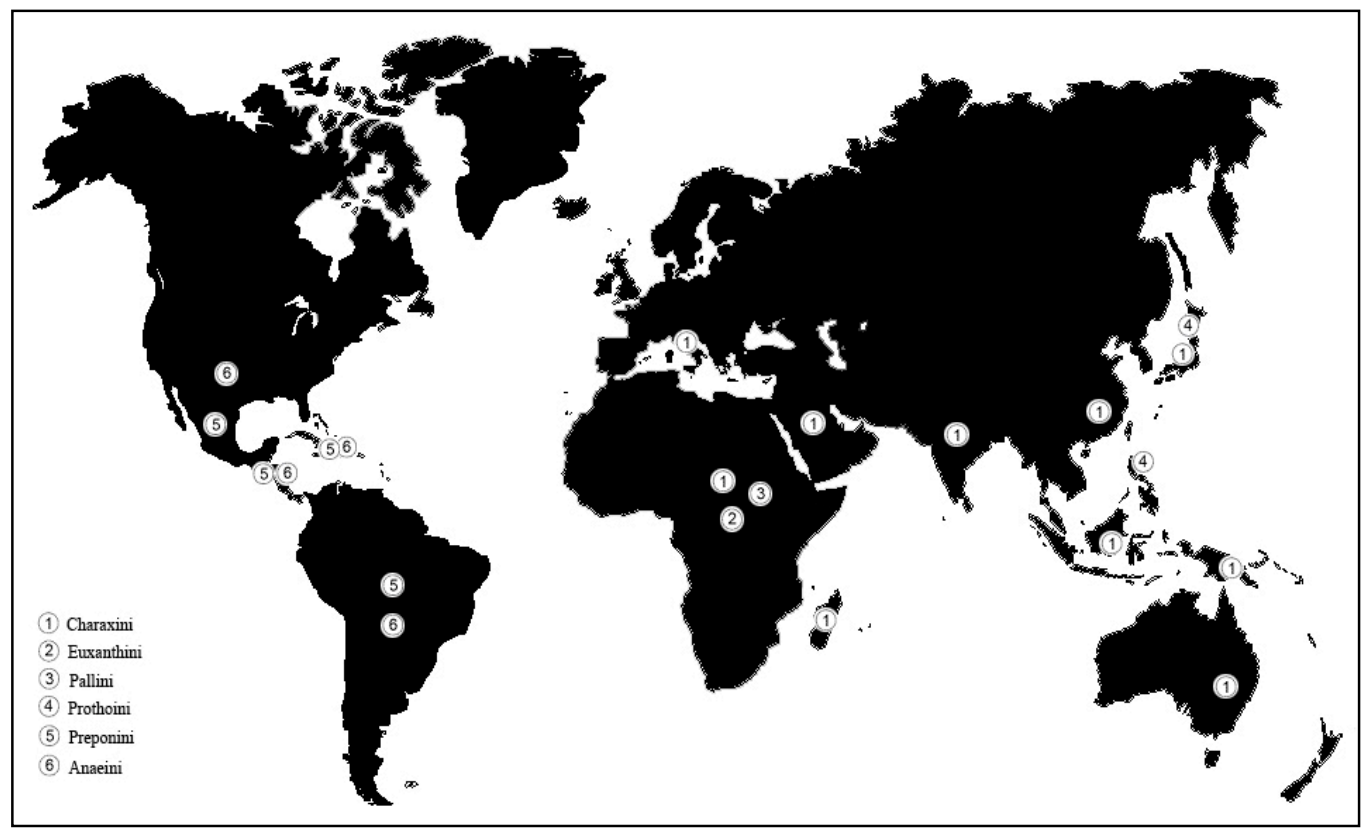

Figura 1. Distribuição geográfica das tribos de Charaxinae. 
A tribo Charaxini apresenta a maior riqueza de espécies (Tabela I) e está distribuída por todos os continentes, exceto o Americano (Figura 1). A alta riqueza se deve ao grande número de espécies do gênero Charaxes Ochsenheimer, 1816 que tem sua maior distribuição no Continente Africano. A tribo Euxanthini, com um único gênero, Euxanthe Hübner [1819], está restrita ao Continente Africano, bem como a também monotípica tribo Pallini, cujo gênero Palla Hübner [1819] possui larva morfologicamente muito semelhante aos Charaxinae neotropicais, especialmente aos gêneros Siderone Hübner [1823] e Zaretis Hübner [1819] (RYDON, 1971). Este fato sempre intrigou os sistematas cultivando-lhes a dúvida de um possível parentesco entre tais grupos. As tribos Preponini e Anaeini se distribuem apenas na região neotropical (Figura 1), com uma única exceção para Anaea troglodyta andria Scudder, 1875 que ocorre no sul dos Estados Unidos.

A subfamília contém vários gêneros, alvos de grande interesse por parte dos colecionadores, proporcionando maior conhecimento da taxonomia de determinadas espécies. Entretanto, como afirma DE VRIES (1987), a filogenia da subfamília é completamente desconhecida. O entendimento sistemático e a quantidade de trabalhos publicados para a fauna neotropical da subfamília é ainda menor em relação aos Charaxinae do Velho Mundo. A sistemática de Charaxinae sempre foi alvo de bastante controvérsia seja pelo posicionamento de Polyura Billberg, 1820 em relação a Charaxes e o de Palla em relação aos gêneros neotropicais, ou pelas muitas hipóteses de parentesco entre os gêneros de Anaeini. Entre elas, está a proposta do gênero Polygrapha Staudinger, 1887 ter cada uma de suas espécies representando um gênero monotípico (SALAZAR \& Constantino, 2001). Outra questão é a validade do gênero Cymmatograma Doubleday, 1849, cujas espécies atualmente estão sinonimizadas em Anaea Hübner, [1819] e Memphis Hübner, [1819]. Questiona-se ainda o status do gênero Memphis considerado até então uma reunião natural de 61 espécies. 
Tabela I. Classificação atual de Charaxinae, espécies-tipo e número de espécies de cada gênero.

\begin{tabular}{|c|c|c|c|c|}
\hline Tribo & Gênero & Referências & $\begin{array}{c}\text { Número } \\
\text { de } \\
\text { espécies }\end{array}$ & Espécie-tipo \\
\hline \multirow{2}{*}{ Charaxini } & Polyura Billberg, 1820 & Wahlberg et al. (2003) & 21 & Polyura pyrrhus (Linnaeus, 1758) \\
\hline & Charaxes Ochsenheimer, 1816 & Wahlberg et al. (2003) & 188 & Charaxes jasius (Linnaeus, 1767) \\
\hline Euxanthini & Euxanthe Hübner, [1819] & Wahlberg et al. (2003) & 6 & Euxanthe eurinome (Cramer,1775) \\
\hline Pallini & Palla Hübner, [1819] & Wahlberg et al. (2003) & 4 & Palla decius (Cramer, 1777) \\
\hline Prothoini & $\begin{array}{l}\text { Agatasa Moore, } 1899 \\
\text { Prothoe Hübner, [1824] }\end{array}$ & Wahlberg et al. (2003) & $\begin{array}{l}1 \\
3\end{array}$ & $\begin{array}{l}\text { Agatasa calydonia (Hewitson, 1855) } \\
\text { Prothoe franck (Godart, [1824]) }\end{array}$ \\
\hline Preponini & $\begin{array}{l}\text { Agrias Doubleday, [1845] } \\
\text { Anaeomorpha Rothschild, } 1894 \\
\text { Archaeoprepona Frustorfer, } 1916 \\
\text { Noreppa } \text { Rydon, } 1971 \\
\text { Prepona Boisduval, } 1836\end{array}$ & Lamas (2004) & $\begin{array}{l}7 \\
1 \\
8 \\
1 \\
5\end{array}$ & $\begin{array}{l}\text { Agrias claudina (Godart, [1824]) } \\
\text { Anaeomorpha splendida Rothschild, } 1894 \\
\text { Archaeoprepona demophon (Linnaeus, } 1758) \\
\text { Noreppa chromus (Guérin-Méneville, [1844]) } \\
\text { Prepona demodice (Godart, [1824]) (= P. laertes demodice (Godart, [1824])) }\end{array}$ \\
\hline Anaeini & $\begin{array}{l}\text { Coenophlebia } \text { C. Felder \& R. Felder, } 1862 \\
\text { Siderone Hübner, [1823] } \\
\text { Zaretis Hübner, [1819] } \\
\text { Anaea Hübner, [1819] } \\
\text { Consul Hübner, [1807] } \\
\text { Fountainea Rydon, 1971 } \\
\text { Hypna Hübner, [1819] } \\
\text { Memphis Hübner, [1819] } \\
\text { Polygrapha Staudinger, } 1887\end{array}$ & Lamas (2004) & $\begin{array}{c}1 \\
2 \\
6 \\
1 \\
4 \\
8 \\
1 \\
61 \\
4\end{array}$ & $\begin{array}{l}\text { Coenophlebia archidona }(\text { Hewitson, 1860) } \\
\text { Siderone ide Hübner, [1823] (= S. galanthis nemesis (Illiger, 1801)) } \\
\text { Zaretis isidora (Cramer, 1779) } \\
\text { Anaea troglodyta (Fabricius, 1775) } \\
\text { Consul fabius (Cramer, 1776) } \\
\text { Fountainea ryphea (Cramer, 1775) } \\
\text { Hypna clytemnestra (Cramer, 1777) } \\
\text { Memphis odilia (Stoll, 1780) (= M. polycarmes Fabricius, 1775)) } \\
\text { Polygrapha cyanea (Salvin \& Godman, 1868) }\end{array}$ \\
\hline
\end{tabular}




\subsection{ESTADO DA ARTE E HISTÓRICO SISTEMÁTICO DE CHARAXINAE}

As primeiras espécies de Charaxinae a serem descritas foram: Papilio pyrrhus (=Polyura pyrrhus) e Papilio demophon (=Archaeoprepona demophon), em 1758, por LinNAEUS na grande obra Sistema Naturae. Nesta obra, LinNAEUS incluiu os Charaxinae no grupo "Nymphalis" que pertencia aos "Achivi" que, por sua vez, pertencia aos "Equites". Depois desta obra, até a descrição da família Nymphalidae Rafinesque, 1815, as espécies que hoje pertencem a Charaxinae foram incluídas em diferentes grupos que, mais tarde, foram tidos como representantes desta família, e que no início recebeu os mais variados nomes: "Argonautes" por Stoll (1782), "Nymphales" por Jones (1791) e Fabricius (1793) e "Nymphalides" por BoIsduval \& Le Conte (1829-1837). Somente após a melhor definição da família Nymphalidae, os sistematas perceberam que era necessário dividir esta grande e variada família em outras unidades menores e mais coerentes com as características de seus integrantes. Foi com esse intuito que DoHERTY, em 1886, com base em morfologia de ovos, dividiu os Nymphalidae em três famílias: Apaturidae, Charaxidae e Nymphalidae.

Alguns trabalhos dão crédito de autoria da subfamília Charaxinae ou família Charaxidae a DOHERTy (1886), que designou cinco espécies para a família neste trabalho: Charaxes fabius (Fabricius), C. kahruba Moore (=lunawara Doherty), C. polyxena hemana Butler, Polyura athamas (Drury) e P. eudamippus (Doubleday). Entretanto, no ano anterior, GuENÉE (1865) já havia considerado o status de família para Charaxes phraotes Doubleday, 1865 de Madagascar, garantindo assim a autoria da família, e posteriormente da subfamília Charaxinae. 
Em 1892, SchATZ \& RÖBER (apud RYDon, 1971) transferiram outros nove gêneros para a família que até então era composta somente por Charaxes e Polyura: Euxanthe, Palla, Prothoe, Siderone, Zaretis, Coenophlebia, Polygrapha, Prepona e Agrias. No mesmo trabalho, Anaea, Hypna e Consul foram arrolados em outro grupo com base em caracteres larvais. REUTER $(1896,1898)$ propôs uma classificação semelhante com base em morfologia de palpos labiais dos adultos.

O primeiro grande trabalho que tratou especificamente de gêneros e espécies de Charaxinae foi a monografia de ROTHSCHILD \& JORDAN (1898-1903), na qual o gênero Charaxes e os gêneros próximos Palla, Euxanthe e Polyura, do chamado grupo prionóptero, foram revisados. Neste trabalho, há uma caracterização e discussão dos gêneros e cada espécie e subespécie são tratadas de forma a receber uma lista sinonímica, descrição morfológica, discussão de caracteres e informações biogeográficas. No final, são apresentadas pranchas com ilustrações de caracteres morfológicos de genitália masculina e fotografias de algumas espécies.

Em seguida, AURIVILLIUs (1911-1912), abordou todos os gêneros da subfamília em um trabalho que já considerava o grupo uma subfamília, criando os Charaxidinae. FASSL (1909-1924) e FRUSTHORFER (1895-1916) enfatizaram o estudo de Preponini, com muitas descrições de espécies e subespécies e novos registros, bem como descrições de estágios imaturos. FrUhSTORFER (1916b) erigiu a tribo Charaxidi. Neste mesmo ano, FRUHSTORFER acrescentou ao grupo o gênero Anaeomorpha e descreveu o gênero Archaeoprepona para algumas espécies anteriormente alocadas em Prepona. Este mesmo autor contribuiu grandemente para a reunião dos gêneros de Charaxinae em um único grupo, pois em trabalhos anteriores (FRUHSTORFER, 1913-1914) já havia acrescentado Agatasa Moore entre os Charaxinae do Velho Mundo, mantendo-o como um subgênero de 
Prothoe. FRUHSTORFER publicou 34 trabalhos sobre Charaxinae no período de 1895 a 1916.

SCHWANWITSCH, em 1930, fez um minucioso estudo do padrão de asa de Preponini. Neste trabalho, o autor desconsidera Archaeoprepona, proposto por FRUHSTORFER (1916b, 1916c) e FRUHSTORFER \& RÖBER (1916), e trata as espécies deste gênero como pertencentes a Prepona. O trabalho de ScHWANwITSCH (1930) foi pioneiro no estudo das manchas e padrões alares em Charaxinae. Nele, o autor elabora e discute várias hipóteses de evolução dos elementos do padrão de manchas e o relacionamento entre as espécies de Prepona (incl. Archaeoprepona) com base nos dados de padrões alares. Em 1940, SCHWANWITSCH analisou o padrão de asas de Zaretis detalhando a composição das manchas envolvidas na imitação de folha.

A denominação Charaxidini de AuriviLlius (1911-1912) anteriormente citada, ganhou mais adeptos algum tempo depois, como por exemplo, STICHEL (1939), que incluíu o gênero Hypomelaena Aurivillius 1899 (=Euxanthe subgênero Hypomelaena); Em CLARK (1947), a família Charaxidae (segundo os autores anteriores) foi considerada como subfamília de Apaturidae, apesar das diferenças na morfologia dos ovos. Entretanto, foi EHRLICH $(1957,1958 b)$ quem colocou Charaxinae como uma subfamília de Nymphalidae, dando o mesmo posicionamento a Danainae, Ithomiinae, Satyrinae, Morphinae, Calinaginae, Nymphalinae e Acraeinae.

Comstock (1961), em um primoroso trabalho sobre Anaea, cuja equivalência atual é a tribo Anaeini, agregou em um único gênero, Anaea, todas as espécies de todos os gêneros de Anaeini, mantendo estes últimos como subgêneros (os antigos gêneros), fez também uma discussão taxonômica do grupo com base principalmente em caracteres de venação alar e de genitália masculina. $\mathrm{O}$ autor apresenta ainda importantes informações sobre a distribuição geográfica dos gêneros, excelentes pranchas aquareladas e esquemas 
de venação de asas para todas as espécies de Anaeini até então descritas. Também é apresentada uma hipótese filogenética intuitiva (sem a aplicação do método filogenético), com dois ramos principais, um composto por Anaea, Hypna, Zaretis, Siderone e Coenophlebia; outro por Memphis (revalidado nesse trabalho), Consul e Polygrapha. Nessa hipótese, Coenophlebia e Siderone são considerados grupos-irmãos, bem como Consul e Memphis. Em 1961, REBILlard também publica a revisão sistemática com informações sobre distribuição geográfica do gênero Agrias no qual faz um registro completo dos espécimens de Agrias do Museu de História Natural de Paris.

VAN SOMEREN (1963-1975) apresentou em 10 partes a revisão dos Charaxinae africanos, incluindo os gêneros Charaxes, Palla, Euxanthe e Polyura com a apresentação de pranchas e dados de distribuição geográfica. Certamente, este é o trabalho de maior importância taxonômica para a fauna de Charaxinae africanos.

RYDON (1971) desenvolveu um estudo taxonômico amplo sobre a subfamília considerada por ele como família. Nele, o autor discutiu e comparou todos os gêneros de Charaxidae (assim referida pela autor) baseando-se em caracteres morfológicos de adultos e imaturos, forneceu também um detalhado histórico para a família e chaves de identificação para as subfamílias e tribos. Neste artigo, RYDON propôs sete subfamílias para Charaxidae, das quais cinco eram novas: Charaxinae, Euxanthinae, Pallinae, Prothoinae, Preponinae, Anaeinae e Zaretidinae, a maioria delas, atualmente, está arrolada no nível de tribo, exceto Zaretidinae, que está sinonimizada nos atuais Anaeini. O gênero Noreppa é descrito e Cymatogramma Doubleday, 1849 revalidado.

Cymatogramma havia sido erigido por Doubleday (1849) (apud Rydon, 1971) com base em C. echemus Doubleday, 1849. O gênero continha várias espécies que atualmente são arroladas em Memphis, Fountainea, e Anaea. RYDON, em 1971, revalidouo; contudo, nos anos seguintes, outros autores, e. g. LAMAS (2004), desconsideraram o 
gênero e realocaram as suas espécies em Memphis e Anaea novamente, exceto por SALAZAR \& CONSTANTINo (2001) que consideraram o gênero válido.

MuYShONDT (1973-1976) destacou-se pela grande produção de descrições de estágios imaturos para as espécies da maioria dos gêneros neotropicais de Charaxinae.

Em 1979, VAN Son publicou uma série de publicações sobre as borboletas do sudoeste da África, cujo volume sobre Nymphalinae contém a lista de espécies e subespécies de Charaxinae para essa região com informações taxonômicas, descrição de genitália masculina e feminina e dados bionômicos. Esse trabalho é ilustrado com pranchas de fotografias de adultos e ilustrações coloridas de imaturos, incluindo detalhes de ovo, larva (do primeiro ao quinto ínstar), cápsula cefálica, detalhes de segmentos, cerdas, espiráculo e pupa.

$\mathrm{Na}$ década de 1980, outras importantes publicações contribuíram para o conhecimento e sistemática de Charaxinae. Em 1982, SMILES publicou a taxonomia e filogenia do gênero Polyura, e em 1985, de Euxanthe. Simultaneamente em Paris, JaCQUes Plantrou investigava o gênero Charaxes, e em 1983, disponibilizou seu estudo sobre a sistemática, biogeografia e evolução das espécies de Charaxes africanos. Neste mesmo ano, 1983, DARGE publicou um livro sobre o gênero Charaxes na República de Camarões, no qual ele fornece informações biogeográficas, chave de identificação baseada principalmente em padrão de manchas alares, breve descrição das espécies com algumas informações ecológicas e boas dicas de coleta. A maioria das espécies está ilustrada em pranchas com escala de tamanho natural. Ainda em 1983, BARSELOU publica um guia taxonômico ilustrado sobre o gênero Agrias contendo mapas de distribuição.

Descimon (1986) também se dedicou à subfamília Charaxinae, concentrando-se no estudo dos gêneros neotropicais. Contudo, ele utilizou a classificação feita por RYDON (1971) e, portanto, refere-se ao grupo como família. Neste trabalho, DESCIMON abordou os 
padrões de coloração das asas relacionando-os a estratégias adaptativas e cladogênese. Em 1988, HeNNING publicou um livro grandemente influenciado pelo trabalho de VAN SOMEREN (1963-1975) que consiste na reunião mais completa de informações sobre os Charaxinae africanos (os gêneros Charaxes, Palla e Euxanthe), incluindo diagnose, estágios imaturos, plantas-hospedeiras, habitats e distribuição.

SALAZAR \& CONSTANTINO (2001), além das mudanças anteriormente citadas com relação a Cymatogramma, criaram outros cinco gêneros novos a partir de alguns Anaeini até então arrolados em gêneros pré-existentes: Muyshondtia para Polygrapha tyrianthina (Salvin \& Godman, 1868); Pseudocharaxes para Polygrapha xenocrates (Westwood, 1850); Zikania para Polygrapha suprema (Schaus, 1920); Rydonia para Memphis pasibula (Doubleday, 1849) e M. falcata (Hoppfer, 1874); e Annagrapha para Memphis aureola (Bates, 1866), M. anna (Staudinger, 1897), M. polyxo (Druce, 1874) e M. dia (Godman \& Salvin, 1884). Toda esta reclassificação proposta por SALAZAR \& CONSTANTINO (2001) foi sinonimizada na "checklist" de LAMAS (2004).

Os trabalhos com filogenia para essa subfamília são recentes e tiveram início com De JONG et al. (1996) que encontraram a subfamília Charaxinae filogeneticamente próxima de Danainae e Morphinae. Brower (2000) chegou aos mesmos resultados, além de encontrar uma relação filogenética com os Brassolinae e Satyrinae. WAHLBERG et al. (2003) apresentaram soluções mais esclarecedoras com relação à posição filogenética das subfamílias de Nymphalidae apontando os Charaxinae dentro do clado dos satiróides. De acordo com estes autores, na análise molecular esta subfamília está fortemente sustentada, tendo Calinaginae como grupo-irmão, embora este último clado esteja fraca a moderadamente sustentado pelas análises. WAHLBERG et al. (op.cit.), com base em trabalhos de outros pesquisadores nos quais são apontadas sinapomorfias, especialmente com Nymphalinae e Apaturinae, discutiram que a inclusão dos Charaxinae no clado dos 
ninfalóides se deve a uma convergência evolutiva e não a uma relação de parentesco. Em PEÑA et al. (2006), Charaxinae está posicionado como grupo irmão do clado (Satyrinae + (Morphinae + Calinaginae)) na análise de dados morfológicos e moleculares combinados.

Todos os trabalhos mais recentes consideram o grupo no nível de subfamília seguindo as proposições de EHRLICH (1958b). Esta consideração para o status filogenético encontra respaldo nas análises cladísticas recentes (DE JONG et al. 1996; ACKERY et al., 1998, Brower, 2000; WAhlberg et al., 2003;). WAHLBerg et al. (2003) seguiram a classificação feita por HARVEY (1991) e consideraram apenas seis tribos para Charaxinae, ficando Zaretidinae (sensu RYDON, 1971) como subtribo de Anaeini.

Com base em caracteres morfológicos de imaturos e adultos, os resultados de FREITAS \& BROWN (2004) confirmaram o monofiletismo de Charaxinae e sua inclusão no clado dos satiróides e corroboraram o trabalho de WAHLBERG et al. (2003) neste aspecto. Entretanto, ainda inexiste uma concordância sobre o posicionamento sistemático da subfamília. Segundo Freitas \& Brown (op. cit.), Charaxinae surge como um grupo próximo de Apaturinae.

As relações filogenéticas entre as tribos e mesmo entre os gêneros de Charaxinae ainda são bastante obscuras ou de definição ambígua. SMILES (1982) quando apresentou a filogenia do gênero Polyura foi explícito em afirmar que Charaxes é um gênero parafilético porque inclui o grupo-irmão de Polyura. Da mesma forma, a posição taxonômica de Anaeomorpha splendida Rothschild, 1894 ainda hoje gera dúvidas, apesar de ter sido colocada na tribo Preponini por semelhanças morfológicas (RYDON, 1971). 


\section{OBJETIVOS}

- Testar a hipótese de monofiletismo da subfamília Charaxinae, de suas tribos, e dos gêneros com base na morfologia comparada;

- Apresentar uma hipótese de parentesco filogenético entre as tribos e gêneros da subfamília Charaxinae.

\subsection{OBJETIVOS ESPECÍFICOS}

- Levantar caracteres morfológicos no âmbito da variação morfológica da subfamília sob o paradigma da sistemática filogenética;

- Verificar a seqüência de aparecimento das novidades morfológicas na história evolutiva de Charaxinae;

- Contribuir para futuras revisões taxônomicas e para a classificação da subfamília. 


\section{MATERIAL E MÉTODOS}

\subsection{MATERIAL EXAMINADO}

Foram examinados exemplares pertencentes às seguintes instituições (Os acrônimos seguiram ARNETT et al. (1993) com as atualizações de EVENHUIS (2008))

AMNH American Museum of Natural History, New York, NY, USA

DZUP Coleção Entomológica Pe. Jesus Santiago Moure, Departamento de Zoologia da Universidade Federal do Paraná, Curitiba, PR, Brasil

FSMC Allyn Museum of Entomology, Florida Museum of Natural History, Sarasota, FL, USA (coleção incorporada ao McGuire Center for Lepidoptera and Biodiversity Research, Florida Museum of Natural History, Gainesville, FL, USA)

MNRJ Museu Nacional, Universidade Federal do Rio de Janeiro, Rio de Janeiro, RJ, Brasil

MZSP Museu de Zoologia, Universidade de São Paulo, São Paulo, SP, Brasil.

USNM National Museum of Natural History, Smithsonian Institution, Washington, DC, USA

Todas as coleções listadas acima foram visitadas. Indivíduos dos táxons não encontrados no acervo do MZSP foram emprestados das coleções: DZUP, MNRJ e USMN. 


\subsection{TERMINOLOGIA E PROCEDIMENTOS DE DISSECÇÃO}

A terminologia adotada para morfologia externa dos adultos foi baseada em EHRLiCH (1958a) (Figura 2) e para a de imaturos, em Stehr (1987). O estudo dos exemplares foi feito com auxílio de câmara-clara acoplada a estereomicroscópio e microscópio óptico. Para arte final, utilizou-se a técnica de traço a nanquim sobre papel poliéster. Os caracteres e suas variações também foram ilustrados através de fotografia.

O estudo de genitálias envolveu, sempre que possível, ambos os sexos. Para tal estudo, o abdome foi fervido em banho-maria, em solução de hidróxido de potássio a 10\% para amolecimento dos tecidos e clarificação do exoesqueleto, por aproximadamente cinco minutos (partindo da água em ponto de ebulição) para exemplares pequenos (abdome medindo até $7 \mathrm{~mm}$ ) e dez minutos para os exemplares maiores (abdome medindo mais de 7 mm, por exemplo, Coenophlebia archidona, Agatasa calydonia e Charaxes eurialus). Para neutralizar o efeito do hidróxido de potássio, os abdomes dos espécimes foram lavados em água destilada (EHRLICH \& EHRLICH, 1961), depois, transferidos para álcool onde foram examinados e ilustrados e/ou fotografados e posteriormente acondicionados em pequenos tubos com glicerina líquida.

Para o estudo da venação, as asas foram retiradas do exemplar, mergulhadas rapidamente em álcool 70\% para remoção da gordura, transferidas para uma placa de Petri com água sanitária até ficarem diafanizadas (tempo variável de alguns segundos a alguns minutos dependendo da espécie). As asas foram então retiradas da água sanitária e lavadas em água destilada e montadas entre lâminas de vidro (EHRLICH \& EHRLICH, 1961) ou mantidas no próprio exemplar segundo a determinação do curador da coleção. Nesse caso, a diafanização se deu no próprio exemplar com sucessivos banhos de hipoclorito de sódio e a retirada do hipoclorito de sódio com borrifos de água. A secagem deu-se naturalmente. Tal método tem a vantagem de não separar a asa do indivíduo, contudo a membrana da asa 
deve estar em bom estado de conservação (sem rompimento algum), para que não haja aderência de partes quebradas quando da secagem. Contudo, a execução do procedimento no próprio exemplar implica em alguns riscos como a diafanização indesejada de escamas de regiões do corpo próximas à inserção das asas caso não haja uma manipulação cuidadosa da pipeta de água sanitária. Além disso, áreas danificadas da membrana tendem a secar colapsadas, o que não ocorre quando a asa é mantida em lâmina separada do exemplar. Um grande acervo de asas já diafanizadas foi examinado na coleção da Smithsonian Institution. As lâminas foram escaneadas e sua imagem serviu para análise e ilustração dos caracteres.
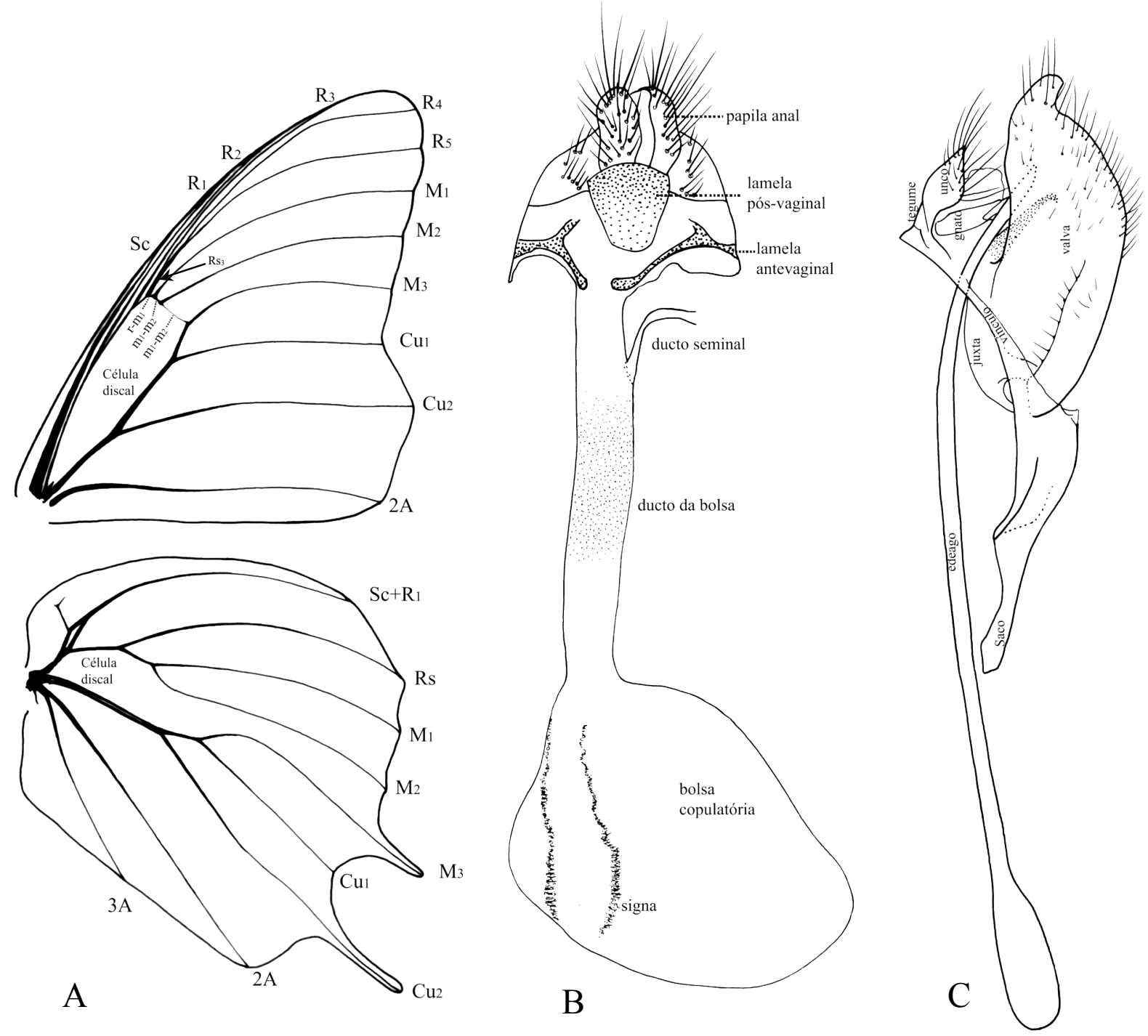

Figura 2. Nomenclatura das estruturas de asa, genitália feminina e masculina. a. Charaxes jasius, b. Siderone galanthis, c. Charaxes varanes. 


\subsection{PADRÃO DE MANCHAS DA ASA}

Os padrões de manchas alares exibem algum grau de similaridade perceptível entre os diferentes grupos de Nymphalidae, outras borboletas e até mesmo mariposas. Contudo, estes padrões são consideravelmente mais complexos do que os de venação alar na qual as hipóteses de homologia primária são mais facilmente percebidas. A dificuldade em estabelecer a homologia primária entre os elementos dos padrões das asas está no fato de que ao longo da evolução dos grupos, tais elementos sofreram modificações muitas vezes difíceis de serem identificadas, como replicação, aumento, redução, perda, fusão e fragmentação.

SCHWANWITSCH (1924) e SÜFFERT (1927) foram os pioneiros no estudo de padrões de manchas. Eles pesquisaram independentemente o mesmo assunto, ao mesmo tempo, e chegaram a conclusões muito parecidas (mais um forte indício que corrobora a hipótese de homologia primária contida por tais elementos). SchWANWITSCH seguiu publicando artigos relativos ao assunto por mais uma década, analisando a evolução do padrão em diferentes grupos de borboletas (gêneros, famílias, etc). Um trabalho muito útil no levantamento de caracteres desta tese foi o de SCHWANwITSCH (1930) que estudou o padrão das asas de Prepona, Archaeoprepona e Agrias (Preponini). Em 1956, este mesmo autor fez uma revisão do assunto para toda a ordem Lepidoptera. Em 1986, NiJHOUT \& WRAY publicaram um estudo sobre os padrões de asa em Charaxes, com uma nomenclatura própria, a qual foi baseada principalmente na nomenclatura de SÜFFERT (1927). Em 1991, Nishout publica um livro sobre desenvolvimento e evolução dos padrões de asa de borboletas, que é, desde então, a obra mais completa no assunto no que se refere à ordem Lepidoptera como um todo.

Os elementos do padrão podem estar presentes tanto na face dorsal como na ventral, mas a maior parte dos estudos enfocaram apenas a face ventral por ser esta a 
superfície evolutivamente mais conservativa, bem como a asa posterior em detrimento da anterior. Existem cinco níveis de homologia para os elementos dos padrões de asas, mas apenas um é concordante com o conceito filogenético (aquele entre espécies considerado por NiJHOUT, 1991). Este é o único nível de homologia abordado neste trabalho, uma vez que os demais níveis são iterativos, pois se configuram por meio de repetições correspondentes entre as asas anterior e posterior, superfícies dorsal e ventral, entre células da mesma asa, e por último, entre elementos dentro da mesma célula.

SCHWANWITSCH (1924) e SÜFFERT (1927) consideraram o plano básico da asa como sendo um sistema de bandas e manchas que correm da margem costal à margem interna, dispostas em seqüência da base da asa até a margem externa. Considerando a nomenclatura utilizada por NIJHOUT (1991), definida a partir daquela criada pelos autores supracitados, é descrito a seguir o elenco de elementos presentes no padrão das asas (Figura 3):

- Banda radical (a): é o elemento mais basal da asa, encontrado em algumas borboletas, porém mais comum em mariposas.

- Sistema de simetria basal $(\mathbf{b}, \mathbf{c})$ : é um par de bandas imediatamente distais à banda radical.

- Sistema de simetria central: ocupa geralmente a porção mediana da asa e é composto pela banda proximal (d), pela mancha discal (e) e pela banda distal (f). As duas bandas são espelhadas e paralelas entre si.

- Banda proximal dos ocelos (g): é a banda que margeia basalmente a linha de ocelos.

- Sistema ocelar (h): uma série de manchas circulares em forma de ocelo na metade distal da asa.

- Elemento parafocal (i): margeia distalmente a linha dos ocelos.

- Banda submarginal (j): banda estreita entre o elemento parafocal e a banda marginal.

- Banda marginal (k): banda estreita na borda da margem externa. 
A maneira mais fácil de reconhecer os vários elementos em uma asa é iniciando pela identificação de e (mancha discal), já que sua determinação é dependente da nervura que fecha a célula discal, à qual se sobrepõe. A banda que está à esquerda da mancha discal é $\mathbf{d}$ e a que está à direita é f. À esquerda de $\mathbf{d}$ estão c e b (a raramente está presente). À direita de $\mathbf{f}$, estão $\mathbf{g}, \mathbf{h}, \mathbf{i}$ e $\mathbf{j}$ (k raramente está presente). Segundo NiJHOUT \& WraY (1986), esta é a forma mais segura de se estabelecer a identidade dos elementos, a partir da posição de $\mathbf{e}$.

O modelo básico ninfalídeo (Figura 3) serviu de base para o levantamento de vários caracteres no presente trabalho, no qual foi utilizada a nomenclatura acima exposta.

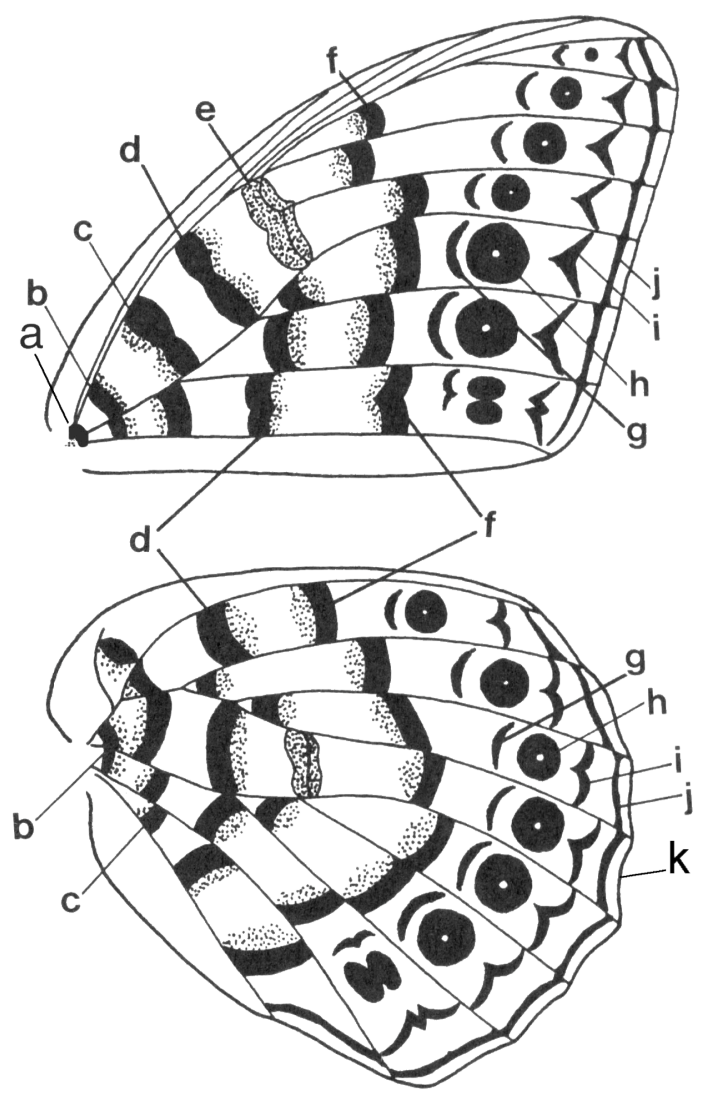

Figura 3. Modelo básico ninfalídeo contendo as letras que representam os elementos do padrão de asa. Modificado de NiJHOUT (1991). 


\subsection{SELEÇÃO DE TÁXONS}

Foram analisadas três espécies de cada gênero para o levantamento de caracteres, sendo uma delas a espécie-tipo (quando possível). Em gêneros numerosos (com mais de cinco espécies), um número maior de espécies foi incluído na análise, seguindo a distribuição de grupos de espécies. Para gêneros morfologicamente homogêneos, como Palla, apenas uma espécie foi analisada, evitando-se assim um número excessivo de táxons terminais.

Como grupo externo foi utilizado um representante de cada uma das seguintes subfamílias: Calinaginae: Calinaga buddha Moore, 1857, Apaturinae: Apatura iris (Linnaeus, 1758), e Morphinae: Antirrhaea archaea Hübner, [1822], seguindo os trabalhos de Wahlberg et al. (2003), Freitas \& Brown (2004) e Peña et al. (2006) que indicam os prováveis grupos-irmãos de Charaxinae. Os resultados de PEÑA et al. (2006) apontam as espécies da subfamília Morphinae incluídas no clado de Satyrinae cujos limites são mais amplos após o referido trabalho. Sendo assim, na presente análise, Antirrhaea archaea é considerada um representante de Satyrinae no grupo externo, embora seja referida como um membro de Morphinae em todo o texto deste trabalho, por não haver uma proposta taxonômica formal com base em PEÑA et al. (2006) que apresente Antirrhaea archaea como pertecente à Satyrinae.

Os 73 táxons terminais escolhidos são apresentados na Tabela II. Os três primeiros consistem no grupo externo.Na seqüência estão alocados os táxons representantes do grupo interno. 
Tabela II. Lista dos táxons terminais e da procedência dos exemplares dissecados para estudo de genitália.

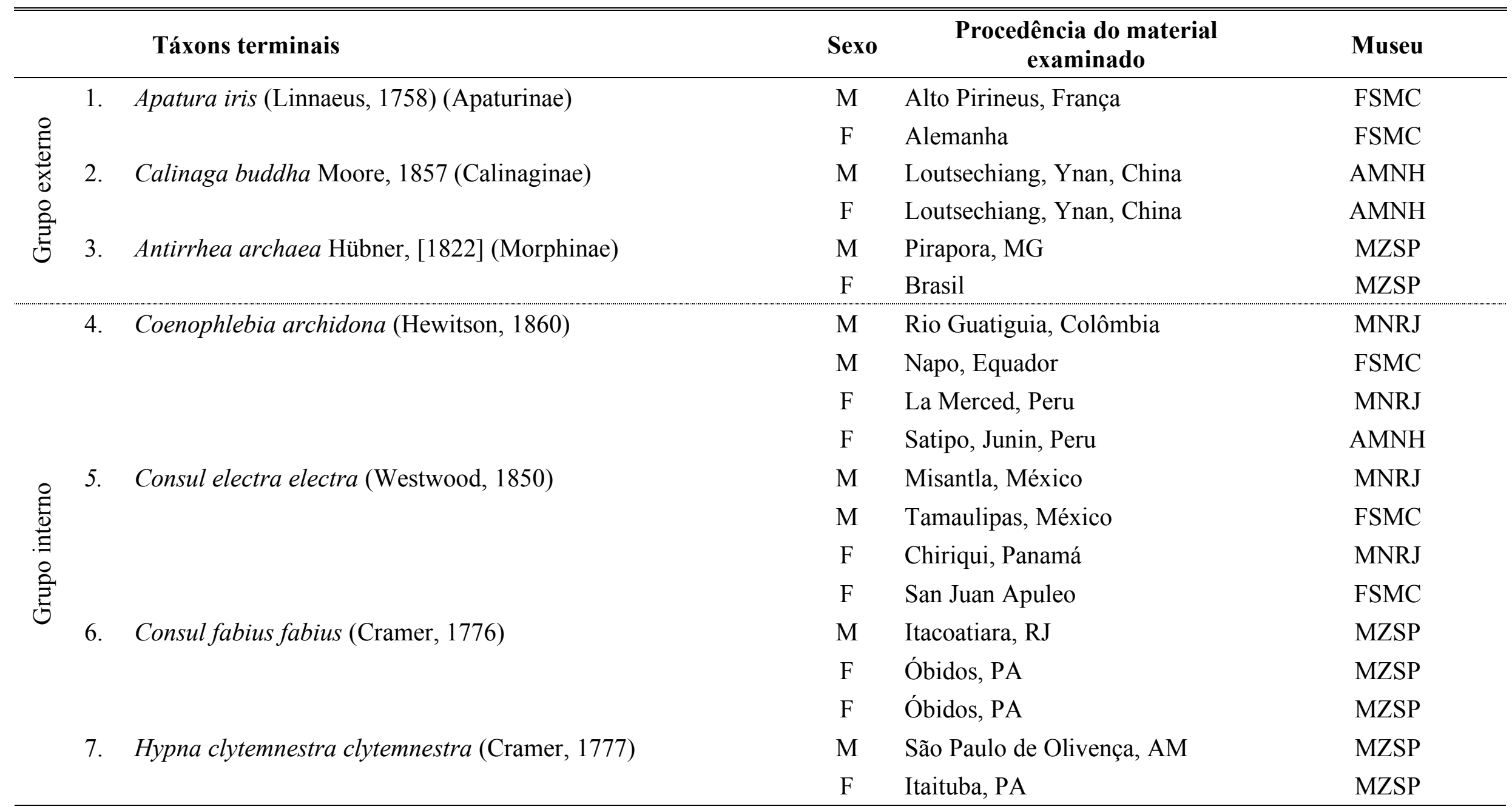


Tabela II. Continuação.

\begin{tabular}{|c|c|c|c|c|}
\hline & Táxons terminais & Sexo & $\begin{array}{c}\text { Procedência do material } \\
\text { examinado }\end{array}$ & Museu \\
\hline \multirow{16}{*}{ 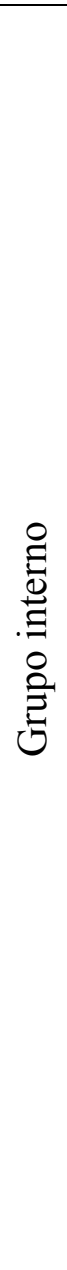 } & \multirow[t]{3}{*}{ 8. Polygrapha cyanea cyanea (Salvin \& Godman, 1868) } & M & Peru & MNRJ \\
\hline & & $\mathrm{M}$ & Uanuco, Peru & FSMC \\
\hline & & $\mathrm{F}$ & Las Yungas, Bolívia & FSMC \\
\hline & \multirow[t]{2}{*}{ 9. Polygrapha suprema (Schaus, 1920) } & M & Virgínia, MG & MZSP \\
\hline & & $\mathrm{F}$ & Passa Quatro, MG & MZSP \\
\hline & \multirow[t]{2}{*}{ 10. Polygrapha tyrianthina (Salvin \& Godman, 1868) } & M & Ituaca, Bolívia & FSMC \\
\hline & & $\mathrm{F}$ & Peru & Coleção Particular \\
\hline & \multirow[t]{2}{*}{ 11. Polygrapha xenocrates xenocrates (Westood, 1850) } & M & Pucalpa, Peru & FSMC \\
\hline & & $\mathrm{F}$ & Jepelacio, Peru & $\mathrm{AMNH}$ \\
\hline & 12. Siderone galanthis galanthis (Cramer, 1775) & M & Tefé, AM & MZSP \\
\hline & \multirow[t]{2}{*}{ 13. Zaretis callidryas (R. Felder, 1869) } & M & - & FSMC \\
\hline & & $\mathrm{F}$ & Chimalapa, Oaxaca, México & FSMC \\
\hline & \multirow[t]{2}{*}{ 14. Zaretis isidora (Cramer, 1779) } & M & Óbidos, PA & MZSP \\
\hline & & $\mathrm{F}$ & Óbidos, PA & MZSP \\
\hline & \multirow[t]{2}{*}{ 15. Anaea troglodyta troglodyta (Fabricius, 1775) } & M & Peralta, Azua, República Dominicana & FSMC \\
\hline & & $\mathrm{F}$ & La Vega, República Dominicana & FSMC \\
\hline
\end{tabular}


Tabela II. Continuação.

\begin{tabular}{|c|c|c|c|c|}
\hline & Táxons terminais & Sexo & $\begin{array}{c}\text { Procedência do material } \\
\text { examinado }\end{array}$ & Museu \\
\hline \multirow{16}{*}{ 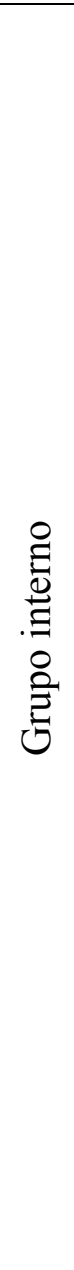 } & \multirow{2}{*}{ 16. Fountainea nessus (Latreille, [1813]) } & M & Cali, Colômbia & MZSP \\
\hline & & $\mathrm{F}$ & Pastaza, La Mascota, Equador & FSMC \\
\hline & \multirow[t]{3}{*}{ 17. Fountainea ryphea ryphea (Cramer, 1775) } & M & Óbidos, PA & MZSP \\
\hline & & $\mathrm{F}$ & Óbidos, PA & MZSP \\
\hline & & $\mathrm{F}$ & Passa Quatro, MG & MZSP \\
\hline & \multirow[t]{2}{*}{ 18. Memphis appias (Hübner, [1825]) } & M & São Paulo, SP & MZSP \\
\hline & & $\mathrm{F}$ & São Paulo, SP & MZSP \\
\hline & \multirow[t]{2}{*}{ 19. Memphis glauce glauce (C. Felder \& R. Felder, 1862) } & M & São Paulo de Olivença, AM & MZSP \\
\hline & & $\mathrm{F}$ & Iquitos, Peru & MZSP \\
\hline & 20. Memphis grandis (H. Druce, 1877) & $\mathrm{M}$ & Óbidos, PA & MZSP \\
\hline & \multirow[t]{3}{*}{ 22. Memphis leonida leonida (Stoll, 1782) } & M & Óbidos, PA & MZSP \\
\hline & & $\mathrm{F}$ & Óbidos, PA & MZSP \\
\hline & & $\mathrm{F}$ & - & FSMC \\
\hline & \multicolumn{4}{|l|}{ 23. Memphis moruus moruus (Fabricius, 1775) } \\
\hline & \multirow[t]{2}{*}{ - $\quad$ Memphis leonida leonida (Stoll, 1782) } & M & Óbidos, PA & MZSP \\
\hline & & $\mathrm{F}$ & Óbidos, PA & MZSP \\
\hline
\end{tabular}


Tabela II. Continuação.

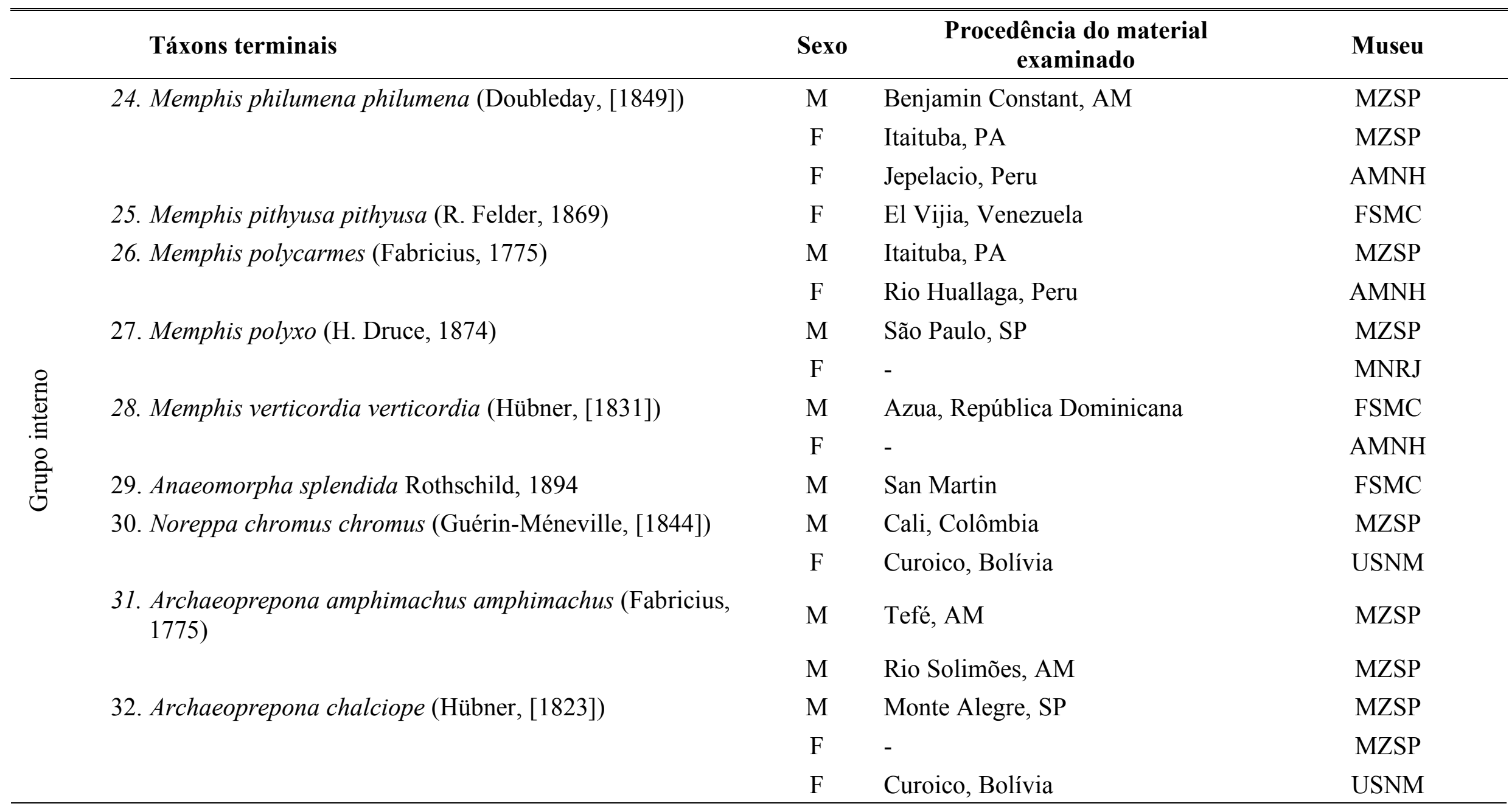


Tabela II. Continuação.

\begin{tabular}{|c|c|c|c|c|}
\hline & Táxons terminais & Sexo & $\begin{array}{c}\text { Procedência do material } \\
\text { examinado }\end{array}$ & Museu \\
\hline \multirow{16}{*}{ 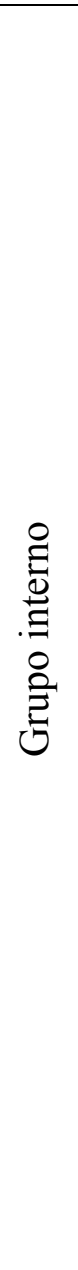 } & \multirow[t]{6}{*}{ 33. Archaeoprepona demophon demophon (Linnaeus, 1758) } & $\mathrm{M}$ & Serra do Navio, AP & MZSP \\
\hline & & $\mathrm{M}$ & Parintins, AM & MZSP \\
\hline & & M & Santarém, PA & MZSP \\
\hline & & M & RO & FSMC \\
\hline & & M & Jaru, RO & FSMC \\
\hline & & $\mathrm{F}$ & Parintins, AM & MZSP \\
\hline & \multirow[t]{3}{*}{ 34. Archaeoprepona demophoon demophoon (Hübner, [1814]) } & M & Porto Cabral, SP & MZSP \\
\hline & & M & São Paulo de Olivença,AM & FSMC \\
\hline & & $\mathrm{F}$ & Salesópolis, SP & MZSP \\
\hline & 35. Archaeoprepona licomedes licomedes (Cramer, 1777) & M & São Paulo de Olivença, AM & MZSP \\
\hline & \multirow{2}{*}{ 37. Prepona laertes laertes (Hübner, [1811]) } & $\mathrm{F}$ & Teresópolis, RJ & DZUP \\
\hline & & $\mathrm{F}$ & Ariquemes, RO & FSMC \\
\hline & \multirow[t]{2}{*}{ 38. Prepona pheridamas (Cramer, 1777) } & M & Parintins, AM & MZSP \\
\hline & & $\mathrm{F}$ & Parintins, AM & MZSP \\
\hline & \multirow[t]{2}{*}{ 39. Prepona pylene pylene Hewitson, [1854] } & M & Rio Juruá, AM & MZSP \\
\hline & & $\mathrm{F}$ & Huanuco, Tingo Maria, Peru & FSMC \\
\hline
\end{tabular}


Tabela II. Continuação.

\begin{tabular}{|c|c|c|c|c|}
\hline & Táxons terminais & Sexo & $\begin{array}{c}\text { Procedência do material } \\
\text { examinado }\end{array}$ & Museu \\
\hline \multirow{13}{*}{ 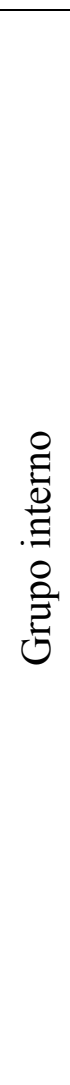 } & \multirow[t]{2}{*}{ 40. Agrias amydon amydon Hewitson, [1854] } & M & Colômbia & FSMC \\
\hline & & $\mathrm{F}$ & Diamantina, MT & USNM \\
\hline & \multirow[t]{2}{*}{ 41. Agrias claudina claudina (Godart, [1824]) } & M & Óbidos, PA & MZSP \\
\hline & & $\mathrm{F}$ & Óbidos, PA & MZSP \\
\hline & \multirow[t]{2}{*}{ 42. Euxanthe eurinome eurinome (Cramer, 1775) } & M & Kasai, Zaire & USNM \\
\hline & & $\mathrm{F}$ & Likpe, Gana & FSMC \\
\hline & \multirow[t]{2}{*}{ 43. Euxanthe trajanus trajanus (Ward, 1871) } & M & Mt Kala, Camarões & USNM \\
\hline & & $\mathrm{F}$ & Bimbo, Rep. Centr. Afric. & USNM \\
\hline & \multirow[t]{2}{*}{ 44. Palla decius (Cramer, 1777) } & M & Likpe, Gana & FSMC \\
\hline & & $\mathrm{F}$ & Likpe, Gana & FSMC \\
\hline & \multirow[t]{2}{*}{ 46. Polyura delphis delphis (Doubleday, 1843) } & M & Tailândia & FSMC \\
\hline & & $\mathrm{F}$ & Wang Chin Phae, Tailândia & Coleção particular \\
\hline & 47. Polyura gamma (Lathy, 1898) & M & Nova Caledônia & FSMC \\
\hline
\end{tabular}


Tabela II. Continuação.

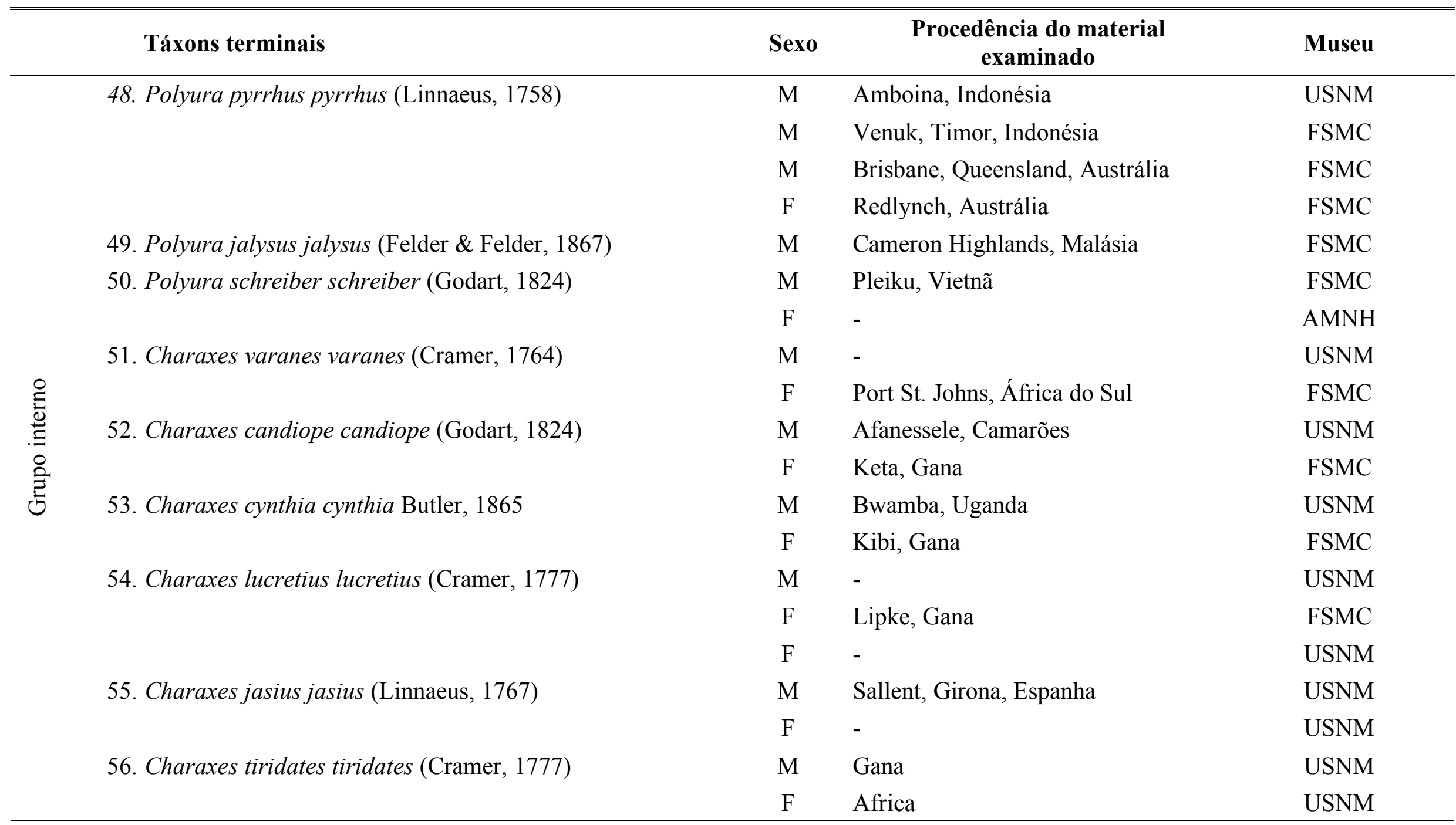


Tabela II. Continuação.

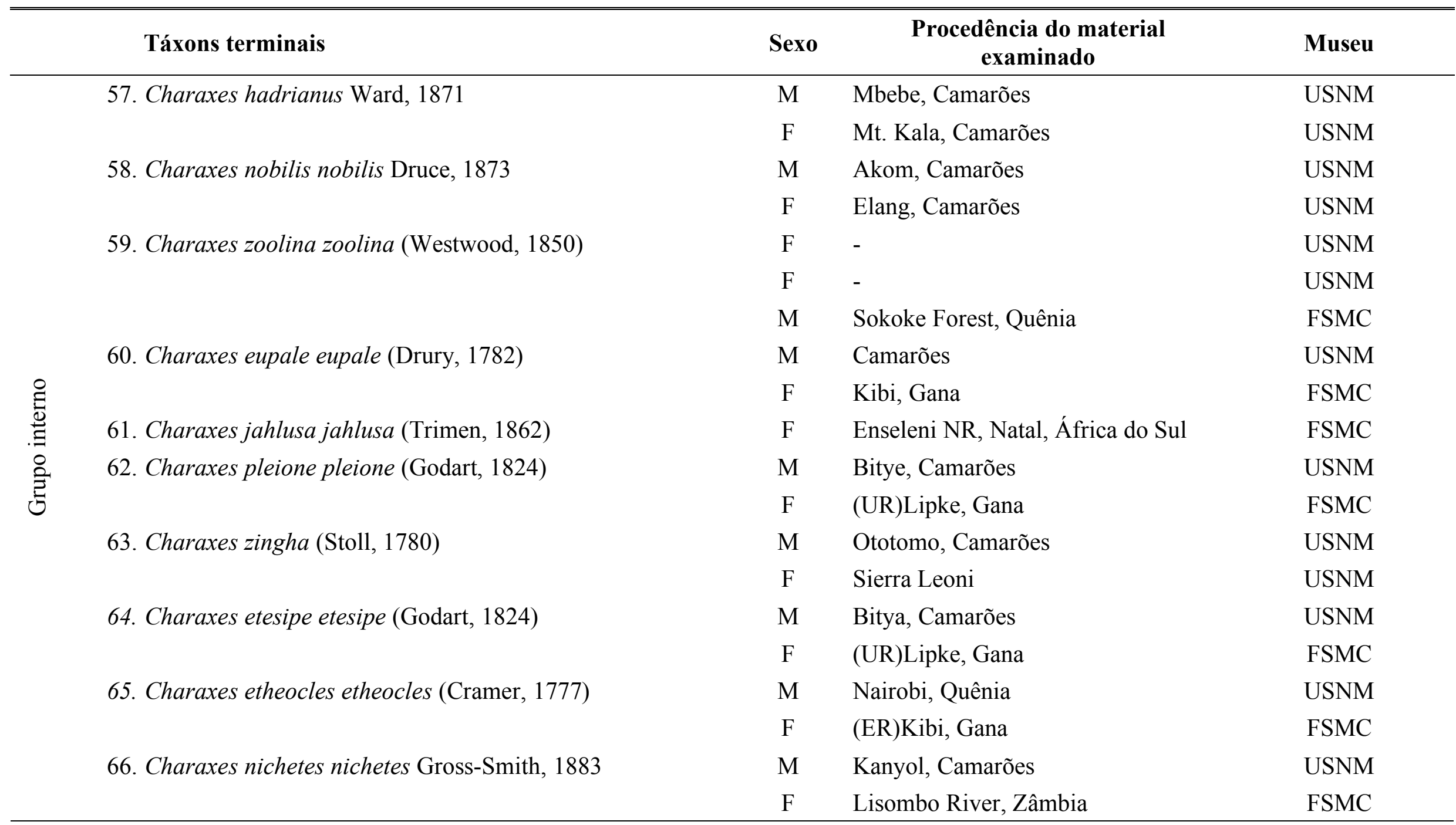


Tabela II. Continuação.

\begin{tabular}{|c|c|c|c|c|}
\hline & Táxons terminais & Sexo & $\begin{array}{c}\text { Procedência do material } \\
\text { examinado }\end{array}$ & Museu \\
\hline \multirow{10}{*}{ 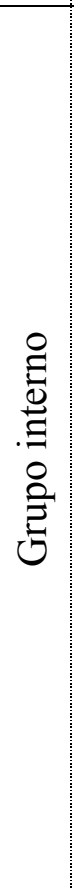 } & 67. Charaxes laodice laodice (Drury, 1782) & M & Bangui, Rep. Cent. Afr. & USNM \\
\hline & & $\mathrm{F}$ & Lipke, Gana & FSMC \\
\hline & 68. Charaxes solon solon (Fabricius, 1793) & $\mathrm{F}$ & Filipinas & MZSP \\
\hline & 69. Charaxes latona latona Butler, 1865 & M & - & USNM \\
\hline & & $\mathrm{F}$ & Nova Guiné & FSMC \\
\hline & & $\mathrm{F}$ & Ceram, Indonésia & FSMC \\
\hline & 71. Agatasa calydonia calydonia (Hewitson, 1854) & M & Malásia & FSMC \\
\hline & & M & Cameron Highlands, Malásia & FSMC \\
\hline & & $\mathrm{F}$ & - & FSMC \\
\hline & 72. Prothoe australis (Guérin-Méneville, [1831]) & M & Nova Guiné & FSMC \\
\hline
\end{tabular}




\subsection{CODIFICAÇÃO DE CARACTERES}

Os caracteres foram codificados segundo as hipóteses de homologias primárias (DE PINNA, 1991) aventadas pelo exame de características morfológicas quaisquer. Foram erigidos apenas caracteres discretos entre os binários e multi-estados.

Construiu-se uma matriz de dados para a fase de imago e outra para a fase de imaturos, incluindo ovo, larva e pupa. Ao final, as matrizes foram fundidas para que houvesse a análise de evidência total dos dados uma vez que os táxons terminais são os mesmos em ambas as matrizes. KLUGE (1998) argumenta em favor da evidência total dizendo que separar os dados em séries atende unicamente a interesses humanos e que esta é uma ação completamente arbitrária. Não houve substituição de táxon para a matriz de imaturos quando faltaram dados, o máximo permitido foi atribuir os imaturos de qualquer das subespécies como representantes da espécie.

Os dados sobre imaturos foram conseguidos através de refêrencias bibliográficas, páginas eletrônicas (JANZEN \& HALLWACHS, 2005) e material fotográfico adquirido em diversos museus e instituições. Os dados sobre planta-hospedeira foram obtidos em HENNING (1988), IgARASHI \& FUKUdA (1996, 2001) e BECCALONI et al. (2008). 


\subsection{ANÁLISE DOS RESULTADOS}

Foram utilizados, no procedimento analítico, os princípios conceituais e metodológicos da Cladística formalmente propostos por HenNiG (1950, 1966), posteriormente discutidos e refinados por outros autores (e.g. WiLLEY, 1981, NELSON \& Platnick, 1981) e mais recentemente bem explicitados em KitCHING et al. (1998) e AMORIM (2002).

A polarização dos caracteres foi obtida pelo método de comparação com o grupoexterno (NIXON \& CARPENTER, 1993). Procedeu-se ao enraizamento entre Apatura iris e os outros terminais.

Utilizou-se o princípio da parcimônia (HENNIG, 1966; FARRIS, 1983) que estabelece que a hipótese mais acertada é aquela mais simples para a explicação do fenômeno em questão, ou seja, com menos premissas (hipóteses ad hoc) a serem assumidas. Em filogenia, isto implica em escolher a hipótese que minimize o requerimento de hipóteses ad hoc que expliquem as homoplasias.

O consenso estrito foi obtido depois da busca das " $n$ " árvores mais parcimoniosas. O consenso estrito (SoKAL \& RoHLF, 1981), ou Árvore de Wagner, é o tipo mais conservativo de consenso para árvores igualmente parcimoniosas e consiste na árvore que contém somente os grupos monofiléticos que ocorrem em todas as árvores do conjunto mais parcimonioso e de comprimento igual resultante da análise.

Após a construção do cladograma de consenso estrito, utilizou-se o método da ponderação sucessiva de caracteres a partir do universo de árvores ótimas. A ponderação sucessiva de caracteres é feita a posteriori quando os pesos são atribuídos aos caracteres depois do cladograma obtido da análise dos caracteres com pesos iguais. A idéia surgiu com Kluge \& FARRIS (1969) e foi aprimorada por Goloboff $(1993,1995)$. O peso de um caráter pode ser entendido como uma função de quanto ele está adequado ao 
cladograma e demanda a consideração tanto de homoplasia quanto de sinapomorfia envolvidas. Isto porque alguns caracteres são cladisticamente mais confiáveis que outros. Os pesos atribuídos afetam o comprimento e a topologia dos cladogramas resultantes, por isso é necessário assegurar que os pesos fiquem estabilizados. Isto implica em um protocolo interativo, onde valores maiores são atribuídos aos caracteres com maior congruência entre si em uma análise com peso igual para todos e conseqüentemente valores mais baixos são assinalados para os caracteres com taxas elevadas de homoplasias. Isto significa amplificar o sinal filogenético para os caracteres mais congruentes e minimizar o ruído filogenético dos caracteres muito homoplásticos.

A partir da árvore obtida com a pesagem sucessiva, foram calculados os índices de retenção e consistência para cada caráter e para o cladograma final (KITCHING et al., 1998). O índice de retenção é calculado como uma razão entre (g-s) e (g-m) onde $g$ é o número máximo de passos que um caráter ou um cladograma pode exibir; $s$ é o número mínimo de passos do mesmo caráter naquele cladograma em questão e $m$ número mínimo de passos que o caráter poderia assumir em qualquer cladograma. $\mathrm{O}$ índice de retenção pode ser interpretado com enfoque no no caráter (ir) ou no cladograma (IR). Para este último, calcula-se a razão de (G-S) e (G-M) como sendo: G, o maior número de passos que todos os caracteres podem assumir; S, o número mínimo de passos que eles podem assumir no cladograma em questão; $\mathrm{M}$, o número mínimo de passos que eles podem assumir em qualquer cladograma.

O índice de consistência (ic) mede a quantidade relativa de homoplasias de um caráter, em um determinado cladograma. Ele deve ser calculado efetuando-se a razão entre $\mathrm{m}$ e $\mathrm{s}$, expostos acima. Este índice também pode dizer respeito ao cladograma (IC) e é calculado pela razão entre $\mathrm{M}$ e $\mathrm{S}$, expostos acima. 
Calculou-se o suporte de Bremer (BREMER, 1994) para a árvore de consenso estrito. O suporte de Bremer consiste no número de passos requeridos para que um determinado clado seja perdido, ou seja, para o colapsamento do ramo da árvore de consenso das árvores subótimas. Para o cálculo do suporte de Bremer de um dado ramo da árvore mais parcimoniosa são tomados todos os cladogramas com um passo a mais que o mínimo encontrado (árvores ótimas e subótimas) e constrói-se uma árvore de consenso destes e da árvore ótima. $\mathrm{O}$ processo é repetido inúmeras vezes, aumentando o comprimento das árvores subótimas de passo em passo até que o clado em questão tenha desaparecido. O número de passos que foram necessários para fazê-lo colapsar é o próprio valor de Bremer para aquele clado.

A matriz de dados foi editada no programa Mesquite versão 2.01 (MADDISON \& MADDISON, 2008) e posteriormente analisada no programa TNT versão 1.1 (GOLOBOFF et al., 2003). Todos os caracteres multi-estados foram tratados como não-ordenados. Dados inaplicáveis foram codificados na matriz como “_" e dados indeterminados como “?”, ainda que o TNT não discrimine entre tais opções. A busca pelas árvores mais parcimoniosas foi efetuada pelo procedimento de busca heurística, utilizando o algoritmo TBR. Optou-se por conservar 10 árvores a cada replicação e um total de 10.000 replicações. Assim, 100.000 árvores foram investigadas. A árvore de consenso desta análise foi obtida no programa TNT, após a busca das árvores com menor número de passos (o conjunto de árvores ótimas) para a matriz considerada.

A ponderação sucessiva foi efetuada utilizando-se a macro REWT.RUN implementada no programa TNT. Levou-se em consideração os FITs 5, 10, 15, 20, 25 e 30. Os índices de retenção e consistência foram calculados no programa TNT com as macros "STATS" e "WSTATS". A distribuição dos caracteres foi analisada no programa WinClada (NIXON, 2002), onde em caso de ambigüidade, optou-se preferencialmente pelas transformações adiantadas (ACCTRAN), em detrimento às atrasadas (DELTRAN), na 
otimização dos caracteres, por ser esta a opção que mais conserva as hipóteses de homologia primária no cladograma. Em poucos casos específicos, julgou-se mais lógico optar pela otimização DELTRAN. Quando existe conflito para a otimização dos estados dos caracteres, a escolha das opções ACCTRAN ou DELTRAN, pode ser feita caso a caso, em que as reversões e os paralelismos indicam as situações evolutivas mais prováveis em cada caso específico. 


\section{RESULTADOS}

\subsection{LISTA DE CARACTERES}

Os 143 caracteres incluídos na matriz são apresentados abaixo. Destes, 89 referem-se ao estágio de imago; na seqüência, são listados os 54 caracteres de imaturos, sendo quatro de ovos (90 a 93), 35 de larva (94 a 129 dos quais todos, exceto o 125, dizem respeito ao quinto ínstar) e 14 de pupa (130 a 143). Entre os caracteres de ovos, o caráter 93 diz respeito ao comportamento de oviposição da fêmea de cada espécie, e entre os de larvas, quatro são comportamentais (caracteres 125 a 128). O caráter 129 envolve aspectos ecológicos das espécies, todos os outros, inclusive os de adultos, são estritamente morfológicos. O estado plesiomórfico é indicado logo após a definição dos estados, em seguida são fornecidas discussões sobre os caracteres, quando pertinentes. O resultado da análise é mostrado nas Figuras 4, 5 e 6 . A Figura 4 contém o resultado do consenso estrito, a Figura 5 contém o resultado da ponderação sucessiva com os clados numerados para sua identificação e a Figura 6 apresenta as transições de estados dos caracteres mostradas no cladograma no qual os círculos negros representam as transições não-ambíguas e círculos abertos, as transições com ambigüidade. No caso da ambigüidade dificultar a determinação do estado plesiomórfico, colocou-se entre parênteses qual otimização foi utilizada para que se recuperasse a informação.

Considera-se a Figura 5 para a discussão dos caracteres quando são mencionados os números dos clados. 


\subsubsection{Caracteres de adultos:}

1. Coloração das escamas do palpo labial (ic: 0,462 ; ir: 0,800 )

0 - predomina um mosaico de escamas de cores variadas (Figura 7c)

1 - metade superior castanha, metade inferior branca (Figura 7d)

2 - uma faixa castanha mais estreita e a maior parte do palpo branca (Figura 7a)

3 - predomina o padrão de listras longitudinais (Figura 8a)

4 - completamente negro

5 - negro com três pontos brancos

6 - completamente branco

Estado plesiomórfico: 2 (acctran)

WiLLMOTT (2003b) utilizou um caráter relativo à coloração de palpo em sua filogenia para o gênero Adelpha Hübner, [1819] (Nymphalidae, Limenitidini), contudo os estados eram diferentes destes apresentados para a filogenia de Charaxinae. PENZ \& DE VRIES (2002) também utilizaram a coloração das escamas do palpo labial na filogenia do gênero Morpho Fabricius, 1807 (Nymphalidae, Morphinae). Este caráter se mostra útil para separar alguns grupos de Charaxinae como Euxanthe que tem um palpo muito peculiar (estado 5). Algumas espécies têm características muito peculiares que dificultam o enquadramento em um ou outro estado. Nesses casos, o estado permaneceu como “?” para aquelas espécies. Os estados 4 (palpo labial completamente negro) e 6 (palpo labial completamente branco) foram criados para contemplar especificamente o grupo externo que não se enquadrava em nenhum dos estados distribuídos entre os Charaxinae. O estado mais amplamente distribuído em Charaxinae é o 1 (metade superior marrom, metade inferior branca), presente no gênero Charaxes (sinapomorfia para o clado 128), em Anaeini e Prothoini. O estado 2 está distribuído predominantemente em Preponini (incluindo 
Anaeomorpha splendida) e pela otimização do caráter, está presente no nó basal da subfamília. O estado 0 (mosaico de escamas coloridas) representa uma sinapomorfia no clado 96 (Memphis glauce (M. $^{+}$

2. Comprimento do palpo labial (ic: 0,250; ir: 0,914)

0 - longo (Figuras $7 \mathrm{~d}, 8 \mathrm{~b}$ )

1 - curto (Figuras 7a, 7c,8a)

Estado plesiomórfico: 0 (acctran)

EHRLICH (1958b) utilizou esse caráter para definir Papilionidae, Lycaenidae e Libytheinae. Nesse trabalho, ele estabeleceu proporções em relação à cabeça e ao tórax. Em Charaxinae, no trabalho de Mielke et al. (2004a), o comprimento do artículo mediano em relação ao basal do palpo labial foi referido para comparar Zaretis itys itylus (Westwood 1950) (Anaeini) e Agrias claudina anetta (Gray, 1832) (Preponini). Nesta tese, optou-se por não definir proporções, a definição dos estados é fornecida pela exemplificação nas pranchas de ilustração do anexo (Figura 7). O caráter também foi citado por RYDON (1971), no qual foi associado à forma de $\mathrm{S}$ ao comprimento longo para os Charaxini, e parte dos Anaeini. Os táxons estudados das tribos Charaxini, Pallini, Euxanthini (RYDON, 1971 considera palpos curtos para esse grupo) e parte de Anaeini (Coenophlebia, Siderone, Zaretis, Hypna e Consul) têm palpo labial longo (estado 0). Os táxons de Preponini (clado 109), Prothoini (clado 143) e parte de Anaeini (Anaea, Fountainea, Polygrapha e Memphis) têm palpo labial curto. Na otimização acctran, o estado 0 (longo) é plesiomórfico porque Apatura iris, que está na raiz do cladograma, apresenta este estado. Contudo, os dois outros táxons do grupo externo apresentam o estado 1 (curto), gerando então o conflito neste caráter. Os nós basais (74, 75 e 80), apresentam o estado "curto", e, dentro do grupo interno, este seria o estado plesiomórfico para o caráter comprimento do palpo labial. 
3. Palpos labiais em vista ventral (ic: 0,143 ; ir: 0,760 )

0 - convergentes (Figura 8d)

1 - paralelos (Figura 8c)

Estado plesiomórfico: 1

A única ambigüidade existente para esse caráter está nos nós 116 e 117, que dão origem aos ramos Palla $^{+}$e Euxanthe ${ }^{+}$. Pela otimização acctran, o estado 0 (palpos convergentes) está presente nesses nós; segundo essa otimização houve reversão para o estado 1 (paralelos) no clado 115 (gênero Euxanthe) e para as espécies Charaxes zoolina e C. jahlusa. Entre os Anaeini, a transição vai de 1 para 0 (paralelos para convergentes), com uma reversão 0 para 1 n o clado 85 (gênero Polygrapha).

4. Borda interna dos palpos labiais brancos (ic: 0,333; ir: 0,875 )

0 - sem faixa de escamas escuras (Figura 7d)

1 - com faixa de escamas escuras (normalmente castanhas) (Figura 7a, 8b)

Estado plesiomórfico: 0

Esse caráter foi primeiramente observado em Preponini cuja faixa de escamas escuras na borda dos palpos é bastante evidente. O surgimento do estado 1 (borda interna dos palpos labiais com faixa de escamas escuras) em Charaxes jasius é independente do surgimento no clado 79 (Prothoini + (Preponini+ Anaeini)). Neste clado, há uma reversão do estado 1 para 0 (borda interna dos palpos labiais sem faixa de escamas escuras) no grupo que forma o clado 76 (Coenophlebia ${ }^{+}$).

5. Palpômero mediano em vista lateral externa (ic: 0,333; ir: 0)

0 - sem cerdas castanhas semelhantes a espinhos (Figura 7a,8a)

1 - com cerdas castanhas semelhantes a espinhos (Figura 7b)

Estado plesiomórfico: 0 
RYDON (1971) menciona o estado 1 (palpo com cerdas castanhas semelhantes a espinhos) para Noreppa chromus, e WiLlmotT (2003b) utilizou-o para separar Adelpha do grupo externo em sua análise. Neste trabalho, observou-se a presença deste estado independentemente nas espécies Noreppa chromus, Prothoe franck e Memphis verticordia. A análise mostrou que os surgimentos do estado 1 nos táxons citados foram independentes.

\section{Escamas brancas na superficie látero-ventral da antena (ic: 0,200; ir: 0,724)}

0 - ausentes ou praticamente ausentes (somente umas poucas escamas no primeiro flagelômero)

1 - presentes apenas nos primeiros antenômeros (metade basal da antena)

2 - presentes em todo o comprimento da antena

Estado plesiomórfico: 0 (acctran)

EHRLICH (1958b) e FREITAS \& BROWN (2004) citaram o caráter de uma forma mais abrangente, considerando apenas a presença e ausência de escamas nas antenas como estados para um caráter de enunciado mais geral. Em Charaxinae verificou-se que seria necessário desmembrar estes estados para adequar às variações que ocorrem na subfamília. O táxon no qual o cladograma foi enraizado, Apatura iris, apresenta o estado 1, contudo após a otimização acctran toda a base do cladograma após o enraizamento apresenta o estado 0 (escamas brancas ausentes ou praticamente ausentes). O estado 2 (presentes em todo o comprimento da antena) está restrito ao clado 90 (Zaretis) e 82 (Consul electra ${ }^{+}$ considerando a otimização acctran), com algumas reversões ocorrendo dentro do segundo. O estado 1 (presença apenas nos primeiros antenômeros) representa uma sinapomorfia para os clados 109 (Preponini) apesar das reversões, e 84 (Siderone galanthis $^{+}$) com transição

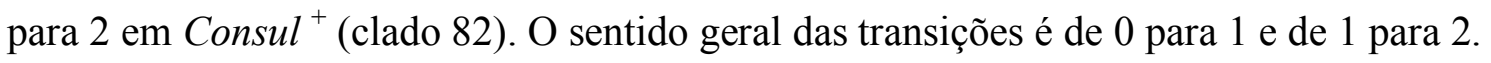

7. Probóscide (ic: 0,500; ir: 0,333) 
0 - castanha (clara a escura)

1 - preta

2 - verde

Estado plesiomórfico: 0

O estado 2 (probóscide verde) mostrou-se homoplástico entre seus representantes, Charaxes candiope e C. eupale. Ainda que o estado 1 (preta) também seja homoplástico para C. hadrianus e Euxanthe, ele representa uma sinapomorfia para as espécies deste último gênero.

8. Tamanho da mancha branca do anel da área paraocular: (ic: 0,500; ir: 0,500)

0 - ponto pequeno

1 - mancha maior, mas circunscrita ao anel

2 - mancha que se estende à pós-gena

Estado plesiomórfico: 1

O estado 1 em Charaxes nobilis é convergente com aquele encontrado em Euxanthe, mas representa para este gênero uma sinapomorfia homoplástica. Palla decius e Charaxes laodice também apresentam homoplasia quanto ao estado 0 . O estado 2 é sinapomorfia do clado 134 (Charaxes eupale ${ }^{+}$).

9. Tufo de escamas brancas na margem proximal do quetosema (ic: 0,111 ; ir: 0,758 )

0 - ausente

1 - presente (Figura 37b)

Estado plesiomórfico: 0

O estado 1 (presente) do caráter é o que está no nó do grupo interno ( clado 80). Neste caráter, ocorreram seis perdas independentes (reversões de 1 para 0): Charaxes 
nichetes, C. zoolina, C. candiope, Agatasa calydonia e nos clados 77 (Anaeomorpha splendida ${ }^{+}$) (com um novo ganho em Hypna clytemnestra) e parte do clado $130(C$. varanes, C. cynthia, C. tiridates, C. eurialus, C. lucretius, C. jasius, C. latona). O ganho após a perda do tufo, para este caráter, não é, de fato, surpreendente, uma vez que este tufo está relacionado a um grupo de escamas brancas que margeiam o quetosema e estão sempre presentes apesar de encobertas. Somente nas espécies cujo estado é "presente", tais escamas se sobressaem e formam o tufo branco que pode ser visto mesmo a olho nu, entre as escamas acinzentadas da cabeça. Este caráter representa uma sinapomorfia para os Charaxinae + Antirrhea archaea com a transição do estado 0 para 1 (ausência para presença do tufo) na base do cladograma.

10. Tufo de escamas brancas anterior ao escapo da antena (ic: 0,111 ; ir: 0,765 )

0 - presente (Figura 37b)

1 - ausente

Estado plesiomórfico: 0 (acctran)

Existe grande ambigüidade quanto à distribuição dos estados para este caráter, contudo tanto pela otimização acctran como pela deltran o estado plesiomórfico é o 0 (presença do tufo). No clado 117 (Palla decius ${ }^{+}$), a perda do tufo ocorreu independentemente em Charaxes nichetes, C. varanes, $C$. candiope e no clado 137 (C. lucretius + C. jasius + C. latona $)$. Já no clado 79 (Prothoini + Preponini + Anaeini) houve perda do tufo para o gênero Prothoe (clado 144) e para todo o clado 77 (Anaeomorpha splendida ${ }^{+}$) exceto para Polygrapha tyrianthina que teve um ganho independente. Em todos os representantes de Preponini (exceto Anaeomorpha splendida que está agrupada com os Anaeini) o tufo está presente.

11. Tufo de escamas brancas entre as antenas (ic: 0,250; ir: 0,750) 
0 - presente (Figura 37b)

1 - ausente

Estado plesiomórfico: 1

O estado apomórfico (presença do tufo), embora tenha aparecido uma única vez no clado 117 (Palla decius ${ }^{+}$), em Charaxes zingha representa uma sinapomorfia de Preponini, exceto quanto à Anaeomorpha splendida, que diverge em muitos outros caracteres da tribo na qual está atualmente alocada. Uma reversão para a perda da estrutura acontece em Noreppa chromus.

12. Tufo de escamas brancas na patágia (ic: 0,143 ; ir: 0,500 )

0 - ausente

1 - presente

Estado plesiomórfico: 0

Esse caráter foi utilizado por PENZ \& DE VRIES (2002) para o gênero Morpho (Morphinae). Embora a presença de tufo (estado 1) se distribua de forma bastante homoplástica no clado 117 (Palla decius $^{+}$), ele se mantém como sinapomorfias homoplásticas para dois gêneros, Euxanthe e Agrias, e para o clado 126 (Charaxes nobilis $^{+}$), com reversões em C. solon, C. zoolina, C. pleione e Polyura athamas.

13. Faixa de escamas castanhas no tórax sob o segundo par de pernas (ic: 0,200; ir: $0,765)$

$$
\begin{aligned}
& 0 \text { - ausente } \\
& 1 \text { - presente }
\end{aligned}
$$

Estado plesiomórfico: 0 
O estado apomórfico apareceu independentemente em três clados: $126(C$. nobilis $^{+}$), com posterior desaparecimento em C. pleione; no clado 143 (Prothoini) e no clado 114 (gênero Agrias). O aparecimento da faixa de escamas castanhas em Charaxes zingha foi independente daquela do clado 126.

14. Margem interna da asa anterior (ic: 0,333 ; ir: 0,800)

0 - reta (Figura 10a)

1 - emarginada no ângulo anal (Figura 10c)

Estado plesiomórfico: 0

Esse caráter foi discutido no trabalho de RYDON (1971) no qual o estado 1 caracterizava alguns gêneros de Anaeini: Zaretis, Siderone e Memphis. Em MiElKe et al. (2004b), o caráter também foi discutido na comparação entre Zaretis itys itylus e Agrias claudina anetta. Pela presente análise, verificou-se que a ocorrência do estado 1 (emarginada no ângulo anal) em Zaretis e Siderone (grupo monofilético) é homoplástico em relação à sua ocorrência em Memphis com reversão em M. polyxo.

15. Torno da asa anterior com emarginação na borda interna (ic: 0,667 ; ir: 0,750 )

0 - não toca o prolongamento da linha da margem interna (Figura 10c)

1 - toca a linha de prolongamento (Figura 13a)

2 - ultrapassa o prolongamento (Figura 13b)

Estado plesiomórfico: 0 (acctran)

Após o exame mais detalhado do caráter anterior, verificou-se que as emarginações eram levemente ou fortemente pronunciadas. Estabelecendo-se uma linha imaginária sobre a margem interna da asa, o torno da asa se comporta de forma a tocar, ou não esta linha ou ainda ultrapassá-la segundo os estados propostos. A otimização revela 
que as transições vão de 0 (não toca) para 1 (toca), e de 1 para 2 (ultrapassa) como era esperado em uma sequência crescente de expansão do torno.

16. Ápice da asa posterior (ic: 1 ; ir: 1)

0 - emarginado, principalmente nas fêmeas (Figura 10c)

1 - não emarginado (Figura 10b)

Estado plesiomórfico: 1

Em MiELKE et al. (2004b), o caráter é citado na comparação entre Zaretis itys itylus e Agrias claudina anetta considerado como uma concavidade entre Sc+R1 e Rs. Em Siderone a emarginação do ápice (estado 0) não foi detectada, mas é possível que seja apenas um grau mais suave de emarginação que esteja críptica. $\mathrm{O}$ estado 0 (ápice emarginado) é sinapomorfia exclusiva para o gênero Zaretis.

17. Escamas androconiais da asa posterior (em machos) (ic: 1; ir: 1)

0 - ausentes

1 - presentes e inseridas além da membrana na veia 2A na sua porção basal

2 - presentes, mas não inseridas na porção basal da veia 2A (Figura 37a)

Estado plesiomórfico: 0

Este caráter é citado em outros trabalhos (RYDON, 1971, Mielke et al., 2004b), com apenas dois estados: presença e ausência das escamas. A divisão dos estados 1 e 2 foi necessária devido à posição das androcônias no gênero Prothoe e em Preponini. A condição plesiomórfica em Charaxinae é a ausência de androcônia (estado 0), sendo a presença de escamas androconiais inseridas além da membrana na veia $2 \mathrm{~A}$ na sua porção basal uma sinapomorfia para o gênero Prothoe e a presença de escamas androconiais não inseridas na porção basal da veia 2A uma sinapomorfia para Preponini (clado 109) exceto 
Anaeomorpha splendida. A otimização resulta em transições dos estados 0 para 1 e 0 para 2.

18. Escamas androconiais (ic: 1 ; ir: 1)

0 - pretas ou castanho-escuras

1 - castanho-claras

2 - amarelas (Figura 37a)

Estado plesiomórfico: 0 (acctran)

Os estados 0 (escamas androconiais pretas ou castanho-escuras) e 2 (escamas androconiais amarelas) foram citados por RYDON (1971), nos gêneros Archaeoprepona (0), Prepona (2) e Agrias (2). No mesmo trabalho, o autor considera o estado 1 (escamas androconiais castanho-claras) igual ao 2 (escamas androconiais amarelas), ou seja, o autor não discrimina entre as androcônias de Prothoe e de Prepona e Agrias, nem mesmo quanto à posição (caráter anterior). Segundo a otimização, as transições foram muito semelhantes às do caráter anterior: 0 para 1 e 0 para 2 independentemente.

19. Prolongamento de M3 (cauda) da asa posterior dos machos (ic: 0,125 ; ir: 0,800)

0 - ausente (Figura 11c)

1 - presente (Figura 11d)

Estado plesiomórfico: 0

CAldas (1993) discutiu o comprimento da cauda na asa posterior de Fountainea ryphea e $F$. eurypyle como uma variação que poderia distinguir as duas espécies ou conduzir a fusão das espécies por conta de um gradiente de variação entre as populações ao longo da América do Sul e Central. O caráter é bastante homoplástico com várias reversões: C. zoolina, clado 88 (Polygrapha xenocrates ${ }^{+}$), Fountainea ryphea, clado 100 
(Memphis hirta + M. polyxo) e M. grandis; mas com poucos surgimentos paralelos: Palla decius, clado 130 (Charaxes varanes ${ }^{+}$), e clado 83 (Hypna clytemnestra ${ }^{+}$).

20. Prolongamento de M3 (cauda) da asa posterior das fêmeas (ic: 0,167; ir: 0,839)

$$
\begin{aligned}
& 0 \text { - ausente (Figura 11c) } \\
& 1 \text { - presente (Figura 11d) } \\
& \text { Estado plesiomórfico: } 0
\end{aligned}
$$

Da mesma forma que no caráter anterior, este também sustenta os clados 83 (Hypna clytemnestra ${ }^{+}$) e 130 (Charaxes varanes $^{+}$), ainda que com vários eventos homoplásticos. Este caráter é distinto do anterior quanto à distribuição de estados para os táxons Memphis grandis, Fountainea ryphea, Zaretis callidryas, Charaxes zoolina e $C$. laodice, os quais apresentam o estado 1.

21. Formato do ápice da cauda em M3 dos machos (ic: 0,500; ir: 0,786)

$$
\begin{aligned}
& 0 \text { - afilado (Figura 11b) } \\
& 1 \text { - arredondado (Figura 11d) } \\
& 2 \text { - dilatado e arredondado (Figura 13b) } \\
& 3 \text { - dilatado e subtriangular (Figura 11a) } \\
& \text { Estado plesiomórfico: } 1 \text { (acctran) }
\end{aligned}
$$

Como o grupo externo não apresenta cauda, o caráter foi considerado inaplicável para as respectivas espécies. Com isso, a otimização acctran (e também a deltran) recupera a informação do estado plesiomórfico. O caráter representa algumas sinapomorfias homoplásticas, como o estado afilado (0) no clado 129 (C. cynthia $\left.{ }^{+}\right)$e $86\left(\right.$ Polygrapha $\left.^{+}\right)$, e a reversão para o formato do ápice da cauda arredondado (estado 1) no clado 94 (Fountainea nessus ${ }^{+}$). O estado dilatado e subtriangular (3), que ocorre apenas em Hypna e 
Consul, é recuperado pela otimização acctran nos nós mais basais a Hypna e Consul e representa sinapomorfia para o clado 79 (Agatasa calydonia ${ }^{+}$) com reversão no clado 86 já comentada.

22. Formato do ápice da cauda em $M_{3}$ das fêmeas (ic: 0,300; ir: 0,682)

$$
\begin{aligned}
& 0 \text { - afilado } \\
& 1 \text { - arredondado } \\
& 2 \text { - dilatado e arredondado } \\
& 3 \text { - dilatado e subtriangular } \\
& \text { Estado plesiomórfico: } 1 \text { (acctran) }
\end{aligned}
$$

O formato do ápice da cauda em $\mathrm{M}_{3}$ em fêmeas fornece sinapomorfias para outros clados que não estão presentes no caráter anterior: estado 2 (dilatado e arredondado) no clado 97 (Memphis grandis ${ }^{+}$), estado 3 (dilatado e subtriangular) no clado 83 (Hypna e Consul) com reversão no clado 86 (Polygrapha $\left.{ }^{+}\right)$a semelhança do caráter anterior, e estado 0 (afilado) no clado 127 (C. candiope $^{+}$) com reversão para 1 em $C$. etheocles e surgimento do estado 2 em C. zoolina.

23. Prolongamento de $\mathrm{Cu}_{2}$ (cauda) da asa posterior (ic: 0,333; ir: 0,882)

0 - ausente em ambos os sexos

1 - presente em ambos os sexos (Figura 12a)

Estado plesiomórfico: 0

O estado 1 (cauda em $\mathrm{Cu}_{2}$ presente) é sinapomórfico para o ramo 129 (C. cynthia $^{+}$), apesar de reversões ocorrerem em Charaxes eurialus e C. pleione.

24. Lobo na margem externa da asa posterior (ic: 0,500; ir: 0,667) 
0 - ausente

1 - presente (formado pelas nervuras $\mathrm{M} 3, \mathrm{Cu}_{1}$ e $\mathrm{Cu}_{2}$ ) (Figura 12d)

Estado plesiomórfico: 0

A presença de um lobo na asa posterior representa uma sinapomorfia para a tribo Prothoini (clado 143) e convergente em relação a Memphis hirta.

25. Projeção caudal no lobo anal da asa posterior (ic: 0,200; ir: 0,500)

0 - ausente

1 - presente (Figuras 10c,d)

Estado plesiomórfico: 0

Este caráter foi utilizado por PENZ \& DE VRIES (1999) para a tribo Lemoniini (Riodinidae) e WiLLMOTT \& HALL (2001) incluíram esta característica típica de Zaretis na chave de identificação para as espécies deste gênero. A presença da projeção caudal no lobo anal (estado 1) representa sinapomorfia homoplástica para os clados 133 ( $C$. nichetes $\left.{ }^{+}\right)$, com reversão no clado $130\left(\right.$ C. varanes $\left.{ }^{+}\right)$; e dentre os Anaeini, nos clados 89 (Siderone + Zaretis), 81 (gênero Consul) e Memphis hirta.

26. Margem costal da asa anterior (ic: 1 ; ir: 1 )

$$
\begin{aligned}
& 0 \text { - serrada (Figuras 13c,d) } \\
& 1 \text { - não-serrada }
\end{aligned}
$$

Estado plesiomórfico: 1

A condição serrada da margem costal da asa anterior em Charaxinae foi mencionada em vários trabalhos de morfologia e taxonomia do grupo. Em ROTHSCHILD \& JORDAN (1898-1903), por exemplo, o caráter é utilizado para delimitar o escopo do estudo 
referente aos gêneros prionópteros (Palla, Euxanthe, Charaxes e Polyura). SMILES (1982, 1985) e HENNING (1988) também observaram a condição serrada nestes gêneros majoritariamente africanos. DE VRIES (1987) argumenta que os dentes na costa da asa anterior seriam usados na defesa contra predadores e nas interações agonísticas entre machos. Uma hipótese mais plausível é a dada por WoOdhall (2008) que relata que a margem costal da asa anterior serrada serve para coagir as outras borboletas competidoras pelas fontes de alimento, a se retirarem. É provável que a serração na costa da asa não represente nenhum obstáculo à predação, e uma vez que as fêmeas também possuam a estrutura denteada sua função não deve estar ligada ao sexo. $\mathrm{O}$ estado 0 representa uma sinapomorfia exclusiva do clado 117 (Pallini + Euxanthini + Charaxini).

27. Manchas ocelares cordiformes das asas anteriores em vista ventral (ic: 0,500; ir: $0,750)$

0 - ausentes

1 - presentes (Figura 37e)

Estado plesiomórfico: 0

Esse caráter é extensivamente tratado no trabalho de ScHWANWITSCH (1930) para o gênero Prepona. Entretanto, a interpretação para este elemento não é homóloga à interpretação fornecida por NIJHOUT (1991), ainda que ambos os trabalhos refiram-se à mesma estrutura. As manchas ocelares cordiformes nas asas anteriores estão presentes no clado 113 (Prepona laertes + P. pylene) e no clado 118 (Polyura athamas ${ }^{+}$).

28. Margem interna da asa posterior na célula $2 A-3 A$ (ic: 0,222 ; ir: 0,462 )

0 - reta (Figura 9d)

1 - levemente sinuosa (Figura 10a) 
2 - bastante sinuosa (Figura 10d)

Estado plesiomórfico: 0

Caráter bastante homoplástico representando uma sinapomorfia no clado 76 (Coenophlebia archidona ${ }^{+}$) com reversão no clado 86 (Polygrapha cyanea ${ }^{+}$). As transições para o estado 1 (margem levemente sinuosa) foram tratadas como surgimentos independentes entre os vários clados e táxons terminais em que o estado ocorre: clado 88 (Polygrapha xenocrates ${ }^{+}$), Anaea troglodyta, M. hirta e clado 102 (M. moruus + M. philumena).

29. Segundo e terceiro par de tíbias e tarsos (ic: 1; ir: 1)

0 - com a mesma cor do fêmur

1 - cor diferente (branco) daquela do fêmur (castanho)

Estado plesiomórfico: 0

O estado 1 (cor diferente daquela do fêmur) para o segundo e terceiro par de tíbias e tarsos representa uma sinapomorfia exclusiva do clado 89 (Siderone + Zaretis).

30. Manchas ocelares nas asas posteriores em vista ventral (ic: 0,300; ir: 0,821)

0 - puntiformes (Figuras 38b,d,e)

1 - circulares (Figuras 37b, 38a,b)

2 - lineares

3 - compostas $(\mathrm{h}+\mathrm{i})$ não-circulares (Figura $38 \mathrm{c}$ )

4 - ausentes

Estado plesiomórfico: 0 
O estado 3 (manchas ocelares compostas por $\mathrm{h}+\mathrm{i}$ ) (ver Figura 3 ) é definido em NiJHOUt (1991). Como existe uma tendência à redução dos elementos do padrão de asas em Anaeini e Preponini parece pouco provável que a composição $\mathrm{h}+\mathrm{i}$ também exista nos grupos neotropicais. A presença de duas ou três cores formando a mancha ocelar puntiforme (estado 0) como em Polygrapha cyanea (Figura 38d) talvez indique a origem comum de $\mathrm{h}+\mathrm{i}$ desse elemento em Charaxinae. Contudo, para decompor os grandes ocelos de algumas espécies de Prepona (Figura 37e), e mesmo as manchas circulares de Agrias (Figura 38a) e Archaeoprepona em $\mathrm{h}+\mathrm{i}$, seria necessário um estudo mais aprofundado sobre os elementos do padrão de asas. No presente trabalho, foi assumido que para essas espécies com manchas circulares e ocelos bem desenvolvidos, o elemento do padrão de asas que as compõe seria apenas o elemento "i". No gênero Charaxes, os elementos "h" e “i” compõem as manchas ocelares facilmente identificáveis por estarem dissociados, diferindo, portanto, das pequenas manchas puntiformes bi ou tricolores de Anaeini, ou dos grandes ocelos do gênero Prepona, os quais não podem ser decompostos em partes com segurança. Este elemento ocelar, neste grupo, parece ser uma estrutura única, ou seja, composto de um único elemento "h" ou "i". O estado 3 (manchas ocelares compostas por $\mathrm{h}+\mathrm{i}$ ) sustenta uma sinapomorfia para o clado 134 (tribo Charaxini) e paralelamente, sinapomorfia da tribo Prothoini (clado 143). A ausência completa de manchas ocelares (estado 4) foi detectada uma única vez em Preponini (clado 109) e quatro vezes em Anaeini (clado 77), considerando Anaeomorpha splendida pertencente a este clado.

31. Manchas ocelares das asas posteriores em vista ventral (exceto para a célula $\mathrm{Cu}_{2}-2 \mathrm{~A}$ ) (ic: 1 ; ir: 1)

0 - única

1 - duplas (bipartidas)

Estado plesiomórfico: 0 
$\mathrm{Na}$ célula $\mathrm{Cu}_{2}-2 \mathrm{~A}$ da superfície ventral da asa posterior em qualquer ninfalídeo, há uma mancha ocelar dupla. Contudo, o estado 1 (manchas ocelares duplas) diz respeito a todas as outras células marginais da asa posterior. Este estado (manchas ocelares duplas) representa uma sinapomorfia exclusiva do gênero Euxanthe (clado 115).

32. Manchas ocelares circulares nas asas posteriores em vista ventral (ic: 1 ; ir: 1)

0 - pequenas (menos de $2 \mathrm{~mm}$ de diâmetro) (Figura 37f)

1 - grandes (mais de 4 mm de diâmetro) (Figura 38a)

Estado plesiomórfico: 0 (acctran)

A ambigüidade gerada neste caráter está no fato de que manchas circulares só existem em Preponini e o estado 0 (manchas pequenas) é característico de Archaeoprepona (0) e o estado 1 (manchas grandes) de Agrias (1). Somente quando se utiliza a otimização acctran, o estado plesiomórfico fica definido. O estado 0 (manchas ocelares circulares pequenas) é compartilhado pelos táxons 107 (Archaeoprepona demophon ${ }^{+}$), mas de acordo com a otimização acctran, esta é uma simplesiomorfia. Em A. chalciope, as manchas ocelares circulares estão ausentes.

33. Mancha ocelar na célula $R s-M_{1}$ da asa posterior em vista ventral (ic: 1 ; ir: 1)

0 - igual às manchas ocelares das outras células marginais (Figura 37f)

1 - diferente das manchas das outras células (ocelo mimético bem desenvolvido) (Figura 37e)

Estado plesiomórfico: 0

O clado 110 (Prepona praeneste ${ }^{+}$) compartilha o estado 1 manchas diferenciadas das outras sob forma de ocelo. Esse caráter é importante para estabelecer a relação de proximidade filogenética entre Prepona praeneste (até agora considerada uma espécie de 
Prepona de posicionamento basal no gênero) e Prepona laertes e P. pylene. Isso faz com que $P$. praeneste ocupe uma posição mais apical em relação a $P$. pheridamas que tem todas as manchas ocelares idênticas às das outras células marginais.

34. Mancha ocelar na célula $\mathrm{Cu}_{1}-\mathrm{Cu} u_{2}$ da asa posterior em vista ventral (ic: 0,500; ir: $0,667)$

0 - igual às manchas ocelares das outras células marginais (Figura 37f)

1 - diferente das manchas das outras células (ocelo mimético bem desenvolvido) (Figura 37e)

Estado plesiomórfico: 0

Este caráter está dissociado do anterior por causa de Palla decius, cujo ocelo está presente apenas na célula $\mathrm{Cu}_{1}-\mathrm{Cu}_{2}$ da asa posterior. A aquisição do estado 1 (manchas diferenciadas) é independente para Palla decius e para o clado 110 (Prepona praeneste ${ }^{+}$).

35. Elemento ocelar da asa posterior ou apenas elemento " $i$ " quando dissociado de " $h$ " (ic: 0,200 ; ir: 0,636$)$

0 - unicolor (Figura 38b)

1 - bicolor (Figura 38e)

2 - tricolor (Figura 38c)

Estado plesiomórfico: 1

O estado 2 (elemento ocelar tricolor) se mostrou bastante homoplástico; contudo, assinala três sinapomorfias relativamente importantes: para os clados 121 (Polyura pyrrhus $^{+}$), 105 (Archaeoprepona licomedes ${ }^{+}$) e 111 (Agrias amydon $^{+}$). Outros surgimentos deste estado ocorreram independentemente nos clados 140 (C. tiridates + C. eurialus), 142 (C. etheocles $+C$. solon) e nos táxons C. latona e C. hadrianus. O estado 0 (unicolor) é 
sinapomorfia para o gênero Euxanthe, sendo este surgimento independente daquele em Prepona pheridamas.

36. Elemento "c" na célula discal da asa anterior em vista ventral (ic: 0,222; ir: 0,667)

0 - como uma faixa contínua que cruza a célula discal (Figura 38c)

1 - como uma faixa dividida em dois fragmentos (Figuras 37e,f, 38a)

2 - como uma faixa dividida mas apenas um segmento visível

3 - mancha indefinida e esmaecida (Figura 38d)

4 - ausente ou indistinto

Estado plesiomórfico: 0

O elemento "c", assim como os elementos dos conjuntos de simetria do padrão de asas, é originalmente uma faixa ou linha que passa por várias células. É bastante provável que "faixa contínua" seja o estado plesiomórfico e os demais estados mais derivados em relação a este. Caráter bastante homoplástico com o estado 1 (faixa dividida em dois fragmentos) representado como sinapomorfia dos clados 109 (Preponini, exceto Anaeomorpha splendida), 143 (Prothoini), 133 (Charaxes nichetes ${ }^{+}$), com reversões pontuais em alguns gêneros e a do clado 128. O estado 2 sustenta apenas autapomorfias para as espécies Archaeoprepona chalciope e Charaxes jahlusa. O estado 3 se distribui predominantemente entre os Anaeini. A ambigüidade que se observa para este estado e o estado 0 no clado 83 (Hypna clytemnestra ${ }^{+}$) fica mais bem interpretada usando a otimização deltran, pois mantém um único surgimento para o estado 3 na base do clado 77 (Anaeomorpha splendida ${ }^{+}$), o mesmo pode ser dito para o estado 1 no clado 116 (Euxanthe eurinome $^{+}$) que, com a otimização deltran, tem um único surgimento na base do clado 75 (Antirrhea archaea ${ }^{+}$).

37. Elementos "d" e "f" na célula $C u_{2}-2 A$ da asa posterior (ic: 0,222; ir: 0,714) 
0 - separados

1 - fundidos

2 - ausentes ou indistintos

Estado plesiomórfico: 0 (acctran)

O estado 1 ("d" e "f" fundidos) é sinapomórfico para os clados 141 (Charaxes. zoolina + C. pleione $)$ e 118 (Polyura athamas $\left.{ }^{+}\right)$. A ausência de "d" e "f" na célula $\mathrm{Cu}_{2}-2 \mathrm{~A}$ da asa posterior (estado 2) é sinapomórfico para o clado 78 (Preponini + Anaeini) com reversão no gênero Consul (clado 81). Contudo, o estado 2 é o que deveria ser considerado o estado plesiomórfico, uma vez que existe ambigüidade na distribuição dos estados para o grupo externo. Pela distribuição acctran a ausência (estado 2) ocorre nos nós 74 e 75 que antecedem o nó do grupo interno (nó 80). Pela otimização deltran o estado plesiomórfico é o 0 (d e f separados). A sequência de transições apresentada pela otimização acctran é mais provável que aquela apresentada pela deltran de 2 para 0 e de 0 para 1 , considerando então o estado 2 de Antirrhea archaea e Calinaga buddha como o estado plesiomórfico e não o estado 0 de Apatura iris.

38. Elementos "d" e "f" na célula anal da asa posterior em vista ventral (ic: 0,273; ir:

0 - fundidos

1 - parcialmente fundidos

2 - não-fundidos

3 - ausentes ou indistintos

Estado plesiomórfico: 3

A hipótese inicial era que o estado "fundido" para "d" e "f" na célula anal da asa posterior agrupasse as espécies que portam essa característica bastante peculiar, o que não 
aconteceu, sendo, portanto, interpretado como convergência em cada um dos surgimentos (Charaxes nichetes, C. latona, C. etesipe e C. pleione). O estado 2 (“d" e "f" não-fundidos) representa uma sinapomorfia para o clado $126\left(C\right.$. nobolis $\left.{ }^{+}\right)$contendo uma reversão no clado 122 (C. zoolina $\left.{ }^{+}\right)$e outra para os Prothoini (clado 143). Além desses clados, há surgimentos independentes do estado 2 em C. jasius, Siderone galanthis e Memphis polyxo. O estado 1 (parcialmente fundidos) é autapomórfico para C. eurialus.

39. Elemento "c" na célula discal na superfície ventral da asa posterior como (ic: 0,200; ir: 0,613$)$

0 - uma faixa contínua que cruza a célula discal (Figura 38c)

1 - uma faixa dividida em dois fragmentos (Figura 37e)

2 - uma faixa dividida mas apenas um segmento visível

3 - ausente

Estado plesiomórfico: 3 (acctran)

Apesar do surgimento independente como autapomorfia em $C$. zingha e $C$. jahlusa, Agatasa calydonia e Polygrapha tyrianthina, o estado 1 é sinapomórfico para o clado 109 (Archaeoprepona chalciope ${ }^{+}$) sem a otimização nesta ambigüidade, ou pela otimização acctran essa sinapomorfia é transferida para o clado 79 (Agatasa calydonia ${ }^{+}$) com reversão para a ausência (estado 3) em 77 (Anaeomorpha splendida ${ }^{+}$). A ocorrência do estado 2 no clado 109 (Archaeoprepona demophon, Agrias amydon e Prepona pheridamas) é autapomórfica para cada espécie que a contém, derivando do estado 1 . O estado 0 (faixa contínua) é condição sinapomórfica para o clado 130 (C. varanes $\left.^{+}\right)$com reversão para o estado 3 no clado 119 (Polyura delphis ${ }^{+}$).

40. Elementos complexos de "a" a "f" na superficie ventral das asas (ic: 0,333; ir: 0) 
0 - ausentes

1 - presentes

Estado plesiomórfico: 0 (acctran)

Segundo NiJHOUT (1991), elementos complexos são aqueles que possuem várias faixas coloridas contornando um elemento do padrão de asas. A presença de tais elementos (estado 1) compartilhada por Charaxes etesipe e C. jasius não tem origem comum como esperado.

41. Quitina das nervuras das asas (ic: 0,133 ; ir: 0,350)

0 - de castanha a preta

1 - de transparente a amarelo translúcida

2 - verde

Estado plesiomórfico: 0

A cor verde está presente independentemente nos táxons C. eupale, C. jahlusa e C. candiope.

42. Segmento $R_{3}$ e nervura M1 da asa anterior (ic: 0,125; ir: 0,708)

0 - separados por $r-m_{1}$ (Figura 11a)

1 - unidos na base (Figura 12d)

Estado plesiomórfico: 1

Entre as nervuras $M_{1}$ e a base de $R_{3}+R_{4}+R_{5}$ (segmento $R_{3}$ ) pode haver um pequeno segmento no final da célula discal chamado $\mathrm{r}-\mathrm{m}_{1}$ (disco-celular superior) (Figura

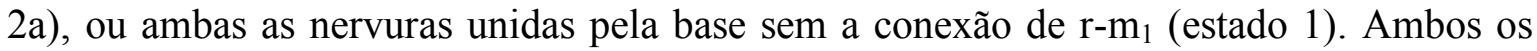
estados 1 e 0 estão no grupo externo o que faz com que os nós mais basais do cladograma 
apresentem o estado 0 depois da otimização. A reversão posterior para o estado 1 é a sinapomorfia que sustenta o clado $122\left((\text { C. zoolina }+ \text { C. pleione })^{+}\right)$. Também aconteceu o mesmo tipo de reversão independentemente nos clados 109 (Preponini exceto Anaeomorpha splendida) e 144 (gênero Prothoe).

43. $\mathrm{m}_{1}-\mathrm{m}_{2}$ da asa anterior (ic: 0,143 ; ir: 0,520 )

0 - maior que $r-m_{1}$

1 - menor que $r-m_{1}$

2 - aproximadamente o mesmo comprimento de r-m

Estado plesiomórfico: 0

Entre as nervuras $\mathrm{M}_{1}$ e $\mathrm{M}_{2}$ no final da célula discal pode haver um segmento de nervura chamado $\mathrm{m}_{1}-\mathrm{m}_{2}$ (disco-celular mediano) (Figura 2a). Duas sinapomorfias são importantes neste caráter: o estado 1 representando o clado 76 (Coenophlebia archidona ${ }^{+}$) e o estado 2 representando o clado $123\left(\right.$ C. jahlusa ${ }^{+}$), apesar de outros surgimentos do estado, mais basais ao clado 123, em Euxanthe eurinome e $C$. jasius, e reversões em ramos mais apicais (Polyura pyrrhus e P. jalysus + P. schreiber) ou em outros clados (Prothoe franck, Consul fabius, P. xenocrates, Fountainea nessus e M. pithyusa).

44. Alargamento apical da célula $R_{3}-R_{4}$ (ic: 0,143 ; ir: 0,714 )

$$
\begin{aligned}
& 0 \text { - ausente (Figura 10a) } \\
& 1 \text { - presente (Figura 9a) } \\
& \text { Estado plesiomórfico: } 0
\end{aligned}
$$

O caráter foi observado por RYdon (1971) e HENNING (1988). O alargamento apical da célula $R_{3}-R_{4}$ é uma sinapomorfia para a subfamília Charaxinae (clado 80 ). A reversão para a ausência, no clado 94 (Fountainea nessus ${ }^{+}$) e em outras espécies de 
gêneros mais basais em Anaeini (Coenophlebia, Zaretis, Consul e Polygrapha), representa um segundo momento na história desse caráter para a subfamília onde a célula $R_{3}-R_{4}$ voltou a ter uma aparência estreita.

45. Origem da nervura $R_{3}$ (ic: 1 ; ir: 1$)$

0 - a partir do mesmo setor radial de $\mathrm{R}_{4}$ e $\mathrm{R}_{5}$ (Figura 9c)

1 - a partir do mesmo setor radial de $\mathrm{R}_{2}, \mathrm{R}_{4}$ e $\mathrm{R}_{5}$

Estado plesiomórfico: 1

Este caráter representa apenas uma transição dentro do grupo externo no clado 75 (Antirrhea archaea $^{+}$) fazendo com que Antirrhea archaea tenha mais similaridades em comum com a subfamília Charaxinae do que Calinaga buddha.

46. Surgimento de $R_{3}$ em relação a $R_{5}$ na asa anterior (ic: 0,500; ir: 0,944)

$$
\begin{gathered}
0 \text { - basalmente (Figura 9c) } \\
1 \text { - apicalmente (Figura 11a) } \\
\text { Estado plesiomórfico: } 0
\end{gathered}
$$

Este caráter foi sugerido por COMSTOCK (1961) para distinguir dois grupos em Anaeini: os basais (Coenophlebia, Siderone, Zaretis, Hypna e Anaea) e os mais apicais (Memphis, Polygrapha e Consul). A transição para o estado 1 se dá no clado 82 com uma única reversão em Anaea troglodyta. Nesta última, por ter uma asa muito atípica com redução de nervuras inteiras, é muito provável que se trata de um outro evento evolutivo a ser considerado nesta posição do cladograma e que o ancestral deste táxon apresentava a condição apomórfica.

47. Nervuras Sc e radiais da asa anterior (ic: 1 ; ir: 1) 
0 - livres (Figura 12e)

1 - anastomosadas (Figura 10d)

Estado plesiomórfico: 0

Este caráter foi baseado nas observações de COMSTOCK (1961). As ilustrações contidas neste livro serviram de base para o levantamento dos estados deste caráter para os Anaeini. Contudo, a ilustração apresentada para o gênero Zaretis não está correta. Analisando as asas diafanizadas de Zaretis isidora e Zaretis callidryas, verificou-se que as nervuras da margem costal estão muito próximas, as quais foram interpretadas por Comstock (1961) como anastomosadas. Dessa forma, no presente estudo as nervuras da margem costal em Zaretis são consideradas livres apesar da proximidade entre elas, às vezes chegando mesmo a se tocarem, porém não com anastomose. A única transição de estado se dá no clado 83 (Hypna clytemnestra ${ }^{+}$).

48. Segmento precedente à junção das nervuras $R 4+R 5$ (ic: 0,500 ; ir: 0,667 )

\author{
0 - longo ( razão $\mathrm{R}$ maior que 1,2) (Figura 12e) \\ 1 - curto ( razão R menor que 0,8 ) (Figura 12a) \\ Estado plesiomórfico: 0
}

RYDON (1971) sugeriu que a existência de um tronco curto comum a $R_{4}$ e $R_{5}$ seria a sinapomorfia mais consistente de Charaxinae. Outros autores (ACKERY et al., 1998; SAlAZAR \& CONSTANTINo, 2001) consideram a evidência como válida. Contudo, no presente trabalho, essa informação foi transformada em uma razão matemática para que os indivíduos das espécies terminais pudessem ser comparados entre si. Esta razão (R) consiste na proporção entre o comprimento do segmento de nervura da célula discal ao forquilhamento de $\mathrm{R}_{4}$ e $\mathrm{R}_{5}$ e o comprimento de $\mathrm{R}_{5}$ a partir do forquilhamento. Este caráter, 
no seu estado 1, é sinapomórfico para a subfamília toda (clado 80), confirmando a hipótese de Rydon (op. cit.). Há uma reversão para Anaea troglodyta cuja venação é bem atípica em relação ao grupo, como já foi discutido no caráter 46.

49. Segmento curto precedente à junção das nervuras $R_{4}+R_{5}$ (ic: 0,100 ; ir: 0,571 )

0 - com razão R menor que 0,4 (Figura 12a)

1 - com razão $\mathrm{R}$ entre 0,4 e 0,8 (Figura 11 c)

Estado plesiomórfico: 0

Para este caráter, foi utilizada a mesma razão (R) entre o segmento de nervura $\mathrm{Rs}_{3}$ e o segmento de nervura do forquilhamento de $R_{3}$ e $R_{4}$ até a extremidade de $R_{5}$, citada no caráter anterior. Verificou-se que dentro da classe "curto" do caráter anterior, havia duas subclasses (curto e muito curto). O estado 1 representa uma sinapomorfia para o clado 77 (Anaeomorpha splendida ${ }^{+}$), com algumas reversões para o estado 0 (Siderone galanthis, Consul electra, P. cyanea, $P$. suprema, Memphis hirta e M. philumena). Isto significa que os membros mais basais de Charaxinae tinham o tronco comum de $\mathrm{R}_{4}$ e $\mathrm{R}_{5}$ muito curtos; em Anaeini, há uma tendência para reversão para o aumento do tamanho deste segmento, observada nos vários surgimentos do estado $1 \mathrm{em}$ Anaeini e do estado longo do caráter anterior em Anaea troglodyta.

50. Célula discal da asa posterior (ic: 0,200; ir: 0,667)

0 - fechada (Figura 12e)

1 - aberta (Figura 9d)

Estado plesiomórfico: 0 (acctran)

O caráter foi citado em vários trabalhos anteriores: EHRLICH (1958b); SMILES (1985), para Euxanthe; FREITAS \& BROWN (2004); e RYDON (1971) que descreve a célula 
discal da asa posterior fechada entre as características de Preponini. É bastante difícil esclarecer o que determina a célula discal aberta ou fechada. Há autores que consideram fechada somente se houver nervura tubular. Neste conceito, todos os Charaxinae teriam célula discal aberta. Contudo, o exame das asas diafanizadas revela que há espécies com célula discal completamente aberta, sem nenhum vestígio de fechamento, e há algumas espécies cuja célula discal contem a marcação de uma nervura fraca encerrando a célula. Neste estudo, este último caso apresentado é considerado como estado 0 (fechada) apesar da nervura não ser tubular. O caráter apresenta homoplasias, mas também distingue vários clados com sinapomorfias: 115 (Euxanthe), 121 (Polyura) e 143 (Prothoini) cuja célula discal é aberta.

51. Base de $R_{1}$ (entre a célula discal e $S c$ ) (ic: 1; ir: 1)

0 - ausente ou reduzida (Figura 11d)

1 - presente (Figura 11b)

Estado plesiomórfico: 1

O caráter foi abordado em CoMstock (1961). O estado ausência da base de $\mathrm{R}_{l}$ está restrito a duas espécies de Anaeini: Anaea troglodyta e Memphis verticordia. Esta é a única sinapomorfia exclusiva que une as duas espécies em um ramo monofilético.

52. Faixa branca longitudinal mesodorsal do tórax (ic: 1; ir: 1)

0 - ausente

1 - presente

Estado plesiomórfico: 0

Esta é uma sinapomorfia exclusiva para o gênero Euxanthe (clado 115). 
53. Tégula (ic: 0,500 ; ir: 0,500 )

0 - da mesma cor que o tórax

1 - branca margeada de castanho diferindo da coloração do tórax

Estado plesiomórfico: 0

A coloração da tégula foi usada por Penz \& De VRIES (2002) para o gênero Morpho (Morphinae). Contudo, no presente trabalho, novos estados foram estabelecidos de acordo com a variação encontrada nos táxons estudados. As espécies do gênero Euxanthe apresentam independentemente o estado 1 em relação à Charaxes zingha, representando uma convergência.

54. Esclerotização da parapatágia (ic: 1 ; ir: 1)

0 - ausente

1 - presente

Estado plesiomórfico: 0

Esse caráter é citado desde RYDON (1971) e outros autores (ACKERY et al., 1998; SalazAr \& Constantino, 2001; Freitas \& Brown, 2004) constituindo-se em uma sinapomorfia exclusiva de Charaxinae para o estado "presença" de esclerotização da parapatágia bem corroborada.

55. Placa glandular pleural do terceiro segmento abdominal (em machos) (ic: 0,333; ir: $0,833)$

0 - ausente

1 - presente (Figuras 37c,d)

Estado plesiomórfico: 0 
O caráter retirado de MiELKE et al. (2004c) que ilustraram a placa glandular para Agrias claudina anetta (Gray, 1832). O estado 1 é sinapomórfico para o clado 109 (Preponini exceto Anaeomorpha splendida) e também para o gênero Prothoe independentemente.

\subsubsection{Genitália masculina}

56. Região distal da valva (ic: 0,250 ; ir: 0,838 )

0 - desprovida de processos (Figura 14b)

1 - terminando em um espinho distal sem formar um lobo pronunciado (Figuras 19c, 22a)

2 - terminando em uma expansão (com ou sem espinhos) (Figuras 24b, 29a,b)

Estado plesiomórfico: 1

PenZ \& De VRies (2002) e Willmott (2003b) consideram esse caráter apenas para a ausência e presença de espinhos distais na margem posterior da valva. O estado 0 (região distal da valva desprovida de processos) é homoplasticamente sinapomórfico para os clados 112 (Prepona pheridamas ${ }^{+}$) e 103 (Memphis polycarmes $^{+}$), e ainda está presente em Hypna clytemnestra e Antirrhaea archaea. O estado 2 (região distal da valva terminando em uma expansão) é sinapomórfico para o clado 116 (Euxanthe eurinome ${ }^{+}$) com reversão em Charaxes laodice.

57. Lobo interno ao espinho distal (ic: 1; ir: 1)

0 - ausente (Figura 19c)

1 - presente (Figura 39a)

Estado plesiomórfico: 0 
A presença do lobo localizado internamente ao espinho distal da valva representa uma sinapomorfia compartilhada por todas as espécies de Archaeoprepona e Noreppa chromus (clado 108).

58. Gnato em relação ao tegume (ic: 0,100; ir: 0,571)

0 - livre (Figura 17c)

1 - preso (Figura 20b)

Estado plesiomórfico: 1

O caráter é bastante homoplástico principalmente quanto aos Charaxinae do Velho Mundo (clado 117), mas o estado 0 (livre) aponta uma sinapomorfia para o clado dos Preponini (exceto Anaeomorpha splendida).

59. Tegume (ic: 0,333 ; ir: 0,931 )

0 - reduzido (Figura 24a)

1 - bem desenvolvido (Figura 19b)

Estado plesiomórfico: 1

O estado redução do tegume (0) é o que caracteriza Apatura iris no qual a raiz do cladograma foi fixada. Os outros representantes do grupo externo apresentam o estado 1, e portanto este é o estado plesiomórfico considerado para este caráter. Palla decius compartilha o estado 1 com Anaeini, Preponini e parte de Prothoini, demonstrando que o ancestral de Charaxinae deve ter tido o tegume bem desenvolvido.

60. Unco (ic: 0,400 ; ir: 0,900$)$

0 - pronunciado (Figura 22c)

1 - não-pronunciado (Figura 25b) 
2 - pronunciado, mas curvado para o interior (Figuras 14b,15a)

Estado plesiomórfico: 0

61. Forma do unco não-pronunciado (ic: 0,333; ir: 0,800)

0 - arredondado

1 - bífido

Estado plesiomórfico: 0 (acctran)

Caráter adaptado de EHRLICH (1958b) que menciona unco simples em contraposição a bífido. RYDON (1971) ao descrever a genitália de Charaxinae distingue o unco bífido de algumas espécies de Charaxes e Polyura do unco proeminente das espécies de Anaeini. O estado bífido para a forma do unco é sinapomórfico para o clado 130 ( $C$. varanes $^{+}$) sofrendo reversão no clado 125 (C. etesipe $\left.{ }^{+}\right)$.

62. Unco pronunciado em vista lateral (ic: 0,500 ; ir: 0,917 )

0 - subtubular (Figura 22c)

1 - dilatado dorsalmente (Figura 16a)

Estado plesiomórfico: 0

O estado apomórfico (1) está presente na tribo Preponini (clado 109), sendo esta uma sinapomorfia consistente para o grupo. O mesmo estado para o unco consta para Hypna clytemnestra, contudo diferenças morfológicas são perceptíveis e, todavia, difíceis de descrever, o estado 1 nesta espécie é uma autapomorfia homoplástica com o clado 109.

63. Valva (ic: 0,333 ; ir: 0,714 )

0 - alongada (Figura 22a)

1 - curta (Figura 15c) 
Estado plesiomórfico: 0

Caráter retirado de Freitas \& Brown (2004). Ehrlich (1958b) considera a distinção entre valva bem desenvolvida, larga e completa em oposição à valva reduzida, estreita e simples quando discute caracteres primitivos e especializados em Papilionoidea. Estes estados propostos por EHRLICH (op. cit.) não se adequam perfeitamente às características das valvas de Charaxinae. MielKe et al. (2004c), consideram os formatos retangular e triangular para distinguir a valva de Zaretis itys e Agrias claudina respectivamente. Estes dois estados são bem adequados para os Charaxinae neotropicais, mas não contemplam o formato das valvas dos Charaxinae do Velho Mundo. O estado 1 é sinapomorfia do clado 108 (Archaeoprepona + Noreppa). Este estado também aparece, independentemente, em Anaeomorpha splendida e Hypna clytemnestra.

64. Tamanho do saco (ic: 0,400 ; ir: 0,870 )

0 - pequeno (Figura 17b)

1 - médio (Figura 26a)

2 - grande (longo) (Figura 28b)

Estado plesiomórfico: 0

Caráter retirado de Freitas \& Brown (2004). O estado 1 (médio) é sinapomórfico para o gênero Euxanthe e para o clado 131 (C. laodice ${ }^{+}$) com reversão no clado 142 (C. etheocles + C. solon). O estado 2 (grande) ocorre independentemente no gênero Prothoe e em C. zoolina.

65. Gnato (ic: 0,200; ir: 0,742)

0 - fracamente esclerotizado (Figura 17c)

1 - medianamente esclerotizado (Figura 17b) 
2 - fortemente esclerotizado (Figura 16a)

Estado plesiomórfico: 0

Adaptado do caráter 31 de PenZ \& DE VRIES (2002). No referido caráter, os autores consideram outra característica em conjunto com o nível de esclerotização do gnato que não se adequa à Charaxinae, por isso neste caráter, resolveu-se levar em conta apenas o grau de esclerotização da estrutura. Considera-se o estado "fracamente esclerotizado" quando a cor do tegumento do gnato é a mesmo da genitália em geral, "medianamente esclerotizado" quando a cor da quitina do gnato é acentuadamente mais escura que o restante da genitália, e "altamente esclerotizado" quando o gnato ou sua extremidade é completamente preto. $\mathrm{O}$ estado 1 tem várias aparições homoplásticas pelo cladograma, mas é uma sinapomorfia para o clado $82\left(\right.$ Consul $\left.^{+}\right)$e 112 (Prepona + Agrias $)$. O alto nível de esclerotização do gnato (estado 2) é sinapomórfico para o gênero Archaeoprepona (incluindo Noreppa chromus) embora ocorra homoplasticamente em mais dois táxons isoladamente (Memphis glauce e Prothoe australis).

66. Gnato (ic: 0,500; ir: 0,667)

0 - liso

1 - estriado (Figura 16c)

2 - com alguns espinhos (Figura 17c)

3 - com muitos espinhos (Figura 17a)

Estado plesiomórfico: 0

Adaptado do caráter 28 de PENZ \& DE VRIES (2002), este caráter é relevante para a caracterização de Preponini como um clado monofilético. O estado gnato estriado é uma sinapomorfia para o clado 107 (Archaeoprepona demophon ${ }^{+}$) com reversão para liso em $A$. amphimacus. O caráter é importante também porque corrobora a hipótese de parentesco 
entre Noreppa chromus e o gênero Archaeoprepona. Pela presente hipótese, o estado 2 teve surgimento anterior ao estado 3 e confirma a posição mais basal de Prepona pheridamas em relação às outras espécies de Prepona e em relação às espécies de Agrias já demonstrada em outros caracteres.

67. Juxta (ic: 0,250 ; ir: 0,750)

0 - ausente

1 - presente (Figura 17a)

Estado plesiomórfico: 1

Retirado de WiLlmotT \& FrEITAS (2006) que utilizaram o caráter para Ithomiinae. Em Anaeini, ao contrário de Charaxini e Euxanthini, há uma tendência geral para a redução e até mesmo o desaparecimento da juxta. A ausência da juxta é o estado apomórfico deste caráter e ocorre nos ramos mais apicais de Anaeini no cladograma, representando a sinapomorfia do clado 96 (Memphis glauce ${ }^{+}$). O desaparecimento da juxta em Hypna clytemnestra, Polygrapha xenocrates e Palla decius é um evento independente em cada um dos casos.

68. Juxta (ic: 1 ; ir: 1)

0 - elevada e bastante alongada (Figura 24a)

1 - inserida em uma posição baixa, na base da valva, e de formato compacto (Figura 17a)

Estado plesiomórfico: 1

RYDON (1971) refere-se a essa estrutura bastante modificada nos gêneros de Charaxinae africanos (exceto em Palla), nos quais a juxta está presente como uma estrutura associada ao gnato formando um funil bem desenvolvido, o qual ROTHSCHILD \& 
JORDAN (1898) chamaram de funil do pênis, descrevendo a juxta como "shoe-hornshaped”. Segundo Plantrou (1983), a juxta é a peça da genitália que, durante a cópula, assume a função de ancoragem na genitália feminina nos representantes das tribos Charaxini e Euxanthini. O estado apomórfico para a juxta é "elevada e bastante alongada" (0) que representa o monofiletismo do clado 116 (Euxanthe $\left.{ }^{+}\right)$.

69. Formato da juxta em vista lateral inserida em posição baixa (ic: 0,200; ir: 0,429)

$$
\begin{aligned}
& 0 \text { - triangular (pequena) (Figura 18b) } \\
& 1 \text { - forma de palheta (Figura 17c) } \\
& \text { Estado plesiomórfico: } 1
\end{aligned}
$$

Willmott (2003b) usou um caráter para o formato da juxta, mas os estados diferem completamente dos apresentados no presente trabalho. WiLlmotT (op. cit.) considera quatro estados para a juxta: estreita, em forma de V com placas de cerdas na margem dorsal; estreita, em forma de V com placas de cerdas abaixo da margem dorsal; larga, em forma de $\mathrm{V}$, com placas de cerdas na margem dorsal; uma estrutura alongada sem placas de cerdas. Nenhum destes estados ocorre em Charaxinae e são específicos para o gênero Adelpha Hübner (Nymphalidae, Limenitidinae).

70. Espinhos na parte distal do edeago (ic: 0,333; ir: 0,882)

$$
\begin{aligned}
& 0 \text { - ausentes } \\
& 1 \text { - presentes }
\end{aligned}
$$

\section{Estado plesiomórfico: 0}

O caráter foi citado sob forma descritiva em RYdon (1971), Plantrou (1983) e HENNING (1988). Tais espinhos variam em número e posição e é provável que sejam de grande utilidade em uma filogenia dentro do gênero Charaxes para se averiguar e definir 
os grupos de espécies e as relações de parentesco entre eles. Neste trabalho, definiu-se apenas os estados para a ausência e presença dos espinhos. A presença é o estado apomórfico que representa o monofiletismo do clado $133\left(\right.$ C. nichetes $\left.{ }^{+}\right)$com uma posterior reversão em todo o gênero Polyura.

71. Aleta subdistal do edeago (ic: 0,250; ir: 0,250)

0 - ausente

1 - presente

Estado plesiomórfico: 0

Foram quatro surgimentos independentes para a aleta subdistal no edeago, sendo que um deles é uma sinapomorfia homoplástica para um pequeno clado (Charaxes etheocles + C. solon)

72. Edeago (ic: 0,200; ir: 0,765)

0 - longo (Figura 24c)

1 - médio (Figura 31a)

2 - curto (Figura 16b)

Estado plesiomórfico: 1 (acctran)

RYDON (1971), em sua discussão sobre as tribos de Charaxinae, faz menção ao comprimento do edeago como uma característica distintiva para as tribos e gêneros. Pallini é a tribo basal do clado 117 (Palla decius $^{+}$) cujo edeago é de comprimento médio. A transição para o aumento no comprimento do edeago (estado 0) se deu entre Pallini e o clado 116 (Euxanthe eurinome ${ }^{+}$). A única reversão para o comprimento médio (estado 1) ocorreu em Charaxes zingha. A redução do comprimento do edeago (transição do estado 1 para 2) parece ser uma tendência entre os Charaxinae neotropicais, tendo ocorrido 
independentemente várias vezes em Anaeini. Contudo, a grande redução do comprimento do edeago em Archaeoprepona é uma sinapomorfia para o clado 108 (Archaeoprepona chalciope $^{+}$) que inclui Noreppa chromus, cujo edeago é o mais reduzido de todos os Charaxinae. Neste caráter, a ordenação dos estados, apesar de intuitiva, seria completamente infundada, já que as transições se deram de 1 para 0 e de 1 para 2, e não em uma ordem crescente ou decrescente de comprimento.

73. Angulo entre o saco e o vínculo (ic: 0,500; ir: 0,926)

0 - próximo a 45 graus

1 - próximo a 90 graus

2 - próximo a 150 graus

Estado plesiomórfico: 1

A ocorrência do estado 0 não resultou em nenhum agrupamento sendo os dois eventos (M. polycarmes e Agatasa calydonia) convergentes. Contudo o estado 2 representa uma sinapomorfia para o clado 134 (C. eupale $\left.{ }^{+}\right)$.

\subsubsection{Genitália feminina}

74. Signos da bolsa copulatória (ic: 0,091 ; ir: 0,091 )

0 - ausentes

1 - presentes (Figura 34b)

Estado plesiomórfico: 0

Caráter retirado de PENZ \& DE VRIES (1999).

75. Corpo da bolsa (C: 0,286; ir: 0,821) 
0 - arredondado (Figuras 35c,d)

1 - oval, alongado na direção do ducto (Figura 34a)

2 - alongada em direção oposta aos signos (Figuras 34c)

Estado plesiomórfico: 0 (acctran)

Adaptado de Penz \& De Vries (2002) e Freitas \& Brown (2004). O estado plesiomórfico está presente no táxon 1, Apatura iris, no qual a raiz do cladograma foi fixada. Os outros representantes do grupo externo possuem bolsa copulatória com formato oval. No grupo interno, o estado 2 ocorre como sinapomorfia homoplástica para o clado 116 (Euxanthe $^{+}$) e algumas espécies do clado 79 que exibe na maioria dos táxons o estado plesiomórfico, já o estado 1 é sinapomorfia exclusiva do clado 112 (Prepona pheridamas ${ }^{+}$)

76. Ducto da bolsa (ic: 0,333; ir: 0,920)

0 - membranoso (Figura 35a)

1 - parcialmente esclerotizado (Figuras 36c, 39c)

Estado plesiomórfico: 0 (acctran)

A esclerotização do ducto da bolsa é uma sinapomorfia para o clado 134 ( $C$. eupale ${ }^{+}$.

77. Porção esclerotizada do ducto da bolsa correspondendo a (ic: 0,182 ; ir: 0,182 )

0 - cerca de 1/3 ou menos de seu comprimento (Figura 36c)

1 - cerca da metade de seu comprimento (Figura 39c)

2 - mais de $2 / 3$ de seu comprimento

Estado plesiomórfico: 0 (acctran)

78. Lamela antevaginal (ic: 0,100; ir: 0,308) 
0 - não-esclerotizada ou pouco esclerotizada

1 - fortemente esclerotizada (Figura 39b)

Estado plesiomórfico: 1

79. Posição da lamela antevaginal (ic: 0,500; ir: 0,966)

0 - na borda do segmento A7 margeando o óstio ventralmente (Figura 39d)

1 - mais interna e profunda, margeando o antro ventralmente (Figura 38f)

Estado plesiomórfico: 0

As lamelas ante e pós-vaginal em Anaeini formam uma estrutura complexa e bastante modificada em relação aos demais Charaxinae. Estes últimos normalmente possuem duas esclerotizações externas ao redor do óstio da bolsa, facilmente distinguíveis (Figura 39d), ou apresentam a estrutura denominada esterigma (Figura 38b) onde as duas lamelas estão completamente fundidas formando uma placa única ao redor do óstio em que as lamelas tornam-se indistinguíveis entre si (KLOTS, 1970). Em Anaeini, as lamelas estão conectadas por extensões esclerotizadas dos braços da lamela antevaginal, mas não formam o esterigma e suas delimitações são bem discerníveis. Nesse grupo, a lamela antevaginal não margeia o óstio da bolsa, mas sim o antro (Figura 34c, 38f). O estado 1 é sinapomórfico para o clado 78 (Preponini + Anaeini)

80. Lamela antevaginal interna (ic: 0,333 ; ir: 0,800 )

0 - fendida formando duas alças que se ligam à apófise anterior (Figura 35a)

1 - partes completamente fundidas, formando uma placa contígua (Figuras 34a,b)

Estado plesiomórfico: 0

A lamela antevaginal, como foi discutido no caráter 79, é originalmente uma placa única. A ocorrência de uma lamela antevaginal fendida ventralmente é intrigante, 
principalmente em alguns táxons em que a estrutura desaparece ventralmente e restam apenas as alças laterais como na Figura 35a. Tais alças laterais poderiam ser interpretadas como o resultado da expansão de esclerotização para conectar a lamela antevaginal à lamela pós-vaginal e à apófise anterior (caráter 89) e em Siderone galanthis (Figura 35a), as alças laterais, são essencialmente tudo o que restam da lamela antevaginal. A fusão ventral das alças da lamela antevaginal (estado 1) é uma sinapomorfia do clado 109 (Preponini exceto Anaeomorpha splendida). A ocorrência do mesmo estado em Polygrapha cyanea parece ser uma convergência com Preponini.

81. Lamela antevaginal fendida (ic: 0,250 ; ir: 0,769 )

0 - alças simétricas e sem torção (Figura 35a)

1 - com torção e assimetria das alças (Figura 35c)

Estado plesiomórfico: 0

Considerando o que foi discutido no caráter 80, é possível fazer uma segunda especulação acerca da evolução da morfologia da lamela antevaginal. Após o desaparecimento da parte ventral desta lamela, as alças que estavam distantes voltaram a se reaproximar e se enrolaram sobre si mesmas, ocasionando a torção e assimetria (Figura 35c). Essa especulação se baseia na constatação de que a mesma genitália com torção das alças, exibia uma aparência de alças fundidas logo após a dissecção do exemplar, decorrido algum tempo após dissecção, o mesmo exemplar sofreu o desenrolamento das alças expondo as extremidades das alças separadas, comprovando que a referida espécie continha o estado 0 do caráter 80 . A torção das alças e consequente assimetria da genitália feminina ocorre nos gêneros Memphis, Anaea e Fountainea (clado 94), e além destes, em Noreppa chromus, Consul fabius e Polygrapha tyrianthina. Nestas duas últimas espécies, a torção e assimetria das alças pode ter tido a mesma origem que no clado 94, pois há 
ambigüidade na otimização deste caráter para os clados anteriores ao 94. Pela otimização acctran o estado 1 teve origem no clado 83 (Hypna clytemnestra ${ }^{+}$) mesmo esta espécie não apresentando o estado.

82. Lamela antevaginal fundida (ic: 0,667 ; ir: 0,750 )

0 - em forma de Y (Figura 34b)

1 - em forma de $\mathrm{V}$

2 - em forma de U (Figura 34a)

Estado plesiomórfico: 0 (acctran)

O estado plesiomórfico está presente apenas no clado 111 (Agrias amydon $^{+}$) e o estado apomórfico (lamela antevaginal em forma de U) sustenta o monofiletismo do clado 108 (gênero Archaeoprepona). O estado 2 é autapomórfico para Noreppa chromus.

83. Lamela pós-vaginal (ic: 0,125; ir: 0,500)

0 - ausente ou indistinta (não-esclerotizada) (Figura 34a)

1 - conspícua (esclerotizada) (Figuras 36a, 39d)

Estado plesiomórfico: 0

O estado apomórfico ocorre em três clados distintos: 133 (C. nichetes $\left.{ }^{+}\right), 108$ (Archaeoprepona chalciope $^{+}$) e 76 (Coenophlebia archidona $\left.{ }^{+}\right)$.

84. Lamela pós-vaginal esclerotizada (ic: 0,500; ir: 0,958)

0 - saliente, em forma de escudo (Figura 36a)

1 - não-saliente (Figura 39d)

Estado plesiomórfico: 1 
A lamela pós-vaginal saliente e em forma de escudo é sinapomórfico para o clado $\left.84(\text { Siderone })^{+}\right)$.

85. Formato da lamela pós-vaginal saliente (ic: 0,231; ir: 0,091)

0 - palheta de borda arredondada (Figura 36a)

1 - palheta com a borda superior bilobada (Figura 34d)

2 - palheta com a borda superior bastante alongada (Figura 35d)

3 - palheta achatada (Figura 36b)

Estado plesiomórfico: 0

86. Oitavo tergito (ic: 0,125 IR: 0,632 )

0 - fracamente esclerotizado

1 - fortemente esclerotizado (Figura 36b)

Estado plesiomórfico: 0

87. Sinus vaginal (ic: 1 ; ir: 1$)$

0 - ausente

1 - presente (Figura 34d)

Estado plesiomórfico: 0

Após o exame das genitálias masculinas e femininas dissecadas para diferentes gêneros de Charaxinae, chegou-se a conclusão de que o sinus vaginal tem função de encaixar o unco subtubular do macho durante a cópula. Nas espécies de Charaxinae cujo unco não é proeminente, por exemplo, no gênero Charaxes, as genitálias femininas carecem do sinus vaginal. A presença dessa estrutura (estado 1) suporta o monofiletismo do clado 76 (Coenophlebia archidona $\left.{ }^{+}\right)$. 
88. Inserção do ducto seminal (ic: 0,167 ; ir: 0,722 )

0 - próximo ao antro (Figura 35a)

1 - em posição mediana ou submediana (Figura 34a)

2 - próximo ao corpo da bolsa (Figura 36d)

Estado plesiomórfico: 0 (acctran)

89. Apófises anteriores (ic: 0,500; ir: 0,966)

0 - separadas da alça da lamela antevaginal

1 - fundidas às alças da lamela antevaginal (Figura 38f)

Estado plesiomórfico: 0

Na genitália feminina de Charaxinae, duas apófises podem ser visualizadas com facilidade devido a sua característica alongada, as apófises anteriores e posteriores. As apófises posteriores são apódemas ligados às papilas anais, já as apófises anteriores são apódemas ligados lateralmente à margem proximal do segmento A8. A conexão da alça da lamela antevaginal com a extremidade da apófise posterior é vista na Figura 38f. Em todo o grupo neotropical (clado 78: Anaeini + Preponini), as extremidades das apófises anteriores são fundidas às alças da lamela antevaginal representando uma sinapomorfia para o grupo. Nos demais Charaxinae, ocorre o estado plesiomórfico, em que as apófises são completamente livres. 


\subsubsection{Caracteres de imaturos:}

\subsubsection{Ovo}

90. Cor do ovo (ic: 0,308 ; ir: 0,700 )

0 - branco (Figura 39e)

1 - verde

2 - amarelo (Figura 39f)

3 - amarelo claro esverdeado

4 - róseo

Estado plesiomórfico: 0

O caráter foi modificado de FreITAS \& BROWN (2004). O ovo róseo é sinapomorfia exclusiva para o gênero Archaeoprepona. Todos os outros estados têm distribuições muito homoplásticas.

91. Formato do ovo (ic: 1 ; ir: 1$)$

0 - hemisférico

1 - esférico (Figuras 39e,f)

Estado plesiomórfico: 0

Muyshondt (1976) discute o formato dos ovos em algumas subfamílias de Nymphalidae e argumenta que Apaturinae, Limenitidinae e Charaxinae estão distantemente relacionadas devido às características do ovo que diferem muito entre si. Ovos lisos e praticamente esféricos são característicos de Charaxinae. FREITAS \& BROWN (2004) e WiLlmotT \& FREITAS (2006) usaram a proporção comprimento/diâmetro para 
interpretar a forma do ovo para Ithomiinae. No presente trabalho, optou-se pela definição de formato, um atributo qualitativo. O estado 1 é sinapomorfia exclusiva de Charaxinae.

92. Ápice do ovo (ic: 1 ; ir: 1)

0 - côncavo a ligeiramente achatado (Figura 39f)

1 - convexo

Estado plesiomórfico: 1

Modificado do caráter 12 de FreITAS \& BROWN (2004) e caráter 2 de WillmotT \& FREITAS (2006). O estado apomórfico representa uma sinapomorfia exclusiva para a subfamília Charaxinae (clado 80). Em outros lepidópteros pode ocorrer o formato esférico do ovo, mas Charaxinae é o único grupo que tem o ovo esférico com ápice côncavo.

93. Face da folha da planta hospedeira onde ocorre a oviposição (ic: 0,500 ; ir: 0,962 )

$$
\begin{aligned}
& 0 \text { - abaxial } \\
& 1 \text { - adaxial }
\end{aligned}
$$

Estado plesiomórfico: 1

Caráter sugerido pelo Dr. Jorge Bizarro (comunicação pessoal) e modificado do caráter 14 de FREITAS \& BROWN (2004). O estado plesiomórfico encontra-se distribuído por todo o clado 117 (Palla decius $^{+}$) com exceção de Polyura athamas. O comportamento de oviposição na face abaxial da planta-hospedeira é observado em todos os membros do grupo neotropical e na tribo Prothoini. Este caráter é importante na associação dessa tribo com os Charaxinae neotropicais. 
4.1.2.2. Larvas de quinto instar (exceto caráter 125 e 126)

94. Cabeça da larva (ic: 0,600; ir: 0,938)

0 - arredondada (Figura 41f)

1 - quadrada com achatamento frontal (Figura 44b)

2 - trapezoidal (Figura 40b)

3 - piramidal (Figura 40e)

Estado plesiomórfico: 0 (acctran)

Modificado do caráter 100 de FreitAs \& BROWN (2004). O estado 1 (cabeça quadrada com achatamento frontal) é sinapomórfico para o clado 117 (Palla decius $\left.{ }^{+}\right)$. O estado 2 (cabeça trapezoidal) é sinapomórfico para o clado 108 (Archaeoprepona + Noreppa) e o estado 3 (piramidal) é típico de Prepona e Agrias (clado 111).

95. Aparecimento da cabeça da larva durante o desenvolvimento embrionário (ic: 1; ir: 1)

0 - lateralmente

1 - apicalmente

Estado plesiomórfico: 1

Caráter sugerido pelo Dr. Jorge Bizarro (comunicação pessoal). O aparecimento lateral é o estado apomórfico que acrescenta mais um elemento que demonstra o monofiletismo do clado 78 (Anaeini + Preponini).

96. Inclinação da cabeça em relação ao corpo (ic: 1; ir: 1)

0 - aproximadamente 120 graus

1 - aproximadamente 90 graus

Estado plesiomórfico: 1 
Os gêneros Euxanthe, Charaxes e Polyura (clado 116) possuem a cabeça menos perpendicular em relação ao substrato que outros Charaxinae. Tal característica pode estar relacionada à cripsis em relação à planta hospedeira, pois o corpo da larva é achatado dorso-ventralmente. A cabeça inclinada a 120 graus faz com que os cornos fiquem encostados ao corpo e não chamem muita atenção de possíveis predadores.

97. Número de cornos da cápsula cefálica (ic: 0,500; ir: 0,935)

$$
\begin{aligned}
& 0 \text { - nenhum } \\
& 1 \text { - dois } \\
& 2 \text { - quatro }
\end{aligned}
$$

Estado plesiomórfico: 1

O estado 2 é sinapomorfia exclusiva do clado 116 (Euxanthe $\left.{ }^{+}\right)$. A presença de dois cornos pequenos laterais aos cornos dorsais na maioria das espécies de Archaeoprepona poderia indicar um parentesco com os gêneros do clado 116 (Figura 5) tendo como base uma hipótese de homologia primária construída por similaridade de posição. Esta hipótese foi posteriormente refutada pelas análises que mostraram que os cornos laterais das larvas de Archaeoprepona, e de Charaxes, Euxanthe e Polyura têm origens evolutivas distintas, e portanto, em Archaeoprepona os cornos não são vestigiais (caráter 101) como se pensava, mas um aparecimento independente daquele do clado 116.

98. Cornos dorsais da cabeça (ic: 1 ; ir: 1)

0 - separados (Figura 40b)

1 - próximos (Figura 40e)

Estado plesiomórfico: 0 
A proximidade dos cornos dorsais da cabeça é uma sinapomorfia exclusiva dos gêneros Prepona e Agrias (clado 112).

99. Cornos dorsais: (ic: 0,333 ; ir: 0,636 )

0 - maiores que os laterais

1 - do mesmo comprimento que os laterais

2 - menores que os laterais

Estado plesiomórfico: 0

100. Cornos dorsais (ic: 0,375; ir: 0,762)

0 - retos (Figuras 44f,g)

1 - retos com os ápices levemente curvados (Figura 43a)

2 - curvados para dentro em relação à linha mesodorsal (Figuras 45a,c)

3 - curvados para trás (Figura 40c)

Estado plesiomórfico: 0

101. Cornos laterais (ic: 1 ; ir: 1)

0 - bem desenvolvidos (Figura 45a)

1 - acentuadamente reduzidos (Figura 40c)

Estado plesiomórfico: 0 (acctran)

102. Par de espinhos situados entre o par de cornos dorsais (ic: 0,333; ir: 0,920)

0 - ausentes

1 - presentes (Figura 43e)

Estado plesiomórfico: 0 
Este caráter foi mencionado em RYDON (1971) com respeito aos gêneros Charaxes, Polyura e Euxanthe. A presença de um par de espinhos entre o par de cornos dorsais sustenta o monofiletismo do clado 116 (Euxanthe $^{+}$) com uma reversão em Charaxes zoolina.

103. Espinho situado entre os cornos dorsal e lateral (ic: 0,167; ir: 0,375)

$$
0 \text { - ausente }
$$

1 - presente (Figura 43g)

Estado plesiomórfico: 0 (acctran)

RYDON (1971) mencionou a estrutura para caracterizar as espécies africanas de Charaxinae e as do gênero Polyura. A presença do espinho (estado 1) é sinapomorfia do clado 133 (Charaxes nichetes ${ }^{+}$) com várias perdas dentro do ramo.

104. Faixa lateral clara da cabeça (ic: 0,250 ; ir: 0,806 )

0 - ausente

1 - presente até a base do corno lateral

2 - presente até a base do corno dorsal

Estado plesiomórfico: 0

105. Sutura epicraneal (ic: 0,500; ir: 0,929)

0 - marcada com coloração escura

1 - não marcada

Estado plesiomórfico: 1

O estado 0 é sinapomórfico para o clado 83 (Hypna clytemnestra ${ }^{+}$). 
106. Calazas da cabeça (ic: 0,667 ; ir: 0,917 )

0 - ausentes (Figura 40e)

1 - pequenas (Figura 41g)

2 - grandes (Figura 41c)

Estado plesiomórfico: 0

Este caráter foi retirado de WiLlmotT (2003a). Também existe referência para este caráter em RYDON (1971), contudo este autor as denomina de tubérculos e papilas ao invés de calazas. O estado plesiomórfico é a ausência e as transições se sucederam de 0 para 2 e de 2 para 1. A primeira transição se dá antes do nó 83 (Hypna clytemnestra ${ }^{+}$), e a segunda antes do nó 99.

107. Listras do disco facial (ic: 0,667; ir: 0,909)

0 - ausentes

1 - convergentes (Figura 41f)

2 - divergentes (Figuras 45d,e)

Estado plesiomórfico: 0

Verificou-se que Charaxes zoolina e C. pleione apresentavam listras na cabeça (Figuras 45d,e) bem como a maioria das espécies de Memphis e Consul. Contudo, foi observado que essas eram listras diferentes nos vários gêneros de Anaeini e em Charaxes, principalmente quanto à direção em que ocorriam. Em Memphis e Consul, as listras acompanham a inclinação do frontoclípeo, já em Charaxes zoolina e C. pleione as listras divergem em relação ao clípeo. $\mathrm{O}$ estado 2 é então uma sinapomorfia exclusiva de $C$. zoolina e C. pleione (clado 141) e o estado 1 uma sinapomorfia do clado $82\left(\right.$ Consul $\left.^{+}\right)$. Uma reversão para a ausência de listras ocorre em Anaea troglodyta. 
108. Mancha avermelhada frontal na cabeça (ic: 0,500; ir: 0,750)

0 - ausente

1 - presente (Figura 41g)

Estado plesiomórfico: 0

Uma mancha de coloração vermelha está presente em várias espécies de Memphis. Algumas têm a mancha bastante nítida, enquanto em outras é mais tênue. O estado presença da mancha é sinapomorfia exclusiva do clado 96 (Memphis glauce ${ }^{+}$) com reversão em $M$. pithyusa que não possui a mancha vermelha.

109. Comprimento dos cornos dorsais (ic: 0,500 ; ir: 0,938 )

0 - longos

1 - curtos (reduzidos nos dois últimos ínstares)

Estado plesiomórfico: 0

Sinapomorfia homoplástica para o clado 83 (Hypna clytemnestra ${ }^{+}$) e para o clado 115 (gênero Euxanthe).

110. Faixa clara subespiracular (ic: 0,100; ir: 0,100)

$$
\begin{aligned}
& 0 \text { - ausente } \\
& 1 \text { - presente }
\end{aligned}
$$

Estado plesiomórfico: 0

111. Área supra-espiracular dos segmentos A3-A6 (ic: 0,500; ir: 0,929)

0 - sem linha

1 - com linha (Figuras 40f, 41i) 
Estado plesiomórfico: 0

Informações de estágios imaturos de Anaeomorpha splendida e Coenophlebia archidona seriam essenciais para definir onde ocorreu a transição do estado plesiomórfico para o apomórfico neste caráter, uma vez que o clado 89 (Siderone + Zaretis) apresenta a linha na área supra-espiracular assim como todo o clado 109 (Preponini). Pela otimização acctran, a origem da transição é comum a ambos os clados e deveria constar nas larvas de Anaeomorpha splendida e Coenophlebia archidona. A reversão para o estado plesiomórfico ocorreu no grupo irmão do ramo 89, o clado 83 (Hypna clytemnestra ${ }^{+}$).

112. Segmentos $A 3$ e $A 5$ (ic: 0,333; ir: 0,895)

0 - sem ornamentação dorsal

1 - ornamentados dorsalmente (Figura 43a)

Estado plesiomórfico: 0

A ornamentação dorsal em A3 e A5 é típica do clado 117 (Palla decius ${ }^{+}$).

113. Forma das ornamentações em A3 e A5 (ic: 0,429; ir: 0,429)

0 - mancha branca arredondada (Figura 44b)

1 - mancha branca semelhante a anel do segmento (Figura 45b)

2 - mancha semelhante a tridente (Figura 43a)

3 - mancha semelhante a diamante com saliência

Estado plesiomórfico: 1 (acctran)

O estado 3 (ornamentação em forma de diamante) é sinapomorfia exclusiva do gênero Euxanthe. O estado 2 (ornamentação em forma de tridente) tem ocorrência homoplástica no gênero Charaxes e Polyura. 
114. Manchas disruptivas no corpo da larva (ic: 0,200; ir: 0,636)

0 - ausentes

1 - presentes (Figura 45d)

Estado plesiomórfico: 0 (acctran)

Neste caráter considerou-se manchas disruptivas aquelas em forma de anéis presentes nos segmentos que imitam folíolos da planta hospedeira, no caso, da família Leguminosae. São três ocorrências independentes em $C$. eupale, no clado 138 ( $C$. tiridates $\left.^{+}\right)$e no clado $124\left((C \text {. etheocles }+ \text { C. sólon })^{+}\right)$, com reversão no clado 121 (Polyura pyrrhus ${ }^{+}$.

115. Padrão das manchas disruptivas (ic: 1 ; ir: 1)

0 - formando faixas dorsais (Figura 45b)

1 - formando desenhos diagonais laterais (Figura 45d)

Estado plesiomórfico: 0

Para as manchas disruptivas, o estado 1 (manchas diagonais) é uma sinapomorfia exclusiva de (C. zoolina + C. pleione $)$.

116. Linha mesodorsal preta (ic: 0,500; ir: 0,714)

0 - ausente

1 - presente até T3

2 - presente ao longo do corpo (Figura 41d)

Estado plesiomórfico: 0

117. Segmento anal (ic: 0,429; ir: 0,818) 
0 - bifurcado (Figura 44d)

1 - subquadrado (Figura 40g)

2 - arredondado (Figura 41d)

3 - agudo

Estado plesiomórfico: 0 (acctran)

O segmento anal da larva de quinto ínstar de Apatura iris é agudo (estado 3); já para Calinaga buddha é bifurcado (0) e este é definido pela otimização acctran como o estado plesiomórfico. A forma subquadrada do segmento anal é homoplástica, mas o estado arredondado (2) é uma sinapomorfia do ramo 94 (Fountainea nessus ${ }^{+}$) e do gênero Consul (clado 81). Pela otimização acctran ambas as ocorrências têm origem comum no clado $82\left(\right.$ Consul $\left.^{+}\right)$.

118. Cauda bífida do corpo (ic: 0,500; ir: 0,917 )

$$
\begin{aligned}
& 0 \text { - longa (Figura 40f) } \\
& 1 \text { - curta (Figura 44d) } \\
& \text { Estado plesiomórfico: } 1
\end{aligned}
$$

Adaptado de FreItAS \& BROWN (2004). Apesar de Antirrhea archaea possuir cauda bífida longa, o estado plesiomórfico apontado pela otimização é cauda bífida curta, presente em Calinaga buddha. Cauda longa é um estado sinapomórfico para o clado 109 (Preponini exceto Anaeomorpha splendida).

119. Região dorsal do segmento T3 (ic: 1; ir: 1)

0 - não-elevada

1 - com uma corcova saliente (Figura 39b)

Estado plesiomórfico: 0 
O estado 1 (segmento T3 com uma "corcova" saliente) é uma das três sinapomorfias exclusivas que dão suporte ao monofiletismo do gênero Archaeoprepona incluindo Noreppa chromus (clado 108 ).

120. Segmento A2 (ic: 0,750; ir: 0,938)

0 - não dilatado (igual aos outros segmentos)

1 - dilatado sem projeções laterais (Figura 40f)

2 - dilatado com projeções laterais afiladas (Figura 40h)

3 - dilatado com projeções laterais arredondadas

Estado plesiomórfico: 0

Neste caráter, cada estado apomórfico representa uma sinapomorfia exclusiva de um clado com exceção do estado 1 (dilatado sem projeções laterais) que é compartilhado homoplasticamente pelo clado 109 (Preponini) e Palla decius. Sempre houve, entre os sistematas, a dúvida sobre Palla decius ter ou não um ancestral comum com os Charaxinae neotropicais, dúvida fundamentada na aparência da larva, especialmente pelas características do segmento A2 e formato da cabeça (RYDON, 1971). A análise não apontou o parentesco entre esses dois grupos (Pallini e Charaxinae neotropicais) sendo, portanto, uma convergência na aparência larval dos dois grupos. O estado 2 (dilatado com projeções laterais afiladas) é sinapomorfia para o clado 89 (Siderone + Zaretis) e o estado 3 (dilatado com projeções laterais arredondadas) é sinapomórfico para o clado 143 (Prothoini).

121. Ornamentação do segmento A2 quando dilatado (ic: 0,600; ir: 0,882)

0 - ausente

1 - em forma de meia lua negra (Figura 40g)

2 - um par de manchas ocelares látero-dorsais (Figura 40a) 
3 - uma faixa escura terminando em uma mancha branca (Figura 41e)

Estado plesiomórfico: 0

Neste caráter, dois estados representam importantes sinapomorfias: estado 1 para o clado 89 (Siderone + Zaretis) e estado 2 para o clado 109 (Preponini).

122. Tegumento geral (ic: 0,750 ; ir: 0,941 )

0 - com cerdas abundantes, sem calazas

1 - liso com poucas calazas pequenas

2 - de aspecto papilado com muitas calazas diminutas

3 - com calazas conspícuas com cerdas brancas longas

Estado plesiomórfico: 2

123. Espiráculo do segmento A2 (ic: 0,333; ir: 0,500)

0 - alinhado com os demais

1 - acima da linha espiracular

Estado plesiomórfico: 0

Este caráter foi retirado dos trabalhos de MUYSHONDT (1973-1976), onde foi descrita a posição elevada dos espiráculos para todos os Charaxinae, contudo com deslocamento mais acentuado nos gêneros Siderone, Zaretis e em Preponini (caráter 124). O estado 1 é sinapomórfico para a subfamília (clado 80).

124. Grau de desvio do segundo par de espiráculos abdominais em relação aos demais espiráculos abdominais (ic: 0,500; ir: 0,929)

0 - discreto

1 - evidente 
Estado plesiomórfico: 0

MuyshondT (1976) mencionou tal característica para a tribo Preponini e os gêneros Zaretis e Siderone. Neste caráter, assim como no caráter 111, a informação de estágios imaturos de Anaeomorpha splendida e Coenophlebia archidona seria essencial para definir onde ocorreu a transição do estado plesiomórfico para o apomórfico, uma vez que o clado 89 (Siderone + Zaretis) apresenta a linha na área supra-espiracular assim como o clado 109 (Preponini). Com a otimização acctran, a transição de 0 para 1 é comum a ambos os clados e deveria estar presente nas larvas de Anaeomorpha splendida e Coenophlebia archidona. A reversão para o estado plesiomórfico ocorreu no grupo irmão do ramo 89, o clado 83 (Hypna clytemnestra ${ }^{+}$).

125. Confecção e utilização de suporte de excrementos (poleiro) até o terceiro ínstar (ic: 0,500; ir: 0,966)

0 - ausente

1 - presente (Figura 41g)

Estado plesiomórfico: 0

Caráter comentado descritivamente em todos os trabalhos de MUYSHONDT (1973-1976) e no presente trabalho, adaptado do caráter 115 de FREITAS \& BROWN (2004). Todos os Charaxinae neotropicais, exceto Prepona deiphile em Quercus sp. (Fagaceae) (J. Bizarro, comunicação pessoal), utilizam o suporte de excrementos até o terceiro ínstar, enquanto os outros gêneros não-neotropicais, em sua maioria, não fazem uso do suporte de excrementos nos ínstares iniciais. Exceção seja feita a Prothoe e Agatasa, dois gêneros asiáticos com registros de utilização do suporte em suas plantas hospedeiras (IGARASHI \& 
FuKudA, 1996). Todo o clado 79 (Prothoini + Anaeini + Preponini) confecciona o suporte de excrementos (estado 1). A confecção desse suporte está ausente em todos os demais táxons da subfamília. Contudo, no grupo externo, este comportamento também pode ser encontrado em Calinaga buddha (IgARASHI \& FUKUDA, 2000). A análise mostra que são ocorrências homoplásticas.

126. Uso da folha enrolada em funil como abrigo após o terceiro ínstar (ic: 1; ir: 1)

0 - ausente

1 - presente (Figura 41f)

Estado plesiomórfico: 0

Caráter comentado descritivamente em todos os trabalhos de MUYSHONDT (1973-1976), e neste trabalho, foi adaptado do caráter 110 de FREITAS \& BROWN (2004). Somente alguns Anaeini utilizam o funil como abrigo. A utilização do abrigo em forma de funil (estado 1) é sinapomorfia exclusiva do clado $82\left(\right.$ Consul $\left.{ }^{+}\right)$.

127. Movimento oscilatório da larva quando perturbada (ic: 0,500; ir: 0,933)

$$
\begin{aligned}
& 0 \text { - ausente } \\
& 1 \text { - presente } \\
& \text { Estado plesiomórfico: } 0
\end{aligned}
$$

Muyshondt (1976) observou esse comportamento em larvas de Preponini. Com menor freqüência, esse mesmo comportamento pode ser encontrado em Siderone e Zaretis (Anaeini) (J. Bizarro, comunicação pessoal). Assim como nos caracteres 111 e 124, a posição da transição, se no clado 78 (Preponini + Anaeini) ou dois surgimentos (um no clado 109 e outro no clado 89) depende da verificação dos estados deste caráter em 
Anaeomorpha splendida e em Coenophlebia archidona cujos estágios imaturos são ainda desconhecidos. Entretanto, pela otimização, neste caráter, mesmo que nestas duas espécies fosse verificado o estado ausência, a transição de 0 para 1 teria acontecido no clado 78 (Preponini + Anaeini)

128. Posição da cabeça e da cauda em situação de repouso (ic: 1; ir: 1)

0 - alinhadas com o corpo

1 - inclinadas para o lado do galho

Estado plesiomórfico: 0

RYDON (1971) e MUYSHONDT (1976) mencionam este comportamento em Preponini. Tal comportamento está relacionado ao "display" contra predadores, onde tal postura de repouso confere à larva a aparência reptiliana (a semelhança de uma lagartixa). O estado 1 é uma das quatro sinapomorfias exclusivas que sustenta o monofiletismo da tribo Preponini.

129. Planta-hospedeira (ic: 0,652 ; ir: 0,692 )

$\begin{array}{ll}0 \text { - Euphorbiaceae } & 9 \text { - Poaceae } \\ 1 \text { - Piperaceae } & 10 \text { - Verbenaceae } \\ 2 \text { - Flacourtiaceae } & 11 \text { - Ochnaceae } \\ 3 \text { - Erythroxylaceae } & 12 \text { - Convolvulaceae } \\ 4 \text { - Lauraceae } & 13 \text { - Monimiaceae } \\ 5 \text { - Sapindadeae } & 14 \text { - Moraceae } \\ 6 \text { - Chrysobalanaceae } & 15 \text { - Salicaceae } \\ 7 \text { - Leguminosae } & 16 \text { - Violoaceae } \\ 8 \text { - Annonaceae } & 17 \text { - Myrtaceae }\end{array}$


18 - Arecaceae

Estado plesiomórfico: 0 (acctran ou deltran)

O caráter é apontado por OTERO (1990) como de grande importância no respaldo a evidências de monofiletismo de determinados grupos. O número de plantas hospedeiras utilizado pela subfamília é grande, contudo, alguns clados têm sinapomorfia representada pelo uso de uma família específica, como as espécies do clado 89 (Siderone + Zaretis) que se alimentam de Flacourtiaceae (estado 3), do clado 81 (Consul) cujas larvas se alimentam exclusivamente de Piperaceae (estado 1), do clado 106 (Archaeoprepona demophoon ${ }^{+}$) corroborando a inclusão de Noreppa chromus no grupo de espécies de Archaeoprepona ao se alimentarem de Lauraceae (estado 4), as espécies do clado 143 (Prothoini) cujas larvas alimentam-se de Annonaceae (estado 8), do clado 83 (Hypna clytemnestra ${ }^{+}$) que se alimentam em Croton spp. (Euphorbiaceae) (estado 0) e do clado 131 (C. laodice ${ }^{+}$) cuja planta hospedeira é predominantemente Leguminosae (estado 7).

\subsubsection{Pupa}

130. Cor da pupa (ic: 0,286 ; ir: 0,615 )

0 - verde (Figuras 42c,d,e)

1 - castanha

2 - bicolor marmoreado (Figura 42i)

3 - verde com manchas disruptivas brancas ou rosadas (Figuras 42a,b)

4 - castanha com pontos prateados

Estado plesiomórfico: 0 
Modificado do caráter 119 de FrEITAS \& BROWN (2004) incluindo as sugestões de J. BizArRo (comunicação pessoal) para a definição dos estados. A cor da pupa e o padrão de manchas, quando existente, são características importantes para os gêneros Memphis, Consul, Fountainea e para a tribo Preponini.

131. Pupa (ic: 0,286 ; ir: 0,722 )

0 - comprimida dorso-ventralmente (Figuras 42b, 46e,f)

1 - comprimida lateralmente (Figura 42a)

2 - sem achatamento (Figura 42h,i)

Estado plesiomórfico: 0 (acctran)

O estado 2 é sinapomórfico para o clado 116 (Euxanthe $\left.{ }^{+}\right)$e homoplasticamente convergente com o clado $82\left(\right.$ Consul $\left.^{+}\right)$. O estado 1 (pupa achatada lateralmente) é sinapomorfia do clado 109 (Preponini).

132. Segmentos abdominais da pupa (ic: 0,333; ir: 0,846)

0 - sem arqueamento evidente (Figura 42a)

1 - arqueados com retração telescópica dos segmentos na parte ventral (Figura $42 \mathrm{c}, \mathrm{d}, \mathrm{e})$

Estado plesiomórfico: 0 (acctran)

133. Cremáster (ic: 0,167 ; ir: 0,706 )

0 - verde (Figura 42a)

1 - castanho a negro (Figuras 42c,e)

Estado plesiomórfico: 1 
Modificado de WillmotT \& FReITAS (2006). Cremáster verde é sinapomorfia homoplástica do clado 109 (Preponini) e do clado 115 (Euxanthe).

134. Arco de verrugas esclerotizadas dorsal ao cremáster (ic: 0,500; ir: 0,933)

0 - ausente

1 - presente

Estado plesiomórfico: 0

Sinapomorfia homoplástica do clado 84 (Siderone $^{+}$) e Agatasa calydonia (Prothoini).

135. Forma da pupa em vista lateral (ic: 0,333; ir: 0,833)

$$
\begin{aligned}
& 0 \text { - oval (Figura 42h) } \\
& 1 \text { - triangular (Figura 42a) } \\
& 2 \text { - barril (Figuras 42c,g) } \\
& \text { Estado plesiomórfico: } 0 \text { (acctran) }
\end{aligned}
$$

Este caráter foi estudado por RYDON (1971). Contudo os estados foram modificados em relação à caracterização que esse autor faz para o formato da pupa em Charaxinae. O estado 1 (forma triangular da pupa) é sinapomórfico para o clado 109 (Preponini) e o estado 2 (pupa em forma de barril) é sinapomórfico para o clado 84 (Siderone $^{+}$) com reversão no caldo 98 (Memphis pithyusa ${ }^{+}$).

136. Cabeça da pupa (ic: 0,143 ; ir: 0,700 )

0 - não-bifurcada

1 - bifurcada 
Estado plesiomórfico: 0 (acctran)

Este caráter foi mencionado por RYDON (1971), no qual ele descreve os estados: truncado, arredondado e bífido. Pela dificuldade encontrada em distinguir os dois primeiros estados, foi adotada esta simplificação de apenas dois estados para evitar erros de interpretação nos estados intermediários. A cabeça bifurcada (estado 1) está presente no clado 79 (Agatasa calydonia ${ }^{+}$) com reversões no clado 86 e 89 além de Prothoe franck.

137. Olhos da pupa (ic: 1 ; ir: 1)

0 - sem contorno

1 - contornados a semelhança de óculos (Figura 42i)

Estado plesiomórfico: 0

MuYShONDT (1973-1976), em seus trabalhos, faz menção a esta característica peculiar de pupas de Memphis. O estado 1 (olhos contornados) é sinapomorfia exclusiva para o clado 101 (M. leonida $\left.{ }^{+}\right)$.

138. Margem lateral da teca alar em vista lateral (ic: 0,333; ir: 0,739)

0 - sem vinco (Figuras 42h,i)

1 - ligeiramente vincada (Figuras 43, 44, 45)

2 - com aresta (Figura 42e,f)

3 - aresta bastante saliente semelhante a uma quilha (Figuras 42c,d)

Estado plesiomórfico: 0 (acctran)

O estado 1 (margem da teca alar ligeiramente vincada) é compartilhado homoplasticamente por dois clados $129\left(\right.$ C. cynthia $\left.^{+}\right)$e 109 (Preponini). O estado 3 é característico dos gêneros Siderone e Zaretis (clado 89), o estado 1 ocorre no clado 83 
(Hypna clytemnestra ${ }^{+}$) e sofre reversão para o estado plesiomórfico (0) no clado 98 ( $M$. pithyusa $^{+}$.

139. Linha lateral clara da teca alar (ic: 0,200; ir: 0,385)

0 - ausente

1 - presente com constrição castanha (Figura 42d)

2 - presente sem constrição (Figuras $42 \mathrm{c}, \mathrm{g}$ )

Estado plesiomórfico: 0 (acctran)

140. Região dorsal entre o tórax e abdome em vista lateral (ic: 1; ir: 1)

0 - sem cavidade

1 - com cavidade acentuada

Estado plesiomórfico: 0

Sinapomorfia exclusiva que sustenta o monofiletismo do gênero Prothoe (clado 144).

141. Terceiro e quarto segmentos abdominais (ic: 0,200; ir: 0,852)

0 - sem saliência (Figura 42i)

1 - salientes em relação aos demais (Figuras 42a,c,f)

Estado plesiomórfico: 0 (acctran)

Segmentos salientes estão presentes nos clados 115 (Euxanthe) e 79 (Prothoini + Preponini + Anaeini) com reversão no clado 96 (Memphis glauce ${ }^{+}$) (otimização acctran) e em M. verticordia.

142. Porção dorsal do quarto segmento abdominal (ic: 0,400; ir: 0,769) 
0 - sem formar cumeeira (Figura 42i)

1 - formando uma cumeeira reta (Figuras $42 \mathrm{e}, \mathrm{g}$ )

2 - formando uma cumeeira irregular

Estado plesiomórfico: 0

143. Porção dorsal do terceiro segmento abdominal (ic: 1; ir: 1)

0 - sem faixa preta

1 - com faixa preta (Figuras 42h,i)

Estado plesiomórfico: 0

A faixa preta no terceiro segmento abdominal (estado 1) é sinapomorfia exclusiva do clado $101\left(M\right.$. leonida ${ }^{+}$), ou pela otimização acctran, do clado 97 ( $M$. grandis $\left.^{+}\right)$. 


\subsection{ANÁLISE E CLADOGRAMAS OBTIDOS}

A análise da matriz obtida com a codificação dos caracteres acima listados resultou em 942 árvores mais parcimoniosas com 727 passos. A busca encontrou o mesmo resultado em 183 das 10.000 réplicas efetuadas. A árvore de consenso (Figura 4) tem 978 passos e difere consideravelmente da árvore obtida para o suporte de ramos (melhor resolvida nos níveis menos inclusivos). Isso significa que o programa não teve condições de visitar um número satisfatório de árvores ótimas e subótimas para que o consenso destas fosse semelhante ao consenso estrito das árvores ótimas. $\mathrm{O}$ índice de suporte de Bremer deve, então, ser interpretado com cautela. A árvore de consenso estrito dos cladogramas ótimos tem $\mathrm{IC}=0,319$ e IR $=0,785$.

$\mathrm{Na}$ ponderação sucessiva, cada fit testado $(5,10,15,20,25$ e 30$)$ resultou em apenas uma árvore e foram necessárias apenas duas pesagens até o que o resultado se estabilizasse para cada um deles. Todas árvores dos diferentes fits foram idênticas e é esperado que se mantenham idênticas mesmo em fits um pouco mais altos, e portanto optou-se por essa árvore como a representante da análise (Figuras 5 e 6). Essa árvore gerada após as pesagens sucessivas, obviamente apresenta uma resolução muito melhor que a árvore de consenso cujos caracteres recebem pesos iguais. Análises com grande número de caracteres são normalmente típicas de grupos internos muito grandes (com grande número de táxons), e, muito diversos; resultam, por conseguinte, em muitas ambigüidades. Para estes casos, a implementação da ponderação sucessiva na análise é extremamente eficiente para reduzir o ruído causado pelos conflitos como foi o caso nesta análise. Por esta razão, a árvore de consenso de caracteres com igual peso é apresentada na 
Figura 4, mas não rege a discussão e otimização de caracteres aqui empreendidas. A discussão está elaborada com base na árvore resultante da pesagem sucessiva (Figura 5).

É importante salientar que todos os clados monofiléticos presentes na árvore de consenso com caracteres com mesmo peso estão presentes na árvore resultante da ponderação; de fato, não há diferenças topológicas na árvore para os ramos mais inclusivos, apenas os ramos menos inclusivos ganham resolução com a implementação do protocolo de ponderação.

A árvore após a ponderação sucessiva (Figura 5) tem índice de consistência de 0,319, índice de retenção de 0,785 e comprimento de 727 passos, o mesmo comprimento do conjunto de árvores ótimas da análise de parcimônia. 


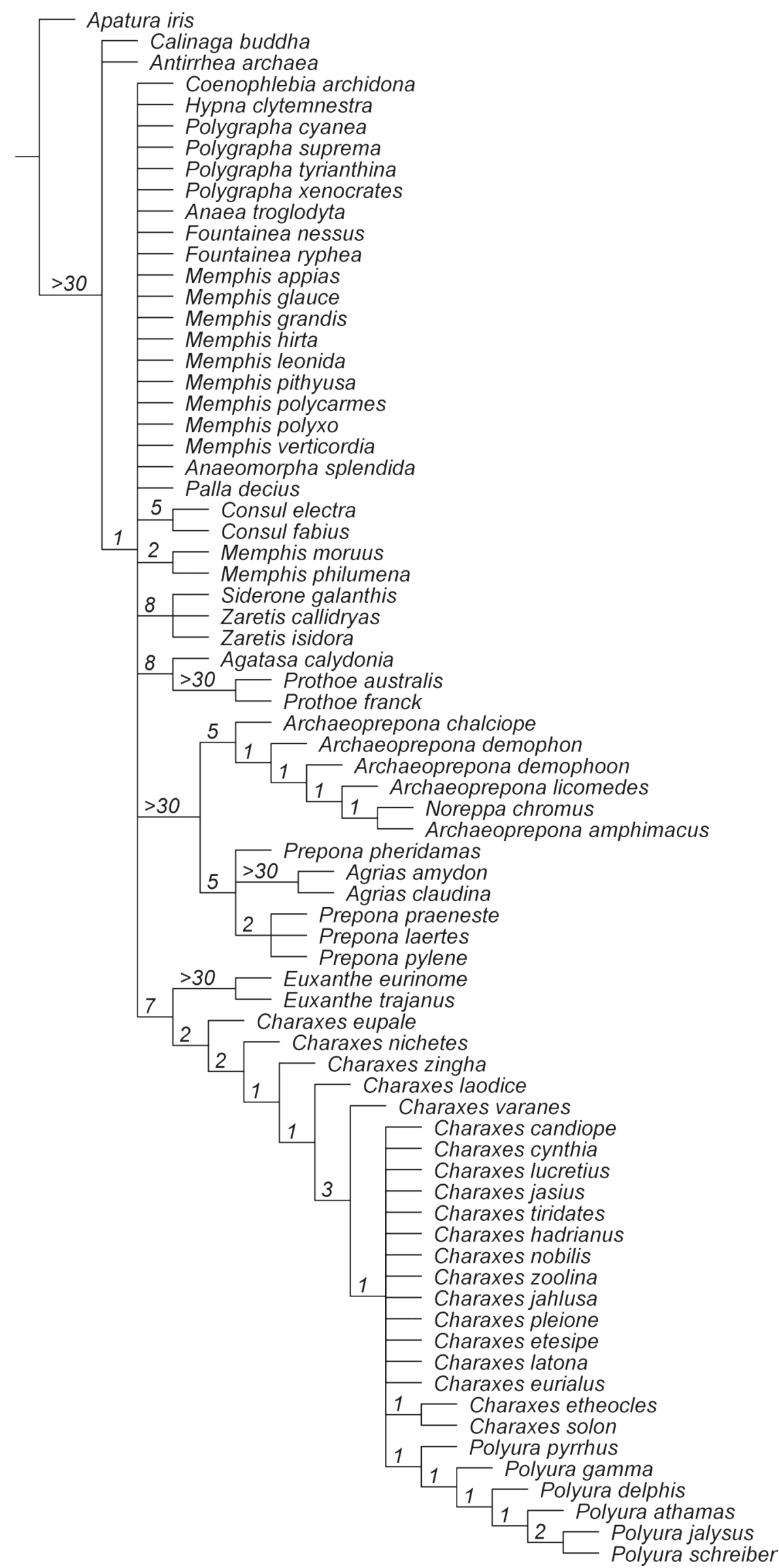

Figura 4. Cladograma de consenso das hipóteses mais parcimoniosas para a subfamília Charaxinae com os valores de Bremer assinaladas para cada clado. 

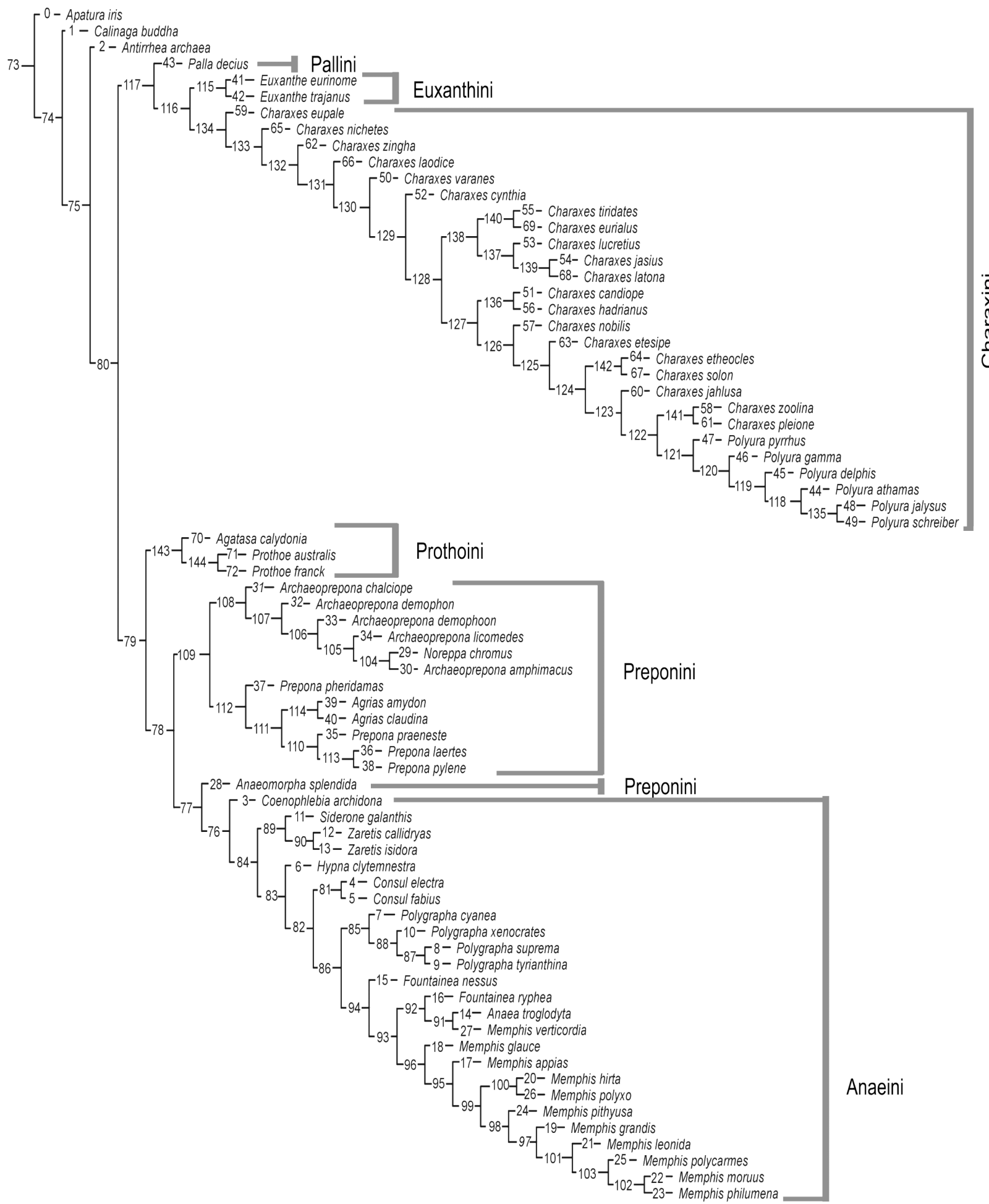

Anaeini

Figura 5. Cladograma resultante da ponderação sucessiva dos fits 5, 10, 15, 20, 25 e 30 . Os números são identificadores de cada clado. IC: 0,319, IR: 0,785. 


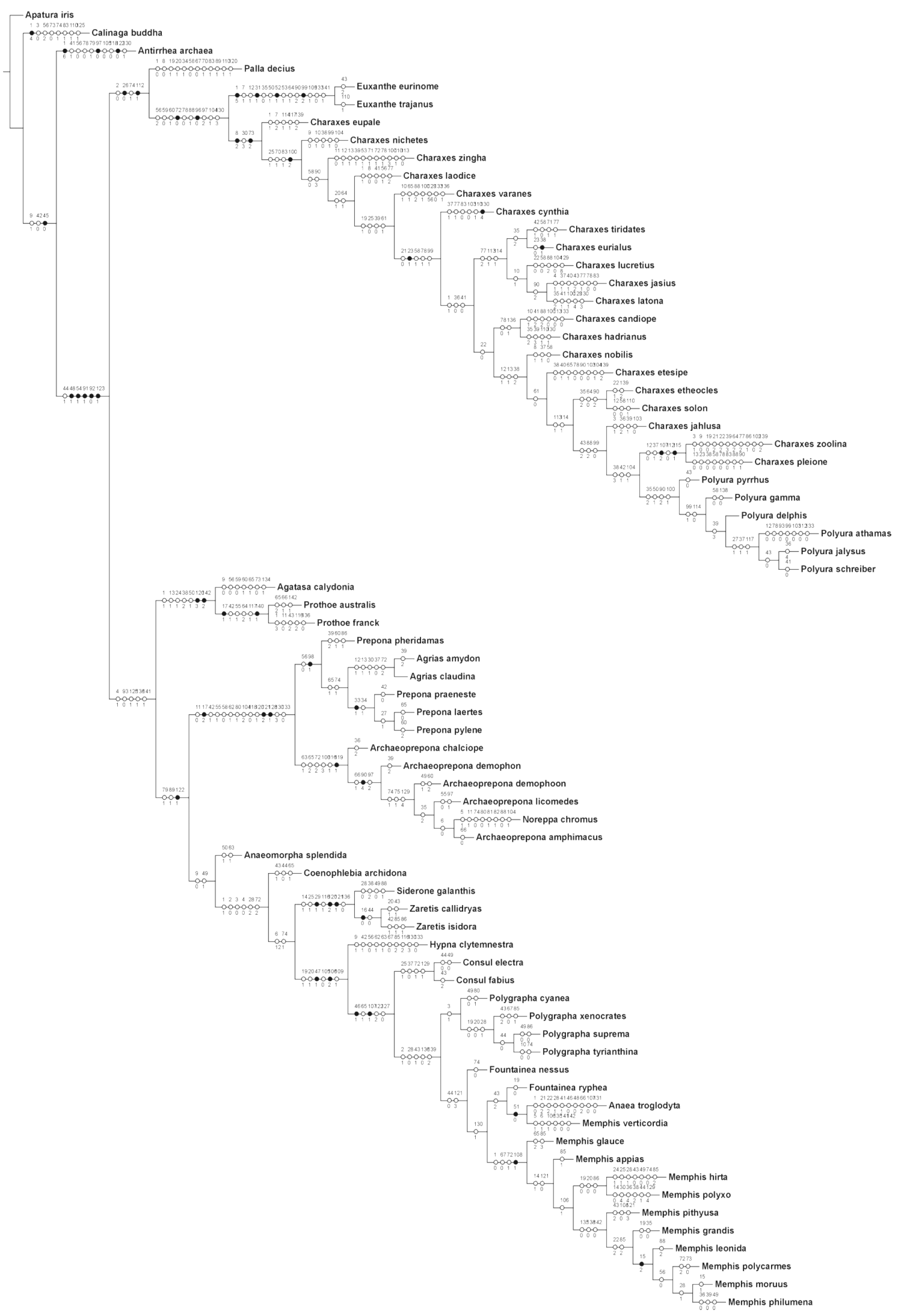

Figura 6: Transições dos estados no cladograma resultante da ponderação sucessiva dos fits $5,10,15,20,25$ e 30 . Os círculos escuros mostram as sinapomorfias exclusivas e os círculos abertos, as sinapomorfias homoplásticas. Os números acima indicam o caráter e abaixo o estado para qual a transição ocorreu. IC: 0,319, IR: 0,785. 


\section{DISCUSSÃO}

\subsection{O MONOFILETISMO DE CHARAXINAE E SEU POSICIONAMENTO EM RELAÇÃO AO GRUPO EXTERNO}

O monofiletismo da subfamília Charaxinae, representada pelo clado 80 (Figura 4), está sustentado por cinco sinapomorfias: segmento precedente a $\mathrm{R}_{4}$ e $\mathrm{R}_{5}$ curto, parapatágia esclerotizada, ovo esférico, ovo com ápice côncavo ou ligeiramente côncavo e espiráculo do segmento A2 em posição mais elevada que os outros, além de uma sinapomorfia homoplástica, alargamento apical da célula $\mathrm{R}_{3}-\mathrm{R}_{4}$. Desde os trabalhos de EHRLICH (1958b) e RYDON (1971), o monofiletismo do grupo era uma hipótese robusta baseada em pelo menos dois caracteres: parapatágia com algum sinal de esclerotização (EHRLICH, 1958b), e $\mathrm{R}_{4}$ e $\mathrm{R}_{5}$ com origem em uma base curta (RYDON, 1971). Todos estes caracteres, exceto o alargamento da célula apical e $R_{4}$ e $R_{5}$ com origem em uma base curta foram testados e confirmados por FREITAS \& BROWN (2004). No presente estudo, todas as sinapomorfias reconhecidas pelos autores anteriores foram incluídas e posteriormente confirmadas nos resultados obtidos, além do reconhecimento de mais duas sinapomorfias: o formato esférico do ovo e o espiráculo no segmento A2 em desalinho com os outros espiráculos, ou seja, deslocado para cima. Este último caráter já havia sido mencionado por MUYSHONDT (1976), mas não havia sido testado em análises filogenéticas.

Após as análises desenvolvidas no presente trabalho a subfamília Charaxinae aparece mais proximamente relacionada com Satyrinae (sensu PEÑA et al. 2006) representada por Antirrhea archaea, do que com Calinaginae. Esta relação está sustentada pelo caráter 45 , em que o surgimento da nervura $R_{3}$ se dá a partir do mesmo setor radial de 
$\mathrm{R}_{4}$ e $\mathrm{R}_{5}$, e não do ramo que dá origem à $\mathrm{R}_{2}$. Em Apaturinae e Calinaginae, $\mathrm{R}_{3}$ está associada à $\mathrm{R}_{2}$.

A hipótese de Calinaginae como grupo-irmão de Charaxinae surgiu no trabalho de WAHLBERG et al. (2003) com base em dados moleculares, portanto as sinapomorfias dessa relação não são corroboradas pelos com dados morfológicos incluídos nesta análise. (Figura 4). Em outro trabalho de WAHLBERG et al. (2005), novamente com dados moleculares, apresentam a hipótese de Charaxinae como grupo-irmão de ((Morphinae + Calinaginae $)+($ Brassolinae + Satyrinae $))$. Já a hipótese de que Satyrinae seja mais próximo de Charaxinae do que de outras subfamílias é oriunda de FREITAS \& BROWN (2004), considerando a árvore resultante da pesagem sucessiva. Isto é corroborado por PEÑA et al. (2006). Ambos os trabalhos chegaram à conclusão de que Calinaginae ocupa uma posição imediatamente mais basal em relação a Charaxinae, sendo esta, grupo-irmão de um grande clado que inclui (Satyrinae + (Morphinae + Brassolinae)) para FrEITAS $\&$ BROWN (2004). Os dados discutidos no presente trabalho corroboram os resultados dos referidos trabalhos sobre o relacionamento de Charaxinae com Satyrinae,considerando Morphinae incluída nesta subfamília (sensu PEÑA et al., 2006) e Calinaginae.

\subsection{A DICOTOMIA DO CLADO 80 (CHARAXINAE)}

A subfamília está dividida em dois grandes clados (79 e 117): um formado pelas duas tribos neotropicais (Anaeini e Preponini) e pelos Prothoini que são asiáticos, e outro contendo todas as tribos africanas (Pallini, Euxanthini e Charaxini), incluindo as espécies de Charaxes e Polyura asiáticas e australianas (Figura 4). O clado 117 está sustentado por duas sinapomorfias exclusivas (costa da asa anterior serrada e segmentos A3 e A5 da larva 
de quinto instar com ornamentação) e duas não homoplásticas (palpo labial longo e signos da bolsa copulatória presentes). O clado 79 não é sustentado por nenhuma sinapomorfia exclusiva, mas cinco homoplásticas (borda interna dos palpos labiais com faixa de escamas escuras, oviposição na face abaxial da folha da planta-hospedeira, confecção de suporte de excrementos até o terceiro ínstar da larva, cabeça da pupa bifurcada e terceiro e quarto segmentos abdominais salientes na larva de quinto ínstar).

A princípio, a hipótese a ser testada era se as espécies de Charaxini (Charaxes e Polyura) estariam filogeneticamente relacionadas às espécies de Prothoini, também asiáticas. Essa hipótese tinha como base a distribuição geográfica dos táxons. Os resultados da presente análise mostram que a distribuição australo-asiática de Prothoini e parte de Charaxini não tem origem comum, pois ambos divergiram em momentos distintos. É provável que a origem de Charaxinae não esteja no Novo Mundo, mas na Ásia, como um ancestral de Prothoini, ou na África, como um ancestral de Palla.

Especulações acerca das relações de parentesco com os Charaxinae neotropicais sempre foram empreendidas na tentativa de compreender as relações de ancestralidade entre o grupo neotropical e os demais Charaxinae do Velho Mundo. (RYdon, 1971, Muyshondt, 1976). Rydon (1971), comparou as larvas de Palla com as de Siderone e Zaretis descrevendo semelhanças morfológicas que poderiam ser um sinal filogenético do parentesco de gêneros assinalados como basais de Anaeini (Siderone e Zaretis) com os Charaxini africanos. A hipótese de um ancestral comum recente entre os Charaxinae africanos e os neotropicais seria bem aceita já que haveria um suporte biogeográfico evidente. Contudo, essa hipótese não foi confirmada no presente trabalho. As similaridades entre as larvas de Palla e Siderone parecem ser convergentes. Entretanto, Palla encontra-se na base do clado que deriva todos os outros Charaxinae africanos e as semelhanças entre as 
larvas de Palla e Siderone poderiam ser consideradas da mesma proporção que as observadas entre as larvas de Palla e das espécies de Prothoini, ou as dessas com as de Siderone, ou destas com um Preponini (nesse caso, semelhanças pouco mais consistentes). Provavelmente o ancestral de Charaxinae teria uma larva com aparência mista entre as larvas de Palla e Agatasa.

\subsection{O CLADO 117 (PALLINI + (EUXANTHINI + CHARAXINI))}

O monofiletismo de Pallini não pôde ser testado, pois apenas uma espécie representante da tribo está presente na análise. Contudo, essa tribo é monotípica e é consenso que as espécies de Palla são muito semelhantes e homogêneas, indicando que esse gênero pode ser monofilético, e consequentemente, a tribo também.

Euxanthini é outra tribo cujo monofiletismo é bastante óbvio, pois esta também é monotípica. A característica mais marcante dos táxons arrolados em Euxanthini é o mimetismo com algumas espécies de Danaini africanas o que resulta em muitas sinapomorfias para o gênero. $O$ monofiletismo da tribo (Figura 4) foi corroborado nesse trabalho pelos caracteres 1:5, 31:1, 52:1, 99:2, e ainda outros homoplásticos: 7:1, 12:1, $35: 0,50: 1,53: 1,64: 1,90: 2,109: 1,133: 0$ e 141:1.

O monofiletismo de Charaxini não foi confirmado nesta análise (Figura 4). SMILES (1982) já havia sugerido que o grupo-irmão de Polyura estaria entre as espécies de Charaxes e que este gênero era, portanto, parafilético. SMILES (op. cit.) estava correto em suas conjecturas a respeito do posicionamento de Polyura. O grupo-irmão deste gênero, conforme suportam as análises do presente trabalho, é o clado 141, formado pelo grupo monofilético Charaxes pleione e Charaxes zoolina (Figura 4). Resulta dessa situação que o 
gênero Charaxes, não sendo monofilético, necessita revisão taxonômica e deve incluir as espécies de Polyura sinonimizando-se este gênero em Charaxes. Há também a possibilidade de Charaxes ser dividido em gêneros menores, mantendo Polyura como gênero válido, já que este é um clado monofilético.

\subsection{O CLADO 79 (PROTHOINI + (PREPONINI + ANAEINI))}

A proximidade filogenética entre os Prothoini, que se distribuem pela Ásia e Austrália, e os Charaxinae neotropicais (Anaeini e Preponini) é um fato surpreendente e seria pouco provável se já não houvesse outros grupos de Lepidoptera com história biogeográfica semelhante com suportes e evidências morfológicas e moleculares para este fato. Para Willmott \& Freitas (2006), por exemplo, o grupo-irmão de Ithomiinae, uma subfamília neotropical de Nymphalidae, é Tellervo Kirby, 1894 (Tellervinae), um gênero encontrado na Nova Guiné e Austrália. Da mesma maneira, Silva-Brandẽo et al. (2008) propuseram que o grupo-irmão do clado que congrega os gêneros neotropicais de Acraeini é um grupo de espécies de Acraea Fabricius, 1807 do Velho Mundo, algumas das quais são asiáticas.

No clado 109 (Preponini, excluido Anaeomorpha splendida) (Figura 4) há uma forte evidência de monofiletismo com 14 sinapomorfias sustentando o clado, das quais quatro sem nenhuma homoplasia envolvida. O clado é dicotomizado entre o das espécies de Archaeoprepona e o de Prepona. O gênero Noreppa se posicionou entre as espécies de Archaeoprepona; com Noreppa chromus como grupo-irmão de Archaeoprepona amphimacus (Figura 4). Desse modo, não há razão para manter Noreppa como um gênero monotípico. A sinonimização seria aconselhável, mesmo considerando as características 
muito peculiares da espécie como olho piloso (Figura 7b), edeago muito curto (Figura 16c) e palpos labiais com cerdas diferenciadas evidentes (Figura 7b). Esses caracteres, de fato, devem ser definidos como autapomorfias da espécie. O estágio de imago de Noreppa chromus tem todas as evidências do parentesco com outras espécies de Archaeoprepona, especialmente com A. amphimacus. Mas, foram os dados de imaturos que colocaram Noreppa chromus no clado de Archaeoprepona. A larva se enquadra perfeitamente em aparência no perfil das larvas do gênero Archaeopreona (Figuras 40a,b,c,d e 41i).

Uma sinapomorfia exclusiva (cornos dorsais da cabeça da larva muito próximos) e uma homoplástica (região distal da valva da genitália masculina desprovida de processos) sustentam o clado 112 (Prepona pheridamas ${ }^{+}$) (Figura 4). O gênero Prepona, também se revelou parafilético com a inclusão das espécies de Agrias. O grupo das espécies de Agrias é monofilético, mas está incluído entre as espécies do gênero Prepona. A semelhança entre Agrias e Prepona está na morfologia de genitália, e é o grupo de caracteres desta estrutura que mais fornece suporte e evidência para a inclusão das espécies de Agrias em Prepona.

Anaeomorpha spendida mostrou maior afinidade com Anaeini do que com Preponini. Esta espécie compartilha poucos caracteres com a tribo a qual pertence até o momento e deveria ter ocupado um status de excertae sedis ao invés de ter sido alocada em Preponini por RYDON (1971). No presente trabalho, sugere-se que a ausência de androcônia em Anaeomorpha splendida seja um dos critérios para transferir a espécie de Preponini para Anaeini. 


\subsection{O MONOFILETISMO DE ANAEINI}

A tribo Anaeini é monofilética, mas apresenta como grupo-irmão Anaeomorpha splendida (clado 77) (Figura 4). A referida espécie poderia ser alocada em uma tribo à parte, mantendo a composição atual de Anaeini, conforme a classificação vigente da tribo (LAmas, 2004) (com Coenophlebia archidona na base de Anaeini), ou Anaeomorpha splendida poderia vir a integrar a tribo Anaeini em uma colocação mais basal que Coenophlebia archidona como indicado pelo cladograma.

O posicionamento de Anaeomorpha splendida na tribo Preponini sempre foi controverso e faltam evidências definitivas. Por se tratar de uma espécie rara, faltam dados de genitália feminina. Até onde se tem conhecimento, fêmeas dessa espécie nunca foram coletadas. Dados de imaturos são imprescindíveis para confirmar o posicionamento taxonômico deste gênero monotípico. Por enquanto apenas com base nos dados de machos adultos, as análises do presente trabalho sugerem que este gênero pertença à Anaeini, ocupando a posição mais basal no grupo. Os gêneros basais de Anaeini compartilham muitas características com os de Preponini, especialmente com Siderone e Zaretis. Contudo, tais semelhanças compartilhadas principalmente nos estágios imaturos, quanto aos caracteres $72,88,105,111,116,122,124$ e 127, não os agrupam no cladograma.

O clado que diverge em Anaeini, distalmente a Coenophlebia archidona, é o de Siderone + Zaretis (Figura 4). As larvas destes dois gêneros são praticamente indistintas e têm morfologias bastante diferenciadas daquela de Anaeini mais apicais, como por exemplo, Memphis. Chegam a se assemelhar mais com as larvas de Preponini do que com as de Memphis, Anaea, Consul ou mesmo com as de Hypna que vem posicionado no clado imediatamente seguinte. No grupo Siderone + Zaretis, as larvas não apenas se assemelham 
em morfologia como em comportamento, como assinalado no caráter 127 referindo-se ao típico movimento oscilatório da larva quando perturbada.

Basalmente, até o nó de Hypna clytemnestra, incluindo esta espécie, as larvas a partir do terceiro ínstar, não se abrigam em funil de folha enrolada. Em Hypna, isto seria impossível com seus espinhos dorsais que estão ausentes nas demais espécies da subfamília. Distalmente a Consul (clado 82), todas as larvas abrigam-se em funil a partir do terceiro ínstar, e têm morfologia externa muito parecida. Para as espécies que não se conhece os estágios imaturos, como na maioria das espécies de Polygrapha, é esperado que as larvas exibam esse padrão morfológico e comportamental dos Anaeini mais apicais. Com isso, somente a informação acerca dos imaturos poderia refutar a hipótese de monofiletismo de Polygrapha e confirmar a proposta de SALAZAR \& Constantino (2001) para a criação de vários gêneros que acomodem as espécies de Polygrapha.

O gênero Fountainea se apresentou parafilético, uma vez que Fountainea ryphea é grupo-irmão de Anaea troglodyta + Memphis verticordia (clado 92) ao invés de Fountainea nessus. Contudo, o agrupamento de Fountainea ryphea com o clado 91 é sustentado por apenas uma sinapomorfia homoplástica $\left(\mathrm{m}_{1}-\mathrm{m}_{2}\right.$ da asa anterior com aproximadamente o mesmo tamanho de $\left.\mathrm{r}-\mathrm{m}_{1}\right)$. Já o clado 91 com suporte em uma sinapomorfia exclusiva (base da nervura $\mathrm{R}_{1}$ da asa anterior ausente ou reduzida), traz a confirmação da validade do gênero Cymmatograma Doubleday, 1849 criado para Memphis echemus (=Memphis verticordia) que também inclui Anaea troglodyta. Esse gênero foi sinonimizado várias vezes com o gênero Memphis, Anaea e Fountainea. Contudo, a validade do gênero Cymatogramma segundo a concepção de SALAZAR \& CONSTANTINO (2001), não é confirmada pelo presente trabalho, uma vez que Memphis pithyusa e $M$. appias não pertencem a este clado (Figura 4). Para as outras espécies que foram 
anteriormente incluídas em Cymatogramma (Fountainea halice, M. arginussa, e $M$. xenocles), não é possível confirmar a inclusão de tais espécies no referido gênero porque elas não foram consideradas nesta análise. Seria necessário um novo estudo filogenético restrito à subfamília Anaeini que compreendesse todas as espécies de Memphis, Fountainea e Anaea para que os limites destes gêneros fossem estabelecidos com confiança.

O gênero Memphis (clado 96) tem seu monofiletismo confirmado somente com a exclusão de $M$. verticordia. A grandeza deste gênero demanda um esforço concentrado unicamente sobre ele. Muito ficou a ser resolvido em relação ao parentesco entre as espécies nele incluídas. Novos estudos devem ser empreendidos com enfoque nos apontamentos feitos em SALAZAR \& CONSTANTINO (2001) principalmente quanto à existência dos gêneros Rydonia, Annagrapha e Cymatogramma, cujas espécies, atualmente, estão arroladas majoritariamente em Memphis atualmente. 


\section{CONCLUSÕES}

- A subfamília Charaxinae é monofilética suportada por cinco sinapomorfias: parapatágia esclerotizada ou com algum sinal de esclerotização, base comum à $\mathrm{R}_{4} \mathrm{e}$ $\mathrm{R}_{5}$ curta, ovo com formato esférico, depressão apical na região da micrópila do ovo e espiráculo larval do segmento A2 em posição elevada em relação aos outros.

- Preponini é monofilética se Anaeomorpha splendida for excluída da tribo. A ausência de androcônia é a maior evidência de que esta espécie não pertence a esta tribo.

- As espécies de Prothoini, grupo asiático, não estão relacionadas filogeneticamente com as espécies de Charaxini asiáticos e sim com as de Preponini e Anaeini, grupo neotropical.

- Charaxes não é um gênero monofilético. Para que isso aconteça deve incluir todas as espécies de Polyura. Esses gêneros necessitam ser revisados.

- O gênero Prepona deve incluir as espécies de Agrias para tornar-se monofilético. Esses gêneros necessitam ser revisados.

- Noreppa chromus deve ser transferida para o gênero Archaeoprepona para que este seja monofilético.

- O gênero Polygrapha apresentou-se monofilético.

- O gênero Memphis e Fountainea não são monofiléticos e precisam ser mais bem estudados para que seus limites sejam criteriosamente definidos. 


\section{REFERÊNCIAS BIBLIOGRÁFICAS}

Ackery, P. R.; De Jong, R.; Vane-Wright, I. R. 1998. The butterflies: Hedyloidea, Hesperioidea and Papilionoidea, In: KRISTEnSEN, N. P. (Ed.). Lepidoptera, moths and butterflies. 1. Evolution, Systematics and Biogeography. Berlin, De Gruyter, p. 263-300. (Handbook of Zoology, v. 4, pt. 35).

Amorim, D. S. 2002. Fundamentos de Sistemática Filogenética. Ribeirão Preto, Holos Editora. $154 \mathrm{p}$.

Arnett, R. H.; Samuelson, G. A.; Nishida, G. M. 1993. The Insect and Spider Collections of the World, 2. ed. Gainesville, SandHill Crane Press. Inc. 310p.

Aurivillius, C. 1911-1912. In Seitz, A. Die Gross-Schmetterlinge der Erde. v. 13: p. 122-124. Stuttgard.

Barselou, P. 1983. The Genus Agrias: A taxonomic and illustrated guide (Lepidoptera; Nymphalidae). Hillside, 1983. 96p., 15 colour plates, maps.

Beccaloni, G. W.; Viloria, A. L.; Hall, S. K.; Robinson, G. S. 2008. Catalogue of the hostplants of the Neotropical butterflies. Zaragosa, Sociedad Entomológica Aragonesa. 536p.

Boisduval, J. B. A.; Le Conte, J. E. 1829-1937. Histoire générale et iconographie des lépidoptères et des chenilles de l'Amérique septentrionale. Paris, MéquignonMarvis; Crochard; Roret. v. 1, p. 1-16, pls. 1-3, v. 2, p. 17-24, pls. 4-6, v. 3/4, p. 25-40, pls. $7-12$, v. $5 / 6$, p. $41-56$, pls. $13-18$, v. 7/8, p. 57-80, pls. 19-24, v. 9/10, p. 81-100, pls. 25-30, v. 11-22, p. 101-196, pls. 31-65, v. 23-26, p. 197-228, pls. 66-78.

BREMER, K. 1994. Branch support and tree stability. Cladistics, 10(3): 295-304 
Brower, A. V. Z. 2000. Phylogenetic relationships among the Nymphalidae (Lepidoptera inferred from partial sequences of the wingless gene. Proceedings of the Royal Society of London, B. 267: 1201-1211.

BROWN JR, K. S. 1991. Conservation of Neotropical Environments: Insects as Indicators. In: Collins, N. M.; Thomas, J. A. (Eds.). The conservation of insects and their habitats. New York: Academic Press. p. 349-404.

1996. Conservation of threatened species of Brazilian Butterflies. In:

Decline and conservation of butterflies in Japan III: Proceedings International Symposium on Butterfly Conservation Osaka, Japan 1994. p. 45-62.

1997. Diversity, disturbance, and sustainable use of Neotropical forest: insects as indicators for conservation monitoring. Journal of Insect Conservation, 1: $1-18$.

2001. Insetos indicadores da História, composição, diversidade e integridade de matas ciliares. In: ROdRIGUes, R. R. F.; H. F. DE FilHo LeITÃo, (Eds.). Matas Ciliares: conservação e recuperação. 2. ed. São Paulo: Ed. da Universidade de São Paulo FAPESP. p. 223-232.

Brown JR, K. S.; Freitas, A. V. L. 2000. Atlantic Forest Butterflies: Indicators for Landscape Conservation. Biotropica, 32 (4b): 934-956.

2002. Butterflies communities of urban Forest fragments in Campinas, São

Paulo, Brazil: Structure, instability, environmental correlates, and conservation. Journal of insect conservation, 6: 217-231.

CALDAS, A. 1995. Intraspecific variation in Anaea ryphea Cramer and Anaea eurypyle C. and R. Felder (Nymphalidae). Journal of Research on the Lepidoptera 32: 37-44. 
Clark, A. H., 1947. The Interrelationships of the several groups within the butterfly super family Nymphaloidea. Proceedings Entomological Society of Washington, 49 (6): 148-149.

Comstock, W. P. 1961. Butterflies of the American Tropics. The Genus Anaea Lepidoptera, Nymphalidae. New York, The American Museum of Natural History. $214 \mathrm{p} .+30 \mathrm{pl}$

Darge, P. 1983. Faune de la Republique Unie du Cameroun. Vol. 1. Le Genre Charaxes Ochs. (Lepidoptera Charaxidae Doherty). Venette, Sciences Nat. 136p. + 40pl.

De Jong, R.; VAne-Wright, R. I.; ACKery, P. R. 1996. The higher classification of butterflies (Lepidoptera): problems and prospects. Entomologica Scandinavica, 27 (1): $65-101$.

DE PinNA, M. C. 1991. Concepts and tests of homology in the cladistic paradigm. Cladistics, 7(4): 367-394.

Descimon, H. 1986. L'évolution de la coloration chez les Charaxidae Néotropicaux: strategies adaptatives et cladogênese. (Lepidoptera Rhopalocera). Bulletin de la Societé Zoologique de France, 111 (3-4): 261-295.

Doherty, W. 1886. A list of Butterflies taken in Kumaon. Journal of Asiatic Society of Bengal, 55 (2): 103-140.

De VRIES, P. J. 1987. The Butterflies of Costa Rica and their natural history. Papilionidae, Pieridae, Nymphalidae. Princeton University Press. $x x+327 p$.

EHrlich, P. R. 1957. Systematists and subspecies. The Lepidopterists' News, 11 (4-5): $155-157$.

1958a. The integumental anatomy of the monarch butterfly Danaus plexippus L. (Lepidoptera: Danaiidae). The University of Kansas Science Bulletin, 38(18): 1315-1349. 
1958b. The comparative morphology, phylogeny and higher classification of the butterflies (Lepidoptera: Papilionoidea). The University of Kansas Science Bulletin, 39: 305-370.

Ehrlich, P. R.; Ehrlich, A. H. 1961. How to know the butterflies. Dubuque, Wm. C. Brown Company Publishers, VIII + 266p.

ERHARDT, A.; THOMAS, J. A. 1991. Lepidoptera as indicators of change in the seminatural grasslands of lowland and upland Europe, p. 213-236. In: COLlins, N. M.; THOMAS, J. A. (Eds.). The conservation of insects and their habitats. New York: Academic Press.

Evenhuis, N. L. 2008. The Insect and Spider Collections of the world. Bishop Museum - Search List of Insect and Spider Collections $<$ http://hbs.bishopmuseum.org/codens/codensearC.html $>$.

FABRicius, J. C. 1793. Entomologia systematica emendata et aucta. Secundum classes, ordines, genera, species adjectis synonimis, locis, observationibus, descriptionibus. Hafniae, Christian Gottlieb Proft, Fil. et Soc. v. 3, p. 1, [vi] +488 p.

FARRIS, S. 1983. The logical basis of phylogenetic analysis.. In: Platnick, N. I.; Funk, V. A. (Eds) Advances in Cladistics, Proceedings of the Second Meeting of the Willi Hennig Society. New York, Columbia University Press, p. 1-47

FAssl, A. H. 1909. Anaea rosae nov. spec. und ab. sex. \& laticincta. Societas entomologica, 24(11): 81-83, figs.

1910. Anaea laura Druce und Anaea rosae Fassl. Societas entomologica, 25(9): 33.

1911. Das $q$ von Agrias amydon Hew. und eine neue $\widehat{\jmath}$ Form. Societas entomologica, 26(7): 27. 
1912a. Nochmals über Agrias amydon und eine neue sardanapalus-Form aus Columbien. Entomologische Rundschau, 29(2): 9-10.

1912b. Das $q$ von Prepona praeneste Hew. Entomologische Rundschau, 29(11): 76 .

1912c. Anaea ludmilla m. eine neue Form aus der panariste-Gruppe.

Entomologische Rundschau, 29(13): 85-86, figs.

1912d. Neue Nymphaliden aus Südamerika. Entomologische Rundschau, 29(19): 121-123.

1913a. Das $q$ von Prepona buckleyana. Entomologische Rundschau, 30(7): 40 .

1913b. Neue Preponen aus Bolivien. Entomologische Rundschau, 30(8):

$43-44$.

1913c. Die Agriasformen Boliviens. Entomologische Rundschau, 30(21):

121-123.

1916a. Anaea chaeronea corita Fruhst. betreffend. Societas entomologica, 31(6): 25-26.

1916b. Nochmals Anaea corita betreffend. Societas entomologica, 31(13):

$62-63$.

1921a. Neue und wenig bekannte Agrias-Formen des unteren Amazonas.

Entomologische Rundschau, 38(2): 9-10.

1921b. Neue und wenig bekannte Agrias-Formen des unteren Amazonas.

Entomologische Rundschau, 38(3): 12-13, (4): 18, (5): 19-20. 
1921c. Agrias-Formen vom Rio Xingu. Entomologische Rundschau, 38(8): 33-35.

1921d. Agrias-Formen vom Rio Maués. Entomologische Rundschau, 38(9): 38 .

1921e. Zwei neue Lokalformen von Agrias hewitsonius Von Manicoré am Rio Madeira. Entomologische Zeitschrift, 35(14): 55.

1921f. Agrias-Formen vom Rio Maués. Entomologische Rundschau, 38(10): 41-42.

1921g. Meine Agrias-Ausbeute von Itaituba am Rio Tapajoz. Entomologische Rundschau, 38(11): 45-46, (12): 49-51.

1922a. In eigener Sache! Entomologische Zeitschrift, 35(26): 106.

1922b. Neue Schmetterlingsformen aus Brasilien. Entomologische

Zeitschrift, 36(10): 38-39; (11): 42-43; (12/13): 45-46.

1924a. Nachträge: Gattung Agrias. In: SEITZ, A. (Ed.), Die Gross-

Schmetterlinge der Erde. Stuttgart, Alfred Kernen. v. 5, p. 1037-1040, pl. 113B.

1924b. Die Weibchen von zwei Agrias-Stammformen entdeckt.

Entomologische Rundschau, 41(4): 14-15; (5): 160.

Frushtorfer, H. 1895a. Allerlei Neues über Agrias. Entomologische Nachrichten, 21(10): 151-153.

1895b. Noch mehr Neues über Agrias. Entomologische Nachrichten,

21(14): 217-220.

1895c. [A note]. Berliner entomologische Zeitschrift, 40(2): (14). 
1895d. Noch einmal Agrias claudia Schulz [sic]. Societas entomologica, 10(11): 81-82.

1897a. Neue Tagfalter aus Südamerika. Entomologische Nachrichten, 23(14): 220-223.

1897b. Neue Tagfalter aus Südamerika. Entomologische Nachrichten, 23(16): 252-254.

1898a. Agrias boliviensis Fruhst. nova ab. amydonides m. Entomologische

Zeitschrift, 11(21): 166.

1898b. Etwas über ein Hauptvergnügen der Augen, genannt "Agrias".

Berliner entomologische Zeitschrift, 42(3/4): 289- 300, pl. 1.

1898c. Agrias aurantiaca Fruhst. Deutsche entomologische Zeitschrift

"Iris", 11(1): 155-158, pl. 2; fig. 2.

1898d. Agrias boliviensis Fruhstorfer. Deutsche entomologische

Zeitschrift "Iris", 11(1): 158-159, pl. 2; fig. 3.

1898e. [A note]. 43 Berliner entomologische Zeitschrift (1/2): (8).

1898f. [A note]. Berliner entomologische Zeitschrift, 43(1/2): (9).

1899a. [Agrias aurantiaca and boliviensis]. Deutsche entomologische

Zeitschrift "Iris", 11(2), pl. 2.

1899b. [Notes]. Berliner entomologische Zeitschrift, 44(1/2): (2)-(3),

(18), (21)-(22), (24), (26).

1901. [A note]. Insekten-Börse, 18(46): 365.

1902a. [A note]. Insekten-Börse, 19(4): 29. 
1902b. Eine neue Lokalform der seltenen Ag. amydonius Stdgr. Deutsche entomologische Zeitschrift "Iris", 14(2): 327-328; 15(1), pl. 3; fig. 2.

1902c. Eine neue Agrias. Deutsche entomologische Zeitschrift "Iris", 14(2): 351-352.

1902d. Neue ostasiatische [sic] Rhopaloceren. Societas entomologica, 17(11): 81-82.

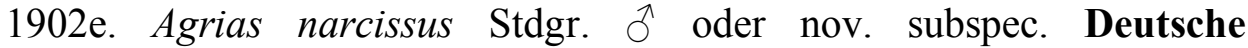
entomologische Zeitschrift "Iris", 15(1): 179, pl. 3; fig. 1.

1904. Neue Prepona-Formen. Insekten-Börse, 21(16): 125-126.

1905. Beitrag zur Kenntnis einiger Prepona-Arten und Übersicht der bekannten Arten dieser Gattung. Deutsche entomologische Zeitschrift "Iris", 17(2): 271-312, pls. 6-9.

1906. Eine neue Prepona aus Brasilien. Entomologische Zeitschrift, 20(21): 150-151.

1909. Neue Zaretes-Formen und Uebersicht der bekannten Rassen. Entomologische Zeitschrift, 23(38): 166-168; figs. 1-4.

1910. Neue Agriasformen: Agrias godmani forma cyanecula und forma derufata nava [sic]. Entomologische Zeitschrift, 24(34): 185.

1912. Neue netropische [sic] Nymphaliden. Entomologische Rundschau, 29(6): 45-46.

1913-1914. In SEITZ, A. Die Gross-Schmetterlinge der Erde. v. 9: p.

712-717. Stuttgard. 
1914. Eine neue Agrias-Rasse aus Brasilien. Entomologische Rundschau, 31(5): 30 .

1915c. Beitrag zur Morphologie der Prepona- und Agrias-Arten.

Entomologische Rundschau, 32(8): 45-47; figs. 1-7.

1915d. Neue neotropische Nymphaliden. Societas entomologica, 30(12):

66.

1916a. Eine neue neotropische Nymphalide. Societas entomologica, 31(3):

14.

1916b. 55. Gattung: Prepona Bsd. - 56. Gattung Agrias Dbl. In: Seitz, A.

(Ed.), Die Gross-Schmetterlinge der Erde. Stuttgart, Alfred Kernen. v. 5, p. 550-568.

1916c. 55. Gattung: Prepona Bsd. - 56. Gattung Agrias Dbl. [continuação].

In: Seitz, A. (Ed.), Die Gross-Schmetterlinge der Erde. Stuttgart, Alfred Kernen. v.

5, p. 569-576.

1916d. Anaea chaeronea corita Fruhst. Societas entomologica, 31(6): 26.

Fruhstorfer, H.; RöBer, J. 1916. 55. Gattung: Prepona Bsd. - 56. Gattung Agrias Dbl. [continued]. In: Seitz, A. (Ed.), Die Gross-Schmetterlinge der Erde. Stuttgart, Alfred Kernen. v. 5, p. 577, pls. 111-113, 113B, 114-115.

Freitas, A. V. L.; Brown JR, K. S. 2004. Phylogeny of the Nymphalidae (Lepidoptera). Systematic Biology, 53: 363-383.

GolobofF, P.A. 1993. Estimating character weights during tree-searC. Cladistics, 9, p.8391. 1995. Parsimony and weighting: a reply to Turner and Zandee. Cladistics, 11(1), p.91-104. 
Goloboff, P.; Farris, J.; NiXon, K. 2003. TNT. Tree Analysis Using New technogy, version 1.1. Program and documentation, available from the authors and at www.zmuc.dk/public/phylogeny.

Grimaldi, D.; Engel, M. S. 2005. Evolution of the insects. New York, Cambridge University Press, 755p.

GuenÉE, A. 1865. Annexe F. Lépidoptères de Madagascar. In: Vinson, A. Voyage à Madagascar au couronnement de Radama II. Paris, Roret. p. 25-48, pls. 207 4-7.

HARVEY, D. J. 1991. Higher classification of the Nymphalidae, In: NiJHOUt, H. F. (Ed.)

The development and evolution of butterfly wing patterns. Whashington, D.C., Smithsonian Institution Press, Appendix B p. 255-273.

Hennig, W. 1950. Grundzüge einer Theorie der phylogenetischen Systematik. Berlin, Deutscher Zentralverlag, 370p.

1966. Phylogenetic Systematics. Urbana, Univ. Illinois Press, 269p.

Henning, S. F. 1988. The Charaxinae butterflies of Africa. Johanesburg, Aloe Books Frandsen. 457p.

Heppner, J. B. 1991. Faunal regions and the diversity of Lepidoptera. Tropical Lepidoptera, 2 (Suppl. 1): 1-85.

Igarashi, S.; Fukuda, H. 1996. The life histories of Asian butterflies. Tokyo, Tokai University Press, v. 1, 550p. + 240pl.

2000. The life histories of Asian butterflies. Tokyo, Tokai University Press, v. 2, 742p. +427 pl.

Janzen, D. H.; Hallwachs, W. 2005. Dynamic database for an inventory of the macrocaterpillar fauna, and its food plants and parasitoids, of Area de Conservacion Guanacaste (ACG), northwestern Costa Rica (nn-SRNP-nnnnn voucher codes) $<$ http://janzen.sas.upenn.edu $>$. 
Jones, W. 1791. A new arrangement of papilios. Transactions of the Linnean Society of London, 2: 63-69.

Kitching, I. J.; Forey, P.L.; Humphries, C. J.; Williams, D. M. 1998. Cladistics: the theory and pratice of parsimony analysis. 2. ed. Oxford, Oxford University Press. xiii $+228 \mathrm{p}$.

Klots, A. B. 1970. Lepidoptera. In: TuXen, S. L. (Ed.). Taxonomist's glossary of genitalia in insects. 2. ed. Copenhagen, Munksgaard. p. 115-130.

KLUGE, A. G. 1998. Total evidence or taxonomic congruence: Cladistics or consensus classification. Cladistics, 14: 151-158.

Kluge, A. G.; FARRIS, K. J. S. 1969. Quantitative phyletics and the evolution of anurans. Systematic Zoology, 18(1): 1-32.

Kristensen, N. P. 1997. Early Evolution of the Lepidoptera + Trichoptera Lineage: Phylogeny and the Ecological Scenario. In: GRANDCOLAS, P. (Ed), The Origin of Biodiversity in Insects: Phylogenetic Tests of Evolutionary Scenarios. Mémoires. du Muséum National d'Histoire Naturelle, 173: 253-271.

Kristensen, N. P.; Scoble, M.; Karsholt, O. 2007. Lepidoptera phylogeny and systematics: the state of inventorying moth and butterfly diversity. Zootaxa, 1668: 699-747. (Linnaeus Tercentenary: Progress in Invertebrate Taxonomy ed. by, Z. Q. ZHANG; W.A. SHEAR)

Lamas, G. 2004. Checklist: Part 4A. Papilionoidea - Hesperioidea. In: HePPner, J. B. (Ed.). Atlas of Neotropical Lepidoptera. Gainesville, Scientific Publishers. 2008. La sistemática sobre mariposas (Lepidoptera: Hesperioidea y Papilionoidea) en el mundo: Estado actual y perspectivas futuras. In: LLORENTE, J. E.; LANTERI, A. (Eds.), Contribuciones taxonómicas en órdenes de insectos hiperdiversos. México, D.F., Universidad Nacional Autónoma de México. p. 57-70. 
Linnaeus, C. 1758. Systema naturae per regna tria naturae, secundum classes, ordines, genera, species, cum characteribus, differentiis, synomymis, locis. Editio Decima, reformata. Holmiae, Laurentius Salvius v. 1, iv $+823+[1]$ p.

MAdDison, W. P.; MAdDISON; D.R.. 2008. Mesquite: a modular system for evolutionary analysis. Version $2.5 \mathrm{http}: / /$ mesquiteproject.org.

Mielke, C. G. C.; Mielke, O. H. H.; Casagrande, M. M. 2004a. Estudo comparado da morfologia externa de Zaretis itys itylus (Westwood) e Agrias claudina anetta (Gray). (Lepidoptera, Nymphalidae, Charaxinae). I. Cabeça, apêndices e região cervical. Revista Brasileira de Zoologia, 21(2): 357-369.

2004b. Estudo comparado da morfologia externa de Zaretis itys itylus (Westwood) e Agrias claudina anetta (Gray). (Lepidoptera, Nymphalidae, Charaxinae). II. Tórax e apêndices. Revista Brasileira de Zoologia, 21(3): 421-433. 2004c. Estudo comparado da morfologia externa de Zaretis itys itylus

(Westwood) e Agrias claudina anetta (Gray). (Lepidoptera, Nymphalidae, Charaxinae).III. Abdome. Revista Brasileira de Zoologia, 21(4): 905-912.

MuYshondt, F. 1973a. Notes on the life cycle and natural history of butterflies of El Salvador. I. Prepona omphale octavia (Nymphalidae). Journal of the Lepidopterists' Society, 27: 210-219.

1973b. Notes on the life cycle and natural history of butterflies of El

Salvador. II. Anaea (Zaretis) itys (Nymphalidae). Journal of the Lepidopterists' Society, 27: 294-302.

1974a. Notes on the life cycle and natural history of butterflies of El Salvador. III. Anaea (Consul) fabius (Nymphalidae). Journal of the Lepidopterists' Society, 28: 81-89. 
1974b. Notes on the life cycle and natural history of butterflies of El

Salvador. IV. Anaea (Memphis) erypyle confusa (Nymphalidae). Journal of the Lepidopterists' Society, 28: 306-314.

1975a. Notes on the life cycle and natural history of butterflies of El

Salvador. V. Anaea (Memphis) morvus boisduvali (Nymphalidae). Journal of the

Lepidopterists' Society, 29: 32-39.

1975b. Notes on the life cycle and natural history of butterflies of El

Salvador. VI. Anaea (Memphis) pithyusa (Nymphalidae). Journal of the

Lepidopterists' Society, 29: 168-176.

1976. Notes on the life cycle and natural history of butterflies of E1

Salvador. VII. Archaeoprepona demophon centralis (Nymphalidae). Journal of the

Lepidopterists' Society, 30(1): 23-32, 22 figs.

Nelson, G. J.; Platnick, N. I. 1981 Systematics and Biogeography. Cladistics and vicariance. New York, Columbia University Press. 567 p.

NiJHout, H. F. 1991. The development and evolution of butterfly wing patterns. Washington, Smithsonian Institution Press. xvi+297p.

Nijhout, H. F.; Wray, G. A. 1986. Homologies in the colour patterns of the genus Charaxes (Lepidoptera: Nymphalidae). Biologcal. Journal of the Linnean Society, 28: $387-410$.

NIXON, K. C. 2002. WinClada ver. 1.00.08. Ithaca, NY, Published by the author.

Nixon, K. C.; CARPEnTER, J. M. 1993. On outgroups. Cladistics, 9: 413-426.

Otero, L. D. 1990. Estudio de algunos caracteres para su uso en la classificación de Eurytelinae (Lepidoptera: Nymphalidae). Boletin de Entomologia Venezolana. N. S., 5 (16): 123-138. 
Peña, C.; Wahlberg, N.; Weingartner, E.; Kodandaramaiah, U.; Nylin, S.; Freitas, A. V. L.; Brower, A. V. Z. 2006. Higher level phylogeny of Satyrinae butterflies (Lepidoptera: Nymphalidae) based on DNA sequence data. Molecular Phylogenetics and Evolution, 40: 29-49.

Penz, C. M.; De VRies, P. J. 1999. Preliminary Assessment of The Tribe Lemoniini (Lepidoptera: Riodinidae) Based on adult Morphology. American Museum Novitates, 3284: 1-32;16 figs, 2 tabelas.

2002. Phylogenetic analysis of Morpho Butterflies (Nymphalidae,

Morphinae): Implications for Classification and Natural History. American Museum Novitates, 3374: 1-33; 17 figs, 2 tabelas.

Plantrou, J. 1983. Systematique biogeographie et evolution des Charaxes Africans

(Lepidoptera, Nymphalidae). Ecole Normale Superieure publications du Laboratoire de Zoologie No 25 (unpublished thesis).

ReBILlaRD, P. 1961. Révision systématique des Lépidoptères Nymphalides du genre Agrias. Mémoires du Muséum Nationale d'Histoire Naturelle (N.S.) sér. A, Zoologie, 22: 157-253.

Reuter, E. R. 1896. Über die Palpen der Rhopalocera. Ein Beitrag zur Erkenntnis der verwandtschaftlichen Beziehungen unter den Tagfaltern. Acta Societatis Scientiarum fennicae 22(1): 1-577, 6 pls. 1898. On a new classification of the Rhopalocera. Entomologist's Record and Journal of Variation, 10(2): 25-26, pl. 1; (3): 75-77; (4): 95-98.

RothSCHILD, W.; JORDAN, K. 1898-1903. A monograph of Charaxes and the allied Prionopterous genera. Novitates Zoologicae, 5: 545-605; 6: 220-286; 7: 281-524; 10: 326-342. 
Rydon, A. H. B. 1971. The Systematics of the Charaxinae (Lepidoptera: Nymphalidae) Entomologist's Record and Journal of Variation, 83: 219-233; 283-287; 310-316; $336-341 ; 386-388$.

Salazar, J. A.; Constantino, L. M. 2001. Synthesis of the Colombian Charaxidae and description of the new genera for the South America: Rydonia, Annagrapha, Pseudocharaxes, Muyshondtia, Zikania (Lepidoptera, Nymphaloidea). Lambillionea CI, 2. suppl. 3: 344-369.

SCHWANWITSCH, B. N. 1924. On the ground-plan of wing-pattern in nymphalids and certain other families of the rhopalocerous Lepidoptera. Proceedings of the zoological Society of London, 1924(2): 509-528, 4 pls. 1930. Studies upon the wing-pattern of Prepona and Agrias Acta zoologica (Stockholm), 11: 289-424. 1940. On a remarkable dead leaf imitation in Zaretis, in Nymphalid butterflies. Zoologischeskoe Zhurnal, 19(1): 14-25.

1956. Color-pattern in Lepidoptera. Entomologicheskoe Obozrenie, 35(3): 530-546, 77 figs.

Silva Brandẽo, K. L.; Wahlberg, N.; Francini, R. B.; Azevedo-Espin, A. M. L.; Brown JR, K. S.; Paluch, M.; Lees, D. C.; Freitas, A. V. L. 2008. Phylogenetic relationships of butterflies of the tribe Acraeini (Lepidoptera, Nymphalidae, Heliconiinae) and the evolution of host plant use. Molecular Phylogenetics and Evolution, (46): 515-531.

Smiles, R. L. 1982. The taxonomy and phylogeny of the genus Polyura. . London. Publ. Br. Mus. $123 p+16 p 1$.

1985. Cladistics and distribution of Euxanthe butterflies (Nymphalidae: Charaxinae). Journal of Natural History, 19: 1165-1189. 
SoKAL, R. R.; ROHLF, F. J. 1981. Taxonomic congruence in the Lepitopodomorpha reexamined. Systematic Zoology, 30: 309-325.

StiChel, H. F. E. J. 1939. Nymphalidae III: Subfam.: Charaxidininae II. Lepidopterorum Catalogus, 93: 543-794.

SteHR, F. W. 1987. Order Lepidoptera. In: STEHR, F. W. (ed.) Immature insects. Dubuque, Kendall / Hunt Publ. p. 288-596.

Stoll, C. 1782. De uitlandische Kapellen voorkomende in de drie Waereld-Deelen Asia, Africa en America. In: CRAMER, P. Papillons exotiques des trois parties du monde l'Asie, l'Afrique et l'Amérique. Amsterdam, J. S.Baalde; Utrecht, Barthelemy Wild. v. 4, pt. 32-34, p. 165-252, pls. 373-400.

SÜFFERT, F. 1927. Zur vergleichenden Analyse der Schmetterlingszeichnung (Vorläufige Mitteilung). Biologisches Zentralblatt, 47(7): 385-413, 9 figs.

Thomas, C. D.; Hill, J. K.; Lewis, O. T. 1998. Evolutionary consequences of habitat fragmentation in a localized butterfly. Journal of Animal Ecology, 67: 485-497.

VAN Son, G. 1979. The butterflies of Southern Africa. Part 4. Nymphalidae: Nymphalinae. Revised and edited by L. Vari. Transvaal Museum Memoirs, 22: 1-286, 76 plates.

VAn Someren, V. G. L. 1963-1975. Revisional notes on african Charaxes I-X. London. British Museum (Nat. Hist.).

WAhlberG, N.; Weigartner, E.; Nylin, S. 2003. Towards a better understanding of the higher Nymphalidae (Lepidoptera: Papilionoidea). Molecular Phylogenetics and Evolution, 28: 473-484.

Wahlberg, N.; Braby, M. F.; Brower, A. V. Z.; De Jong, R.; Lee, M.-M.; Nylin, S.; Pierce, N.; Sperling, F. A.; Vila, R.; Warren, A. D.; Zakharov, E. 2005: Synergistic effects of combining morphological and molecular data in resolving the 
phylogeny of butterflies and skippers. Proceedings of the Royal Society of London Series B Biological Sciences, 272, p.1577-1586.

Wheeler, W.C; Whiting, M.; Wheeler, Q. D.; CARPenter, J.M.. 2001. The phylogeny of extant hexapod orders. Cladistics, 17: 113-169.

Wiley, E. O. 1981. Phylogenetics. The theory and praticeof phylogenetic systematics. New York, John Wiley \& Sons. 439 p.

Willmott, K. R.; Hall, J. P. 2001. Taxonomic notes on the genus Zaretis, with the description of a new species (Lepidoptera: Nymphalidae: Charaxinae). Tropical Lepidotera, 12(1-2): 29-34.

Willmott, K. R.; 2003a. The genus Adelpha: its Systematics, Biology abd Biogeography (Lepidoptera: Nymphalidae: Limenitidini). Gainesville, Scientific Publishers. VIII $+322 p$.

2003b. Cladistic analysis of the neotropical butterfly genus Adelpha

(Lepidoptera: Nymphalidae), with coments on the subtribal classification of Limenitidini. Systematic Entomology, 28: 279-322.

Willmott, K. R.; Freitas, A. V. L.,. 2006. Higher level phylogeny of the Ithomiinae (Lepidoptera: Nymphalidae): classification, patterns of larval hostplant colonization and diversification. Cladistics, 22(4): 297-368, 31 figs., 4 tabs.

Woodhall, S. 2008. What's that butterfly? A starter's guide to butterflies of South Africa. Cape Town, Struik Publishers, 144p. 
FIGURAS 

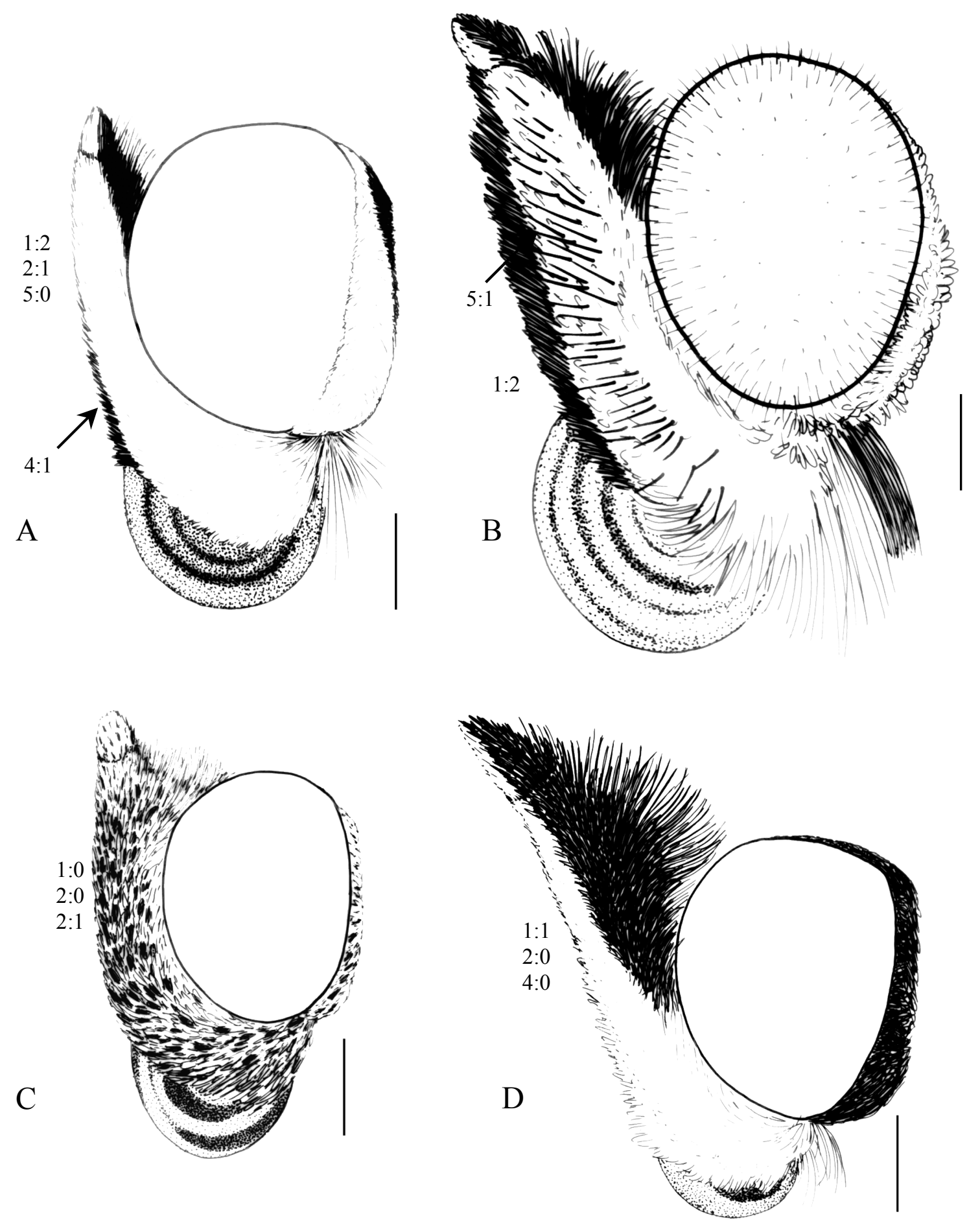

Figura 7. Cabeça. Vista lateral. a. Agrias amydon, b. Noreppa chromus, c. Siderone galanthis, d. Memphis glauce. Escala $=1 \mathrm{~mm}$. 

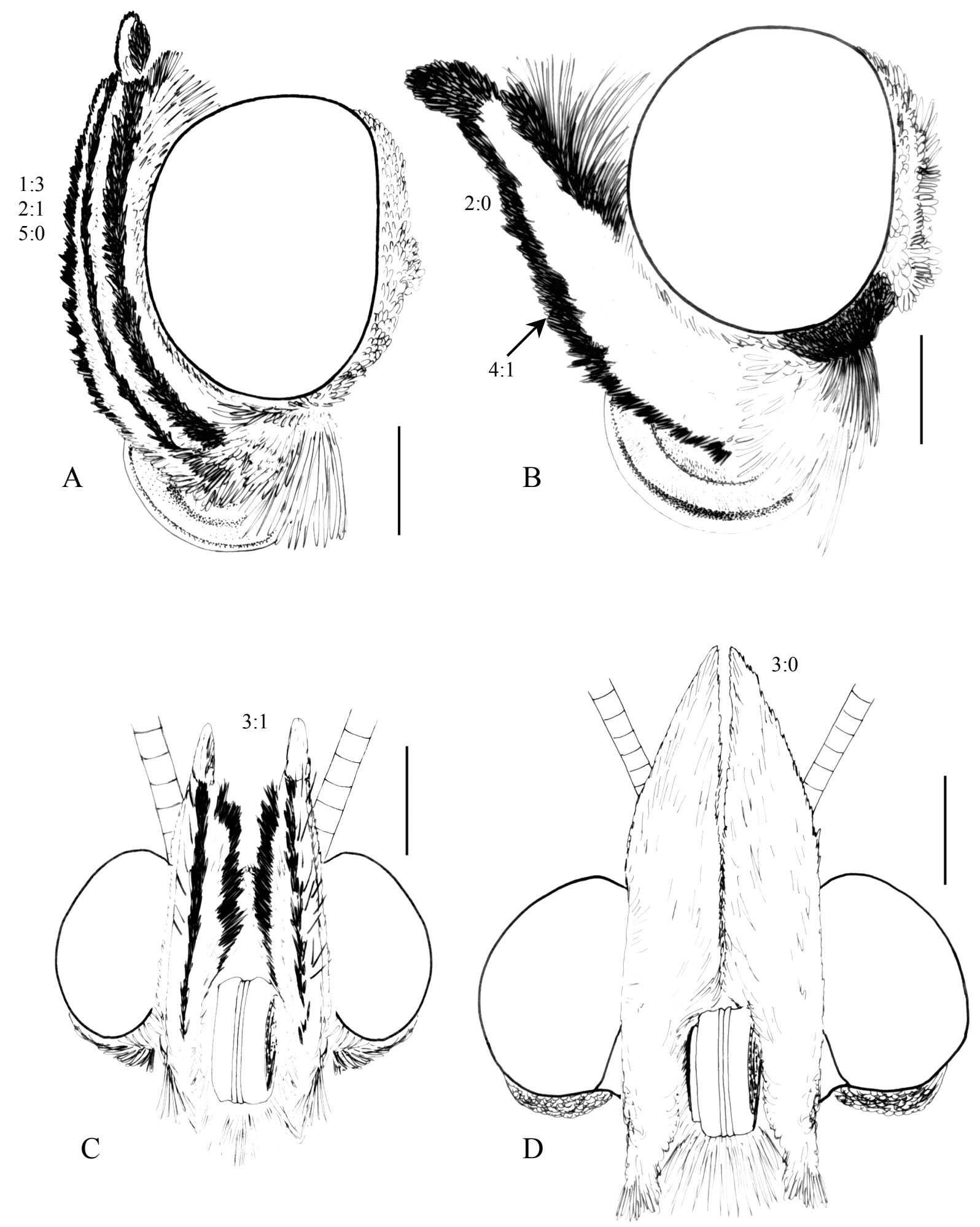

Figura 8. Cabeça. Vista lateral. a. Charaxes jasius,. b. Polygrapha cyanea. Vista frontal: c. Zaretis isidora, d. Memphis verticordia. Escala $=1 \mathrm{~mm}$. 

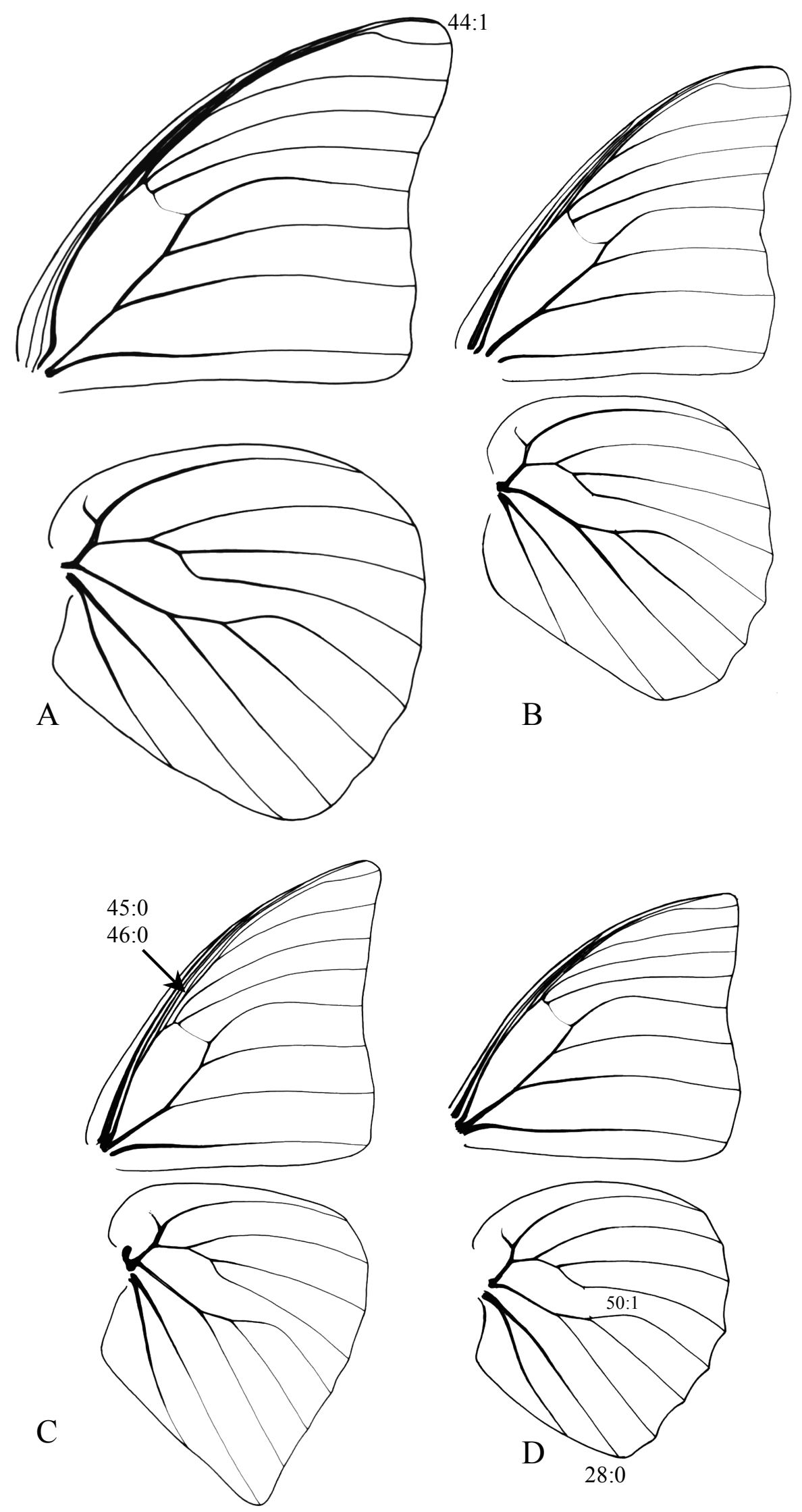

Figura 9. Venação das asas. a. Archaeoprepona demophon, b. Prepona laertes, c. Agrias claudina, d. Anaeomorpha splendida. 

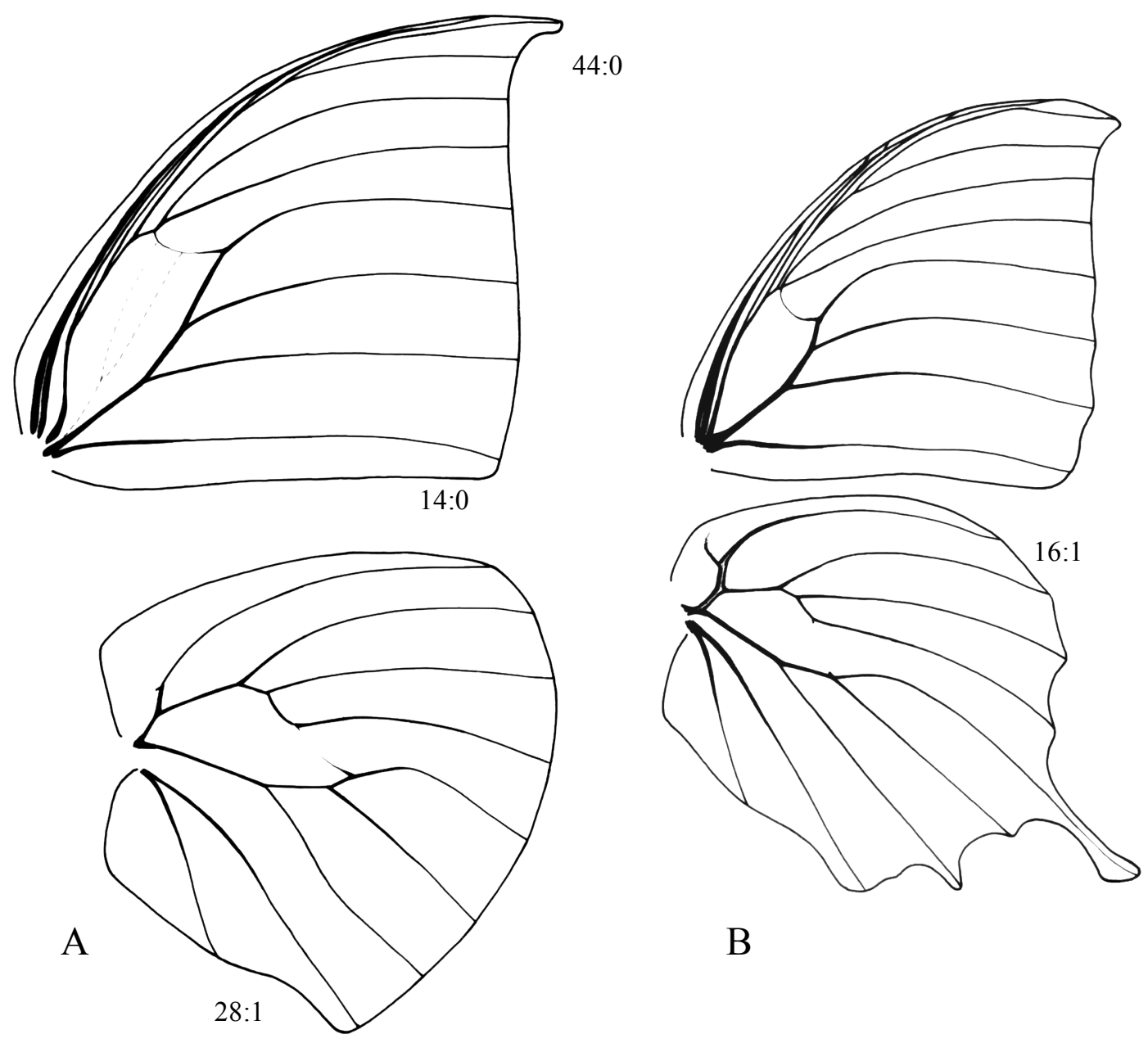

B
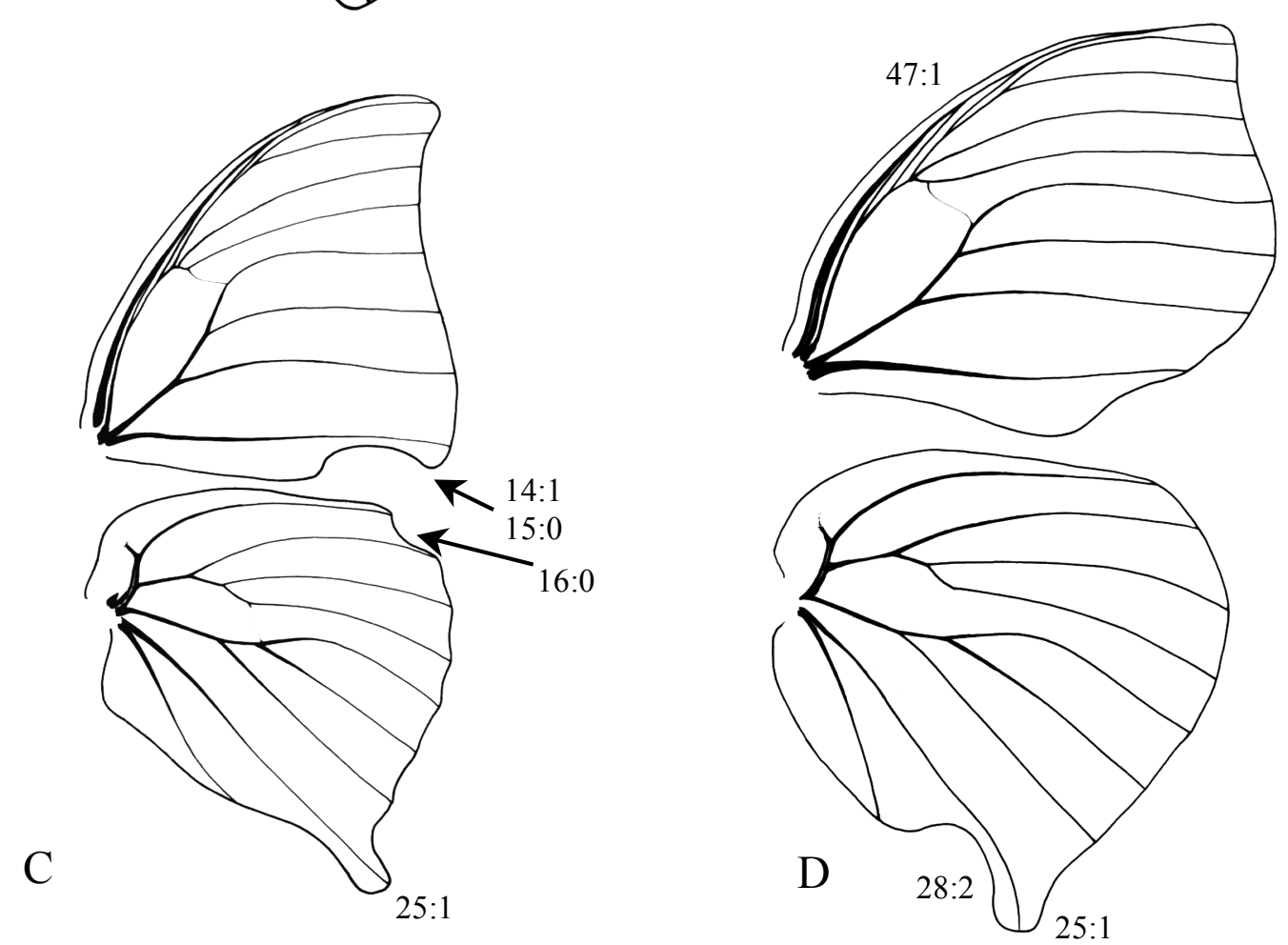

Figura 10. Venação das asas. a. Coenophlebia archidona, b. Hypna clytemnestra. c. Zaretis isidora, d Siderone galanthis. 

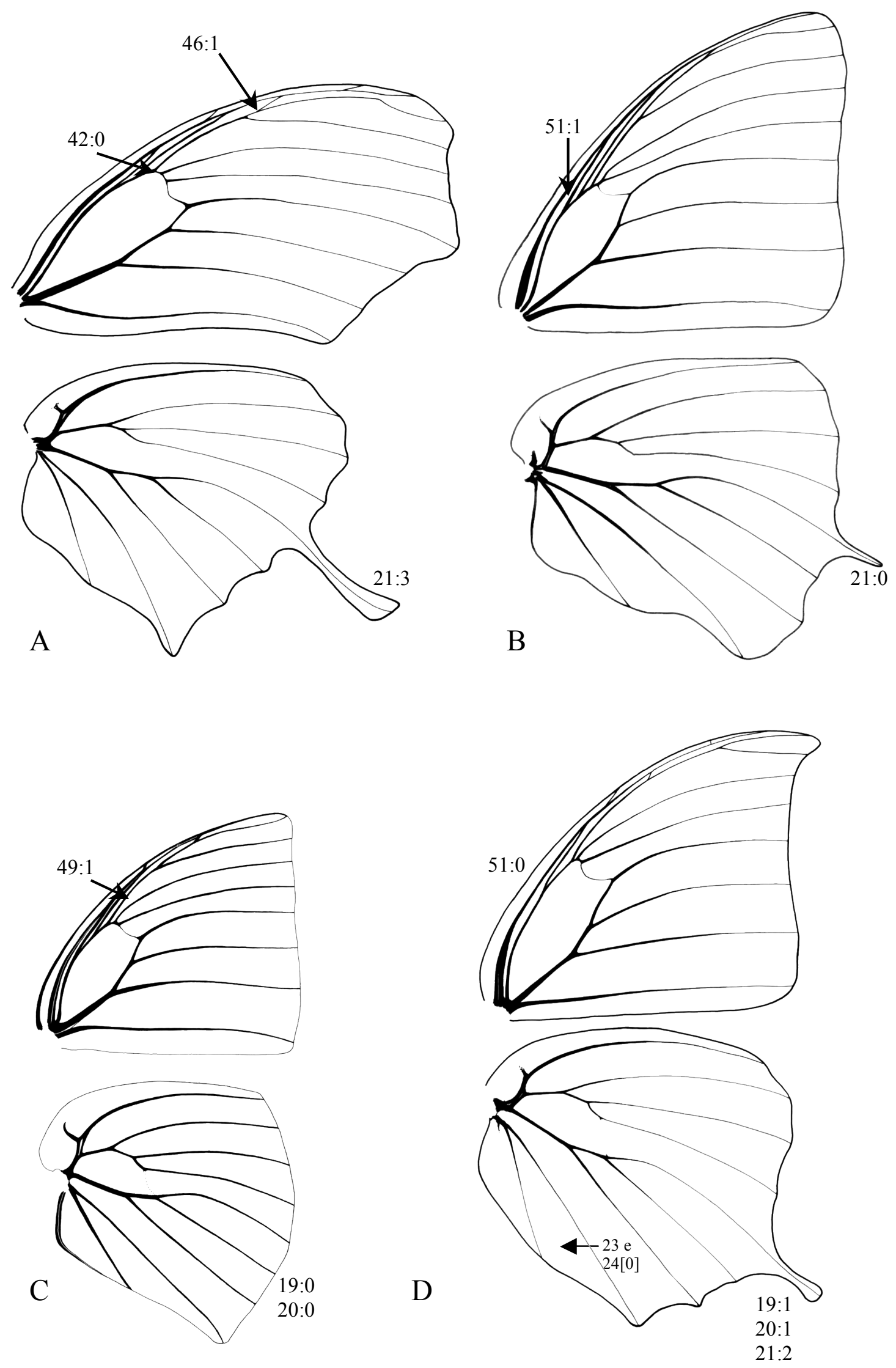

Figura 11. Venação das asas: a. Consul fabius, b. Polygrapha cyanea, c. Fountainea ryphea, d. Anaea troglodyta. 


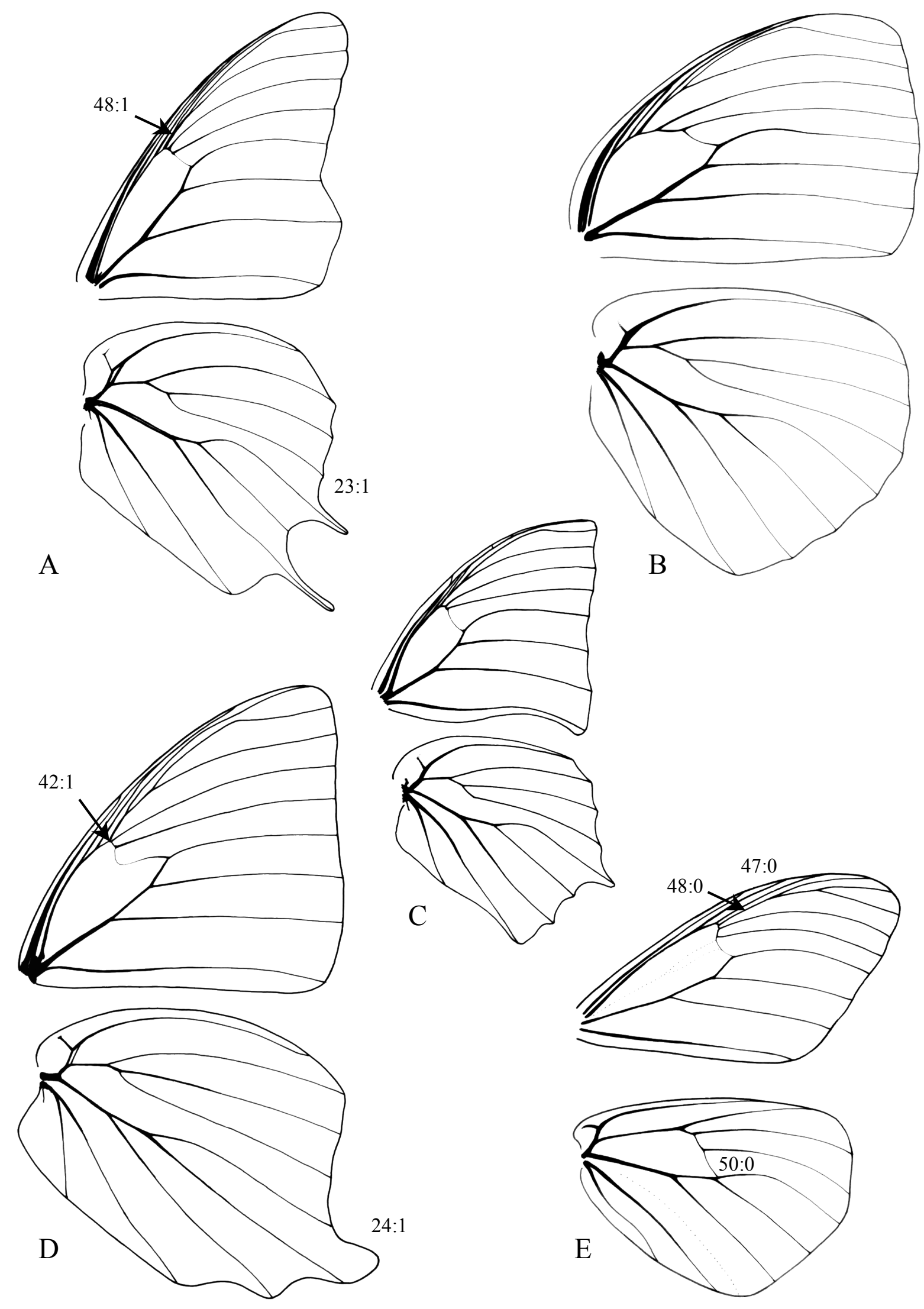

Figura 12. Venação das asas, a. Charaxes jasius, b. Euxanthe eurinome, c. C. pleione, d. Prothoe franck, e. Calinaga buddha. 

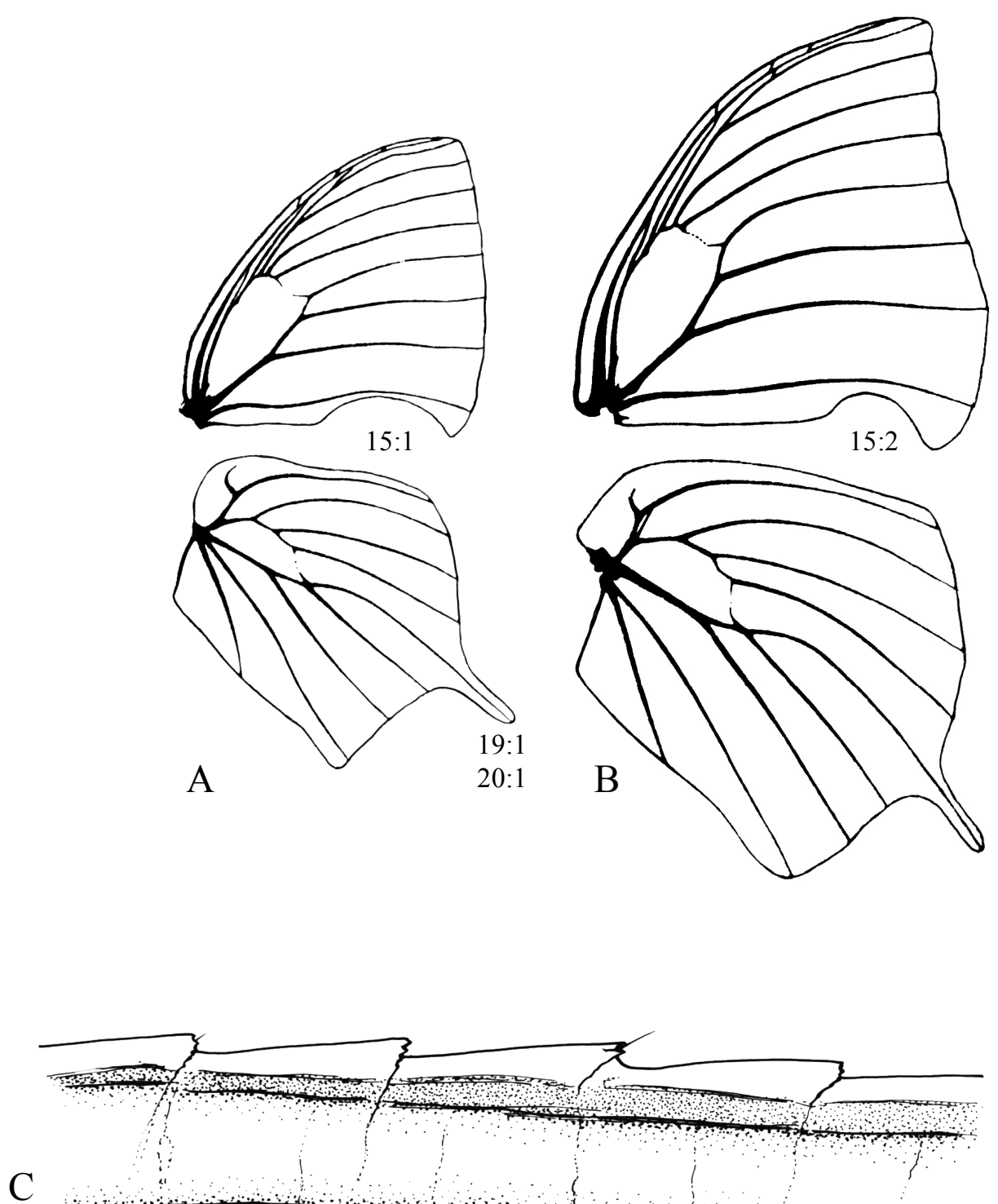

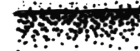

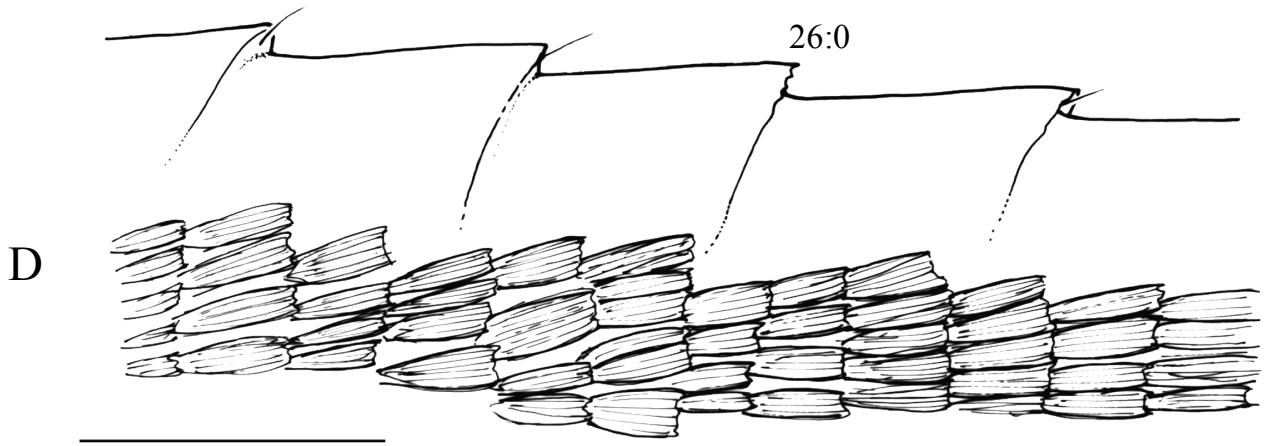

Figura 13. Venação das asas, a. Memphis hirta, b. M. philumena (modificado de Comstock, 1961). c, d. Costa serrilhada de Charaxes tiridates. c. vista ventral, d.vista dorsal. Escala = $0,5 \mathrm{~mm}$. 

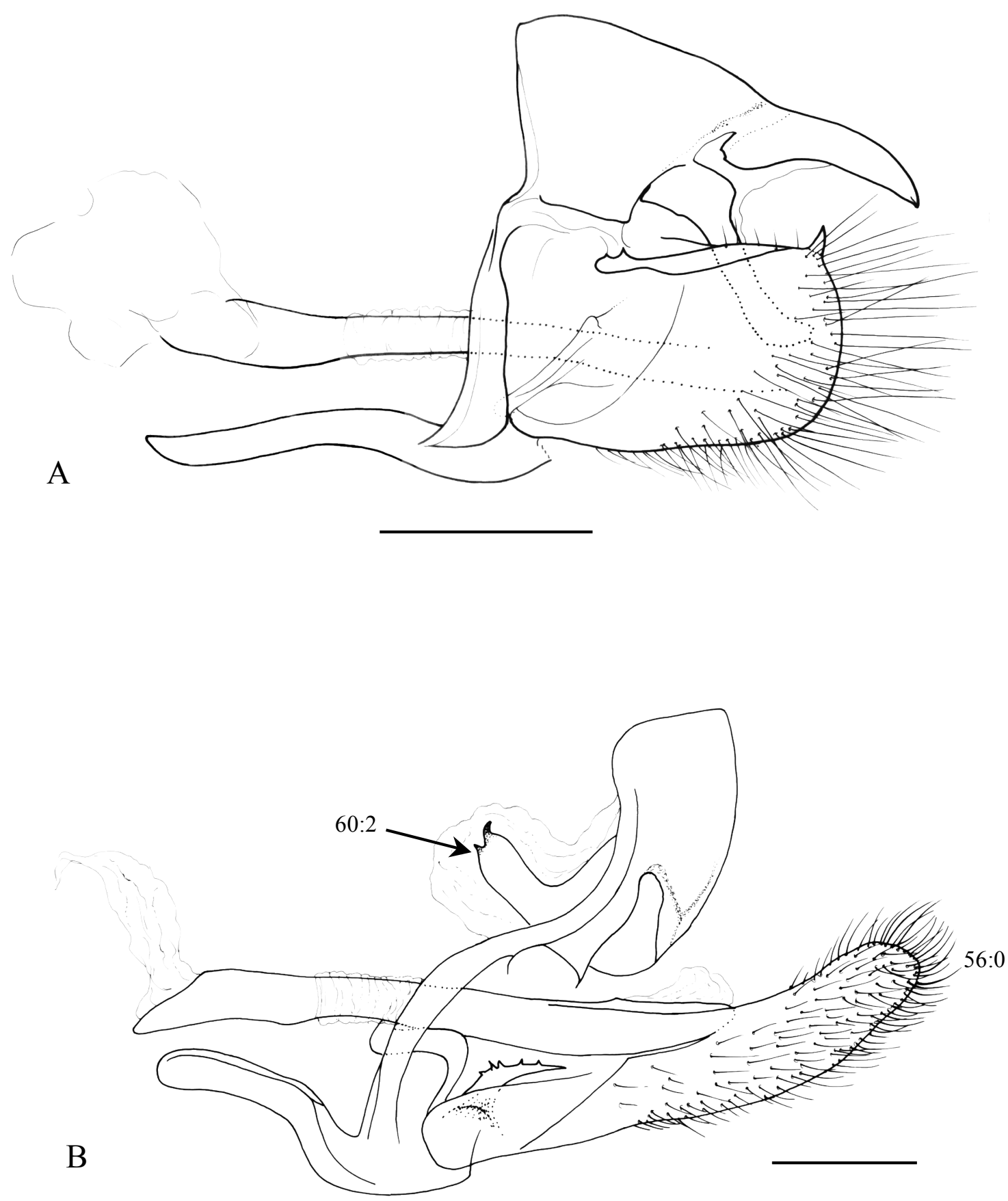

Figura 14. Genitália masculina. Vista lateral, a. Prothoe franck. b. Agatasa calydonia. Escala $=1 \mathrm{~mm}$. 

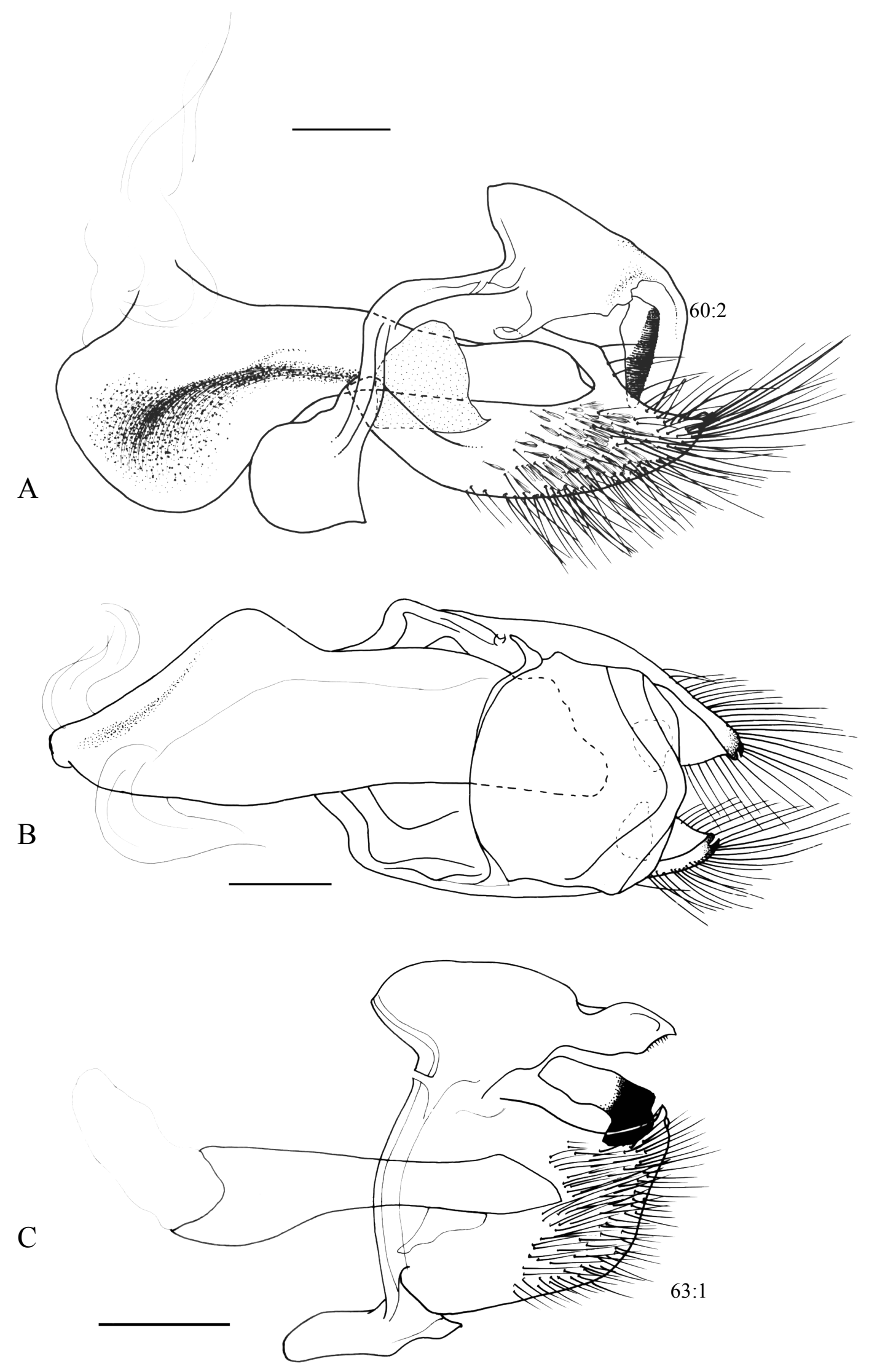

Figura 15. Genitália masculina. Vista lateral, a. Archaeoprepona demophoon, c. A. chalciope. Vista dorsal, b. Archaeoprepona demophoon . Escala $=1 \mathrm{~mm}$. 
A

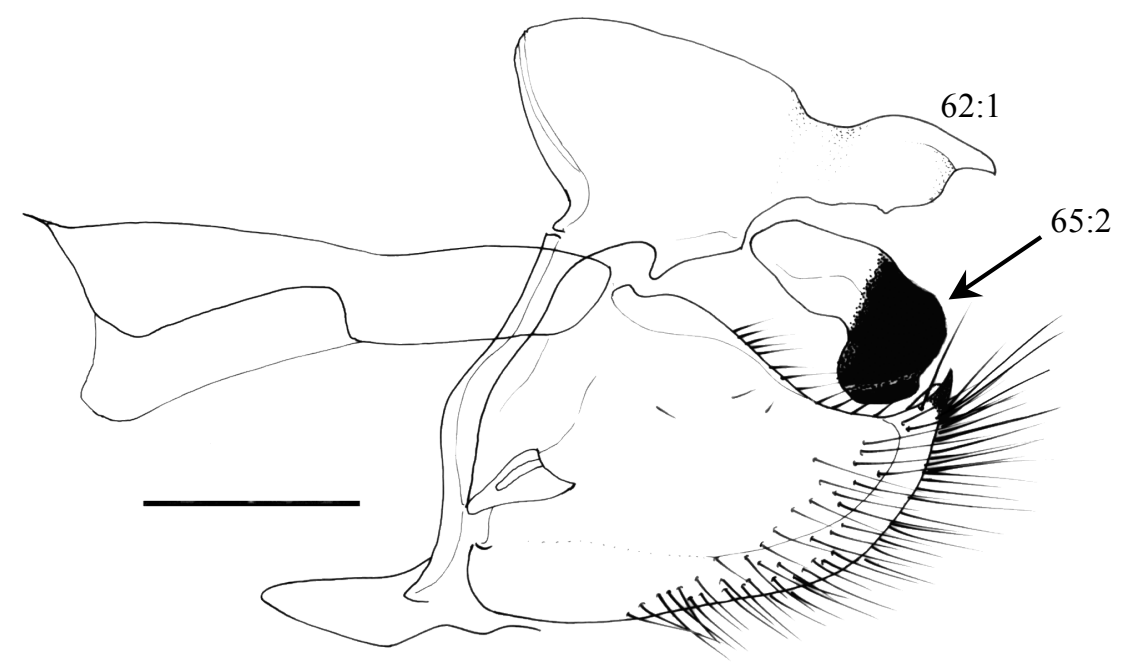

B
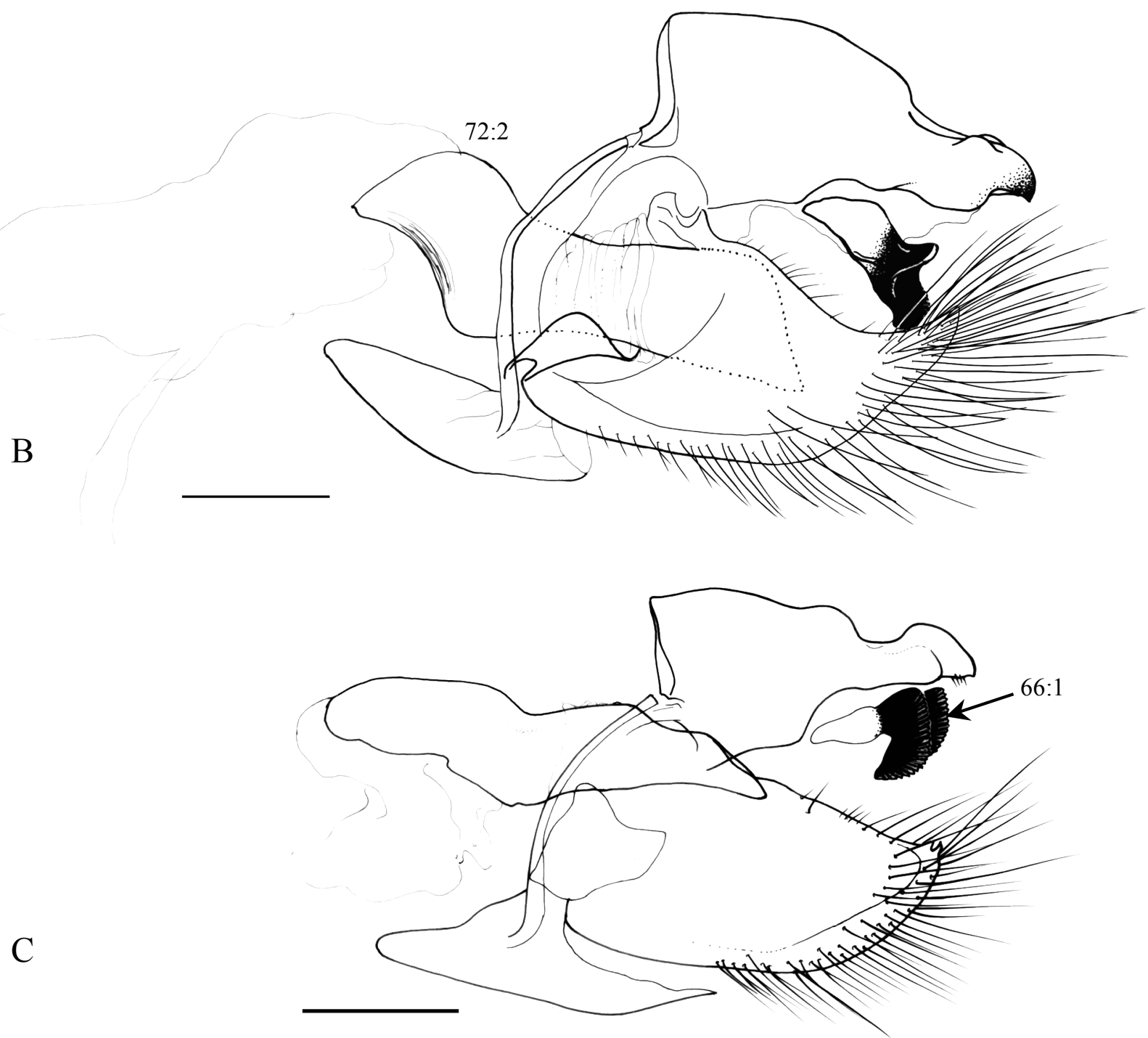

Figura 16. Genitália masculina. Vista lateral. a. Archaeoprepona amphimacus, b. A. licomedes, c. Noreppa chromus. Escala $=1 \mathrm{~mm}$. 


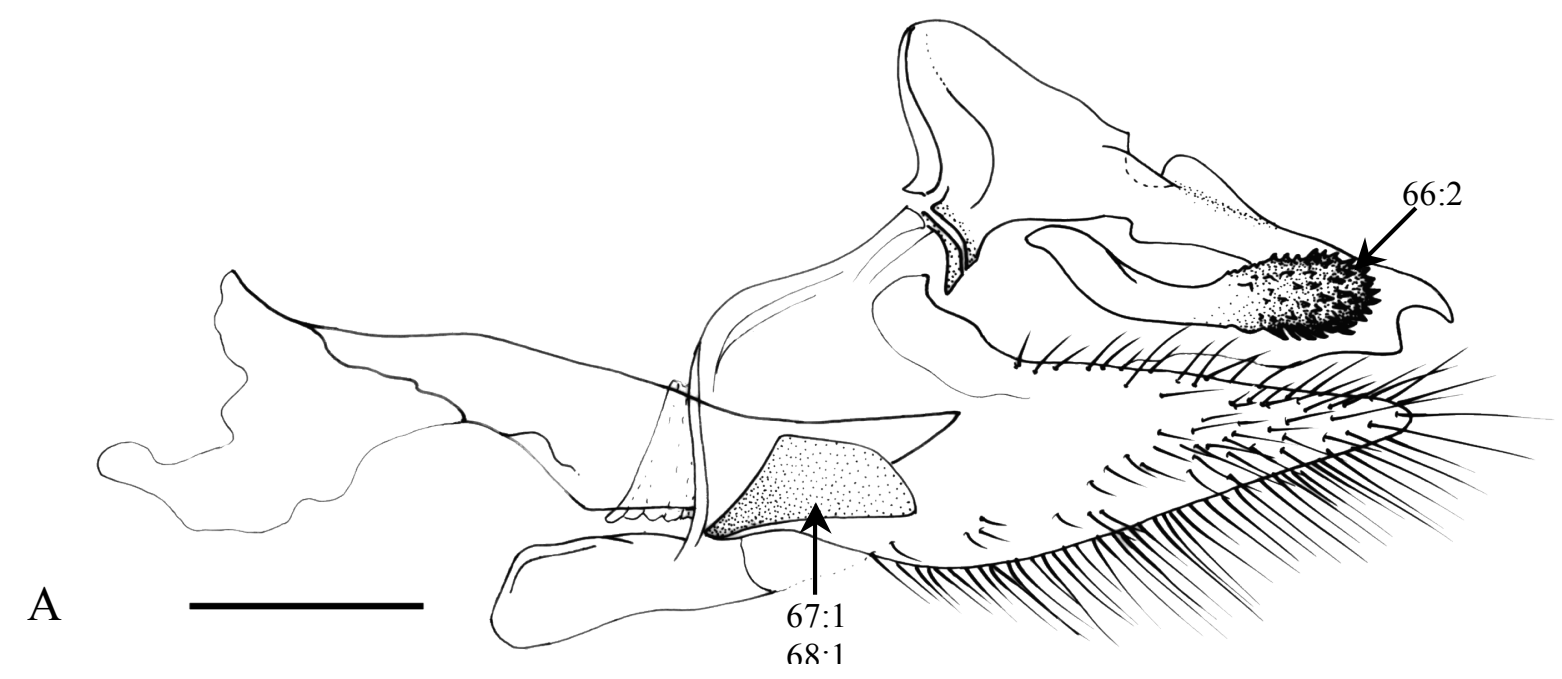

B
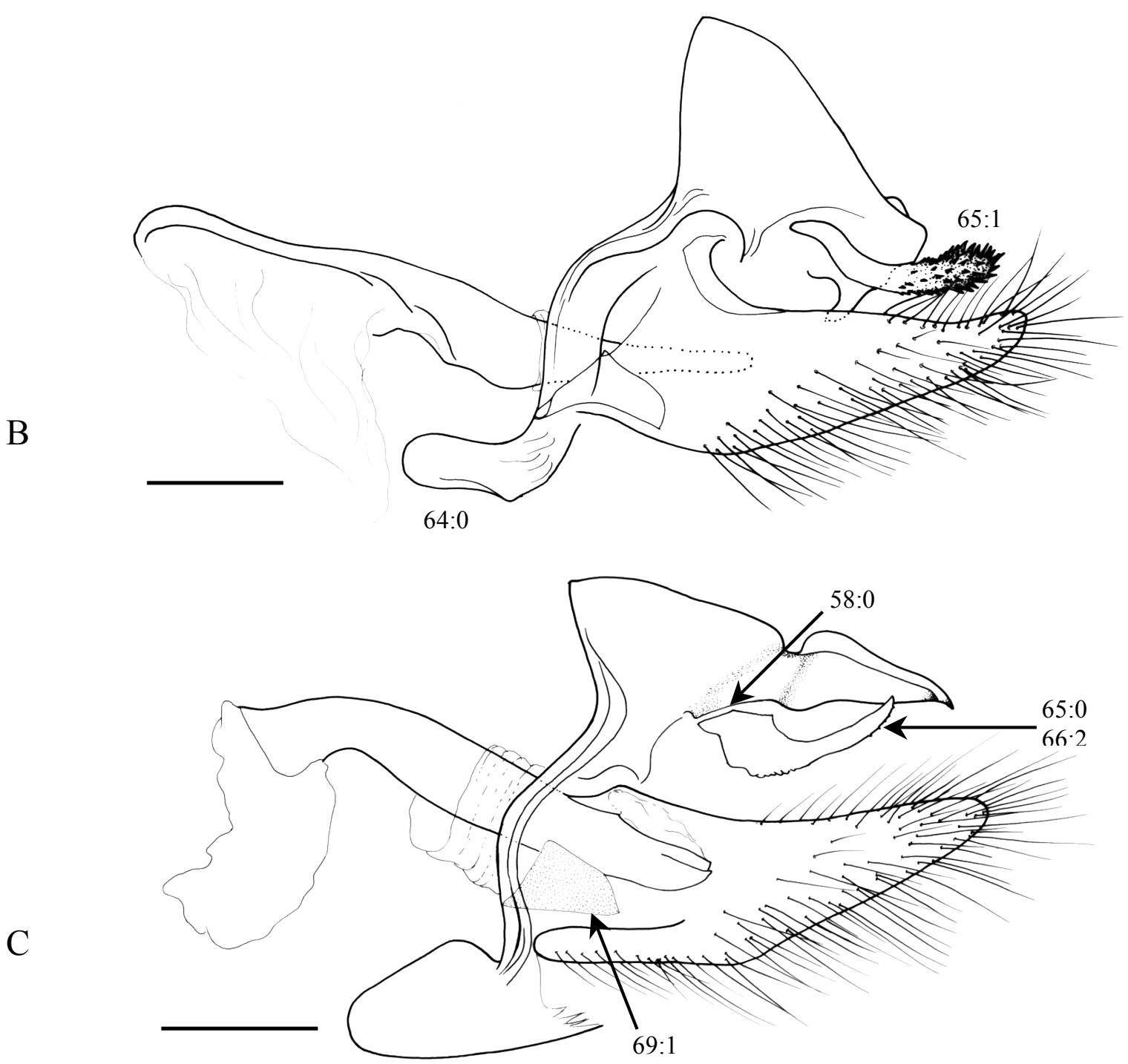

Figura 17. Genitália masculina. Vista lateral, a. Agrias claudina, b. Prepona pylene, c. P. pheridamas. Escala $=1 \mathrm{~mm}$. 
A

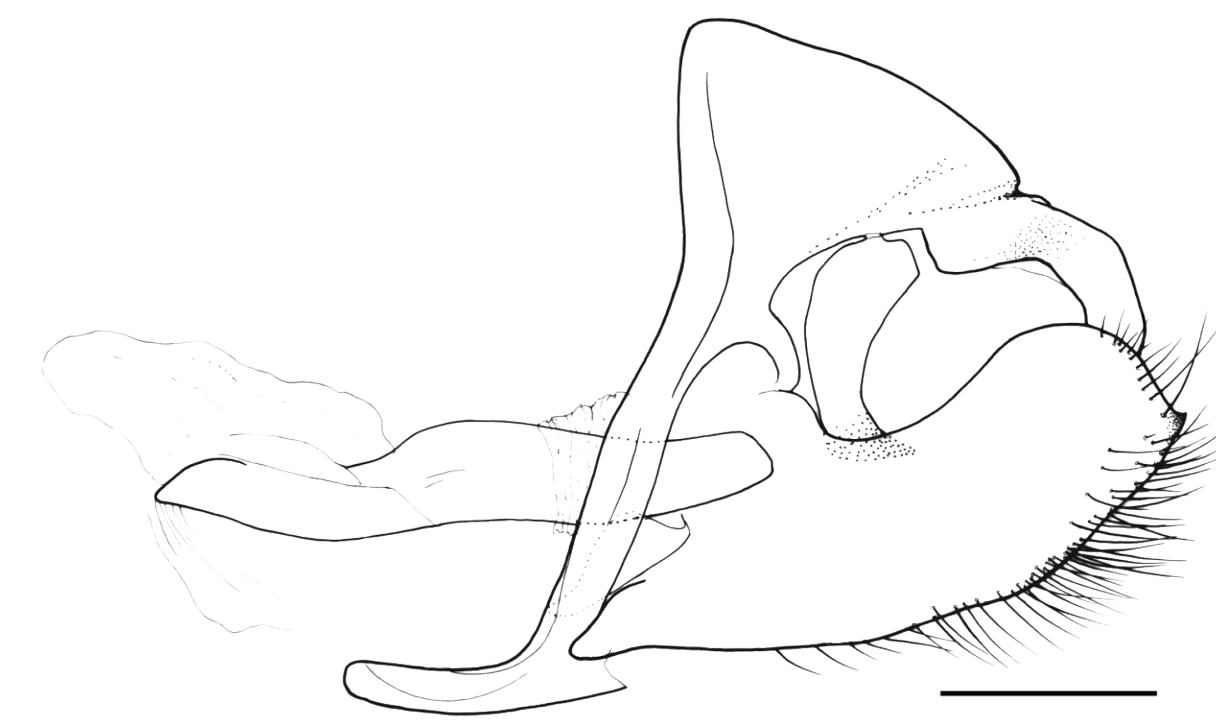

B
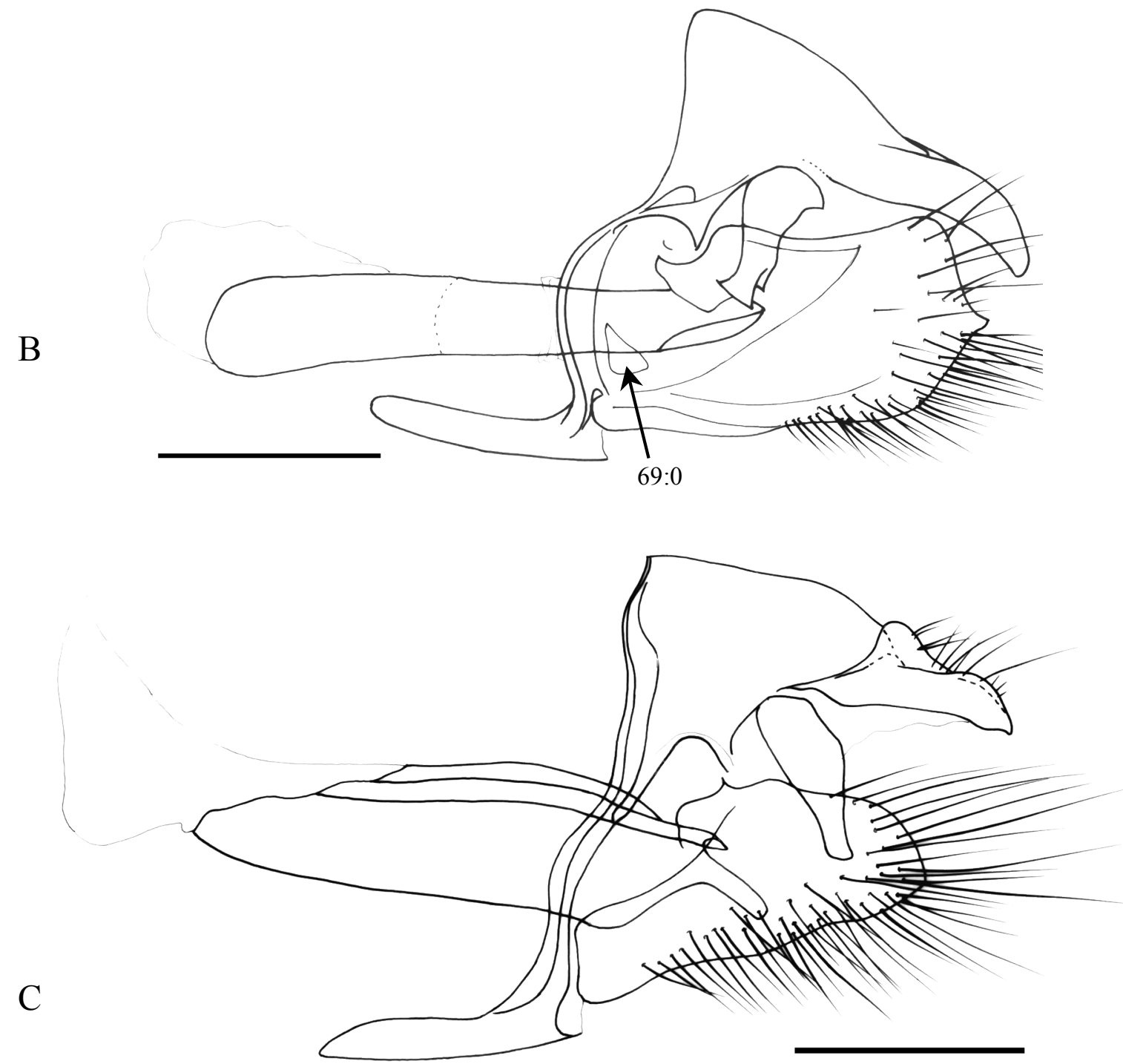

Figura 18. Genitália masculina. Vista lateral, a. Coenophlebia archidona, b. Hypna clytemnestra, c. Consul fabius. Escala $=1 \mathrm{~mm}$. 


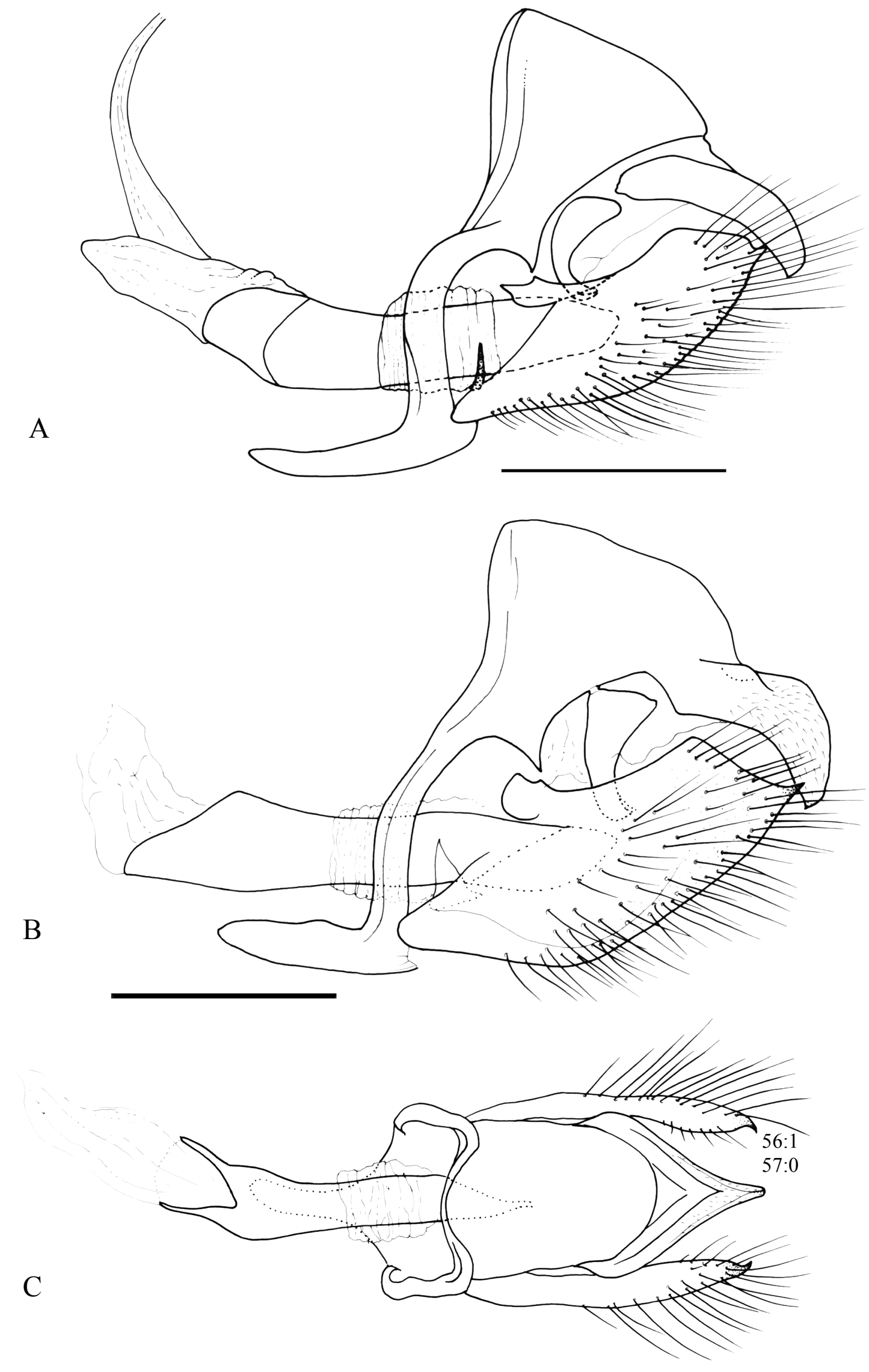

Figura 19. Genitália masculina. Vista lateral, a. Siderone galanthis, b. Zaretis callidryas, Vista dorsal c. Zaretis callidryas. Escala $=1 \mathrm{~mm}$. 

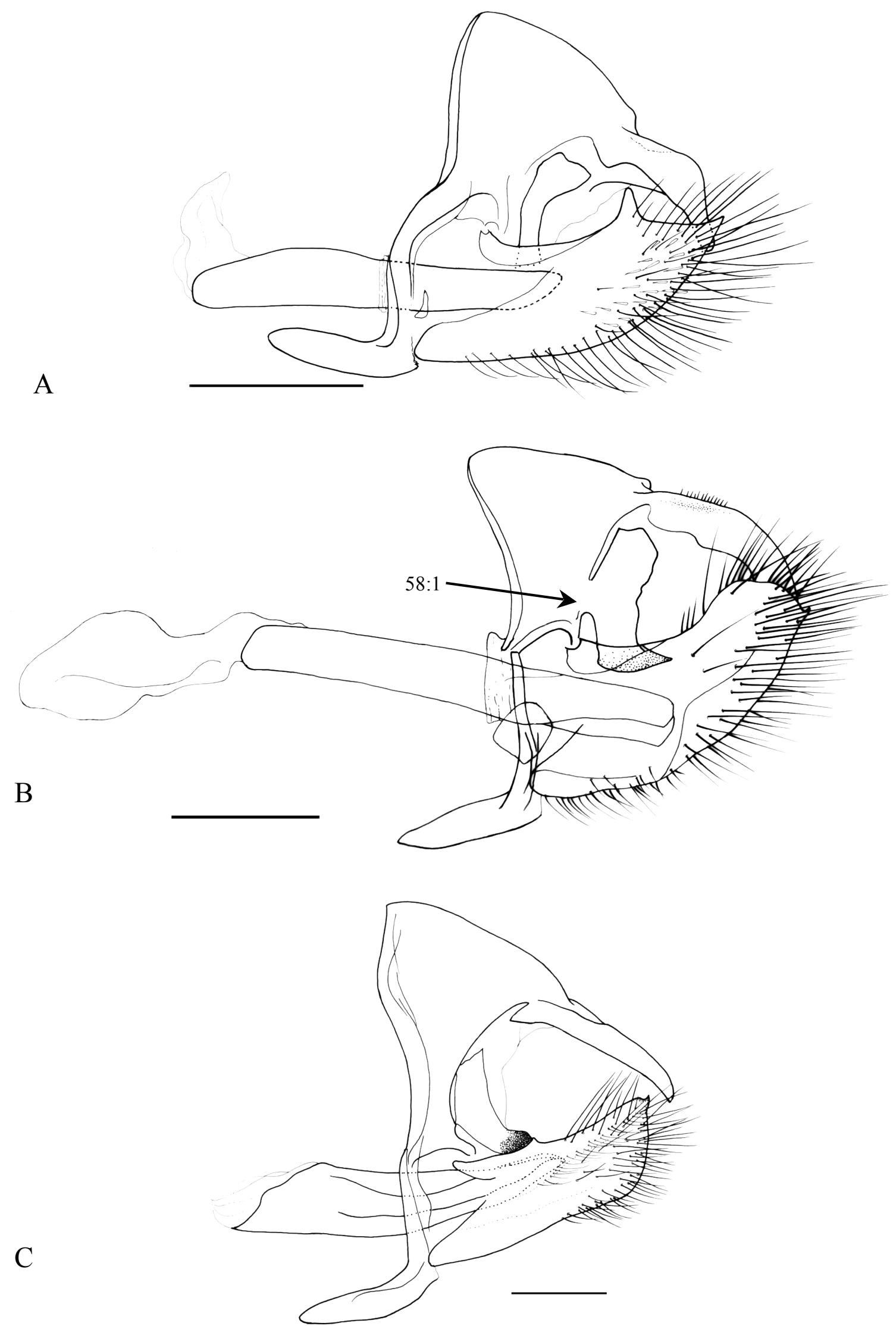

Figura 20. Genitália masculina. Vista lateral, a. Zaretis isidora, b. Polygrapha suprema. b. $P$. xenocrates. Escala $=1 \mathrm{~mm}$. 

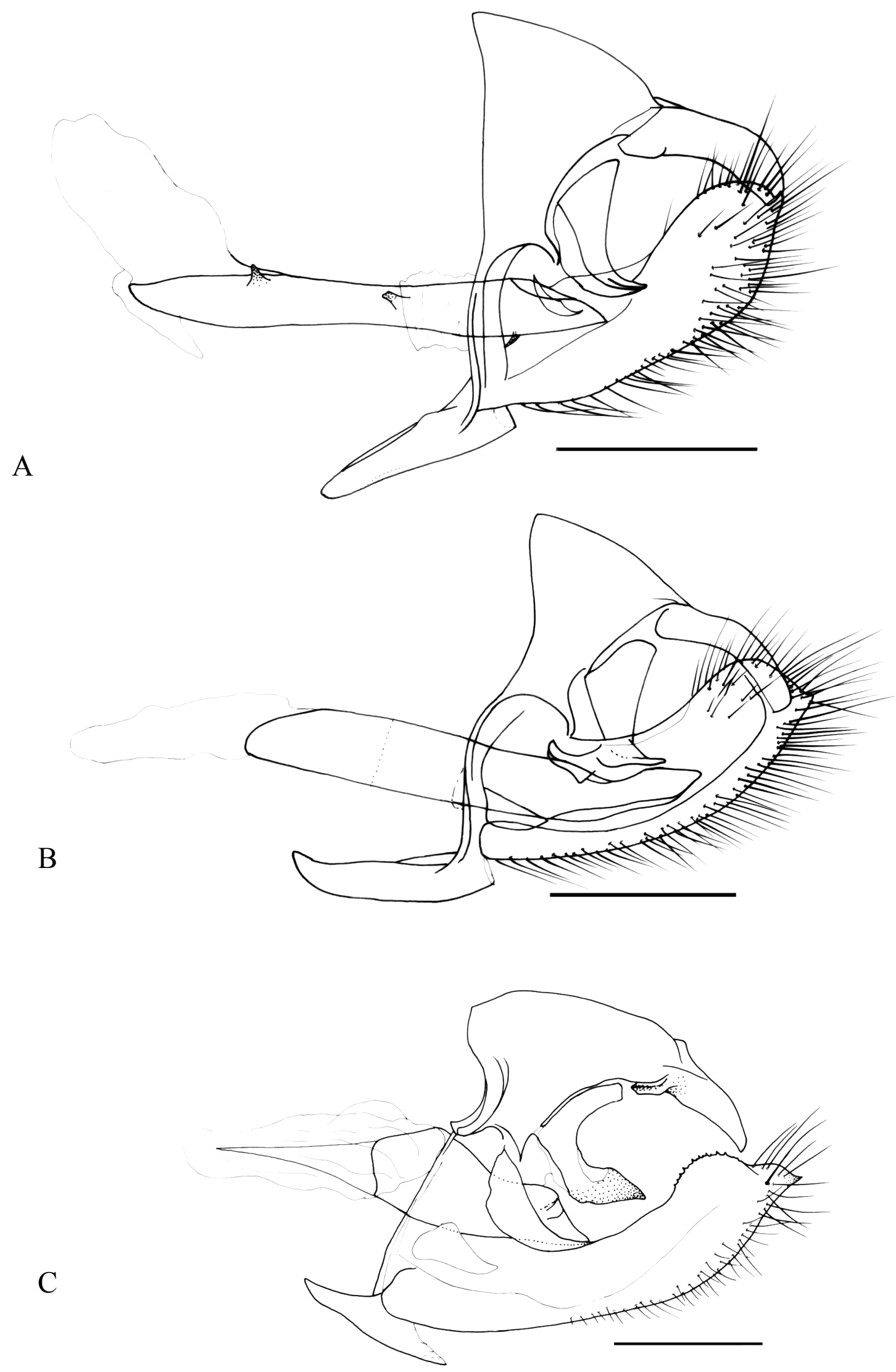

Figura 21. Genitália masculina. Vista lateral, a. Fountainea nessus, b. F. ryphea. c. Memphis verticordia. Escala $=1 \mathrm{~mm}$. 


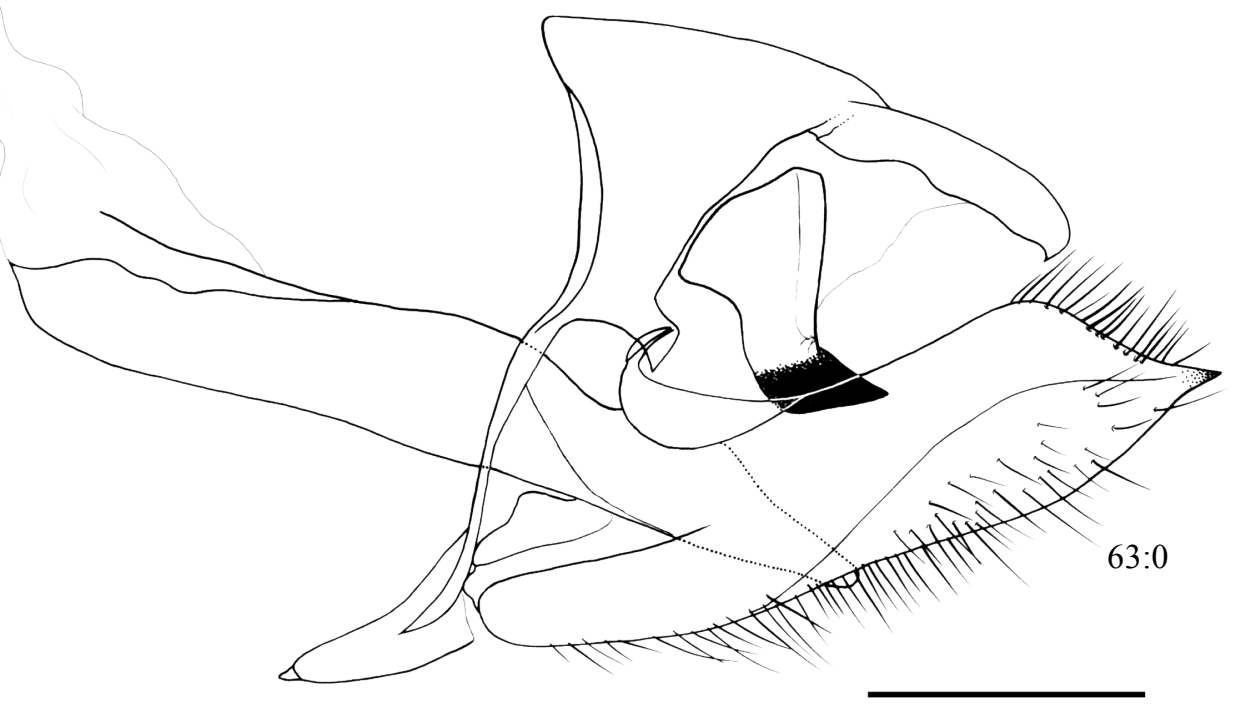

A
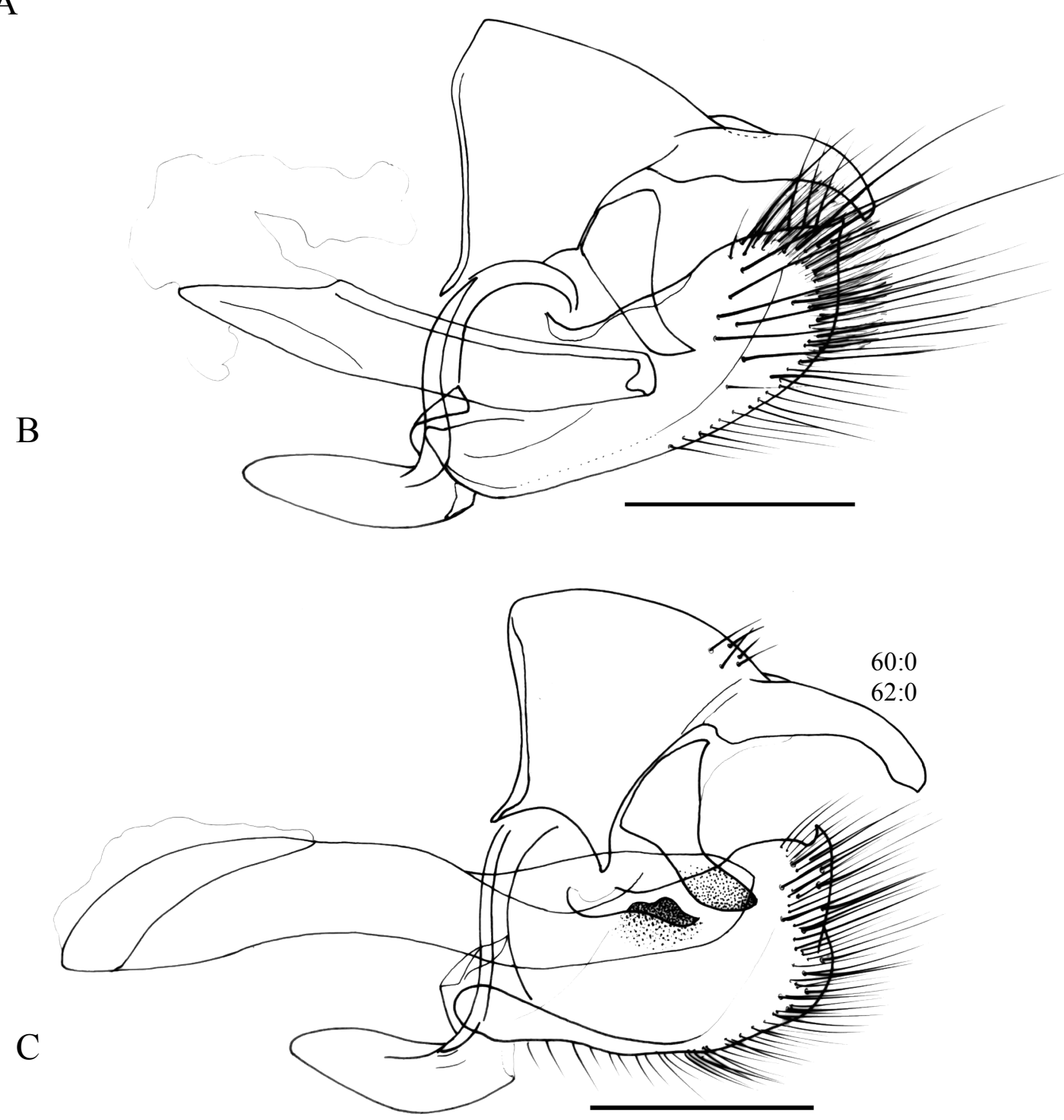

Figura 22. Genitália masculina. Vista lateral. a. Memphis glauce, b. M. grandis, c. M. polyxo. Escala $=1 \mathrm{~mm}$. 


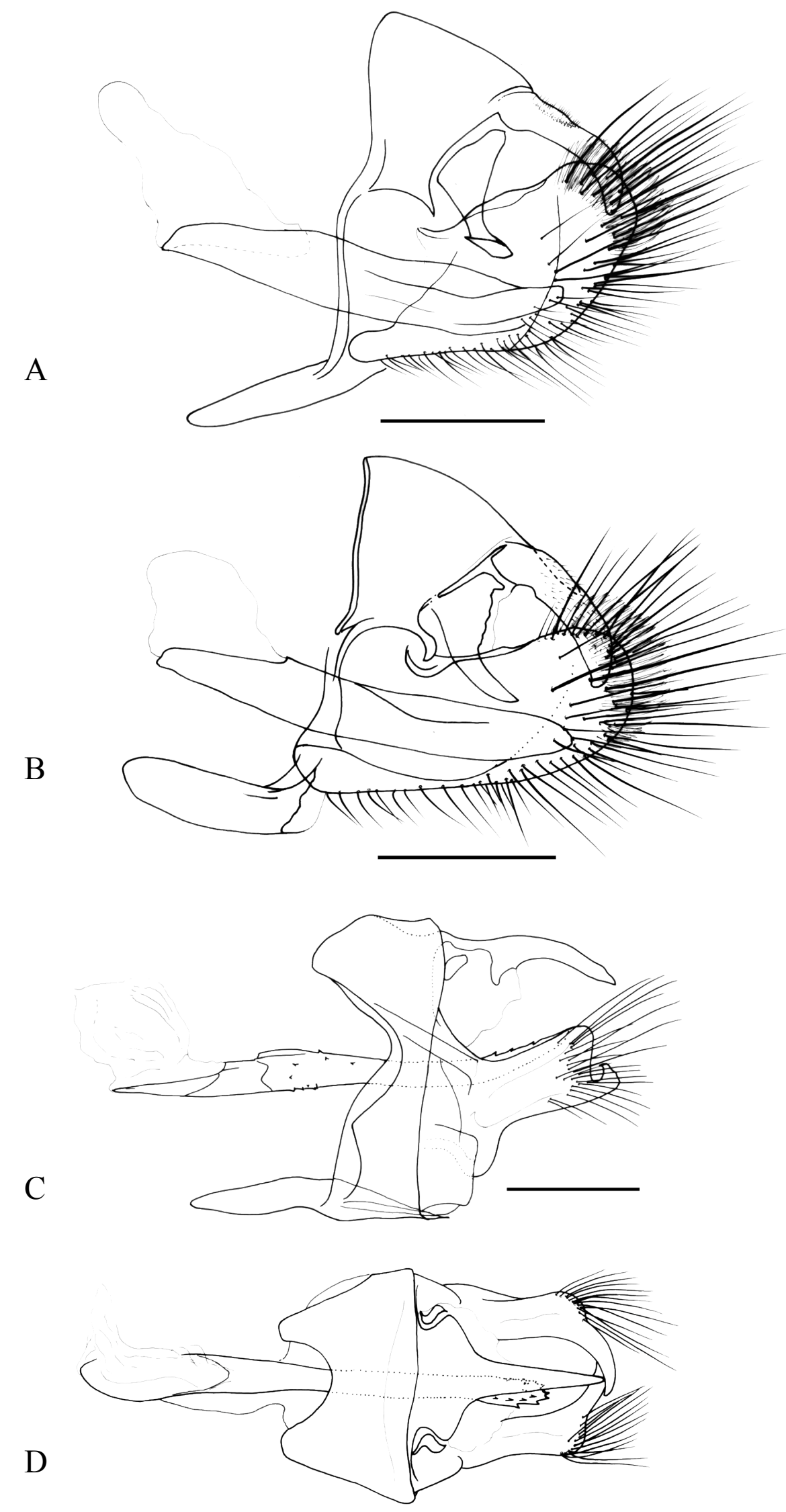

Figura 23. Genitália masculina. Vista lateral. a. Memphis philumena, b. M. polycarmes, c. Palla decius. Vista dorsal. Palla decius. Escala $=1 \mathrm{~mm}$. 


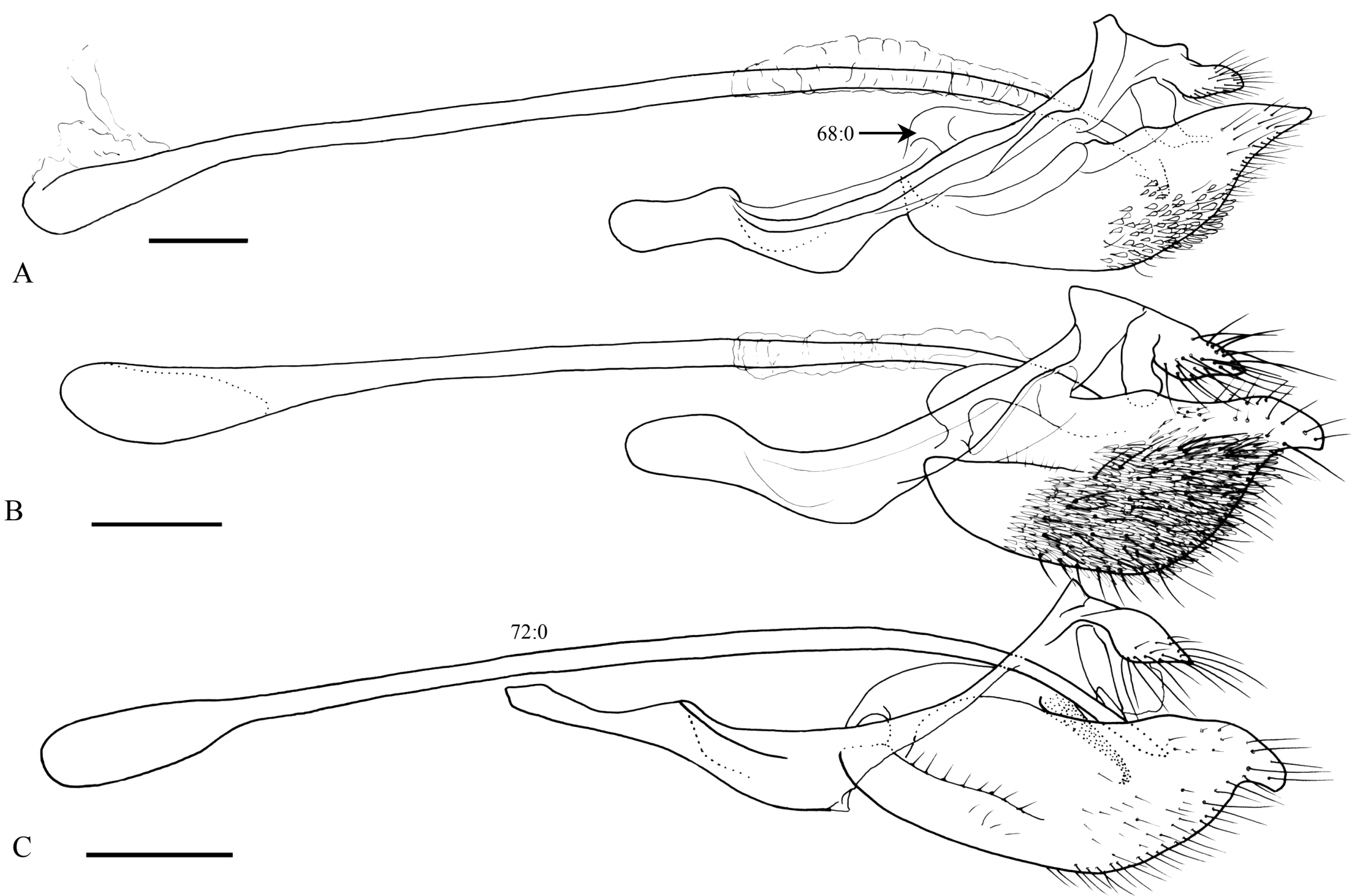

Figura 24. Genitália masculina. Vista lateral, a. Euxanthe eurinome, b. Euxanthe trajanus, c. Charaxes varanes, Escala =1mm. 


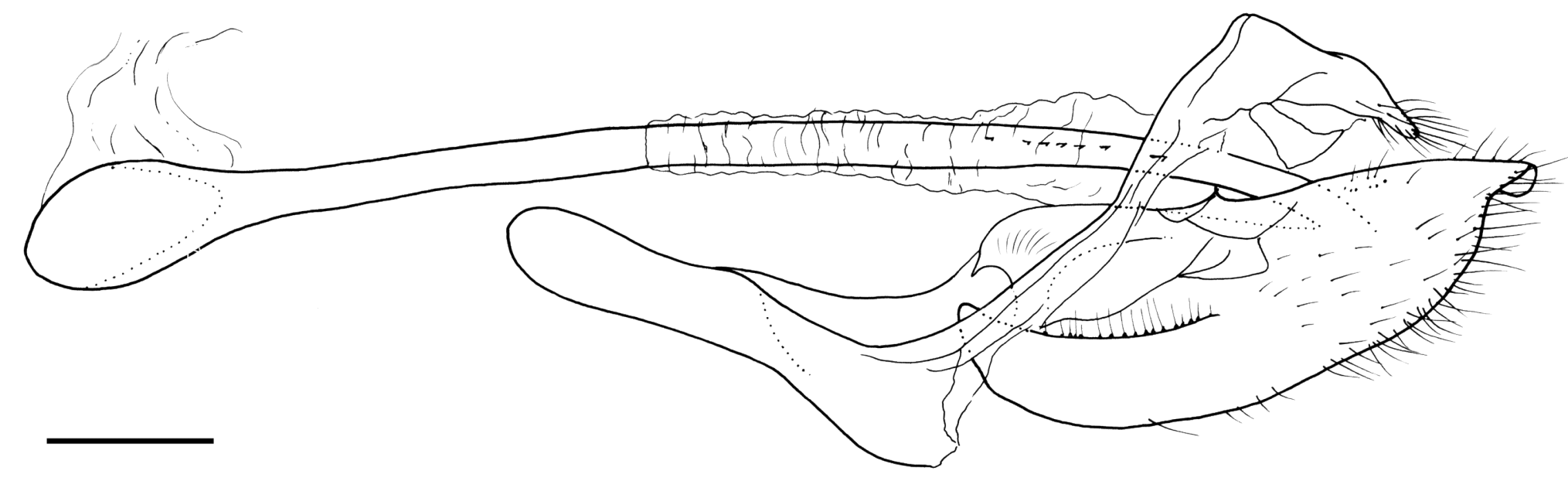

B

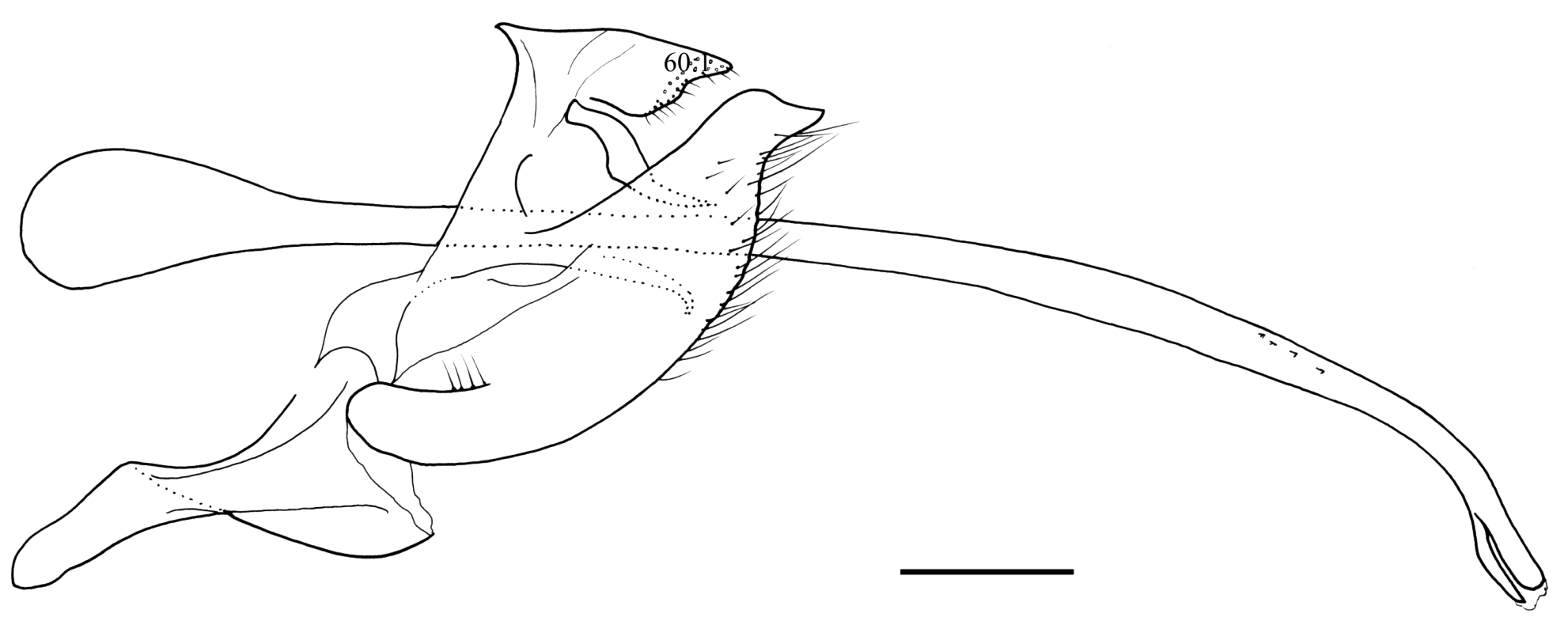

Figura 25. Genitália masculina. Vista lateral, a. C. candiope, b. C. cynthia. Escala $=1 \mathrm{~mm}$. 


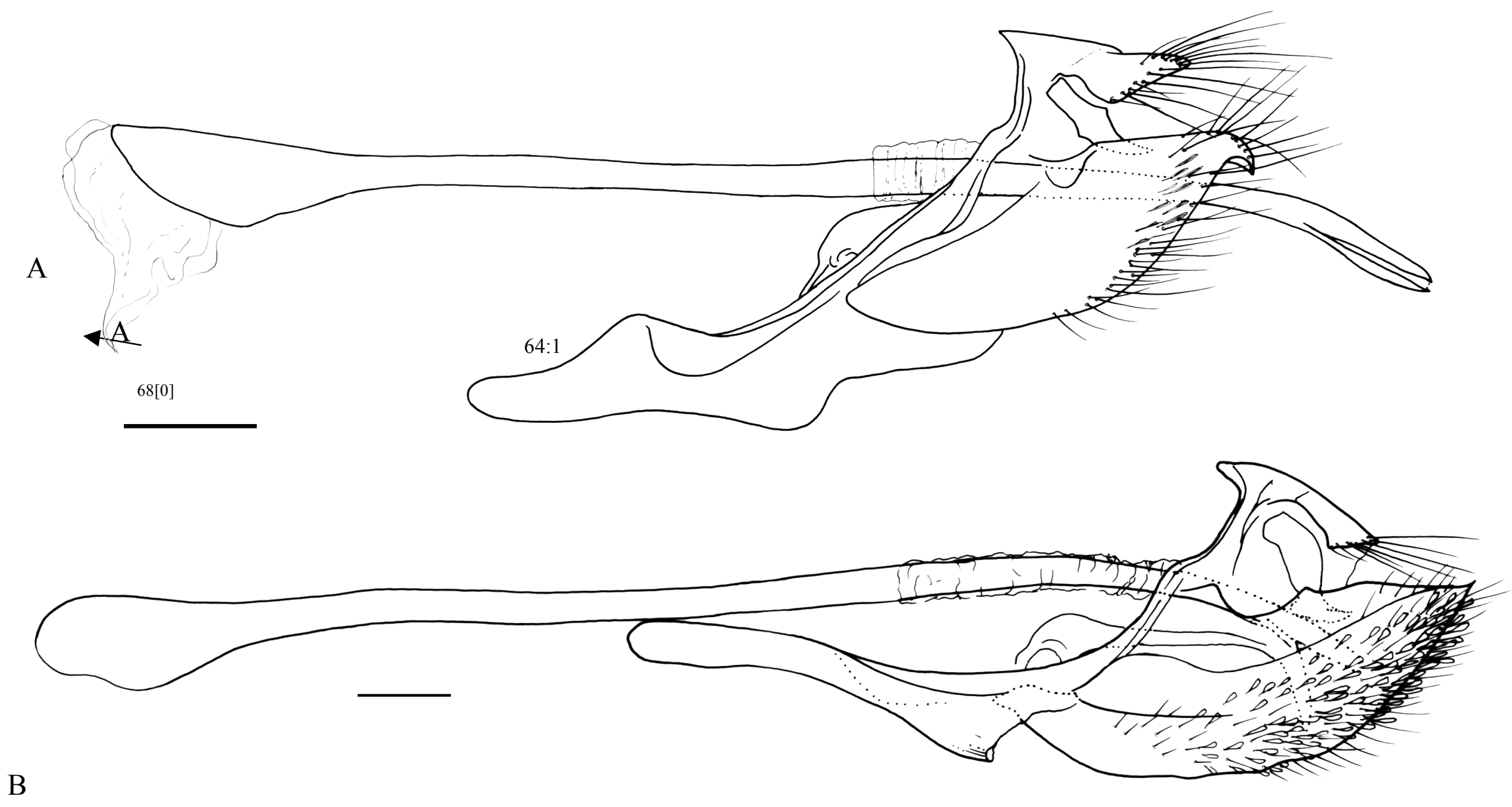

Figura 26. Genitália masculina. Vista lateral, a. Charaxes hadrianus, b. C. laodice. Escala $=1 \mathrm{~mm}$. 

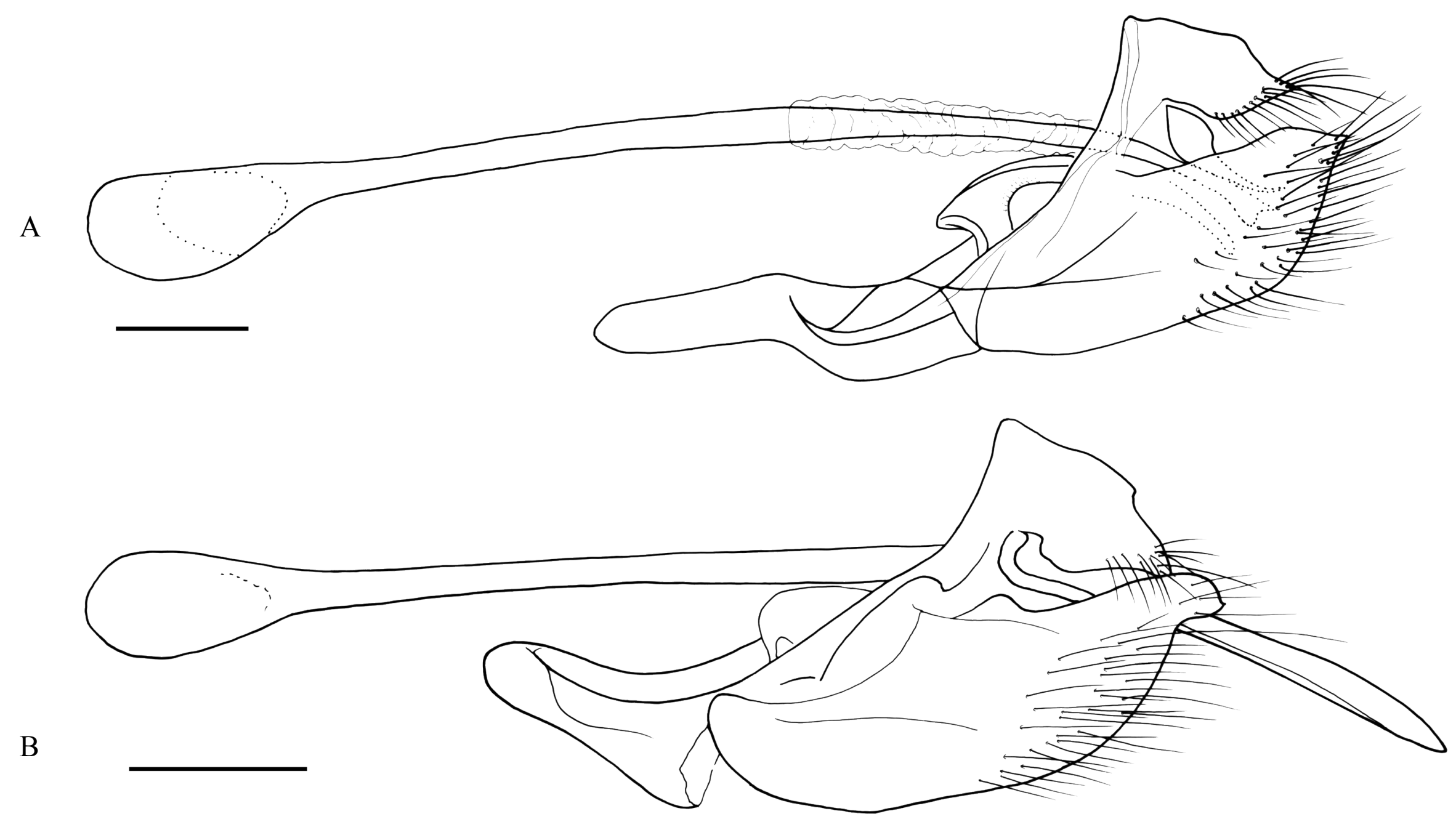

Figura 27. Genitália masculina. Vista lateral. A. C. lucretius, b. C. nichetes. Escala $=1 \mathrm{~mm}$. 

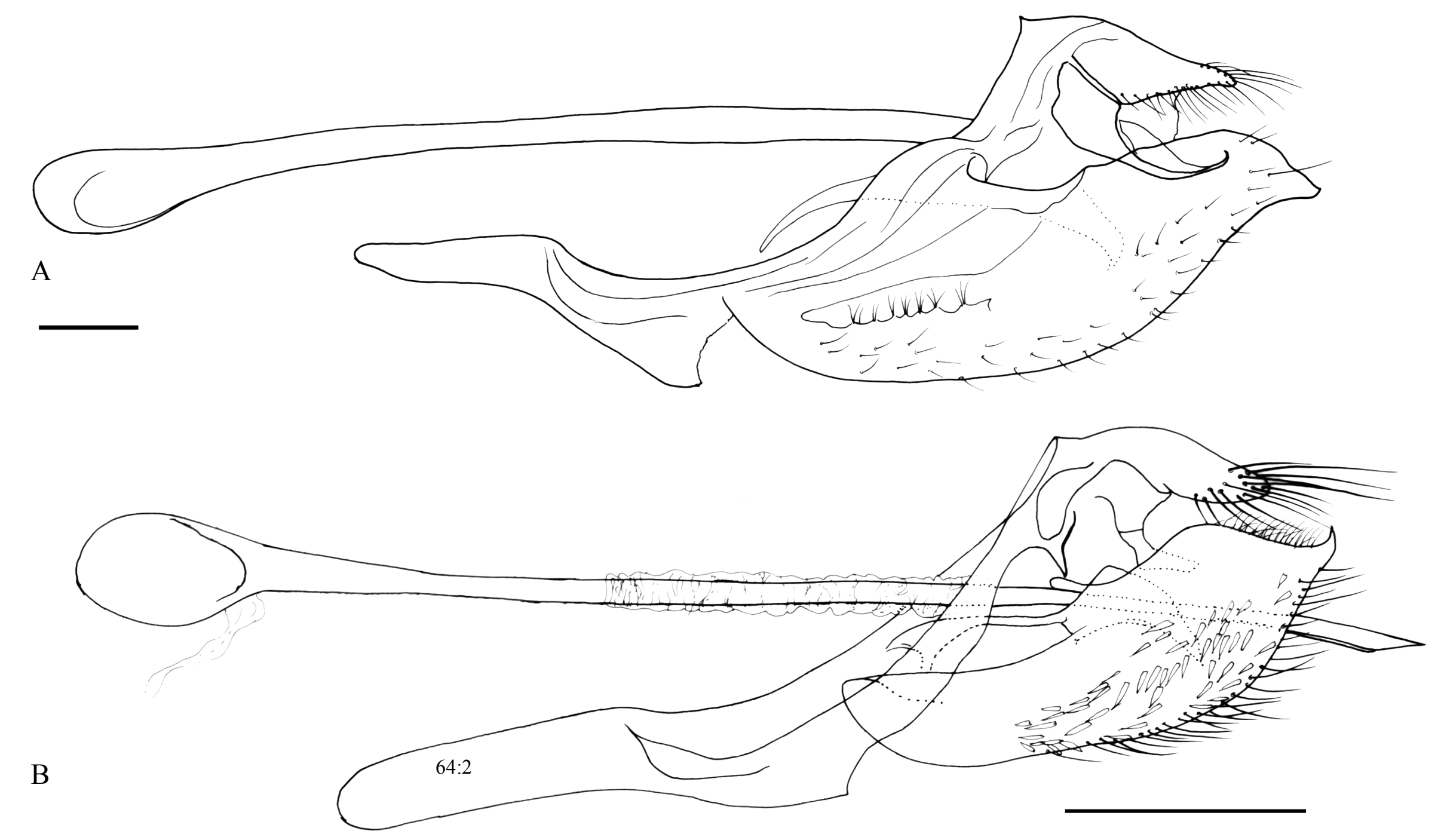

Figura 28. Genitália masculina. Vista lateral. a. Charaxes. nobilis, b. Charaxes zoolina . Escala $=1 \mathrm{~mm}$. 


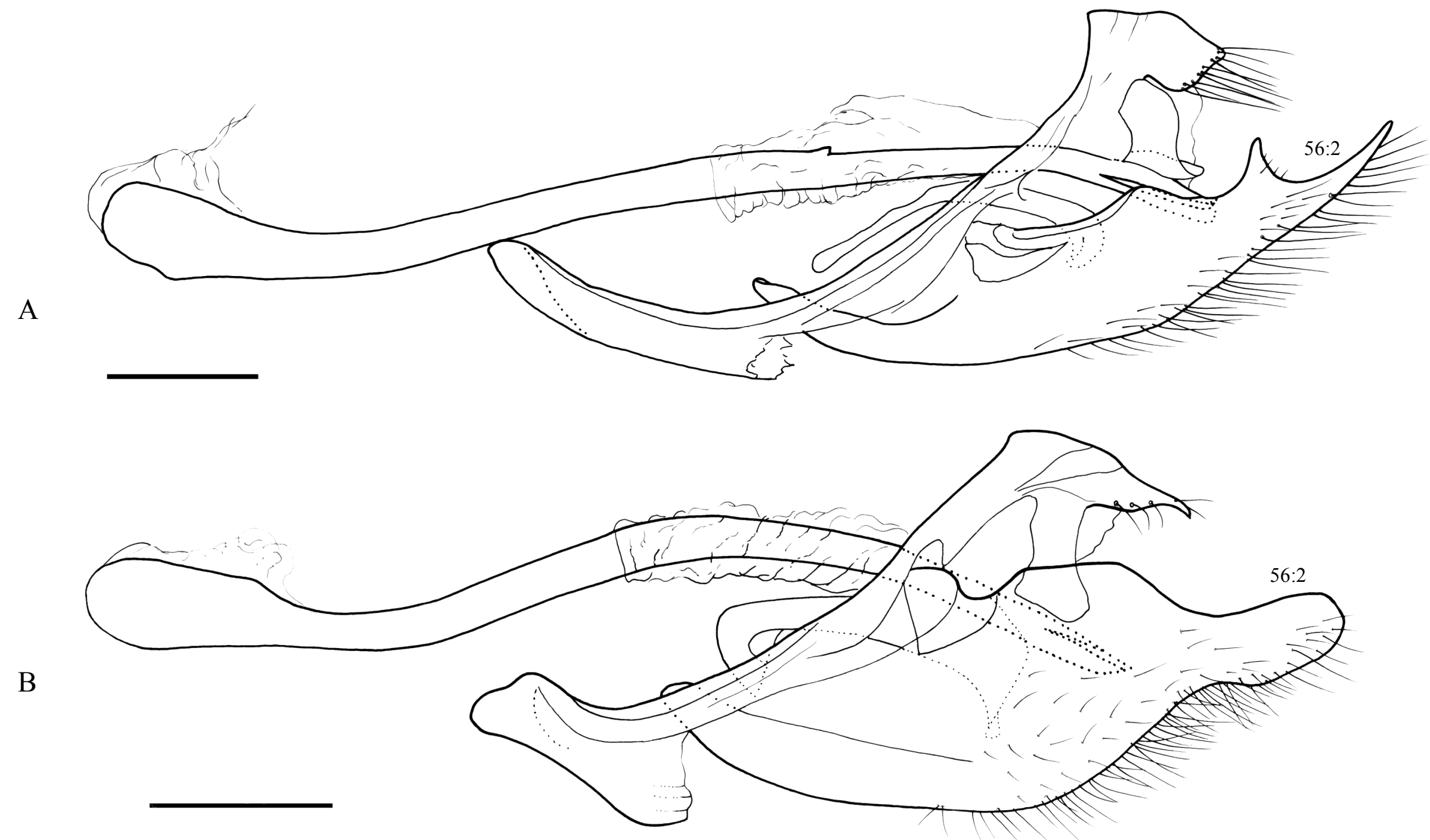

Figura 29. Genitália masculina. Vista lateral. a. C. etesipe, b. C. etheocles. Escala $=1 \mathrm{~mm}$. 

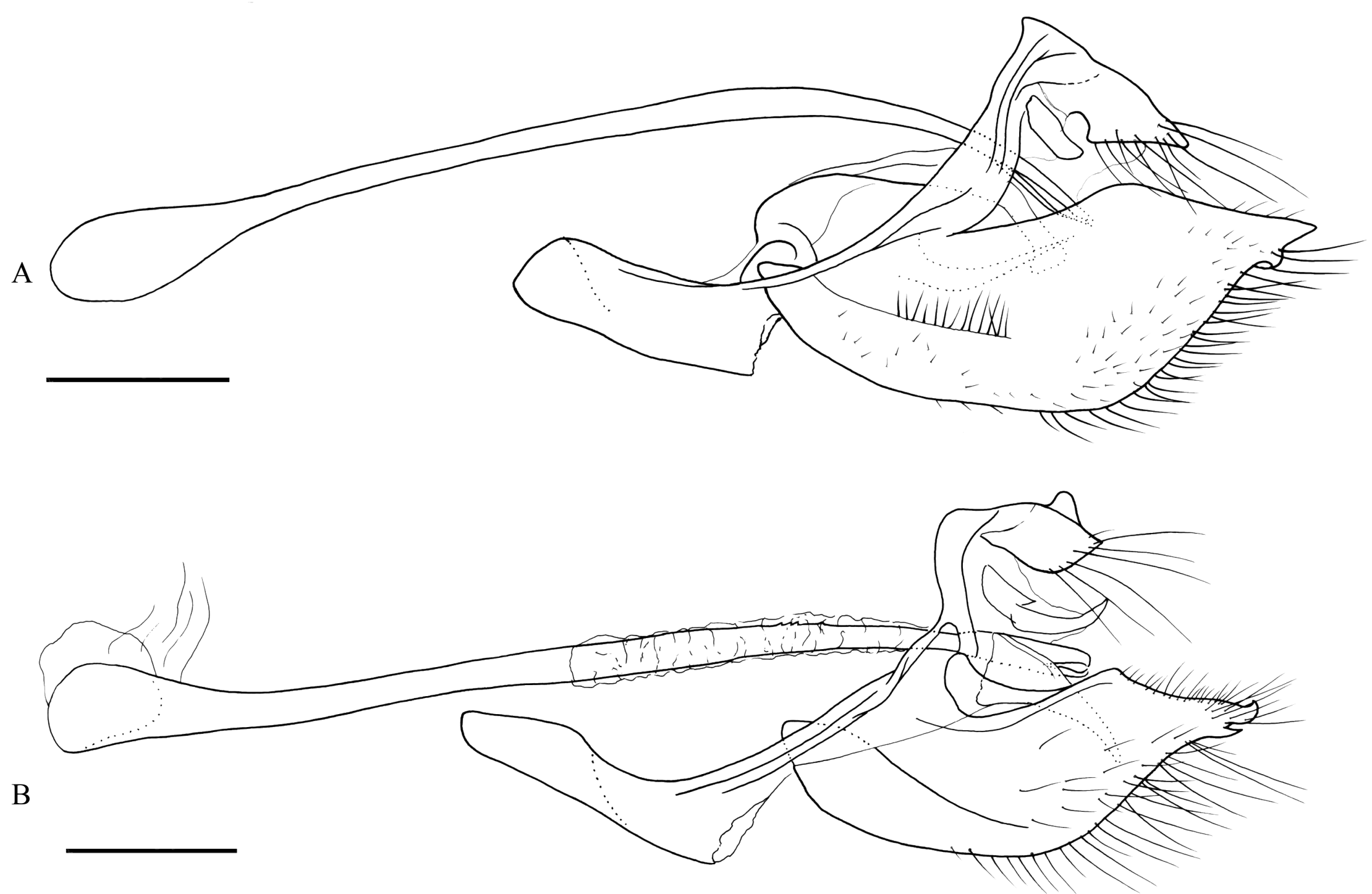

Figura 30. Genitália masculina. Vista lateral. a. C. eupale, b. C. pleione. Escala $=1 \mathrm{~mm}$. 


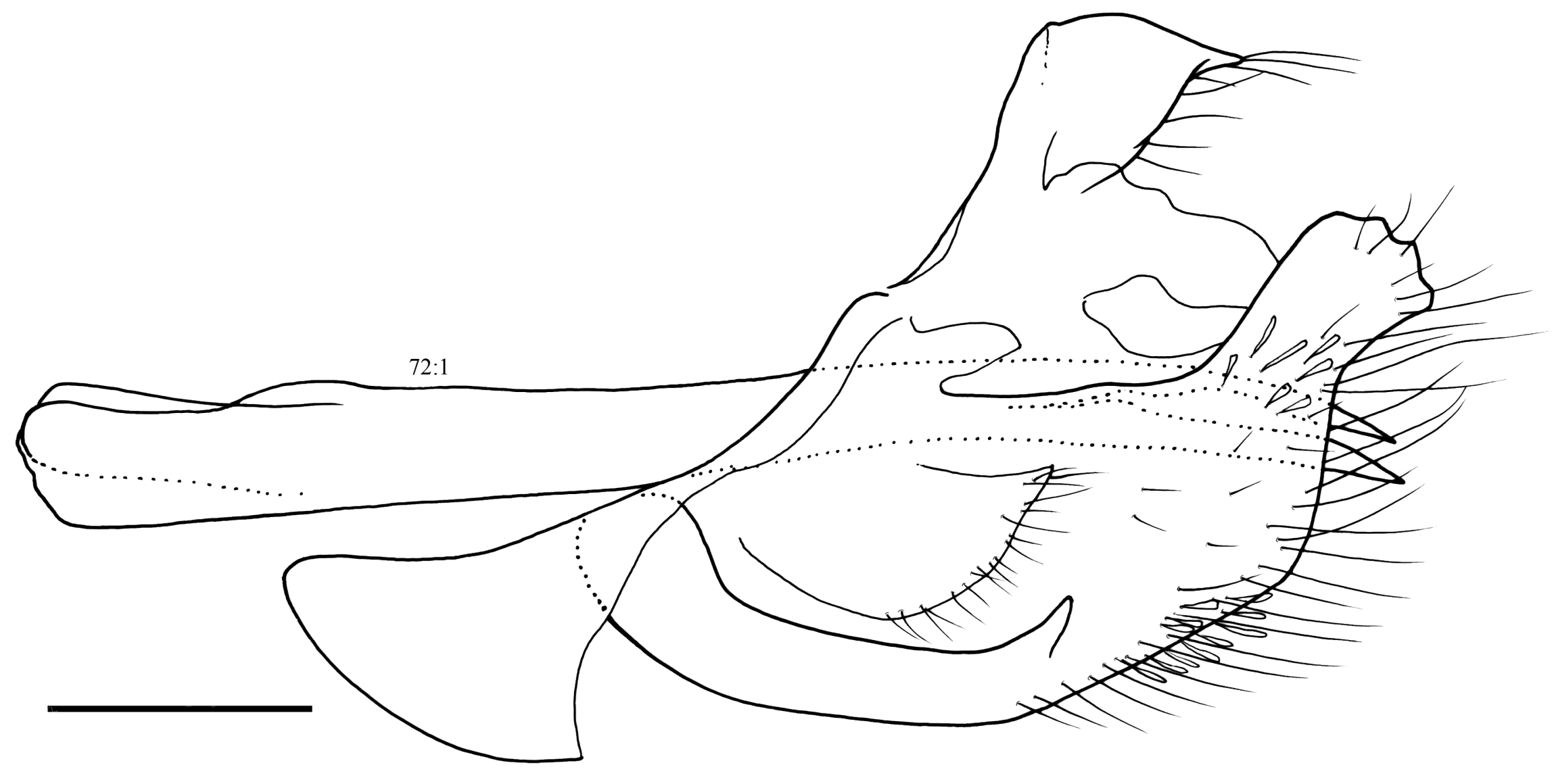

Figura 31. Genitália masculina. Vista lateral. C. zingha. Escala $=1 \mathrm{~mm}$. 


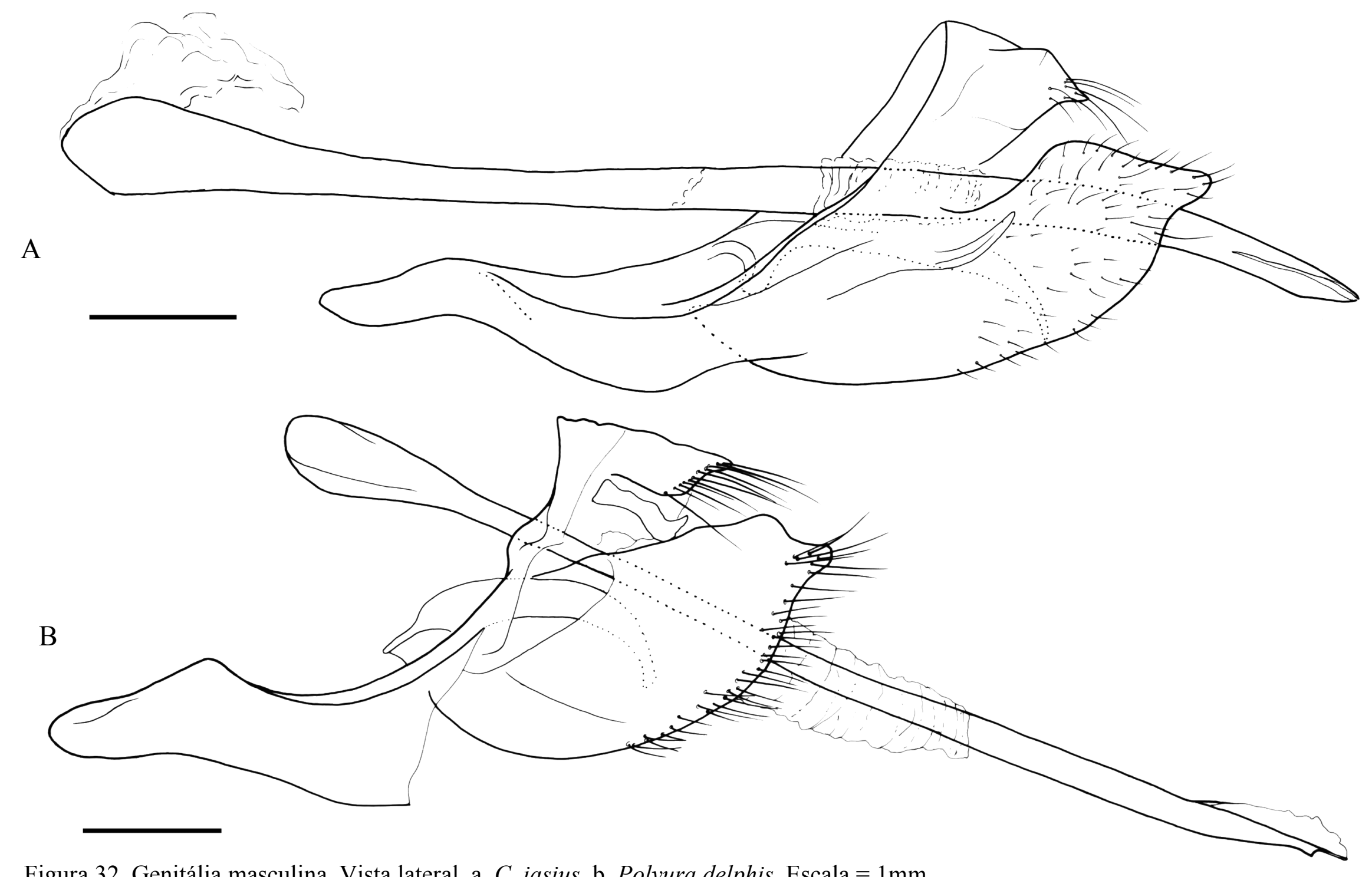

Figura 32. Genitália masculina. Vista lateral. a. C. jasius, b. Polyura delphis. Escala $=1 \mathrm{~mm}$. 


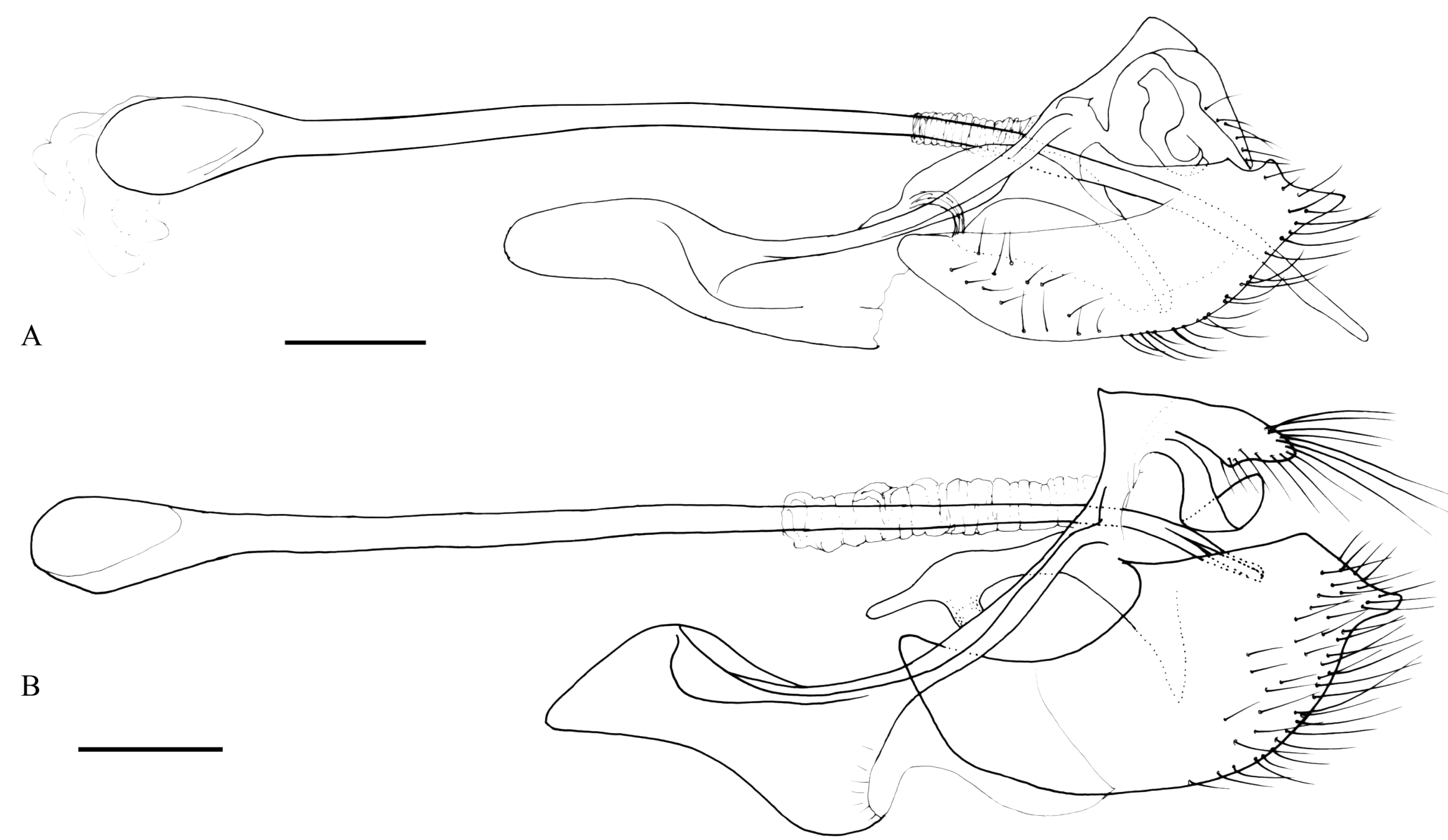

Figura 33. Genitália masculina. Vista lateral. a. Polyura schreiber, b. P. pyrrhus, Escala $=1 \mathrm{~mm}$. 

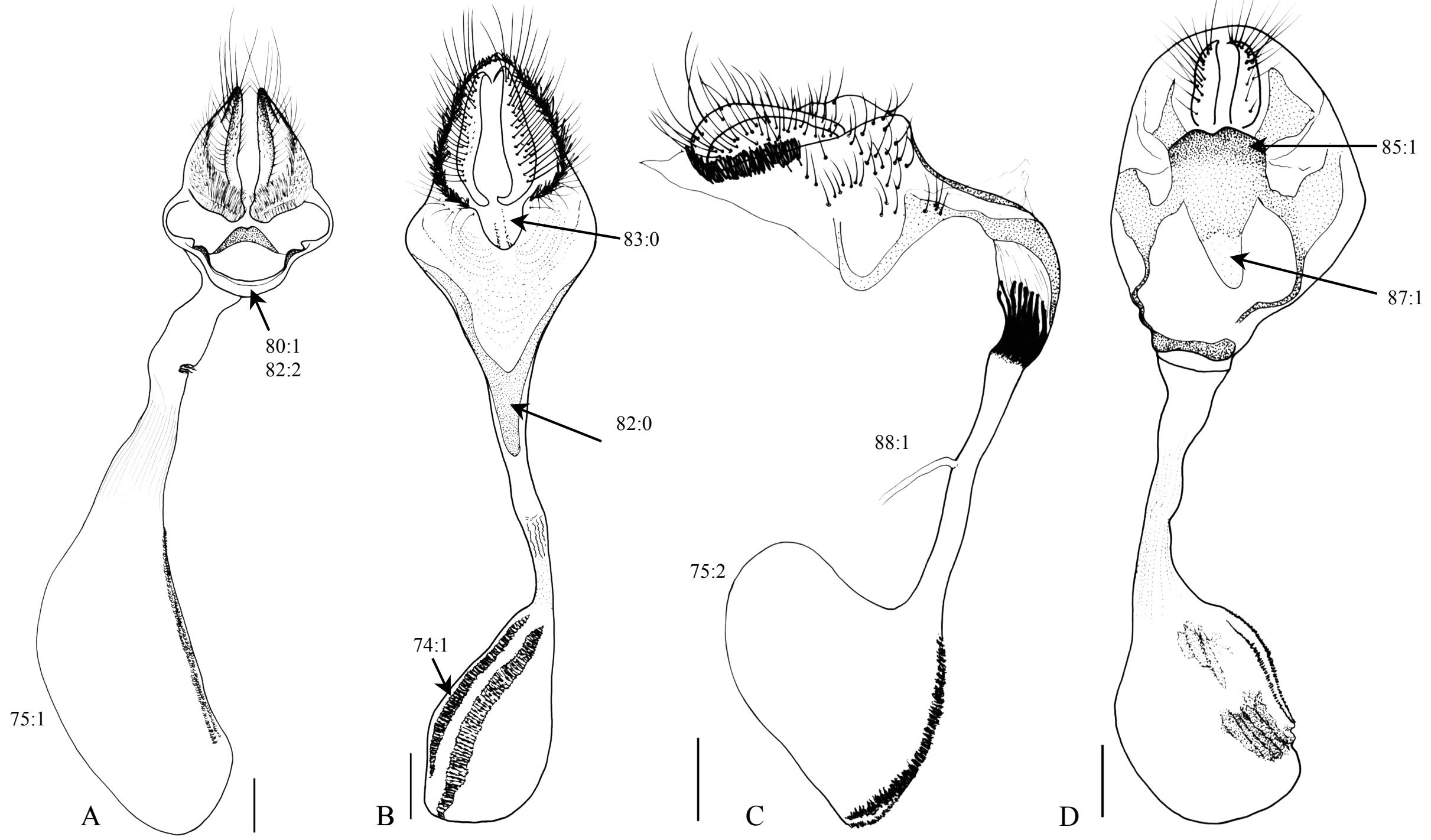

Figura 34. Genitália feminina. Vista ventral. a. Archaeoprepona amphimacus, b. Prepona pylene, d. Polygrapha xenocrates. Vista lateral. c. Prepona laertes. Escala $=1 \mathrm{~mm}$. 

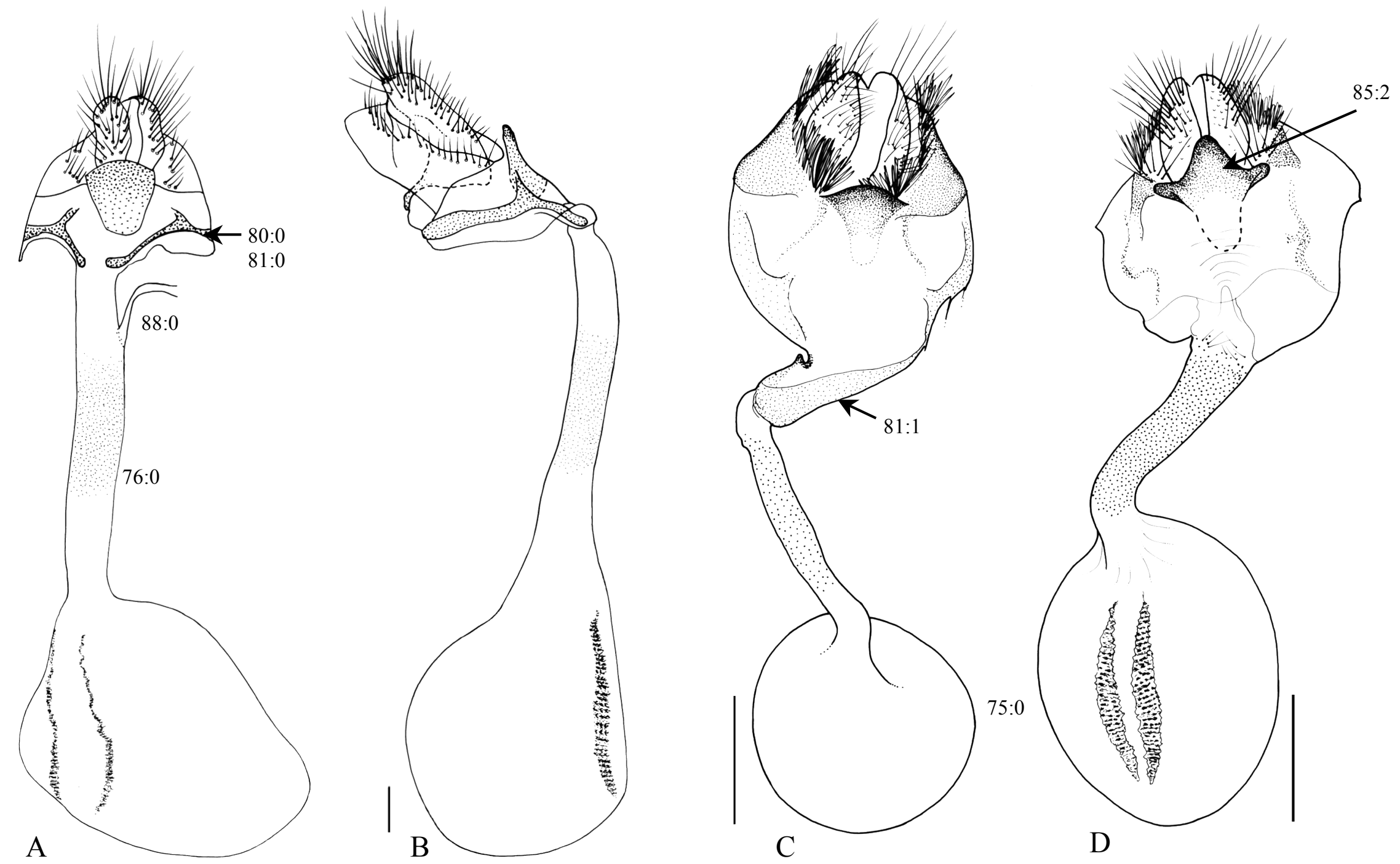

Figura 35. Genitália feminina. Vista ventral. a. Siderone galanthis, b. Fountainea nessus, E. Memphis leonida, Vista lateral. B. Siderone galanthis. Escala $=1 \mathrm{~mm}$. 

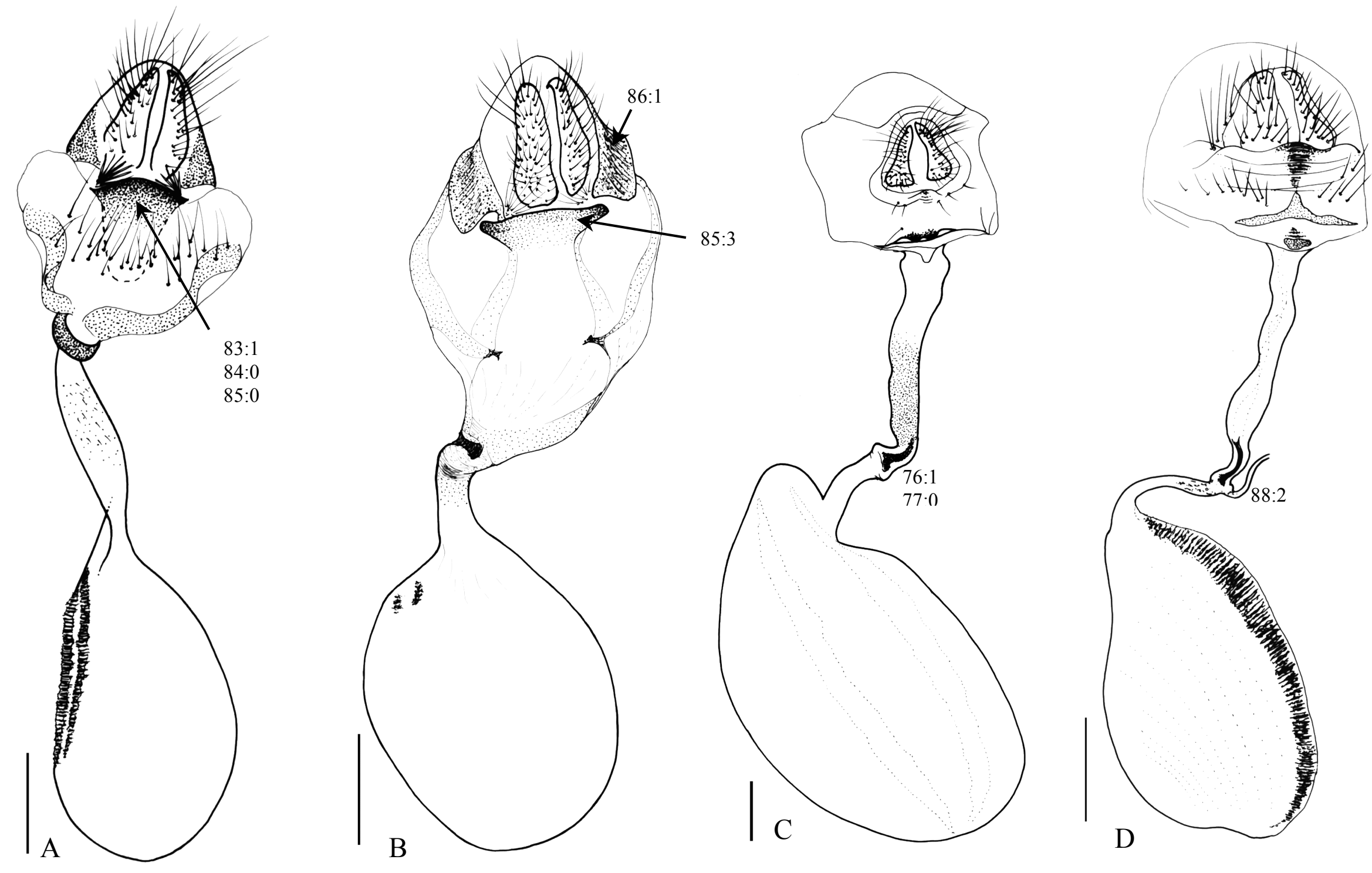

Figura 36. Genitália feminina. Vista ventral. a. M. philumena, b. M. pithyusa, c. Charaxes varanes, d. C. lucretius. Escala = $1 \mathrm{~mm}$. 

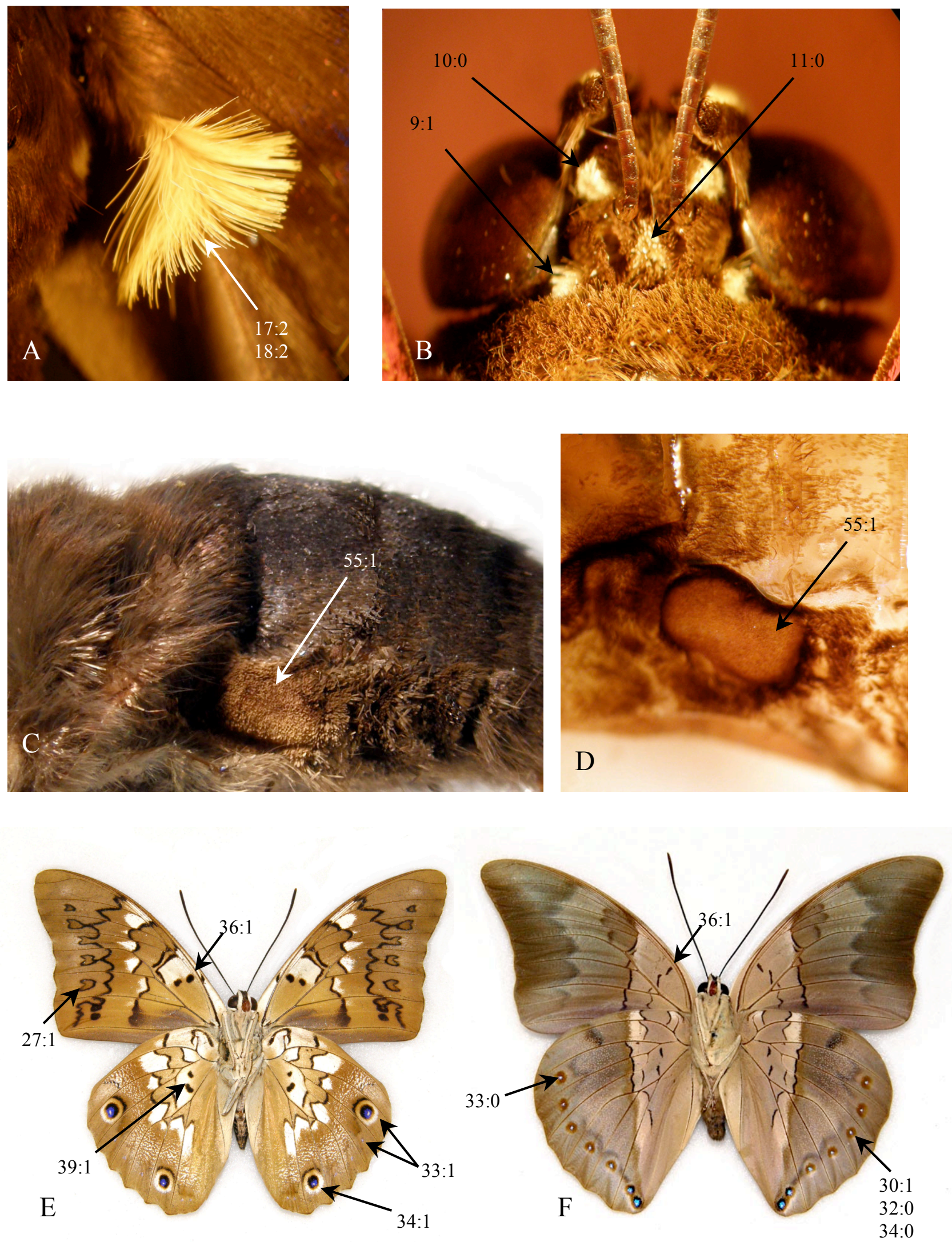

Figura 37. a. Androcônia em Agrias claudina, b. Cabeça de Agrias claudina. Detalhe do abdome em vista lateral: c. Archaeoprepona demophon, d. Prepona praeneste. Vista ventral: e.Prepona pylene, f. Noreppa chromus. 

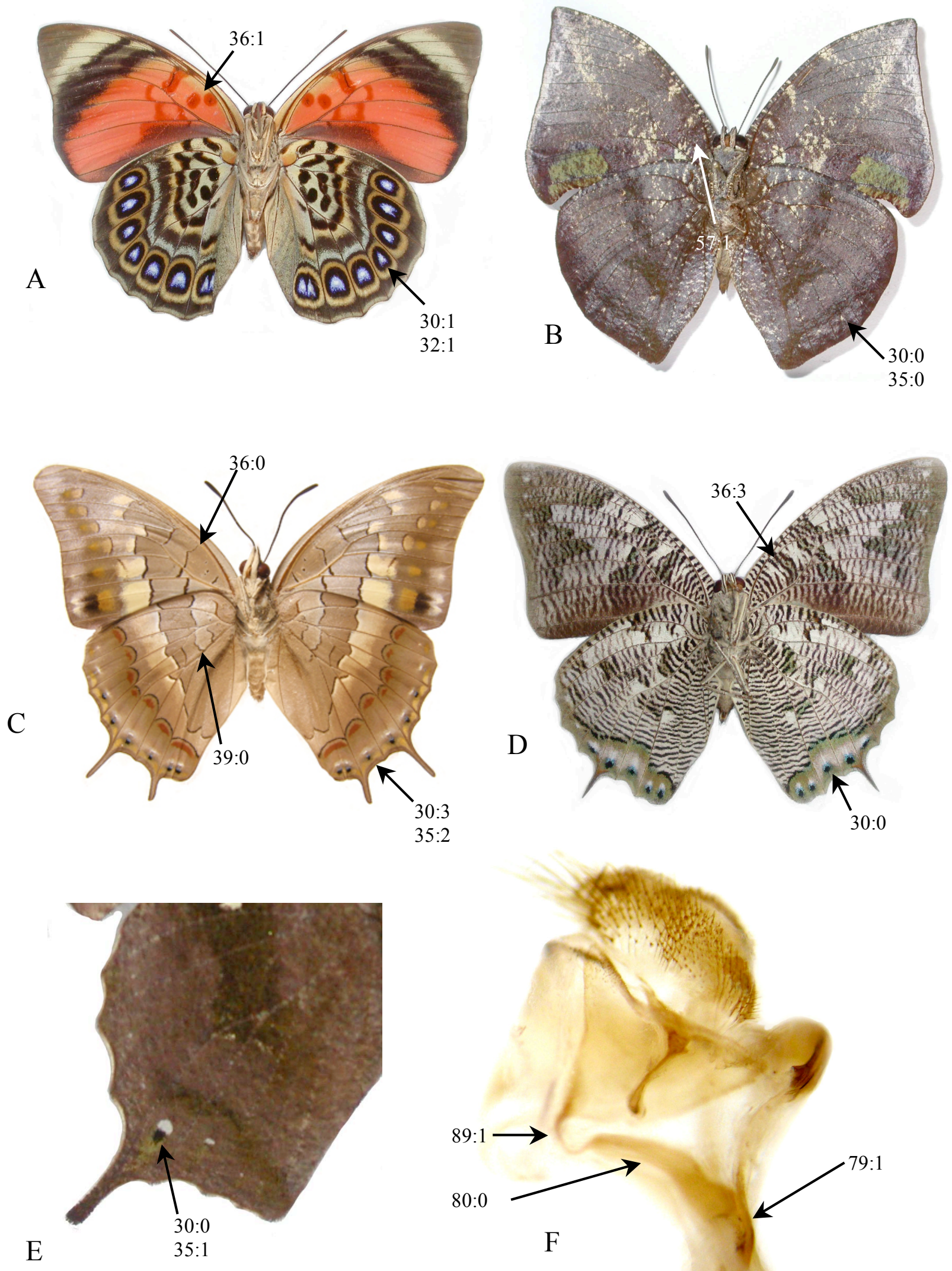

Figura 38. Caracteres de asa em vista ventral e genitália feminina. a. Agrias claudina . b. Archaeoprepona demophon, b. Polygrapha cyanea c. Charaxes solon, d. Memphis grandis, e. detalhe da asa posterior de M. pithyusa, f. Detalhe da genitália feminina de Polygrapha cyanea em vista lateral. 

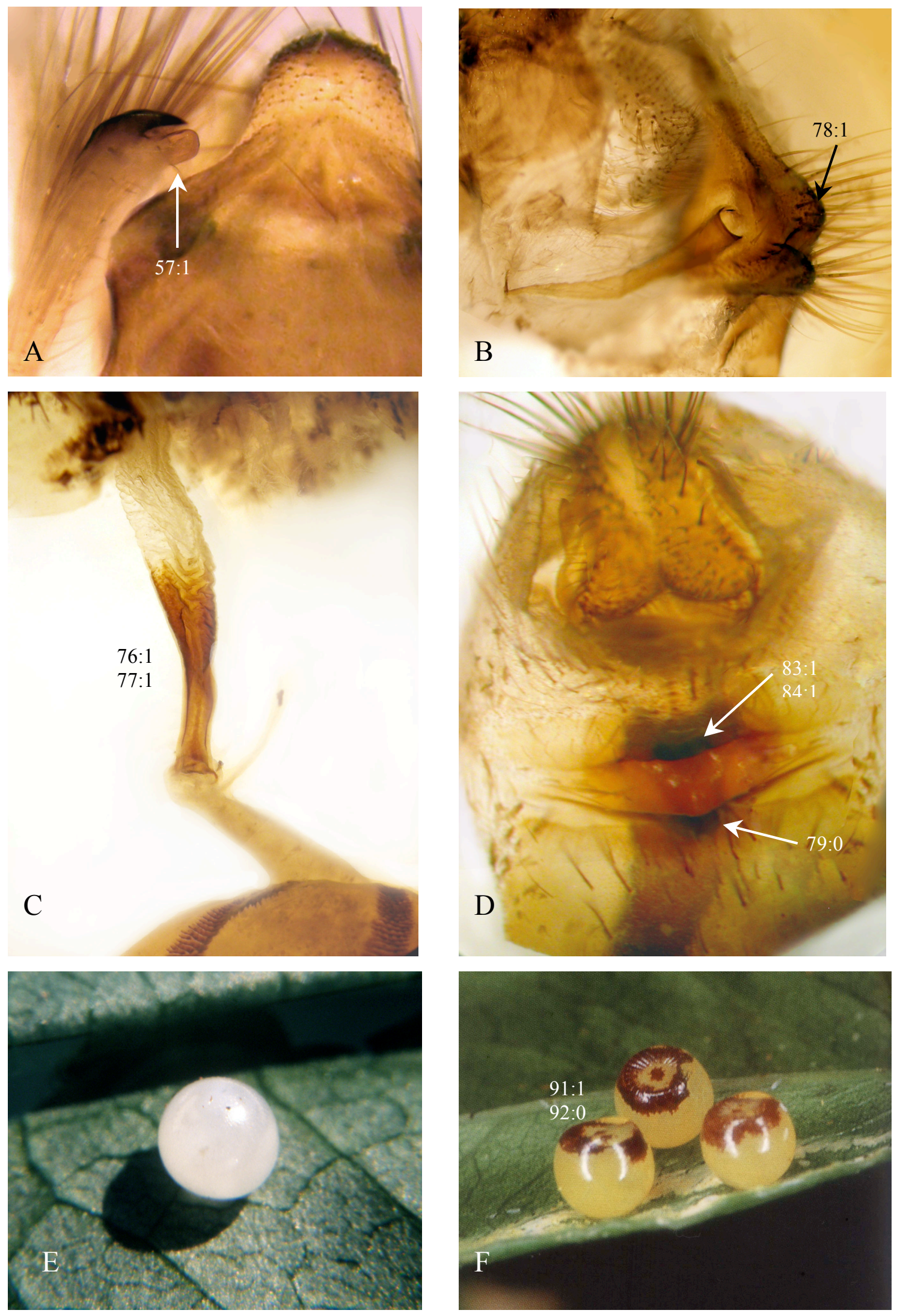

Figura 39. Caracteres de genitália e ovo. a. Detalhe da genitália masculina de Archaeoprepona demophon em vista dorsal, Detalhe da genitália feminina b. Palla decius em vista látero-frontal, c. Charaxes nobilis d. C. tiridates. e. Ovo. Archaeoprepona chalciope (foto: A.V. L. Freitas). f. Charaxes jasius (extraído de Woodhall, 2008). 

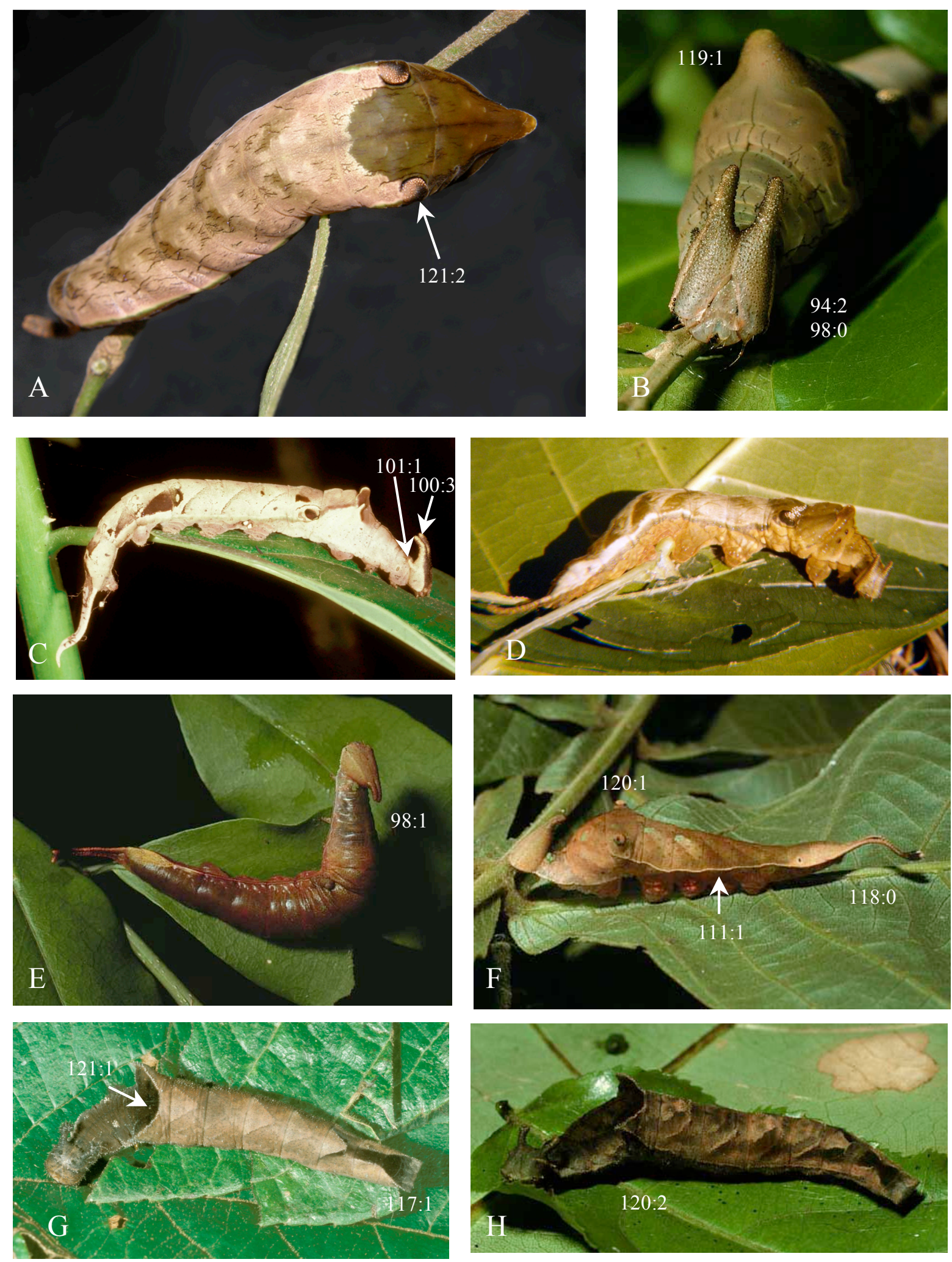

Figura 40. Larva de quinto ínstar. a. A. demophon. b. A. demophoon (foto: D. H. Janzen). c. A. amphimacus UI (foto: G. B. Small), d. A. chalciope (foto: A.V.L. Freitas), e. Agrias amydon, (foto: D. H. Janzen), f. Prepona laertes, (foto: D. H. Janzen), g. Siderone galanthis (foto: G. B. Small), h. Zaretis itys. 

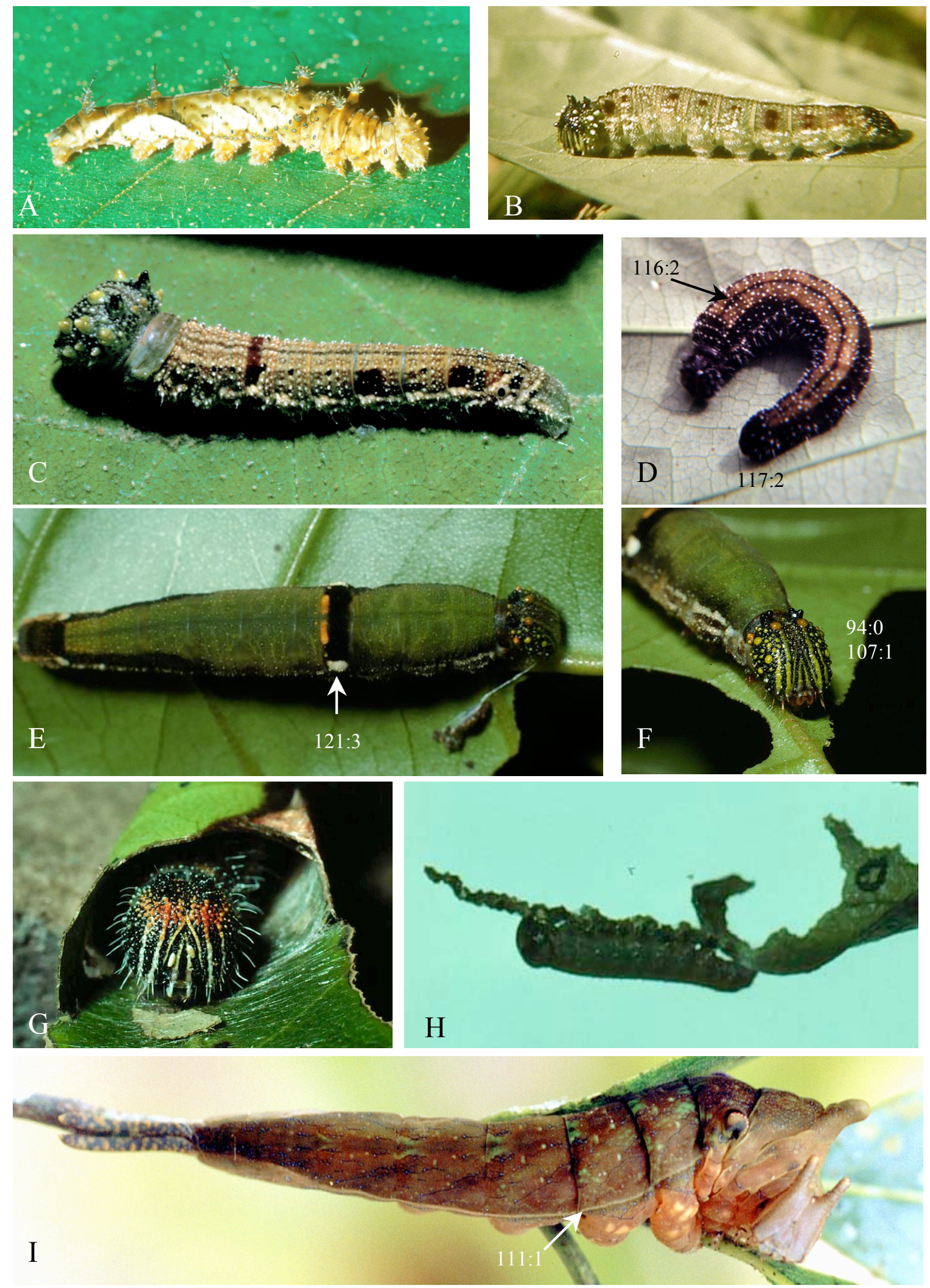

Figura 41. Larva de último ínstar. a. Hypna clytemnestra (foto: G. B. Small), b Consul fabius (foto: A.V. L. Freitas), c. Fountainea ryphea (G. B. Small), d. M. moruus (A.V. L. Freitas), e,f. Memphis pithyusa (foto: D. H. Janzen), e. vista dorsal; f. Vista frontal, g. Abrigo da larva de Memphis moruus (foto: D. H. Janzen), h. Larva de ínstar inicial de $A$. demophon no suporte de excrementos (foto: D. H. Janzen), i. Larva de Noreppa chromus (foto: L. M. Constantino). 

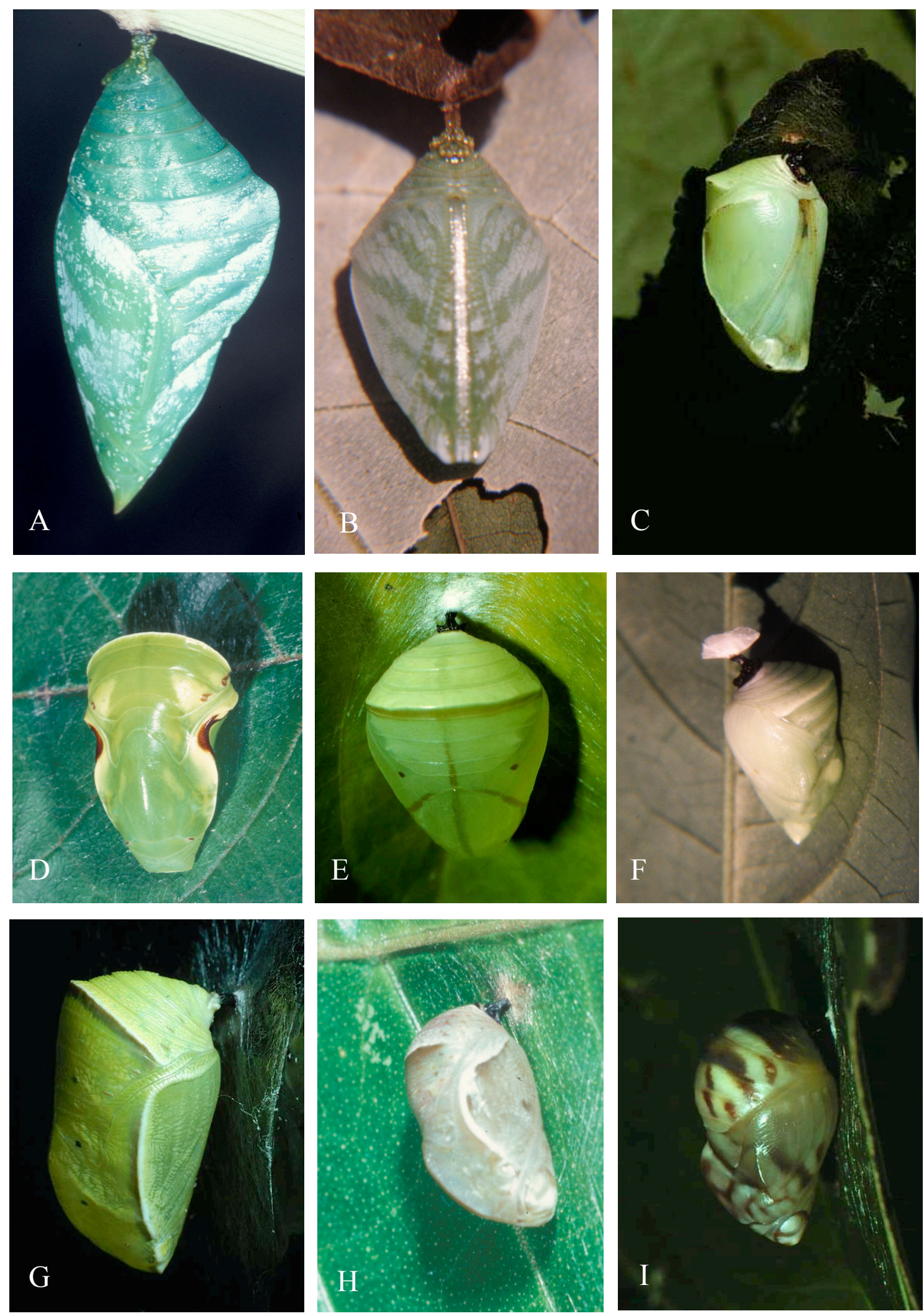

Figura 42. Pupas de Charaxinae. a. Archaeoprepona amphimacus (foto: G. B. Small), b Hypna clytemnestra (foto: A.V. L. Freitas), c. Zaretis isdora (foto: D. H. Janzen), d. Siderone galanthis (foto: G. B. Small), e. Consul electra (foto: D. H. Janzen), f. Consul fabius (foto: A.V. L. Freitas), g. Anaea troglodyta (foto: D. H. Janzen), h. Memphis pithyusa (foto: G. B. Small), i. M. moruus (foto: D. H. Janzen). 


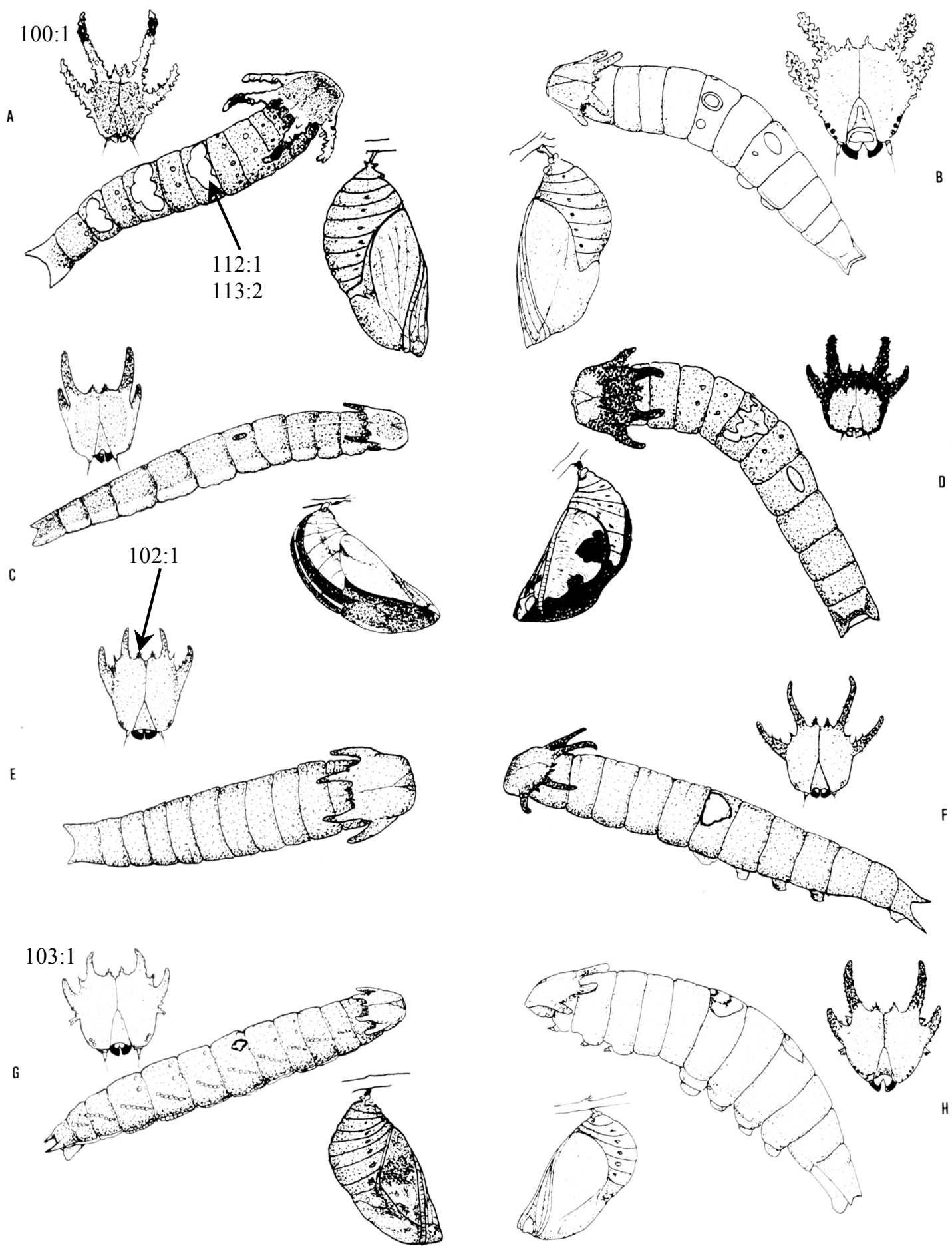

Figura 43. Larvas e pupas de Charaxes: a. grupo varanes, b. grupo candiope, c, d. grupo cynthia, e, f. grupo lucretius, g, h. grupo jasius. (retirado de HeNNING, 1988). 

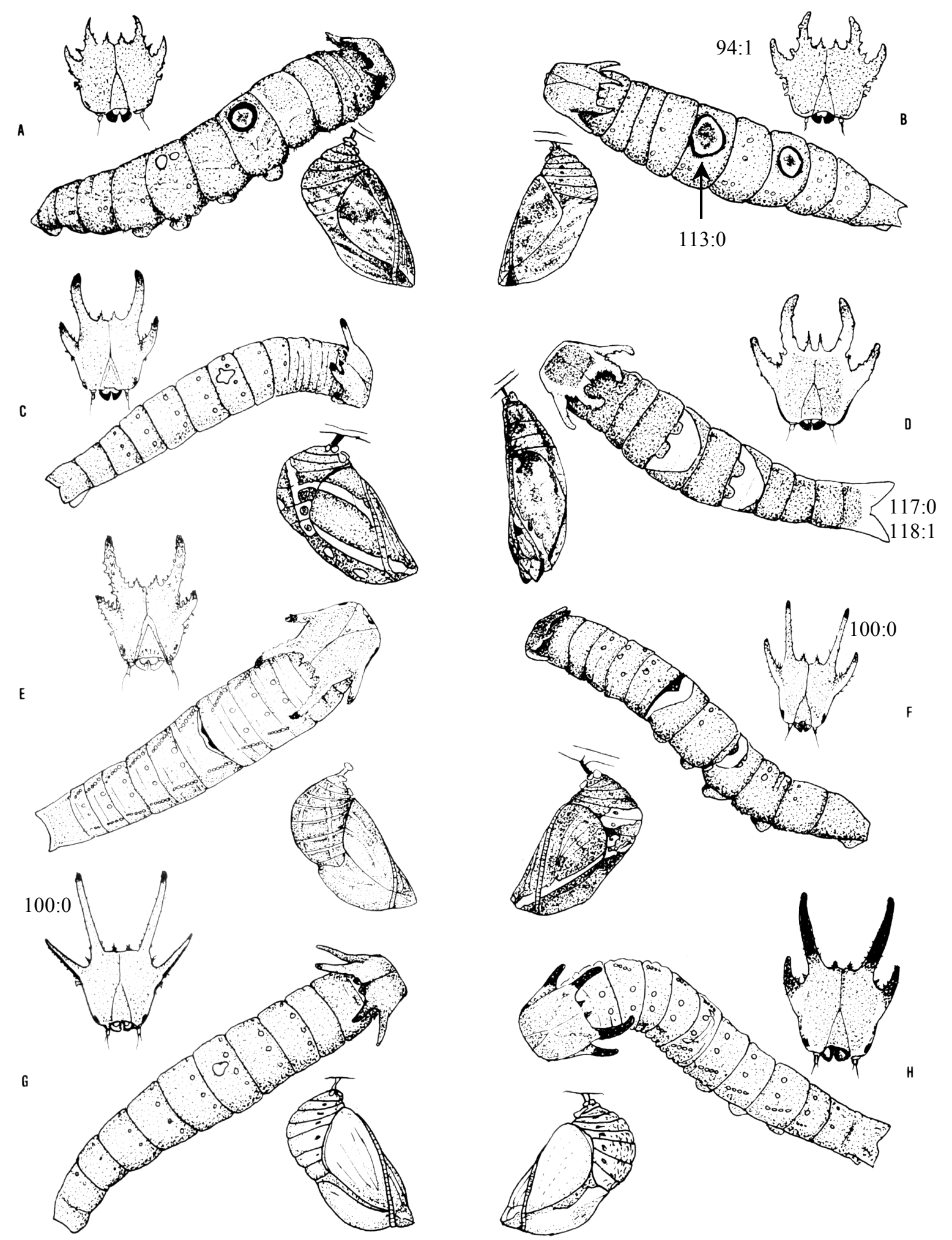

Figura 44. Larvas e pupas de Charaxes: a, b. grupo tiridates, c. grupo etesipe, d. grupo hadrianus, e. grupo jahlusa, f. grupo eupale g, h. grupo etheocles. (retirado de HENNING, 1988). 

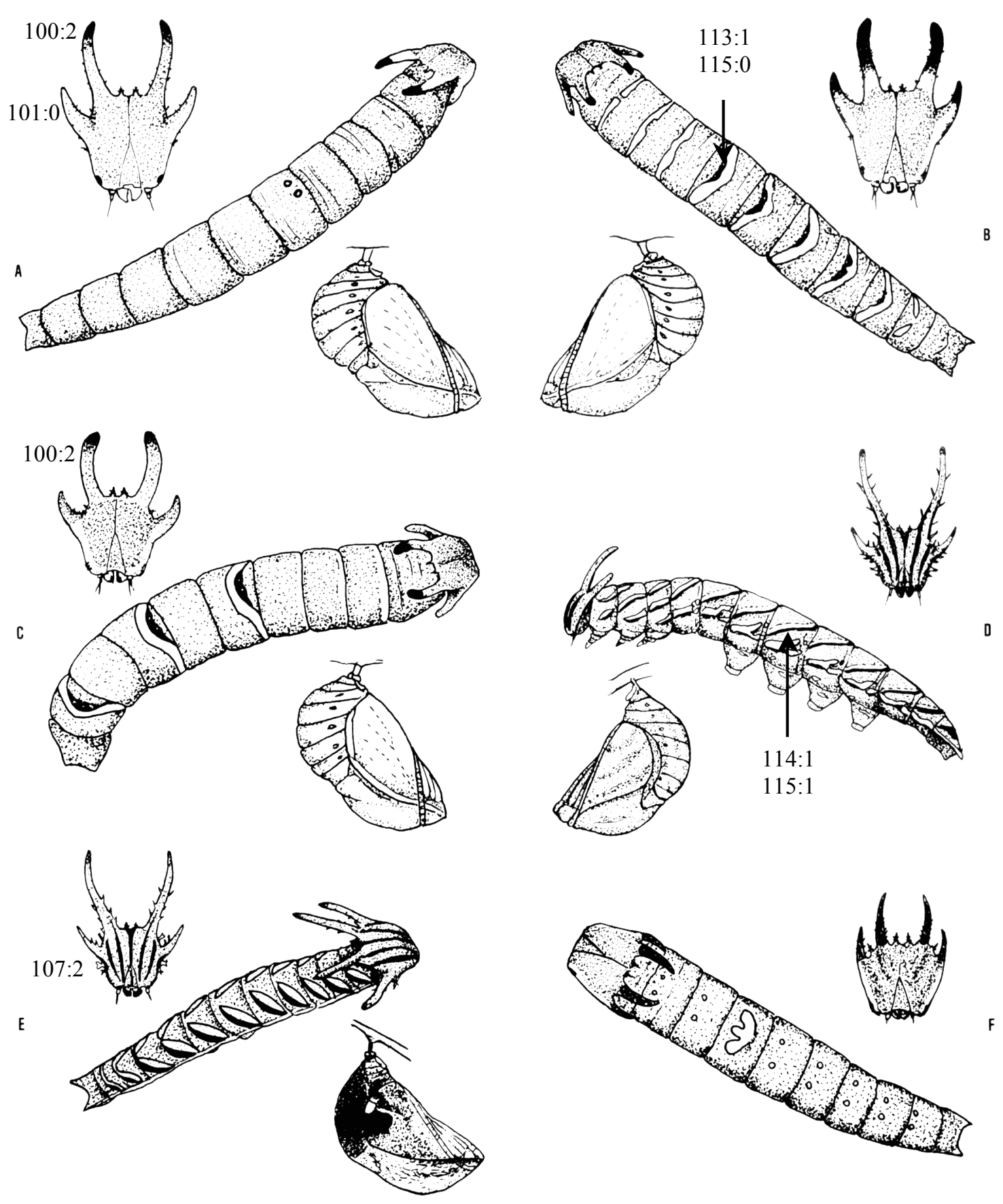

Figura 45. Larvas e pupas de Charaxes: a, b, c. grupo etheocles, d. grupo zoolina, e. grupo pleione, f. grupo nichetes. (retirado de HENNING, 1988). 

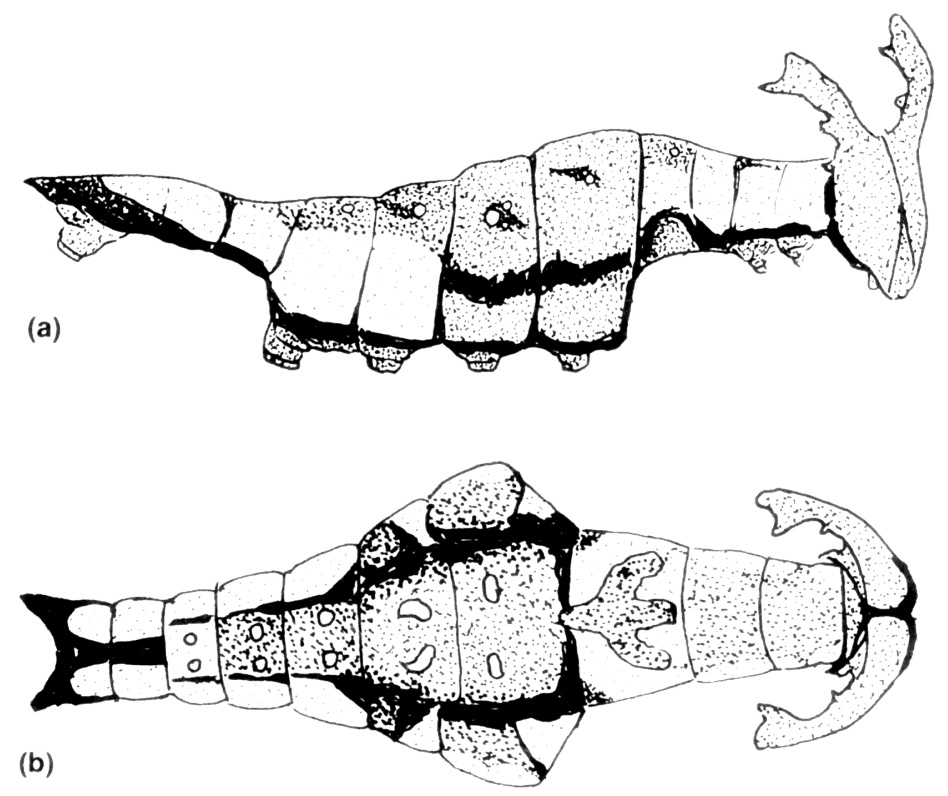

(b)
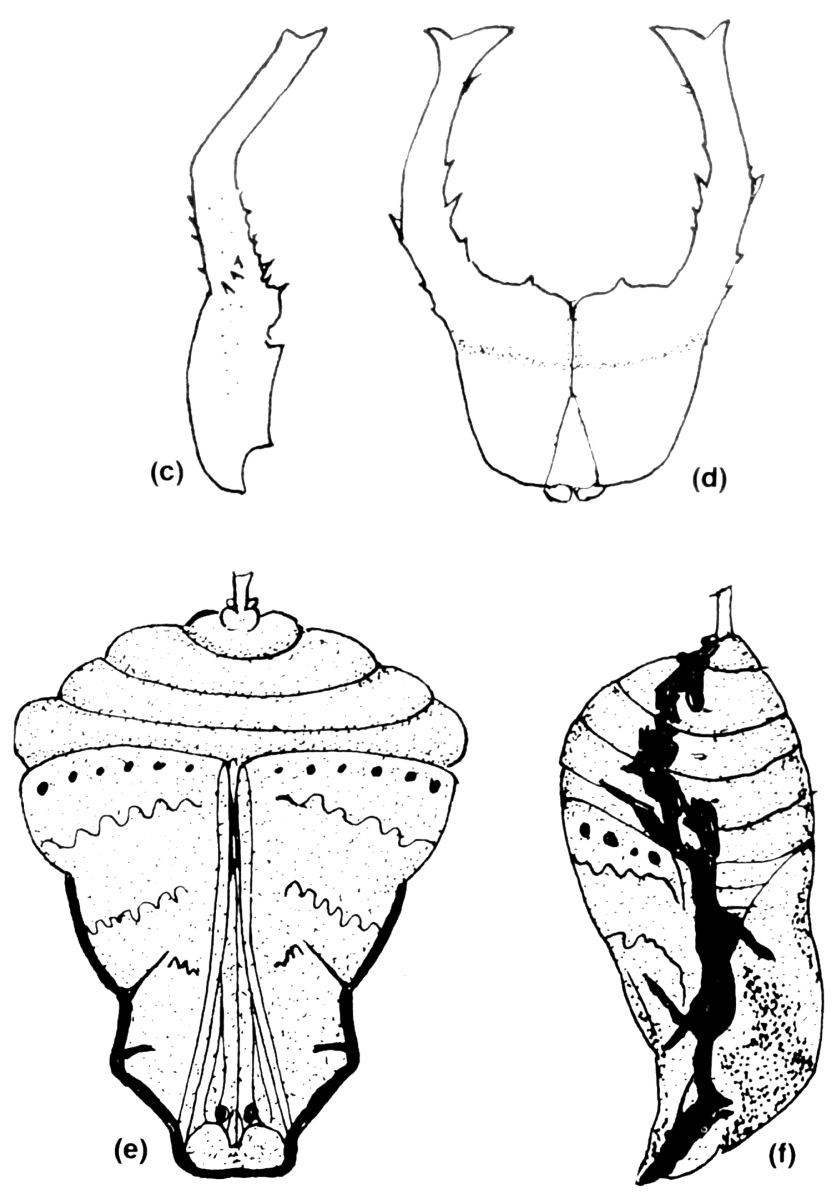

Figura 46. Larvas e pupas de de Palla ussheri. a, b. último ínstar; c, d. cápsula cefálica; e, f. pupa. (retirado de HeNNING, 1988). 


\section{ANEXO: MATRIZ DE CARACTERES}

\begin{tabular}{|c|c|c|c|c|c|c|c|c|c|c|c|c|c|c|c|c|c|c|c|c|c|c|c|c|}
\hline Táxon & & & & & 5 & & & & & $\begin{array}{l}1 \\
0\end{array}$ & & & & & $\begin{array}{l}1 \\
5\end{array}$ & & & & & $\begin{array}{l}2 \\
0\end{array}$ & & & & \\
\hline Apatura ins & 2 & 0 & 1 & 0 & 0 & 1 & 0 & - & 0 & 1 & 1 & 0 & 0 & 0 & - & 1 & 0 & - & 0 & 0 & - & - & 0 & 0 \\
\hline Calinaga buddha & 4 & 1 & 0 & - & 0 & 0 & 0 & - & 0 & 0 & 1 & 0 & 0 & 0 & - & 1 & 0 & - & 0 & 0 & - & - & 0 & 0 \\
\hline Antimhea archaea & 6 & 1 & 1 & 0 & 0 & 0 & 0 & - & 1 & 1 & 1 & 0 & 0 & $?$ & $?$ & 1 & 0 & - & 0 & 0 & - & - & 0 & 0 \\
\hline Coenophlebia archidona & 1 & 0 & 0 & 0 & 0 & 0 & 0 & - & 0 & 1 & 1 & 0 & 0 & 0 & - & 1 & 0 & - & 0 & 0 & - & - & 0 & 0 \\
\hline Consul electra & $?$ & 0 & 0 & - & 0 & 2 & 0 & - & 0 & 1 & 1 & 0 & 0 & 0 & - & 1 & 0 & - & 1 & 1 & 3 & 3 & 0 & 0 \\
\hline Consul fabius & $?$ & 0 & 0 & - & 0 & 1 & 0 & - & 0 & 1 & 1 & 0 & 0 & 0 & - & 1 & 0 & - & 1 & 1 & 3 & 3 & 0 & 0 \\
\hline Hypna clytemnestra & ? & 0 & 0 & - & 0 & 1 & 0 & 1 & 1 & 1 & 1 & 0 & 0 & 0 & - & 1 & 0 & - & 1 & 1 & 3 & 3 & 0 & 0 \\
\hline Polygrapha cyanea & 3 & 1 & 1 & - & 0 & 2 & 0 & - & 0 & 1 & 1 & $0 \& 1$ & 0 & 0 & - & 1 & 0 & - & 1 & 1 & 0 & 0 & 0 & 0 \\
\hline Polygrapha suprema & 3 & 1 & 1 & - & 0 & 2 & 0 & - & 0 & 1 & 1 & 0 & 0 & 0 & - & 1 & 0 & - & 0 & 0 & - & - & 0 & 0 \\
\hline Polygrapha tyrianthina & 3 & 1 & 1 & - & 0 & 2 & 0 & - & 0 & 0 & 1 & 0 & 0 & 0 & - & 1 & 0 & - & 0 & 0 & - & - & 0 & 0 \\
\hline Polygrapha xenocrates & 3 & 1 & 1 & - & 0 & 2 & 0 & - & 0 & 1 & 1 & 0 & 0 & 0 & - & 1 & 0 & - & 0 & 0 & - & - & 0 & 0 \\
\hline Siderone galanthis & 1 & 0 & 0 & 0 & 0 & 1 & 0 & - & 0 & 1 & 1 & 0 & 0 & 1 & 0 & 1 & 0 & - & 0 & 0 & - & - & 0 & 0 \\
\hline Zaretis callydrias & 1 & 0 & 0 & 0 & 0 & 2 & 0 & - & 0 & 1 & 1 & 0 & 0 & 1 & 0 & 0 & 0 & - & 0 & 1 & - & 2 & 0 & 0 \\
\hline Zaretis isidora & 1 & 0 & 0 & 0 & 0 & 2 & 0 & - & 0 & 1 & 1 & 0 & 0 & 1 & 0 & 0 & 0 & - & 0 & 0 & - & - & 0 & 0 \\
\hline A naea troglodyta & 0 & 1 & 0 & - & 0 & 2 & 0 & - & 0 & 1 & 1 & 0 & 0 & 0 & - & 1 & 0 & - & 1 & 1 & 2 & 2 & 0 & 0 \\
\hline Fountainea nessus & 3 & 1 & 0 & - & 0 & 2 & 0 & - & 0 & 1 & 1 & 0 & 0 & 0 & - & 1 & 0 & - & 1 & 1 & 1 & 1 & 0 & 0 \\
\hline Fountainea ryphea & 3 & 1 & 0 & - & 0 & 2 & 0 & - & 0 & 1 & 1 & 0 & 0 & 0 & - & 1 & 0 & - & 0 & 1 & - & 1 & 0 & 0 \\
\hline Memphis appias & 0 & 1 & 0 & - & 0 & 2 & 0 & - & 0 & 1 & 1 & 0 & 0 & 1 & 1 & 1 & 0 & - & 1 & 1 & 1 & 1 & 0 & 0 \\
\hline Memphis glauce & 0 & 1 & 0 & - & 0 & 2 & 0 & - & 0 & 1 & 1 & 0 & 0 & 0 & - & 1 & 0 & - & 1 & 1 & 1 & 1 & 0 & 0 \\
\hline Memphis grandis & 0 & 1 & 0 & - & 0 & 2 & 0 & - & 0 & 1 & 1 & 0 & 0 & 1 & 1 & 1 & 0 & - & 0 & 1 & - & 2 & 0 & 0 \\
\hline Memphis hirta & 0 & 1 & 0 & - & 0 & 2 & 0 & - & 0 & 1 & 1 & 0 & 0 & 1 & 1 & 1 & 0 & - & 0 & 0 & 1 & 1 & 0 & 1 \\
\hline Memphis leonida & 0 & 1 & 0 & - & 0 & 2 & 0 & - & 0 & 1 & 1 & 0 & 0 & 1 & 2 & 1 & 0 & - & 1 & 1 & 1 & 2 & 0 & 0 \\
\hline Memphis moruus & 0 & 1 & 0 & - & 0 & 2 & 0 & - & 0 & 1 & 1 & 0 & 0 & 1 & 1 & 1 & 0 & - & 1 & 1 & 1 & $?$ & 0 & 0 \\
\hline Memphis philumena & 0 & 1 & 0 & - & 0 & 2 & 0 & - & 0 & 1 & 1 & 0 & 0 & 1 & 2 & 1 & 0 & - & 1 & 1 & 1 & 2 & 0 & 0 \\
\hline Memphis pithyusa & 0 & 1 & 0 & - & 0 & 2 & 0 & - & 0 & 1 & 1 & 0 & 0 & 1 & 1 & 1 & 0 & - & 1 & 1 & 1 & 1 & 0 & 0 \\
\hline Memphis polycames & 0 & 1 & 0 & - & 0 & 2 & 0 & - & 0 & 1 & 1 & 0 & 0 & 1 & 2 & 1 & 0 & - & 1 & 1 & - & 2 & 0 & 0 \\
\hline Memphis polyxo & 0 & 1 & 0 & - & 0 & 2 & 0 & - & 0 & 1 & 1 & 0 & 0 & 0 & - & 1 & 0 & - & 0 & 0 & - & - & 0 & 0 \\
\hline Memphis verticordia & 3 & 1 & 0 & - & 1 & 1 & 0 & - & 0 & 1 & 1 & 0 & 0 & 0 & - & 1 & 0 & - & 1 & 1 & 1 & 1 & 0 & 0 \\
\hline Anaeomorpha splendida & 2 & 1 & 1 & 1 & 0 & 0 & 0 & - & 0 & 1 & 1 & 0 & 0 & 0 & - & 1 & 0 & - & 0 & 0 & - & - & 0 & 0 \\
\hline Noreppa chromus & 2 & 1 & 1 & 1 & 1 & 0 & 0 & - & 1 & 0 & 1 & 0 & 0 & 0 & - & 1 & 2 & 0 & 0 & 0 & - & - & 0 & 0 \\
\hline Archaeoprepona amphimacus & 2 & 1 & 1 & 1 & 0 & 0 & 0 & - & 1 & 0 & 0 & 0 & 0 & 0 & - & 1 & 2 & 0 & 0 & 0 & - & - & 0 & 0 \\
\hline Archaeoprepona chalciope & 2 & 1 & 1 & 1 & 0 & 1 & 0 & - & 1 & 0 & 0 & 0 & 0 & 0 & - & 1 & 2 & 0 & 0 & 0 & - & - & 0 & 0 \\
\hline Archaeoprepona demophon & 2 & 1 & 1 & 1 & 0 & 1 & 0 & - & 1 & 0 & 0 & 0 & 0 & 0 & - & 1 & 2 & 0 & 0 & 0 & - & - & 0 & 0 \\
\hline Archaeoprepona demophoon & 2 & 1 & 1 & 1 & 0 & 1 & 0 & - & 1 & 0 & 0 & 0 & 0 & 0 & - & 1 & 2 & 0 & 0 & 0 & - & - & 0 & 0 \\
\hline Archaeoprepona licomedes & 2 & 1 & 1 & 1 & 0 & 1 & 0 & - & 1 & 0 & 0 & 0 & 0 & 0 & - & 1 & 2 & 0 & 0 & 0 & - & - & 0 & 0 \\
\hline Prepona praeneste & 2 & 1 & 1 & 1 & 0 & 1 & 0 & - & 1 & 0 & 0 & 0 & 0 & 0 & - & 1 & 2 & 2 & 0 & 0 & - & - & 0 & 0 \\
\hline Prepona laertes & 2 & 1 & 1 & 1 & 0 & $0 \& 1$ & 0 & - & 1 & 0 & 0 & 0 & 0 & 0 & - & 1 & 2 & 2 & 0 & 0 & - & - & 0 & 0 \\
\hline Prepona pheridamas & 2 & 1 & 1 & 1 & 0 & 1 & 0 & - & 1 & 0 & 0 & 0 & 0 & 0 & - & 1 & 2 & 2 & 0 & 0 & - & - & 0 & 0 \\
\hline Prepona pylene & 2 & 1 & 1 & 1 & 0 & 0 & 0 & - & 1 & 0 & 0 & 0 & 0 & 0 & - & 1 & 2 & 2 & 0 & 0 & - & - & 0 & 0 \\
\hline Agrias amydon & 2 & 1 & 1 & 1 & 0 & 0 & 0 & - & 1 & 0 & 0 & 1 & 1 & 0 & - & 1 & 2 & 2 & 0 & 0 & - & - & 0 & 0 \\
\hline Agrias claudina & 2 & 1 & 1 & 1 & 0 & 0 & 0 & - & 1 & 0 & 0 & 1 & 1 & 0 & - & 1 & 2 & 2 & 0 & 0 & - & - & 0 & 0 \\
\hline Euxanthe eurinome & 5 & 0 & 1 & - & 0 & 0 & 1 & 1 & 1 & 0 & 1 & 1 & 0 & 0 & - & 1 & 0 & - & 0 & 0 & - & - & 0 & 0 \\
\hline Euxanthe trajanus & 5 & 0 & 1 & - & 0 & 0 & 1 & 1 & 1 & 0 & 1 & 1 & 0 & 0 & - & 1 & 0 & - & 0 & 0 & - & - & 0 & 0 \\
\hline Palla decius & 0 & 0 & 0 & - & 0 & 0 & 0 & 0 & 1 & 0 & 1 & 0 & 0 & 0 & - & 1 & 0 & - & 1 & 1 & 1 & 1 & 0 & 0 \\
\hline Polyura athamas & 1 & 0 & 0 & 0 & 0 & 0 & 0 & 2 & 1 & 0 & 1 & 0 & 1 & 0 & - & 1 & 0 & - & 1 & 1 & 0 & 0 & 1 & 0 \\
\hline Polyura delphis & 1 & 0 & 0 & 0 & 0 & 0 & 0 & 2 & 1 & 0 & 1 & ? & 1 & 0 & - & 1 & 0 & - & 1 & 1 & 0 & 0 & 1 & 0 \\
\hline Polyura gamma & 1 & 0 & 0 & 0 & 0 & 0 & 0 & 2 & 1 & 0 & 1 & 1 & 1 & 0 & - & 1 & 0 & - & 1 & 1 & 0 & 0 & 1 & 0 \\
\hline Polyura pymus & 1 & 0 & 0 & 0 & 0 & 0 & 0 & 2 & 1 & 0 & 1 & 1 & 1 & 0 & - & 1 & 0 & - & 1 & 1 & 0 & 0 & 1 & 0 \\
\hline Polyura jalysus & 1 & 0 & 0 & 0 & 0 & 0 & 0 & 2 & 1 & 0 & 1 & 1 & 1 & 0 & - & 1 & 0 & - & 1 & 1 & 0 & 0 & 1 & 0 \\
\hline Polyura schreiber & 1 & 0 & 0 & 0 & 0 & 0 & 0 & 2 & 1 & 0 & 1 & 1 & 1 & 0 & - & 1 & 0 & - & 1 & 1 & 0 & 0 & 1 & 0 \\
\hline Charaxes varanes & 2 & 0 & 0 & 0 & 0 & 0 & 0 & - & 0 & 1 & 1 & 0 & 0 & 0 & - & 1 & $?$ & - & 1 & 1 & 1 & 1 & 0 & 0 \\
\hline Charaxes candiope & 1 & 0 & 0 & 0 & 0 & 0 & 2 & - & 0 & 1 & 1 & 0 & 0 & 0 & - & 1 & 0 & - & 1 & 1 & 0 & 0 & 1 & 0 \\
\hline Charaxes cynthia & 2 & 0 & 0 & 0 & 0 & 0 & 0 & 2 & $0 \& 1$ & 0 & 1 & 0 & 0 & 0 & - & 1 & 0 & - & 1 & 1 & 0 & 1 & 1 & 0 \\
\hline Charaxes lucretius & 1 & 0 & 0 & 0 & 0 & 0 & 0 & - & 0 & 1 & 1 & 0 & 0 & 0 & - & 1 & 0 & - & 1 & 1 & 0 & 0 & 1 & 0 \\
\hline Charaxes jasius & 1 & 0 & 0 & 1 & 0 & 0 & 0 & 2 & 0 & 1 & 1 & 0 & 0 & 0 & - & 1 & 0 & - & 1 & 1 & 0 & 1 & 1 & 0 \\
\hline Charaxes tiridates & 1 & 0 & 0 & 0 & 0 & 0 & 0 & - & 0 & 0 & 1 & 0 & 0 & 0 & - & 1 & 0 & - & 1 & 1 & 0 & 1 & 1 & 0 \\
\hline Charaxes hadrianus & 1 & 0 & 0 & 0 & 0 & 0 & 1 & 2 & 1 & 0 & 1 & $?$ & 0 & 0 & - & 1 & 0 & - & 1 & 1 & 0 & 0 & 1 & 0 \\
\hline Charaxes nobilis & 1 & 0 & 0 & 0 & 0 & 0 & 0 & 1 & 1 & 0 & 1 & 1 & 1 & 0 & - & 1 & 0 & - & 1 & 1 & 0 & 0 & 1 & 0 \\
\hline Charaxes zoolina & 1 & 0 & 1 & 0 & 0 & 0 & 0 & 2 & 0 & 0 & 1 & 0 & 1 & 0 & - & 1 & 0 & - & 0 & 1 & 2 & 2 & 1 & 0 \\
\hline Charaxes eupale & 1 & 0 & 0 & 0 & 0 & 0 & 2 & 2 & $?$ & 0 & 1 & $?$ & 0 & 0 & - & 1 & 0 & - & 0 & 0 & - & - & 0 & 0 \\
\hline Charaxes jahlusa & 1 & 0 & 1 & 0 & 0 & 0 & 0 & - & 1 & 0 & 1 & 1 & 1 & 0 & - & 1 & 0 & - & 1 & 1 & 0 & 0 & 1 & 0 \\
\hline Charaxes pleione & 1 & 0 & 0 & 0 & 0 & 0 & 0 & 2 & 1 & 0 & 1 & 0 & 0 & $?$ & - & 1 & 0 & - & 1 & 1 & 0 & 0 & 0 & 0 \\
\hline Charaxes zingha & 2 & 0 & 0 & 0 & 0 & 0 & 0 & 2 & 1 & 0 & 0 & 1 & 1 & 0 & - & 1 & 0 & - & 0 & 0 & - & - & 0 & 0 \\
\hline Charaxes etesipe & 1 & 0 & 0 & 0 & 0 & 0 & 0 & 2 & 1 & 0 & 1 & 1 & 1 & 0 & - & 1 & 0 & - & 1 & 1 & 0 & 0 & 1 & 0 \\
\hline Charaxes etheocles & 1 & 0 & 0 & 0 & 0 & 0 & 0 & 2 & 1 & 0 & 1 & 1 & 1 & 0 & - & 1 & 0 & - & 1 & 1 & 0 & 1 & 1 & 0 \\
\hline Charaxes nichetes & $?$ & 0 & 0 & 0 & 0 & 0 & 0 & - & 0 & 1 & 1 & 0 & 0 & 0 & - & 1 & 0 & - & 0 & 0 & - & - & 0 & 0 \\
\hline Charaxes laodice & 1 & 0 & 0 & 0 & 0 & 0 & 0 & 0 & 1 & 0 & 1 & 0 & 0 & 0 & - & 1 & 0 & - & 0 & 1 & 1 & 1 & 0 & 0 \\
\hline Charaxes solon & 1 & 0 & 0 & 0 & 0 & 0 & 0 & 2 & 1 & 0 & 1 & 0 & 1 & 0 & - & 1 & 0 & - & 1 & 1 & 0 & 0 & 1 & 0 \\
\hline Charaxes latona & 1 & 0 & 0 & 0 & 0 & 0 & 0 & - & 0 & 1 & 1 & 0 & 0 & 0 & - & 1 & 0 & - & 1 & 1 & 0 & 1 & $?$ & 0 \\
\hline Charaxes eurialus & 1 & 0 & 0 & 0 & 0 & 0 & 0 & ? & 0 & 0 & 1 & 0 & 0 & 0 & - & 1 & 0 & - & 1 & 1 & 0 & 1 & 0 & 0 \\
\hline Agatasa calydonia & 1 & 1 & 1 & 1 & 0 & 0 & 0 & - & 0 & 0 & 1 & $?$ & 1 & 0 & - & 1 & 0 & - & 0 & 0 & - & - & 0 & 1 \\
\hline Prothoe australis & 1 & 1 & 1 & 1 & $?$ & 0 & 0 & - & 1 & 1 & 1 & 0 & 1 & 0 & - & 1 & 1 & 1 & 0 & 0 & - & - & 0 & 1 \\
\hline Prothoe franck & 3 & 1 & 1 & 1 & 1 & 0 & 0 & - & 1 & 1 & 0 & ? & 1 & 0 & - & 1 & 1 & 1 & 0 & 0 & - & - & 0 & 1 \\
\hline
\end{tabular}




\begin{tabular}{|c|c|c|c|c|c|c|c|c|c|c|c|c|c|c|c|c|c|c|c|c|c|c|c|c|}
\hline Táxon & $\begin{array}{l}2 \\
5\end{array}$ & & & & & $\begin{array}{l}3 \\
0\end{array}$ & & & & & $\begin{array}{l}3 \\
5\end{array}$ & & & & & $\begin{array}{l}4 \\
0\end{array}$ & & & & & $\begin{array}{l}4 \\
5\end{array}$ & & & \\
\hline A patura ins & 0 & 1 & 0 & 0 & 0 & 4 & - & - & - & - & - & 0 & 0 & 3 & 3 & 1 & 0 & 1 & 0 & 0 & 1 & 0 & 0 & 0 \\
\hline Calinaga buddha & 0 & 1 & 0 & 0 & 0 & 0 & 0 & - & 0 & 0 & - & 0 & 2 & 3 & 3 & 0 & 0 & 1 & 0 & 0 & 1 & 0 & 0 & 0 \\
\hline Antimea archaea & 0 & 1 & 0 & 0 & 0 & 0 & 0 & - & 0 & 0 & 1 & 3 & 2 & 3 & 3 & 0 & 1 & 0 & 0 & 0 & 0 & 0 & 0 & 0 \\
\hline Coenophlebia archidona & 0 & 1 & 0 & 2 & 0 & 4 & - & - & - & - & - & 3 & 2 & 3 & 3 & 0 & 1 & 0 & 1 & 0 & 0 & 0 & 0 & 1 \\
\hline Consul electra & 1 & 1 & 0 & 2 & 0 & 0 & 0 & - & 0 & 0 & 1 & 0 & 0 & 3 & 3 & 0 & 1 & 0 & 0 & 0 & 0 & 1 & 1 & 1 \\
\hline Consul fabius & 1 & 1 & 0 & 2 & 0 & 0 & 0 & - & 0 & 0 & 1 & 0 & 0 & 3 & 3 & 0 & 1 & 0 & 2 & 1 & 0 & 1 & 1 & 1 \\
\hline Hypna clytemnestra & 0 & 1 & 0 & 2 & 0 & 0 & 0 & - & 0 & 0 & 1 & 0 & 2 & 3 & 3 & 0 & 0 & 1 & ? & 1 & 0 & 0 & 1 & 1 \\
\hline Polygrapha cyanea & 0 & 1 & 0 & 0 & 0 & 0 & 0 & - & 0 & 0 & 1 & 3 & 2 & 3 & 3 & 0 & 0 & 0 & 1 & 1 & 0 & 1 & 1 & 1 \\
\hline Polygrapha suprema & 0 & 1 & 0 & 1 & 0 & 4 & - & - & - & - & - & 3 & 2 & 3 & 0 & 0 & 0 & 0 & 1 & 0 & 0 & 1 & 1 & 1 \\
\hline Polygrapha tyrianthina & 0 & 1 & 0 & 1 & 0 & $?$ & 0 & - & 0 & 0 & 1 & 3 & 2 & 3 & 1 & 0 & 0 & 0 & 1 & 0 & 0 & 1 & 1 & 1 \\
\hline Polygrapha xenocrates & 0 & 1 & 0 & 1 & 0 & 0 & 0 & - & 0 & 0 & 1 & 3 & 2 & 3 & 3 & 0 & 0 & 0 & 2 & 1 & 0 & 1 & 1 & 1 \\
\hline Siderone galanthis & 1 & 1 & 0 & 0 & 1 & 0 & 0 & - & 0 & 0 & $?$ & 3 & 2 & 2 & 3 & 0 & 1 & 0 & $0 \& 2$ & 1 & 0 & 0 & 0 & 1 \\
\hline Zaretis callydrias & 1 & 1 & 0 & 2 & ? & 0 & 0 & - & 0 & 0 & 1 & 3 & 2 & 3 & 3 & 0 & 1 & 0 & 1 & 0 & 0 & 0 & 0 & 1 \\
\hline Zaretis isidora & 1 & 1 & 0 & 2 & 1 & 0 & 0 & - & 0 & 0 & 1 & 3 & 2 & 3 & 3 & 0 & 1 & 1 & 0 & 0 & 0 & 0 & 0 & 1 \\
\hline Anaea troglodyta & 0 & 1 & 0 & 1 & 0 & 0 & 0 & - & 0 & 0 & 1 & 3 & 2 & 3 & 3 & 0 & 1 & 0 & $0 \& 2$ & 0 & 0 & 0 & 1 & 0 \\
\hline Fountainea nessus & 0 & 1 & 0 & 0 & 0 & 0 & 0 & - & 0 & 0 & 1 & 3 & 2 & 3 & 3 & 0 & 0 & 0 & 1 & 0 & 0 & 1 & 1 & 1 \\
\hline Fountainea ryphea & 0 & 1 & 0 & 0 & 0 & 0 & 0 & - & 0 & 0 & 1 & 3 & 2 & 3 & 3 & 0 & 0 & 0 & 2 & 0 & 0 & 1 & 1 & 1 \\
\hline Memphis appias & 0 & 1 & 0 & 0 & 0 & 0 & 0 & - & 0 & 0 & 1 & 3 & 2 & 3 & 3 & 0 & 0 & 0 & 1 & 0 & 0 & 1 & 1 & 1 \\
\hline Memphis glauce & 0 & 1 & 0 & 0 & 0 & 0 & 0 & - & 0 & 0 & 1 & 3 & 2 & 3 & 3 & 0 & 0 & 0 & 1 & 0 & 0 & 1 & 1 & 1 \\
\hline Memphis grandis & 0 & 1 & 0 & 0 & 0 & 0 & 0 & - & 0 & 0 & 0 & 3 & 2 & 3 & 3 & 0 & 0 & 0 & 1 & 0 & 0 & 1 & 1 & 1 \\
\hline Memphis hirta & 1 & 1 & 0 & 1 & 0 & 0 & 0 & - & 0 & 0 & 1 & 3 & 2 & 3 & 3 & 0 & 0 & 0 & 0 & 0 & 0 & 1 & 1 & 1 \\
\hline Memphis leonida & 0 & 1 & 0 & 0 & 0 & 0 & 0 & - & 0 & 0 & 1 & 3 & 2 & 3 & 3 & 0 & 0 & 0 & 1 & 0 & 0 & 1 & 1 & 1 \\
\hline Memphis moruus & 0 & 1 & 0 & 1 & 0 & 0 & 0 & - & 0 & 0 & 1 & 3 & 2 & 3 & 3 & 0 & 0 & 0 & 1 & 0 & 0 & 1 & 1 & 1 \\
\hline Memphis philumena & 0 & 1 & 0 & 1 & 0 & 0 & 0 & - & 0 & 0 & 1 & 0 & 2 & 3 & 0 & 0 & 0 & 0 & 1 & 0 & 0 & 1 & 1 & 1 \\
\hline Memphis pithyusa & 0 & 1 & 0 & 0 & 0 & 0 & 0 & - & 0 & 0 & 1 & 3 & 2 & 3 & 3 & 0 & 0 & 0 & 2 & 0 & 0 & 1 & 1 & 1 \\
\hline Memphis polycames & 0 & 1 & 0 & 0 & 0 & 0 & 0 & - & 0 & 0 & 1 & 3 & 2 & 3 & 3 & 0 & 0 & 0 & 1 & 0 & 0 & 1 & 1 & 1 \\
\hline Memphis polyxo & 0 & 1 & 0 & 0 & 0 & 4 & - & - & - & - & - & 4 & 2 & 2 & 3 & 0 & 0 & 0 & 1 & 1 & 0 & 1 & 1 & 1 \\
\hline Memphis verticordia & 0 & 1 & 0 & 0 & 0 & 0 & 0 & - & 0 & 0 & 1 & 3 & 2 & 3 & 3 & 0 & 0 & $?$ & $?$ & 0 & 0 & 1 & 1 & 1 \\
\hline A naeomorpha splendida & 0 & 1 & 0 & 0 & 0 & 4 & - & - & - & - & - & 4 & 2 & 3 & 3 & 0 & 0 & 0 & 0 & 1 & 0 & 0 & 0 & 1 \\
\hline Noreppa chromus & 0 & 1 & 0 & 0 & 0 & 1 & 0 & 0 & 0 & 0 & 2 & 1 & 2 & 3 & 1 & 0 & 0 & 1 & 0 & 1 & 0 & 0 & 0 & 1 \\
\hline Archaeoprepona amphimacus & 0 & 1 & 0 & 0 & 0 & 1 & 0 & 0 & 0 & 0 & 2 & $1 \& 2$ & 2 & 3 & 1 & 0 & 0 & 1 & 0 & 1 & 0 & 0 & 0 & 1 \\
\hline Archaeoprepona chalciope & 0 & 1 & 0 & 0 & 0 & 4 & - & - & - & - & - & 2 & 2 & 3 & 1 & 0 & 0 & $?$ & $?$ & $?$ & 0 & 0 & 0 & 1 \\
\hline Archaeoprepona demophon & 0 & 1 & 0 & 0 & 0 & 1 & 0 & 0 & 0 & 0 & 1 & 1 & 2 & 3 & 2 & 0 & 0 & 1 & 0 & 1 & 0 & 0 & 0 & 1 \\
\hline Archaeoprepona demophoon & 0 & 1 & 0 & 0 & 0 & 1 & 0 & 0 & 0 & 0 & 1 & 1 & 2 & 3 & 1 & 0 & 0 & 1 & 0 & 1 & 0 & 0 & 0 & 1 \\
\hline Archaeoprepona licomedes & 0 & 1 & 0 & 0 & 0 & 1 & 0 & 0 & 0 & 0 & 2 & 1 & 2 & 3 & 1 & 0 & 0 & 1 & 0 & 1 & 0 & 0 & 0 & 1 \\
\hline Prepona praeneste & 0 & 1 & 0 & 0 & 0 & 0 & 0 & - & 1 & 1 & 2 & 1 & 2 & 3 & 1 & 0 & 0 & 0 & 0 & 1 & 0 & 0 & 0 & 1 \\
\hline Prepona laertes & 0 & 1 & 1 & 0 & 0 & 0 & 0 & - & 1 & 1 & 2 & 1 & 2 & 3 & 1 & 0 & 0 & 1 & 0 & 1 & 0 & 0 & 0 & 1 \\
\hline Prepona pheridamas & 0 & 1 & 0 & 0 & 0 & 0 & 0 & - & 0 & $?$ & 0 & $1 \& 2$ & 2 & 3 & 2 & 0 & 0 & 1 & 0 & 1 & 0 & 0 & 0 & 1 \\
\hline Prepona pylene & 0 & 1 & 1 & 0 & 0 & 0 & 0 & - & 1 & 1 & 2 & 1 & 2 & 3 & 1 & 0 & 0 & 1 & 0 & 1 & 0 & 0 & 0 & 1 \\
\hline Agrias amydon & 0 & 1 & 0 & 0 & 0 & 1 & 0 & 1 & 0 & 0 & 2 & 1 & 0 & 3 & 2 & 0 & 0 & 1 & 0 & 1 & 0 & 0 & 0 & 1 \\
\hline Agrias claudina & 0 & 1 & 0 & 0 & 0 & 1 & 0 & 1 & 0 & 0 & 2 & 1 & 0 & 3 & 1 & 0 & 0 & 1 & 0 & 1 & 0 & 0 & 0 & 1 \\
\hline Euxanthe eurinome & 0 & 0 & 0 & 0 & 0 & 0 & 1 & - & 0 & 0 & 0 & $?$ & $?$ & 3 & 3 & 0 & 0 & 0 & 2 & 1 & 0 & 0 & 0 & 1 \\
\hline Euxanthe trajanus & 0 & 0 & 0 & 0 & 0 & 0 & 1 & - & 0 & 0 & 0 & 4 & $?$ & 3 & 3 & 0 & 0 & 0 & 0 & 1 & 0 & 0 & 0 & 1 \\
\hline Palla decius & 0 & 0 & 0 & 0 & 0 & 0 & 0 & - & 0 & 1 & 1 & 0 & $?$ & 3 & 3 & 0 & 0 & 0 & 0 & 1 & $?$ & 0 & 0 & 1 \\
\hline Polyura athamas & 0 & 0 & 1 & 0 & 0 & 3 & 0 & - & 0 & 0 & 2 & 1 & 1 & 3 & 3 & 0 & 1 & 1 & 2 & 1 & 0 & 0 & 0 & 1 \\
\hline Polyura delphis & 0 & 0 & 0 & 0 & 0 & 3 & 0 & - & 0 & 0 & 2 & 1 & 0 & 3 & 3 & 0 & 1 & 1 & 2 & 1 & 0 & 0 & 0 & 1 \\
\hline Polyura gamma & 0 & 0 & 0 & 0 & 0 & 3 & 0 & - & 0 & 0 & 2 & 0 & 0 & 3 & 0 & 0 & 1 & 1 & 2 & 1 & 0 & 0 & 0 & 1 \\
\hline Polyura pymus & 0 & 0 & 0 & 0 & 0 & 3 & 0 & - & 0 & 0 & 2 & 0 & $?$ & 3 & 0 & 0 & 0 & 1 & 0 & 1 & 0 & 0 & 0 & 1 \\
\hline Polyura jalysus & 0 & 0 & 1 & 0 & 0 & 3 & 0 & - & 0 & 0 & 2 & 4 & 1 & 3 & 3 & 0 & 1 & 1 & 0 & 1 & 0 & 0 & 0 & 1 \\
\hline Polyura schreiber & 0 & 0 & 1 & 0 & 0 & 3 & 0 & - & 0 & 0 & 2 & 1 & 1 & 3 & 3 & 0 & 0 & 1 & 0 & 1 & 0 & 0 & 0 & 1 \\
\hline Charaxes varanes & 0 & 0 & 0 & 0 & 0 & 3 & 0 & - & 0 & 0 & 1 & 1 & 0 & 3 & 0 & 0 & 1 & 0 & 0 & 1 & 0 & 0 & 0 & 1 \\
\hline Charaxes candiope & 0 & 0 & 0 & 0 & 0 & 3 & 0 & - & 0 & 0 & 1 & 0 & 0 & 3 & 0 & 0 & 2 & 0 & 0 & 1 & 0 & 0 & 0 & 1 \\
\hline Charaxes cynthia & 0 & 0 & 0 & 0 & 0 & 3 & 0 & - & 0 & 0 & 1 & 1 & 1 & 3 & 0 & 0 & 1 & 0 & 0 & 1 & 0 & 0 & 0 & 1 \\
\hline Charaxes lucretius & 0 & 0 & 0 & 0 & 0 & 3 & 0 & - & 0 & 0 & 1 & 0 & 0 & 3 & 0 & 0 & 0 & 0 & 0 & 1 & 0 & 0 & 0 & 1 \\
\hline Charaxes jasius & 0 & 0 & 0 & 0 & 0 & 3 & 0 & - & 0 & 0 & 1 & 0 & 1 & 2 & 0 & 1 & 0 & 0 & 2 & 1 & 0 & 0 & 0 & 1 \\
\hline Charaxes tiridates & 0 & 0 & 0 & 0 & 0 & 3 & 0 & - & 0 & 0 & 2 & 0 & 0 & 3 & 0 & 0 & 0 & 1 & 0 & 1 & 0 & 0 & 0 & 1 \\
\hline Charaxes hadrianus & 0 & 0 & 0 & 0 & 0 & 3 & 0 & - & 0 & 0 & 2 & 0 & $?$ & 3 & 3 & 0 & 0 & 0 & 0 & 1 & 0 & 0 & 0 & 1 \\
\hline Charaxes nobilis & 0 & 0 & 0 & 0 & 0 & 3 & 0 & - & 0 & 0 & 1 & 0 & 1 & 2 & 0 & 0 & 0 & 0 & 0 & 1 & 0 & 0 & 0 & 1 \\
\hline Charaxes zoolina & 0 & 0 & 0 & 2 & 0 & 3 & 0 & - & 0 & 0 & 1 & $0 \& 1$ & 1 & 3 & 3 & 0 & 1 & 1 & 2 & 1 & 0 & 0 & 0 & 1 \\
\hline Charaxes eupale & 0 & 0 & 0 & 0 & 0 & 3 & 0 & - & 0 & 0 & 1 & 3 & $?$ & 3 & 3 & 0 & 2 & 0 & 0 & 1 & 0 & 0 & 0 & 1 \\
\hline Charaxes jahlusa & 0 & 0 & 0 & 0 & 0 & 3 & 0 & - & 0 & 0 & 1 & 2 & 0 & 2 & 1 & 0 & 2 & 0 & 2 & 1 & 0 & 0 & 0 & 1 \\
\hline Charaxes pleione & 0 & 0 & 0 & 1 & 0 & 3 & 0 & - & 0 & 0 & 1 & 1 & 1 & 0 & 0 & 0 & 1 & 1 & 2 & 1 & 0 & 0 & 0 & 1 \\
\hline Charaxes zingha & 1 & 0 & 0 & 0 & 0 & 3 & 0 & - & 0 & 0 & 1 & 1 & 0 & 3 & 1 & 0 & 1 & 0 & 0 & 1 & 0 & 0 & 0 & 1 \\
\hline Charaxes etesipe & 0 & 0 & 0 & 0 & 0 & 3 & 0 & - & 0 & 0 & 1 & 0 & 0 & 0 & 0 & 1 & 0 & 0 & 0 & 1 & 0 & 0 & 0 & 1 \\
\hline Charaxes etheocles & 0 & 0 & 0 & 0 & 0 & 3 & 0 & - & 0 & 0 & 2 & 1 & 0 & 2 & 0 & 0 & 0 & 0 & 0 & 1 & 0 & 0 & 0 & 1 \\
\hline Charaxes nichetes & 1 & 0 & 0 & 0 & 0 & 3 & 0 & - & 0 & 0 & 1 & 1 & 0 & 0 & 3 & 0 & 1 & 0 & 0 & 1 & 0 & 0 & 0 & 1 \\
\hline Charaxes laodice & 1 & 0 & 0 & 0 & 0 & 3 & 0 & - & 0 & 0 & 1 & 1 & $?$ & 3 & 3 & 0 & 0 & 0 & 0 & 1 & 0 & 0 & 0 & 1 \\
\hline Charaxes solon & 0 & 0 & 0 & 0 & 0 & 3 & 0 & - & 0 & 0 & 2 & 1 & 0 & 2 & 0 & 0 & 0 & 0 & 0 & 1 & 0 & 0 & 0 & 1 \\
\hline Charaxes latona & 0 & 0 & 0 & 0 & 0 & 3 & 0 & - & 0 & 0 & 2 & 0 & 0 & 0 & 0 & 0 & 1 & 0 & 0 & 1 & 0 & 0 & 0 & 1 \\
\hline Charaxes eurialus & 0 & 0 & 0 & 0 & 0 & 3 & 0 & - & 0 & 0 & 2 & 0 & 0 & 1 & 0 & 0 & 0 & 0 & 0 & 1 & 0 & 0 & 0 & 1 \\
\hline Agatasa calydonia & 0 & 1 & 0 & 0 & 0 & 3 & 0 & - & 0 & 0 & $?$ & 1 & 0 & 2 & 1 & 0 & 0 & 0 & 0 & 1 & 0 & 0 & 0 & 1 \\
\hline Prothoe australis & 0 & 1 & 0 & 0 & 0 & 3 & 0 & - & 0 & 0 & $?$ & 1 & 0 & 2 & $?$ & 0 & $?$ & 1 & 0 & 1 & 0 & 0 & 0 & 1 \\
\hline Prothoe franck & 0 & 1 & 0 & 0 & 0 & 3 & 0 & - & 0 & 0 & 1 & 1 & 0 & 2 & 0 & 0 & 0 & 1 & 2 & 1 & 0 & 0 & 0 & 1 \\
\hline
\end{tabular}




\begin{tabular}{|c|c|c|c|c|c|c|c|c|c|c|c|c|c|c|c|c|c|c|c|c|c|c|c|c|}
\hline Táxon & & $\begin{array}{l}5 \\
0\end{array}$ & & & & & $\begin{array}{l}5 \\
5\end{array}$ & & & & & $\begin{array}{l}6 \\
0\end{array}$ & & & & & $\begin{array}{l}6 \\
5\end{array}$ & & & & & $\begin{array}{l}7 \\
0\end{array}$ & & \\
\hline A patura ins & - & 1 & 1 & 0 & 0 & 0 & 0 & 1 & 0 & 1 & 0 & 0 & - & 0 & $?$ & $?$ & 0 & 0 & 1 & 1 & 1 & 0 & 0 & ? \\
\hline Calinaga buddha & - & 0 & 1 & 0 & 0 & 0 & 0 & 2 & $?$ & 1 & 1 & 0 & - & 0 & 0 & 0 & $?$ & $?$ & 1 & 1 & 1 & 0 & 0 & 2 \\
\hline Antimea archaea & - & 0 & 1 & 0 & 0 & 0 & 0 & 0 & - & $?$ & 1 & 0 & - & $?$ & $?$ & 0 & 0 & 0 & 1 & 1 & $?$ & 0 & 0 & 1 \\
\hline Coenophlebia archidona & 1 & 0 & 1 & 0 & 0 & 1 & 0 & 1 & 0 & 1 & 1 & 0 & - & 0 & 0 & 0 & 1 & 0 & 1 & 1 & 1 & 0 & 0 & 2 \\
\hline Consul electra & 0 & 0 & 1 & 0 & 0 & 1 & 0 & 1 & 0 & $?$ & 1 & 0 & - & 0 & $?$ & 0 & 1 & 0 & 1 & 1 & 0 & 0 & 0 & 1 \\
\hline Consul fabius & 1 & 0 & 1 & 0 & 0 & 1 & 0 & 1 & 0 & $?$ & 1 & 0 & - & 0 & $?$ & 0 & 1 & 0 & 1 & 1 & 0 & 0 & 0 & 1 \\
\hline Hypna clytemnestra & 1 & 0 & 1 & 0 & 0 & 1 & 0 & 0 & $?$ & 1 & 1 & 0 & - & 1 & 1 & 0 & 0 & 0 & 0 & - & $?$ & 0 & 0 & 2 \\
\hline Polygrapha cyanea & 0 & 0 & 1 & 0 & 0 & 1 & 0 & 1 & 0 & $?$ & 1 & 0 & - & 0 & 0 & 0 & 1 & 0 & 1 & 1 & 1 & 0 & 0 & $?$ \\
\hline Polygrapha suprema & 0 & 0 & 1 & 0 & 0 & 1 & 0 & 1 & 0 & 1 & 1 & 0 & - & 0 & 0 & 0 & 1 & 0 & 1 & 1 & 1 & 0 & 0 & 1 \\
\hline Polygrapha tyrianthina & 1 & 0 & 1 & 0 & 0 & 1 & 0 & 1 & 0 & $?$ & 1 & 0 & - & 0 & $?$ & 0 & 1 & 0 & 1 & 1 & 0 & 0 & 0 & $?$ \\
\hline Polygrapha xenocrates & 1 & 0 & 1 & 0 & 0 & 1 & 0 & 1 & 0 & 1 & 1 & 0 & - & 0 & 0 & 0 & 1 & 0 & 0 & - & - & 0 & 0 & 2 \\
\hline Siderone galanthis & 0 & 0 & 1 & 0 & 0 & 1 & 0 & 1 & 0 & $?$ & 1 & 0 & - & 0 & 0 & 0 & 0 & 0 & 1 & 1 & 0 & 0 & 0 & 2 \\
\hline Zaretis callydrias & 1 & 0 & 1 & 0 & 0 & 1 & 0 & 1 & 0 & 1 & 1 & 0 & - & 0 & 0 & 0 & 0 & 0 & 1 & 1 & 0 & 0 & 0 & 2 \\
\hline Zaretis isidora & 1 & 0 & 1 & 0 & 0 & 1 & 0 & 1 & 0 & $?$ & 1 & 0 & - & 0 & 0 & 0 & 0 & 0 & 1 & 1 & 0 & 0 & 0 & 2 \\
\hline Anaea troglodyta & - & 0 & 0 & 0 & 0 & 1 & 0 & 1 & 0 & $?$ & 1 & 0 & - & 0 & $?$ & 0 & 1 & 2 & 1 & 1 & 1 & $?$ & 0 & $?$ \\
\hline Fountainea nessus & 1 & 0 & 1 & 0 & 0 & 1 & 0 & 1 & 0 & $?$ & 1 & 0 & - & 0 & 0 & 0 & 1 & 0 & 1 & 1 & 0 & 0 & 0 & 2 \\
\hline Fountainea ryphea & 1 & 0 & 1 & 0 & 0 & 1 & 0 & 1 & 0 & $?$ & 1 & 0 & - & 0 & $?$ & 0 & 1 & 0 & 1 & 1 & 1 & 0 & 0 & $?$ \\
\hline Memphis appias & 1 & 0 & 1 & 0 & 0 & 1 & 0 & 1 & 0 & $?$ & 1 & 0 & - & 0 & $?$ & 0 & 1 & 0 & 0 & - & - & 0 & 0 & $?$ \\
\hline Memphis glauce & 1 & 0 & 1 & 0 & 0 & 1 & 0 & 1 & 0 & $?$ & 1 & 0 & - & 0 & 0 & 0 & 2 & 0 & 0 & - & - & 0 & 0 & 1 \\
\hline Memphis grandis & 1 & 0 & 1 & 0 & 0 & 1 & 0 & 1 & 0 & 1 & 1 & 0 & - & 0 & 0 & 0 & 1 & 0 & 0 & - & - & 0 & 0 & 1 \\
\hline Memphis hirta & 0 & 0 & 1 & 0 & 0 & 1 & 0 & 1 & 0 & $?$ & 1 & 0 & - & 0 & $?$ & 0 & 1 & 0 & 0 & - & - & 0 & 0 & $?$ \\
\hline Memphis leonida & 1 & 0 & 1 & 0 & 0 & 1 & 0 & 1 & 0 & $?$ & 1 & 0 & - & 0 & $?$ & 0 & 1 & 0 & 0 & - & - & 0 & 0 & $?$ \\
\hline Memphis moruus & 1 & 0 & 1 & 0 & 0 & 1 & 0 & 0 & 0 & $?$ & 1 & 0 & - & 0 & $?$ & 0 & $?$ & 0 & 0 & - & - & 0 & 0 & $?$ \\
\hline Memphis philumena & 0 & 0 & 1 & 0 & 0 & 1 & 0 & 0 & 0 & $?$ & 1 & 0 & - & 0 & 0 & 0 & 1 & 0 & 0 & - & - & 0 & 0 & 1 \\
\hline Memphis pithyusa & 1 & 0 & 1 & 0 & 0 & 1 & 0 & 1 & 0 & $?$ & 1 & 0 & - & 0 & $?$ & 0 & $?$ & 0 & 0 & - & - & 0 & 0 & $?$ \\
\hline Memphis polycames & 1 & 0 & 1 & 0 & 0 & 1 & 0 & 0 & 0 & 1 & 1 & 0 & - & 0 & 0 & 0 & 1 & 0 & 0 & - & - & 0 & 0 & 2 \\
\hline Memphis polyxo & 1 & 0 & 1 & 0 & 0 & 1 & 0 & 1 & 0 & 1 & 1 & 0 & - & 0 & 0 & 0 & 1 & 0 & 0 & - & - & 0 & 0 & 1 \\
\hline Memphis verticordia & 1 & 0 & 0 & 0 & 0 & 1 & 0 & 1 & 0 & 1 & 1 & 0 & - & 0 & 0 & 0 & 1 & 0 & 1 & 1 & 1 & 0 & 0 & 2 \\
\hline A naeomorpha splendida & 1 & 1 & 1 & 0 & 0 & 1 & 0 & 1 & 0 & 1 & 1 & 0 & - & $?$ & 1 & 0 & 0 & 0 & 1 & 1 & 0 & 0 & 0 & 1 \\
\hline Noreppa chromus & 0 & 0 & 1 & 0 & 0 & 1 & 1 & 1 & 1 & 0 & 1 & 0 & - & 1 & 1 & 0 & 2 & 1 & 1 & 1 & 1 & 0 & 0 & 2 \\
\hline Archaeoprepona amphimacus & 0 & 0 & 1 & 0 & 0 & 1 & 1 & 1 & 1 & 0 & 1 & 0 & - & 1 & 1 & 0 & 2 & 0 & 1 & 1 & 1 & 0 & 0 & 2 \\
\hline Archaeoprepona chalciope & 0 & 0 & 1 & 0 & 0 & 1 & 1 & 1 & 1 & 0 & 1 & 0 & - & 1 & 1 & 0 & 2 & 0 & 1 & 1 & 1 & 0 & 0 & 2 \\
\hline Archaeoprepona demophon & 0 & 0 & 1 & 0 & 0 & 1 & 1 & 1 & 1 & 0 & 1 & 0 & - & 1 & 1 & 0 & 2 & 1 & 1 & 1 & 1 & 0 & 0 & 2 \\
\hline Archaeoprepona demophoon & 1 & 0 & 1 & 0 & 0 & 1 & 1 & 1 & 1 & 0 & 1 & 2 & $?$ & 1 & 1 & 0 & 2 & 1 & 1 & 1 & 1 & 0 & 0 & 2 \\
\hline Archaeoprepona licomedes & 0 & 0 & 1 & 0 & 0 & 1 & 0 & 1 & 1 & 0 & 1 & 0 & - & 1 & 1 & 0 & 2 & 1 & 1 & 1 & 1 & 0 & 0 & 2 \\
\hline Prepona praeneste & 1 & 0 & 1 & 0 & 0 & 1 & 1 & 0 & - & 0 & 1 & 0 & - & 1 & 0 & 0 & 1 & 3 & 1 & 1 & 1 & 0 & 0 & 1 \\
\hline Prepona laertes & 0 & 0 & 1 & 0 & 0 & 1 & 1 & 0 & - & 0 & 1 & 0 & - & 1 & $?$ & 0 & 0 & 3 & 1 & 1 & 1 & 0 & 0 & 1 \\
\hline Prepona pheridamas & 0 & 0 & 1 & 0 & 0 & 1 & 1 & 0 & - & 0 & 1 & 1 & $?$ & 1 & 0 & 0 & 0 & 2 & 1 & 1 & 1 & 0 & 0 & 1 \\
\hline Prepona pylene & 1 & 0 & 1 & 0 & 0 & 1 & 1 & 0 & - & 0 & 1 & 2 & - & 1 & 0 & 0 & 1 & 3 & 1 & 1 & 1 & 0 & 0 & 1 \\
\hline Agrias amydon & 0 & 0 & 1 & 0 & 0 & 1 & 1 & 0 & - & 0 & 1 & 0 & - & 1 & 0 & 0 & 1 & 3 & 1 & 1 & 1 & 0 & 0 & 2 \\
\hline Agrias claudina & 0 & 0 & 1 & 0 & 0 & 1 & 1 & 0 & - & 0 & $?$ & 0 & - & 1 & 0 & 0 & 1 & 3 & 1 & 1 & 1 & 0 & 0 & 2 \\
\hline Euxanthe eurinome & 0 & 1 & 1 & 1 & 1 & 1 & 0 & 2 & - & 1 & 0 & 1 & 0 & - & 0 & 1 & 0 & 0 & 1 & 0 & - & 0 & 0 & 0 \\
\hline Euxanthe trajanus & 0 & 1 & 1 & 1 & 1 & 1 & 0 & 2 & - & 1 & 0 & 1 & $?$ & - & 0 & 1 & 0 & 0 & 1 & 0 & - & 0 & 0 & 0 \\
\hline Palla decius & 0 & 0 & 1 & 0 & 0 & 1 & 0 & 1 & - & 0 & 1 & 0 & - & - & $?$ & 0 & 0 & 0 & 0 & $?$ & $?$ & 1 & 0 & 1 \\
\hline Polyura athamas & 0 & 1 & 1 & 0 & 0 & 1 & 0 & 2 & - & 1 & 0 & 1 & 0 & - & 0 & 1 & 0 & 0 & 1 & 0 & - & 0 & 0 & 0 \\
\hline Polyura delphis & 0 & 1 & 1 & 0 & 0 & 1 & 0 & 2 & - & 1 & 0 & 1 & $?$ & - & 0 & 1 & 0 & 0 & 1 & 0 & - & 0 & 0 & 0 \\
\hline Polyura gamma & 0 & 1 & 1 & 0 & 0 & 1 & 0 & 2 & - & 0 & 0 & 1 & $?$ & - & 0 & 1 & 0 & 0 & 1 & 0 & - & 0 & 0 & 0 \\
\hline Polyura pymhus & 0 & 1 & 1 & 0 & 0 & 1 & 0 & 2 & - & 1 & 0 & 1 & 0 & - & 0 & 1 & 0 & 0 & 1 & 0 & - & 0 & 0 & 0 \\
\hline Polyura jalysus & 0 & 1 & 1 & 0 & 0 & 1 & 0 & 2 & - & $?$ & 0 & 1 & 0 & - & 0 & 1 & 0 & 0 & 1 & 0 & - & 0 & 0 & 0 \\
\hline Polyura schreiber & 0 & 1 & 1 & 0 & 0 & 1 & 0 & 2 & - & 1 & 0 & 1 & 0 & - & 0 & 1 & 0 & 0 & 1 & 0 & - & 0 & 0 & 0 \\
\hline Charaxes varanes & 0 & 0 & 1 & 0 & 0 & 1 & 0 & 2 & - & 0 & 0 & 1 & 1 & - & 0 & 1 & 1 & 0 & 1 & 0 & - & 1 & 0 & 0 \\
\hline Charaxes candiope & 0 & 0 & 1 & 0 & 0 & 1 & 0 & 2 & - & 1 & 0 & 1 & 1 & - & 0 & 1 & 0 & 0 & 1 & 0 & - & 1 & 0 & 0 \\
\hline Charaxes cynthia & 0 & 0 & 1 & 0 & 0 & 1 & 0 & 2 & - & 1 & 0 & 1 & 1 & - & 0 & 1 & 0 & 0 & 1 & 0 & - & 1 & 0 & 0 \\
\hline Charaxes lucretius & 0 & 0 & 1 & 0 & 0 & 1 & 0 & 2 & - & 0 & 0 & 1 & 1 & - & 0 & 1 & 0 & 0 & 1 & 0 & - & 1 & 0 & 0 \\
\hline Charaxes jasius & 0 & 0 & 1 & 0 & 0 & 1 & 0 & 2 & - & 1 & 0 & 1 & 1 & - & 0 & 1 & 0 & 0 & 1 & 0 & - & 1 & 0 & 0 \\
\hline Charaxes tiridates & 0 & 0 & 1 & 0 & 0 & 1 & 0 & 2 & - & 0 & 0 & 1 & 1 & - & 0 & 1 & 0 & 0 & 1 & 0 & - & 1 & 1 & 0 \\
\hline Charaxes hadrianus & 0 & 0 & 1 & 0 & 0 & 1 & 0 & 2 & - & 1 & 0 & 1 & 1 & - & 0 & 1 & 0 & 0 & 1 & 0 & - & 1 & 0 & 0 \\
\hline Charaxes nobilis & 0 & 0 & 1 & 0 & 0 & 1 & 0 & 2 & - & 0 & 0 & 1 & 1 & - & 0 & 1 & 0 & 0 & 1 & 0 & - & 1 & 0 & 0 \\
\hline Charaxes zoolina & 0 & 0 & 1 & 0 & 0 & 1 & 0 & 2 & - & 1 & 0 & 1 & 0 & - & 0 & 2 & 0 & 0 & 1 & 0 & - & $?$ & $?$ & 0 \\
\hline Charaxes eupale & 0 & 0 & 1 & 0 & 0 & 1 & 0 & 2 & - & 1 & 0 & 1 & 0 & - & 0 & 0 & 0 & 0 & 1 & 0 & - & 0 & 0 & 0 \\
\hline Charaxes jahlusa & 0 & 0 & 1 & 0 & 0 & 1 & 0 & 2 & - & $?$ & 0 & 1 & 0 & - & 0 & 1 & 0 & 0 & 1 & 0 & - & 1 & 0 & 0 \\
\hline Charaxes pleione & 0 & 0 & 1 & 0 & 0 & 1 & 0 & 2 & - & 0 & 0 & 1 & $?$ & - & 0 & 1 & 0 & 0 & 1 & 0 & - & $?$ & $?$ & 0 \\
\hline Charaxes zingha & 0 & 0 & 1 & 0 & 1 & 1 & 0 & 2 & - & 0 & 0 & 1 & 0 & - & 0 & 0 & 0 & 0 & 1 & 0 & - & 1 & 1 & 1 \\
\hline Charaxes etesipe & 0 & 0 & 1 & 0 & 0 & 1 & 0 & 2 & - & 1 & 0 & 1 & 0 & - & 0 & 1 & 1 & 0 & 1 & 0 & - & 1 & 1 & 0 \\
\hline Charaxes etheocles & 0 & 0 & 1 & 0 & 0 & 1 & 0 & $?$ & - & 1 & 0 & 1 & $?$ & - & 0 & 0 & 0 & 0 & 1 & 0 & - & 1 & 1 & 0 \\
\hline Charaxes nichetes & 0 & 0 & 1 & 0 & 0 & 1 & 0 & 2 & - & 1 & 0 & 1 & 0 & - & 0 & 0 & 0 & 0 & 1 & 0 & - & 1 & 0 & 0 \\
\hline Charaxes laodice & 0 & 0 & 1 & 0 & 0 & 1 & 0 & 1 & - & 0 & 0 & 1 & 0 & - & 0 & 1 & 0 & 0 & 1 & 0 & - & 1 & 0 & 0 \\
\hline Charaxes solon & 0 & 0 & 1 & 0 & 0 & 1 & 0 & 2 & - & 0 & 0 & 1 & 0 & - & 0 & 0 & 0 & 0 & 1 & 0 & - & 1 & 1 & 0 \\
\hline Charaxes latona & 0 & 0 & 1 & 0 & 0 & 1 & 0 & 2 & - & 1 & 0 & 1 & 1 & - & 0 & 1 & 0 & 0 & 1 & 0 & - & 1 & 0 & 0 \\
\hline Charaxes eurialus & 0 & 0 & 1 & 0 & 0 & 1 & 0 & 2 & - & 1 & 0 & 1 & 1 & - & 0 & 1 & 0 & 0 & 1 & 0 & - & 1 & 0 & 0 \\
\hline Agatasa calydonia & 0 & 1 & 1 & 0 & 0 & 1 & 0 & 0 & - & $?$ & 0 & 1 & 1 & - & 0 & 0 & 1 & 0 & 1 & 1 & $?$ & 0 & 0 & 1 \\
\hline Prothoe australis & 0 & 1 & 1 & 0 & 0 & 1 & 1 & 1 & 0 & 1 & 1 & 0 & - & 0 & 0 & 2 & 2 & 1 & 1 & 1 & $?$ & 0 & 0 & 1 \\
\hline Prothoe franck & 0 & 1 & 1 & 0 & 0 & 1 & 1 & 1 & 0 & 1 & 1 & 0 & & 0 & 0 & 2 & 0 & 0 & 1 & 1 & $?$ & 0 & 0 & 1 \\
\hline
\end{tabular}




\begin{tabular}{|c|c|c|c|c|c|c|c|c|c|c|c|c|c|c|c|c|c|c|c|c|c|c|c|c|}
\hline Táxon & & & $\begin{array}{l}7 \\
5\end{array}$ & & & & & $\begin{array}{l}8 \\
0\end{array}$ & & & & & $\begin{array}{l}8 \\
5\end{array}$ & & & & & $\begin{array}{l}9 \\
0\end{array}$ & & & & & $\begin{array}{l}9 \\
5\end{array}$ & \\
\hline A patura ins & 1 & 0 & 0 & 1 & 2 & 1 & 0 & - & - & - & 0 & - & - & 0 & 0 & 2 & 0 & 0 & 0 & 1 & 1 & - & $?$ & 1 \\
\hline Calinaga buddha & 0 & 1 & 1 & 0 & - & 1 & 0 & - & - & - & 1 & 0 & 0 & $?$ & 0 & 0 & 0 & 0 & 0 & 1 & $?$ & - & $?$ & 1 \\
\hline Antimhea archaea & 1 & 0 & 1 & 0 & - & 0 & 1 & 0 & 0 & - & 0 & - & - & 0 & 0 & 0 & $?$ & $?$ & 0 & 1 & $?$ & 0 & 1 & 1 \\
\hline Coenophlebia archidona & 1 & 0 & 0 & 0 & - & 1 & 1 & $?$ & - & - & 1 & $?$ & 0 & 0 & 1 & 0 & 1 & $?$ & $?$ & $?$ & $?$ & $?$ & $?$ & $?$ \\
\hline Consul electra & 1 & 1 & 0 & 0 & - & 1 & 1 & 0 & 0 & - & 1 & 0 & 1 & 0 & 1 & 0 & 1 & 1 & 1 & 0 & 0 & 0 & 0 & 1 \\
\hline Consul fabius & 1 & 1 & 0 & 0 & - & 1 & 1 & 0 & 1 & - & 1 & 0 & 3 & 0 & 1 & 0 & 1 & 1 & 1 & 0 & 0 & 0 & 0 & 1 \\
\hline Hypna clytemnestra & 1 & 1 & 0 & 0 & - & 1 & 1 & $?$ & ? & - & 1 & 0 & 2 & 1 & 1 & 0 & 1 & - & 1 & 0 & 0 & 0 & 0 & 1 \\
\hline Polygrapha cyanea & 1 & 1 & $?$ & 0 & - & 1 & 1 & 1 & - & 1 & 1 & 0 & 0 & 1 & 1 & $?$ & 1 & $?$ & $?$ & $?$ & $?$ & $?$ & $?$ & $?$ \\
\hline Polygrapha suprema & 1 & 1 & 0 & 0 & - & 1 & 1 & $?$ & $?$ & - & 1 & 0 & 0 & 0 & 1 & 0 & 1 & $?$ & 1 & 0 & $?$ & 0 & 0 & 1 \\
\hline Polygrapha tyrianthina & 1 & 0 & 0 & 0 & - & 1 & 1 & 0 & 1 & - & 1 & 0 & 0 & 1 & 1 & 0 & 1 & $?$ & 1 & 0 & ? & $?$ & ? & ? \\
\hline Polygrapha xenocrates & 1 & 1 & 0 & 0 & - & 1 & 1 & 0 & 0 & - & 1 & 0 & 1 & 1 & 1 & 0 & 1 & $?$ & $?$ & $?$ & $?$ & $?$ & $?$ & $?$ \\
\hline Siderone galanthis & 1 & 1 & 0 & 0 & - & 1 & 1 & $?$ & $?$ & - & 1 & 0 & 0 & 0 & 1 & 1 & 1 & 2 & 1 & 0 & 0 & 0 & 0 & 1 \\
\hline Zaretis callydrias & 1 & $?$ & $?$ & 0 & - & 1 & 1 & 0 & 0 & - & 1 & 0 & 0 & 0 & 1 & 0 & 1 & 2 & 1 & 0 & 0 & 0 & 0 & 1 \\
\hline Zaretis isidora & 1 & 1 & 0 & 0 & - & 1 & 1 & $?$ & $?$ & - & 1 & 0 & 1 & 1 & 1 & 0 & 1 & $?$ & 1 & 0 & 0 & 0 & 0 & 1 \\
\hline Anaea troglodyta & 1 & $?$ & $?$ & 0 & - & 1 & 1 & 0 & 1 & - & 1 & 0 & 3 & 1 & 1 & $?$ & 1 & 3 & 1 & 0 & 0 & 0 & 0 & 1 \\
\hline Fountainea nessus & 1 & 0 & 0 & 0 & - & 1 & 1 & 0 & 1 & - & 1 & 0 & 0 & 1 & 1 & 0 & 1 & 3 & 1 & 0 & 0 & 0 & 0 & 1 \\
\hline Fountainea ryphea & 1 & 1 & 0 & 0 & - & 1 & 1 & 0 & 1 & - & 1 & 0 & 0 & 1 & 1 & 0 & 1 & 3 & 1 & 0 & 0 & 0 & 0 & 1 \\
\hline Memphis appias & 1 & 1 & 0 & 0 & - & 1 & 1 & 0 & 1 & - & 1 & 0 & 1 & 1 & 1 & 0 & 1 & 3 & 1 & 0 & 0 & 0 & 0 & 1 \\
\hline Memphis glauce & 1 & 1 & 0 & 0 & - & 1 & 1 & 0 & 1 & - & 1 & 0 & 3 & 1 & 1 & 0 & 1 & 3 & 1 & 0 & 0 & 0 & 0 & 1 \\
\hline Memphis grandis & 1 & 1 & 0 & 0 & - & 1 & 1 & 0 & 1 & - & 1 & 0 & 2 & 1 & 1 & 0 & 1 & 3 & 1 & 0 & 0 & 0 & 0 & 1 \\
\hline Memphis hirta & 1 & 0 & 0 & 0 & - & 1 & 1 & 0 & 1 & - & 1 & 0 & 2 & 0 & 1 & 0 & 1 & 3 & 1 & 0 & 0 & 0 & 0 & 1 \\
\hline Memphis leonida & 1 & 1 & 0 & 0 & - & 1 & 1 & 0 & 1 & - & 1 & 0 & 2 & 1 & 1 & 2 & 1 & 3 & 1 & 0 & 0 & 0 & 0 & 1 \\
\hline Memphis moruus & 1 & 1 & 0 & 0 & - & 1 & 1 & 0 & 1 & - & 1 & 0 & 1 & 1 & 1 & 0 & 1 & 3 & 1 & 0 & 0 & 0 & 0 & 1 \\
\hline Memphis philumena & 1 & 1 & 0 & 0 & - & 1 & 1 & 0 & 1 & - & 1 & 0 & 0 & 1 & 1 & 0 & 1 & 3 & 1 & 0 & 0 & 0 & 0 & 1 \\
\hline Memphis pithyusa & 1 & 1 & 0 & 0 & - & 1 & 1 & 0 & 1 & - & 1 & 0 & 0 & 1 & 1 & 0 & 1 & 3 & 1 & 0 & 0 & 0 & 0 & 1 \\
\hline Memphis polycames & 0 & 1 & 0 & 0 & - & 1 & 1 & 0 & 1 & - & 1 & 0 & 2 & 1 & 1 & 0 & 1 & 3 & 1 & 0 & 0 & 0 & 0 & 1 \\
\hline Memphis polyxo & 1 & 1 & 0 & 0 & - & 1 & 1 & 0 & 1 & - & 1 & 0 & 0 & 0 & 1 & 0 & 1 & 3 & 1 & 0 & 0 & 0 & 0 & 1 \\
\hline Memphis verticordia & 1 & 0 & 1 & 0 & - & 1 & 1 & 0 & 1 & - & 1 & 0 & 1 & 1 & 1 & 0 & 1 & 3 & 1 & 0 & 0 & 0 & 0 & 1 \\
\hline Anaeomorpha splendida & 1 & $?$ & $?$ & $?$ & - & $?$ & $?$ & $?$ & $?$ & $?$ & $?$ & $?$ & $?$ & $?$ & $?$ & $?$ & $?$ & $?$ & 1 & 0 & 0 & $?$ & 0 & $?$ \\
\hline Noreppa chromus & 1 & 0 & $?$ & 0 & - & 1 & 1 & 0 & 1 & 1 & 1 & 1 & - & 0 & 0 & 0 & 1 & $?$ & 1 & 0 & 0 & 2 & 0 & 1 \\
\hline Archaeoprepona amphimacus & 1 & 1 & 1 & 0 & - & 1 & 1 & 1 & 0 & 2 & 1 & 1 & - & 0 & 0 & 1 & 1 & 4 & 1 & 0 & 0 & 2 & 0 & 1 \\
\hline Archaeoprepona chalciope & 1 & 0 & 0 & 0 & - & 1 & 1 & 1 & 0 & 2 & 1 & 1 & - & 0 & 0 & 0 & 1 & 0 & 1 & 0 & 0 & 2 & 0 & 1 \\
\hline Archaeoprepona demophon & 1 & 0 & 0 & 0 & - & 1 & 1 & 1 & 0 & 2 & 1 & 1 & - & 0 & 0 & 1 & 1 & 4 & 1 & 0 & 0 & 2 & 0 & 1 \\
\hline Archaeoprepona demophoon & 1 & 1 & 1 & 0 & - & 1 & 1 & 1 & 0 & 2 & 1 & 1 & - & 0 & 0 & 1 & 1 & 4 & 1 & 0 & 0 & 2 & 0 & 1 \\
\hline Archaeoprepona licomedes & 1 & 1 & 1 & 0 & - & 1 & 1 & 1 & 0 & 2 & 1 & - & - & 0 & 0 & 1 & 1 & 4 & 1 & 0 & 0 & 2 & 0 & 1 \\
\hline Prepona praeneste & 1 & $?$ & $?$ & $?$ & - & $?$ & $?$ & $?$ & $?$ & $?$ & $?$ & - & - & $?$ & $?$ & $?$ & $?$ & $?$ & 1 & 0 & 0 & 3 & 0 & 1 \\
\hline Prepona laertes & 1 & 1 & 2 & 0 & - & 1 & 1 & 1 & 0 & 0 & 0 & - & - & 0 & 0 & 1 & 1 & 0 & 1 & 0 & 0 & 3 & 0 & 1 \\
\hline Prepona pheridamas & 1 & 0 & $?$ & 0 & - & 1 & 1 & 1 & 0 & $?$ & 0 & - & - & 1 & 0 & 1 & 1 & 0 & 1 & 0 & 0 & 3 & 0 & 1 \\
\hline Prepona pylene & 1 & 1 & 2 & 0 & - & 1 & 1 & 1 & 0 & 0 & 0 & - & - & 0 & 0 & 1 & 1 & 0 & 1 & 0 & 0 & 3 & 0 & 1 \\
\hline Agrias amydon & 1 & 1 & 2 & 0 & - & 1 & 1 & 1 & 0 & 0 & 0 & - & - & 0 & 0 & 1 & 1 & 0 & 1 & 0 & 0 & 3 & 0 & 1 \\
\hline Agrias claudina & 1 & 1 & 2 & 0 & - & 1 & 1 & 1 & 0 & 0 & 0 & - & - & 0 & 0 & 1 & 1 & 0 & 1 & 0 & 0 & 3 & 0 & 1 \\
\hline Euxanthe eurinome & 1 & 1 & 1 & 0 & 0 & 0 & 0 & - & - & - & 0 & - & - & 0 & 0 & 1 & 0 & 2 & 1 & 0 & 1 & 1 & 1 & 0 \\
\hline Euxanthe trajanus & 1 & 1 & 1 & 1 & 0 & 0 & 0 & - & - & - & 0 & - & - & 0 & 0 & 1 & 0 & 2 & 1 & 0 & 1 & 1 & 1 & 0 \\
\hline Palla decius & 1 & 1 & 0 & 0 & $?$ & 1 & 0 & - & - & - & 1 & 1 & - & 0 & 0 & 0 & 1 & 0 & 1 & 0 & $?$ & 1 & 1 & 1 \\
\hline Polyura athamas & 2 & 1 & 1 & 1 & 0 & 0 & 0 & - & - & - & 1 & 1 & - & 0 & 0 & 2 & 0 & 2 & 1 & 0 & 0 & 1 & 1 & 0 \\
\hline Polyura delphis & 2 & 1 & 1 & 1 & 0 & 1 & 0 & - & - & - & 1 & 1 & - & 0 & 0 & 2 & 0 & 2 & 1 & 0 & 1 & 1 & 1 & 0 \\
\hline Polyura gamma & 2 & $?$ & $?$ & $?$ & $?$ & $?$ & $?$ & - & - & - & $?$ & $?$ & - & $?$ & 0 & $?$ & $?$ & 2 & 1 & 0 & 1 & 1 & 1 & 0 \\
\hline Polyura pymhus & 2 & 1 & 1 & 1 & 0 & 1 & 0 & - & - & - & 1 & 1 & - & 0 & 0 & 2 & 0 & 2 & 1 & 0 & 1 & 1 & 1 & 0 \\
\hline Polyura jalysus & 2 & $?$ & $?$ & $?$ & $?$ & $?$ & $?$ & - & - & - & $?$ & $?$ & - & $?$ & 0 & $?$ & $?$ & 2 & 1 & 0 & 1 & 1 & 1 & 0 \\
\hline Polyura schreiber & 2 & 1 & 1 & 1 & 2 & 1 & 0 & - & - & - & 1 & 1 & - & 0 & 0 & 2 & 0 & 2 & 1 & 0 & 1 & 1 & 1 & 0 \\
\hline Charaxes varanes & 2 & 1 & 1 & 1 & 0 & 0 & 0 & - & - & - & 1 & 1 & - & 0 & 0 & 2 & 0 & 3 & 1 & 0 & 1 & 1 & 1 & 0 \\
\hline Charaxes candiope & 2 & 1 & 1 & 1 & 0 & 0 & 0 & - & - & - & 1 & 1 & - & 0 & 0 & 2 & 0 & 3 & 1 & 0 & 1 & 1 & 1 & 0 \\
\hline Charaxes cynthia & 2 & 1 & 1 & 1 & 1 & 1 & 0 & - & - & - & 0 & - & - & 0 & 0 & 1 & 0 & - & 1 & 0 & 1 & 1 & 1 & 0 \\
\hline Charaxes /ucretius & 2 & 1 & 1 & 1 & 2 & 1 & 0 & - & - & - & 1 & 1 & - & 0 & 0 & 2 & 0 & 3 & 1 & 0 & 1 & 1 & 1 & 0 \\
\hline Charaxes jasius & 2 & $?$ & $?$ & 1 & 1 & 0 & 0 & - & - & - & 0 & - & - & 0 & 0 & 1 & 0 & 2 & 1 & 0 & 1 & 1 & 1 & 0 \\
\hline Charaxes tiridates & 2 & 1 & 1 & 1 & 1 & 1 & 0 & - & - & - & 1 & 1 & - & 0 & 0 & 1 & 0 & 3 & 1 & 0 & 1 & 1 & 1 & 0 \\
\hline Charaxes hadrianus & 2 & 1 & 1 & 1 & 0 & 0 & 0 & - & - & - & 1 & 1 & - & 0 & 0 & 1 & 0 & - & 1 & 0 & 1 & 1 & 1 & 0 \\
\hline Charaxes nobilis & 2 & 1 & 1 & 1 & 0 & 1 & 0 & - & - & - & 1 & 1 & - & 0 & 0 & 1 & 0 & - & 1 & 0 & 1 & 1 & 1 & 0 \\
\hline Charaxes zoolina & 2 & 1 & 1 & 1 & 2 & 1 & 0 & - & - & - & 1 & 1 & - & 1 & 0 & 2 & 0 & 3 & 1 & 0 & 1 & 1 & 1 & 0 \\
\hline Charaxes eupale & 2 & 1 & 1 & 1 & 0 & 0 & 0 & - & - & - & 0 & - & - & 0 & 0 & 1 & 0 & 0 & 1 & 0 & 1 & 1 & 1 & 0 \\
\hline Charaxes jahlusa & 2 & 1 & 1 & 1 & 1 & 1 & 0 & - & - & - & 1 & 1 & - & 0 & 0 & 2 & 0 & 0 & 1 & 0 & 1 & 1 & 1 & 0 \\
\hline Charaxes pleione & 2 & 1 & 1 & 1 & 0 & 0 & 0 & - & - & - & 0 & - & - & 0 & 0 & 1 & 0 & 1 & 1 & 0 & 1 & 1 & 1 & 0 \\
\hline Charaxes zingha & 2 & 1 & 1 & 1 & 0 & 1 & 0 & - & - & - & 1 & 1 & - & 0 & 0 & 1 & 0 & 1 & 1 & 0 & 1 & 1 & 1 & 0 \\
\hline Charaxes etesipe & 2 & 1 & 1 & 1 & 1 & 0 & 0 & - & - & - & 1 & 1 & - & 0 & 0 & 1 & 0 & 0 & 1 & 0 & 1 & 1 & 1 & 0 \\
\hline Charaxes etheocles & 2 & 1 & 1 & 1 & 1 & 1 & 0 & - & - & - & 1 & 1 & - & 0 & 0 & 1 & 0 & 2 & 1 & 0 & 1 & 1 & 1 & 0 \\
\hline Charaxes nichetes & 2 & 1 & 1 & 1 & 0 & 0 & 0 & - & - & - & 1 & 1 & - & 0 & 0 & 1 & 0 & 0 & 1 & 0 & 1 & 1 & 1 & 0 \\
\hline Charaxes laodice & 2 & 1 & 1 & 1 & 2 & 0 & 0 & - & - & - & 1 & 1 & - & 0 & 0 & 1 & 0 & - & 1 & 0 & 1 & - & 1 & 0 \\
\hline Charaxes solon & 2 & 1 & 1 & 1 & 0 & 1 & 0 & - & - & - & 1 & 1 & - & 0 & 0 & 1 & 0 & 2 & 1 & 0 & 1 & 1 & 1 & 0 \\
\hline Charaxes latona & 2 & 1 & 1 & 1 & 2 & 1 & 0 & - & - & - & 1 & 1 & - & 0 & 0 & 1 & 0 & 2 & 1 & 0 & 1 & 1 & 1 & 0 \\
\hline Charaxes eurialus & 2 & 1 & 1 & 1 & 2 & 1 & 0 & - & - & - & 1 & 1 & - & 0 & 0 & 1 & 0 & $?$ & 1 & 0 & $?$ & 1 & 1 & 0 \\
\hline Agatasa calydonia & 0 & 0 & 0 & 0 & - & 1 & 0 & - & - & - & 0 & - & - & 0 & 0 & 0 & 0 & 3 & 1 & 0 & 0 & 1 & $?$ & 1 \\
\hline Prothoe australis & 1 & $?$ & $?$ & $?$ & $?$ & $?$ & $?$ & $?$ & $?$ & $?$ & $?$ & $?$ & - & $?$ & $?$ & $?$ & $?$ & 0 & 1 & 0 & 0 & 0 & ? & 1 \\
\hline Protho franck & & & & & & & & & & & & & & & & & & & & & & & & \\
\hline
\end{tabular}




\begin{tabular}{|c|c|c|c|c|c|c|c|c|c|c|c|c|c|c|c|c|c|c|c|c|c|c|c|c|}
\hline Táxon & & & & $\begin{array}{l}1 \\
0 \\
0\end{array}$ & & & & & $\begin{array}{l}1 \\
0 \\
5\end{array}$ & & & & & $\begin{array}{l}1 \\
1 \\
0\end{array}$ & & & & & $\begin{array}{l}1 \\
1 \\
5\end{array}$ & & & & & $\begin{array}{l}1 \\
2 \\
0\end{array}$ \\
\hline Apatura ins & 1 & 0 & - & 0 & - & 0 & - & 0 & 1 & 0 & 0 & 0 & 0 & 0 & ? & 0 & - & 1 & - & 0 & 3 & - & 0 & 0 \\
\hline Calinaga buddha & 1 & 0 & - & 0 & - & 0 & - & 0 & 1 & 0 & 0 & 0 & 0 & 1 & 0 & 0 & - & 0 & - & 0 & $0 / 1$ & 1 & 0 & 0 \\
\hline Antimhea archaea & 0 & - & - & - & - & - & - & 0 & 0 & 0 & $?$ & 0 & - & 0 & 0 & 0 & - & 0 & - & 0 & 0 & 0 & 0 & 0 \\
\hline Coenophlebia archidona & $?$ & $?$ & $?$ & $?$ & $?$ & $?$ & $?$ & $?$ & $?$ & $?$ & $?$ & $?$ & $?$ & $?$ & $?$ & $?$ & $?$ & $?$ & - & $?$ & $?$ & - & $?$ & $?$ \\
\hline Consul electra & 1 & 0 & - & - & - & 0 & - & 0 & 0 & 2 & 1 & 0 & 1 & 0 & 0 & 0 & - & 0 & - & 0 & 2 & - & 0 & 0 \\
\hline Consul fabius & 1 & 0 & - & - & - & 0 & - & 0 & 0 & 2 & 1 & 0 & 1 & 0 & 0 & 0 & - & 0 & - & $?$ & 2 & - & 0 & 0 \\
\hline Hypna clytemnestra & 1 & 0 & - & - & - & 0 & - & 0 & 0 & 2 & 0 & 0 & 1 & 0 & 0 & 0 & - & 0 & - & 2 & $0 / 1$ & 1 & 0 & 0 \\
\hline Polygrapha cyanea & $?$ & $?$ & $?$ & - & $?$ & $?$ & - & $?$ & $?$ & $?$ & $?$ & $?$ & $?$ & $?$ & $?$ & $?$ & $?$ & $?$ & - & $?$ & $?$ & - & $?$ & $?$ \\
\hline Polygrapha suprema & 1 & 0 & - & - & - & $?$ & - & $?$ & $?$ & $?$ & $?$ & 0 & $?$ & $?$ & 0 & 0 & - & 0 & - & 0 & 0 & - & 0 & 0 \\
\hline Polygrapha tyrianthina & $?$ & ? & $?$ & - & $?$ & ? & - & $?$ & $?$ & $?$ & $?$ & $?$ & $?$ & ? & $?$ & $?$ & $?$ & 0 & - & $?$ & $?$ & - & ? & $?$ \\
\hline Polygrapha xenocrates & $?$ & $?$ & $?$ & - & $?$ & $?$ & - & $?$ & $?$ & $?$ & $?$ & $?$ & $?$ & $?$ & $?$ & $?$ & $?$ & $?$ & - & $?$ & $?$ & - & $?$ & 0 \\
\hline Siderone galanthis & 1 & 0 & - & - & - & 0 & - & 0 & 1 & 0 & 0 & 0 & 0 & 0 & 1 & 0 & - & 0 & - & 1 & 1 & - & 0 & 2 \\
\hline Zaretis callydrias & 1 & 0 & - & - & - & 0 & - & 0 & 1 & 0 & 0 & 0 & 0 & 0 & 1 & 0 & - & 0 & - & 1 & 1 & - & 0 & 2 \\
\hline Zaretis isidora & 1 & 0 & - & - & - & 0 & - & 0 & 1 & 0 & 0 & 0 & 0 & 0 & 1 & 0 & - & 0 & - & 1 & 1 & - & 0 & 2 \\
\hline Anaea troglodyta & 1 & 0 & - & - & - & 0 & - & 0 & 0 & 2 & 0 & 0 & 1 & 0 & 0 & 0 & - & 0 & - & 0 & 2 & - & 0 & 0 \\
\hline Fountainea nessus & 1 & 0 & - & - & - & 0 & - & 0 & 0 & 2 & $?$ & 0 & 1 & $?$ & 0 & 0 & - & 0 & - & 0 & 2 & - & 0 & 0 \\
\hline Fountainea ryphea & 1 & 0 & - & - & - & 0 & - & 0 & 0 & 2 & 1 & 0 & 1 & 0 & 0 & 0 & - & 0 & - & 0 & 2 & - & 0 & 0 \\
\hline Memphis appias & 1 & 0 & - & - & - & 0 & - & 0 & 0 & 2 & 1 & 1 & 1 & 0 & 0 & 0 & - & 0 & - & 0 & 2 & - & 0 & 0 \\
\hline Memphis glauce & 1 & 0 & - & - & - & 0 & - & 0 & 0 & 2 & 1 & 1 & 1 & 0 & 0 & 0 & - & 0 & - & 0 & 2 & - & 0 & 0 \\
\hline Memphis grandis & 1 & 0 & - & - & - & 0 & - & 0 & $?$ & $?$ & $?$ & $?$ & $?$ & 0 & $?$ & 0 & - & 0 & - & $?$ & 2 & - & 0 & 0 \\
\hline Memphis hirta & 1 & 0 & - & - & - & 0 & - & 0 & 0 & 1 & 1 & ? & 1 & 0 & 0 & 0 & - & 0 & - & 0 & 2 & - & 0 & 0 \\
\hline Memphis leonida & 1 & 0 & - & - & - & 0 & - & 0 & 0 & 1 & 1 & 1 & 1 & 0 & 0 & 0 & - & 0 & - & 0 & 2 & - & 0 & 0 \\
\hline Memphis monus & 1 & 0 & - & - & - & 0 & - & 0 & 0 & 1 & 1 & 1 & 1 & 0 & 0 & 0 & - & 0 & - & 0 & 2 & - & 0 & 0 \\
\hline Memphis philumena & 1 & 0 & - & - & - & 0 & - & 0 & 0 & 1 & 1 & 1 & 1 & 0 & 0 & 0 & - & 0 & - & 0 & 2 & - & 0 & 0 \\
\hline Memphis pithyusa & 1 & 0 & - & - & - & 0 & - & 0 & 0 & 1 & 1 & 0 & 1 & 0 & 0 & 0 & - & 0 & - & 0 & 2 & - & 0 & 0 \\
\hline Memphis polycames & 1 & 0 & - & - & - & 0 & - & 0 & $?$ & $?$ & $?$ & $?$ & 1 & 0 & $?$ & 0 & - & 0 & - & $?$ & 2 & - & 0 & 0 \\
\hline Memphis polyxo & 1 & 0 & - & - & - & 0 & - & 0 & $?$ & $?$ & $?$ & $?$ & $?$ & 0 & $?$ & 0 & - & 0 & - & $?$ & 2 & - & 0 & 0 \\
\hline Memphis verticordia & 1 & 0 & - & - & - & 0 & - & 0 & 0 & 1 & 1 & 0 & 1 & 0 & 0 & 0 & - & 0 & - & 0 & 2 & - & 0 & 0 \\
\hline A naeomorpha splendida & $?$ & $?$ & $?$ & - & - & $?$ & $?$ & $?$ & ? & ? & ? & ? & ? & ? & ? & ? & ? & ? & - & ? & ? & ? & ? & ? \\
\hline Noreppa chromus & 2 & 0 & - & 3 & - & 0 & - & 1 & 1 & 0 & 0 & 0 & 0 & 0 & 1 & 0 & - & 0 & - & ? & 0 & 0 & 1 & 1 \\
\hline Archaeoprepona amphimacus & 2 & 0 & 0 & 3 & 1 & 0 & 0 & 2 & 1 & 0 & 0 & 0 & 0 & 0 & 1 & 0 & - & 0 & - & 1 & 0 & 0 & 1 & 1 \\
\hline Archaeoprepona chalciope & 1 & 0 & - & 3 & - & 0 & - & 2 & 1 & 0 & 0 & 0 & 0 & 0 & 1 & 0 & - & 0 & - & 1 & 0 & 0 & 1 & 1 \\
\hline Archaeoprepona demophon & 2 & 0 & 0 & 3 & 1 & 0 & 0 & 2 & 1 & 0 & 0 & 0 & 0 & 0 & 1 & 0 & - & 0 & - & 1 & 0 & 0 & 1 & 1 \\
\hline Archaeoprepona demophoon & 2 & 0 & 0 & 3 & 1 & 0 & 0 & 2 & 1 & 0 & 0 & 0 & 0 & 0 & 1 & 0 & - & 0 & - & 1 & 0 & 0 & 1 & 1 \\
\hline Archaeoprepona licomedes & 1 & 0 & - & 3 & - & 0 & 0 & 2 & 1 & 0 & 0 & 0 & 0 & 0 & 1 & 0 & - & 0 & - & $?$ & 0 & 0 & 1 & 1 \\
\hline Prepona praeneste & 1 & $?$ & - & 0 & - & 0 & - & $?$ & 1 & 0 & 0 & 0 & 0 & 0 & 1 & 0 & - & 0 & - & $?$ & 0 & 0 & 0 & 1 \\
\hline Prepona laertes & 1 & 1 & - & 0 & - & 0 & - & 2 & 1 & 0 & 0 & 0 & 0 & 0 & 1 & 0 & - & 0 & - & 0 & 0 & 0 & 0 & 1 \\
\hline Prepona pheridamas & 1 & 1 & - & - & - & 0 & - & 2 & 1 & 0 & 0 & 0 & 0 & 0 & 1 & 0 & - & 0 & - & $?$ & 0 & 0 & 0 & 1 \\
\hline Prepona pylene & 1 & 1 & - & 0 & - & 0 & - & 2 & 1 & 0 & 0 & 0 & 0 & 0 & 1 & 0 & - & 0 & - & 0 & 0 & 0 & 0 & 1 \\
\hline Agrias amydon & 1 & 1 & - & 0 & - & 0 & - & 2 & 1 & 0 & 0 & 0 & 0 & 0 & 1 & 0 & - & 0 & - & 0 & 0 & 0 & 0 & 1 \\
\hline Agrias claudina & 1 & 1 & - & 0 & - & 0 & - & 2 & 1 & 0 & 0 & 0 & 0 & 0 & 1 & 0 & - & 0 & - & 0 & 0 & 0 & 0 & 1 \\
\hline Euxanthe eurinome & 2 & 0 & 2 & 0 & 0 & 1 & 1 & 1 & 1 & 0 & 0 & 0 & 1 & 0 & 0 & 1 & 3 & 0 & - & 0 & 0 & 1 & 0 & 0 \\
\hline Euxanthe trajanus & 2 & 0 & 2 & 0 & 0 & 1 & 1 & 1 & 1 & 0 & 0 & 0 & 1 & 1 & 0 & 1 & 3 & 0 & - & 0 & 0 & 1 & 0 & 0 \\
\hline Palla decius & 1 & 0 & - & $?$ & - & $?$ & - & 0 & $?$ & 0 & 0 & 0 & 0 & 1 & 0 & 1 & $?$ & 0 & - & 0 & 0 & 1 & 0 & 1 \\
\hline Polyura athamas & 2 & 0 & 0 & 1 & 0 & 1 & 0 & 1 & 1 & 0 & 0 & 0 & 0 & 1 & 0 & 0 & - & 0 & - & 0 & 1 & - & 0 & 0 \\
\hline Polyura delphis & 2 & 0 & 1 & 1 & 0 & 1 & 1 & 1 & 1 & 0 & 0 & 0 & 0 & 1 & 0 & 1 & 2 & 0 & - & 0 & 0 & 1 & 0 & 0 \\
\hline Polyura gamma & 2 & 0 & 1 & 1 & 0 & 1 & $?$ & 1 & 1 & 0 & 0 & 0 & 0 & $?$ & 0 & $?$ & $?$ & 0 & - & 0 & $?$ & $?$ & 0 & 0 \\
\hline Polyura pymus & 2 & 0 & 0 & 1 & 0 & 1 & 1 & 1 & 1 & 0 & 0 & 0 & 0 & 1 & 0 & 1 & 1 & 1 & 0 & 0 & $0 / 1$ & 1 & 0 & 0 \\
\hline Polyura jalysus & 2 & 0 & 1 & 1 & 0 & 1 & $?$ & 1 & 1 & 0 & 0 & 0 & 0 & $?$ & 0 & $?$ & $?$ & $?$ & $?$ & 0 & $?$ & $?$ & 0 & 0 \\
\hline Polyura schreiber & 2 & 0 & 1 & 1 & 0 & 1 & 1 & 1 & 1 & 0 & 0 & 0 & 0 & 0 & 0 & 1 & - & 0 & - & 0 & 1 & - & 0 & 0 \\
\hline Charaxes varanes & 2 & 0 & 0 & 1 & 0 & 1 & 1 & 2 & 1 & 0 & 0 & 0 & 0 & 0 & 0 & 1 & 2 & 0 & - & 0 & 0 & 1 & 0 & 0 \\
\hline Charaxes candiope & 2 & 0 & 1 & 0 & 0 & 1 & 1 & 2 & 1 & 0 & 0 & 0 & 0 & 0 & 0 & 1 & 0 & 0 & - & 0 & 0 & 1 & 0 & 0 \\
\hline Charaxes cynthia & 2 & 0 & 1 & 2 & 0 & 1 & 0 & 2 & 1 & 0 & 0 & 0 & 0 & 1 & 0 & 1 & $0 / 2$ & 0 & - & 0 & 0 & 1 & 0 & 0 \\
\hline Charaxes lucretius & 2 & 0 & 1 & $?$ & 0 & 1 & 1 & 0 & 1 & 0 & 0 & 0 & 0 & 0 & 0 & $0 / 1$ & $0 / 1$ & 1 & 0 & 0 & 0 & 1 & 0 & 0 \\
\hline Charaxes jasius & 2 & 0 & 1 & 2 & 0 & 1 & 1 & 0,5 & 1 & 0 & 0 & 0 & 0 & $0 / 1$ & 0 & 1 & $0 / 1$ & 1 & 0 & 0 & 0 & 1 & 0 & 0 \\
\hline Charaxes tiridates & 2 & 0 & 1 & 2 & 0 & 1 & 1 & $0 / 1 / 2$ & 1 & 0 & 0 & 0 & 0 & 0 & 0 & 1 & $0 / 1$ & 1 & 0 & 0 & 0 & 1 & 0 & 0 \\
\hline Charaxes hadrianus & 2 & 0 & 1 & 2 & 0 & 1 & 1 & 2 & 1 & 0 & 0 & 0 & 0 & 1 & 0 & 1 & 2 & 0 & - & 0 & 0 & 1 & 0 & 0 \\
\hline Charaxes nobilis & 2 & 0 & $?$ & $?$ & 0 & 1 & $?$ & $?$ & 1 & 0 & 0 & 0 & 0 & $?$ & 0 & $?$ & $?$ & 0 & - & 0 & $?$ & $?$ & 0 & 0 \\
\hline Charaxes zoolina & 2 & 0 & 0 & 2 & 0 & 0 & ? & 1 & 1 & 0 & 2 & 0 & 0 & 0 & 0 & 0 & - & 1 & 1 & 0 & ? & 1 & 0 & 0 \\
\hline Charaxes eupale & 2 & 0 & 0 & 0 & 0 & 0 & 0 & 1 & 1 & 0 & 0 & 0 & 0 & 0 & 0 & 1 & 1 & 1 & 0 & 0 & 1 & - & 0 & 0 \\
\hline Charaxes jahlusa & 2 & 0 & 0 & 2 & 0 & 1 & 0 & 2 & 1 & 0 & 0 & 0 & 0 & 0 & 0 & 1 & 1 & 1 & 0 & 0 & $0 / 1$ & 1 & 0 & 0 \\
\hline Charaxes pleione & 2 & 0 & 0 & 2 & 0 & 1 & ? & 1 & 1 & 0 & 2 & 0 & 0 & 1 & 0 & 0 & ? & 1 & 1 & 0 & 0 & 1 & 0 & 0 \\
\hline Charaxes zingha & 2 & 0 & 0 & 3 & 0 & 1 & 1 & 1 & 1 & 0 & 0 & 0 & 0 & 1 & 0 & 1 & 0 & 0 & - & 0 & 0 & 1 & 0 & 0 \\
\hline Charaxes etesipe & 2 & 0 & $0 / 1$ & 2 & 0 & 1 & 0 & 1 & 1 & 0 & 0 & 0 & 0 & $0 / 1$ & 0 & 1 & $0 / 2$ & 0 & - & 0 & 0 & 1 & 0 & 0 \\
\hline Charaxes etheocles & 2 & 0 & 1 & $0 / 2$ & 0 & 1 & 0/1 & 2 & 1 & 0 & 0 & 0 & 0 & 0 & 0 & 1 & $0 / 1$ & 1 & 0 & 0 & $0 / 1$ & 1 & 0 & 0 \\
\hline Charaxes nichetes & 2 & 0 & 1 & 2 & 0 & 1 & 1 & 0 & 1 & 0 & 0 & 0 & 0 & 0 & 0 & 1 & 2 & 0 & - & 0 & 0 & 1 & 0 & 0 \\
\hline Charaxes laodice & 2 & 0 & $?$ & $?$ & 0 & 1 & $?$ & $?$ & 1 & 0 & 0 & 0 & 0 & $?$ & 0 & $?$ & $?$ & $?$ & $?$ & 0 & 0 & 1 & 0 & 0 \\
\hline Charaxes solon & 2 & 0 & 1 & $0 / 1$ & 0 & 1 & 1 & 2 & 1 & 0 & 0 & 0 & 0 & 1 & 0 & 1 & 1 & 1 & 0 & 0 & $0 / 1$ & 1 & 0 & 0 \\
\hline Charaxes latona & 2 & 0 & 1 & 1 & 0 & 1 & 1 & 2 & 1 & 0 & 0 & 0 & 0 & 0 & 0 & 1 & 1 & 1 & 0 & 0 & 0 & 1 & 0 & 0 \\
\hline Charaxes eurialus & 2 & 0 & $?$ & $?$ & 0 & 1 & 1 & $?$ & 1 & 0 & $?$ & 0 & 0 & $?$ & 0 & $?$ & $?$ & ? & $?$ & 0 & 0 & 1 & 0 & 0 \\
\hline A gatasa calydonia & 1 & 0 & - & - & - & ? & - & 0 & 1 & 0 & 0 & 0 & 0 & 0 & 0 & 0 & - & - & - & 0 & 0 & 1 & 0 & 3 \\
\hline Prothoe australis & 1 & 0 & - & - & - & $?$ & - & 0 & 1 & 0 & 0 & 0 & 0 & 0 & 0 & 0 & - & - & - & 0 & 1 & 1 & 0 & 3 \\
\hline Prothoe franck & 1 & 0 & - & - & - & ? & - & 0 & 1 & 0 & 0 & 0 & 0 & 0 & 0 & 0 & - & - & - & 2 & 1 & 1 & 0 & 3 \\
\hline
\end{tabular}




\begin{tabular}{|c|c|c|c|c|c|c|c|c|c|c|c|c|c|c|c|c|c|c|c|c|c|c|c|}
\hline Táxon & & & & & $\begin{array}{l}1 \\
2 \\
5\end{array}$ & & & & & $\begin{array}{l}1 \\
3 \\
0\end{array}$ & & & & & $\begin{array}{l}1 \\
3 \\
5\end{array}$ & & & & & $\begin{array}{l}1 \\
4 \\
0\end{array}$ & & & \\
\hline Apatura ins & 0 & 2 & 0 & - & 0 & 0 & 0 & 0 & 15 & 0 & 1 & $?$ & 1 & 0 & 1 & 1 & 0 & 1 & 2 & 0 & 1 & 0 & 0 \\
\hline Calinaga buddha & 0 & 2 & 0 & - & 1 & 0 & 0 & 0 & 14 & $0 / 1$ & 2 & 1 & 1 & 0 & 0 & 0 & 0 & 0 & 0 & 0 & 0 & 0 & 0 \\
\hline Antimhea archaea & 0 & 0 & 0 & - & 0 & 0 & 0 & 0 & 18 & 1 & 0 & 0 & $?$ & $?$ & $?$ & 0 & 0 & 0 & 0 & 0 & 0 & 0 & 0 \\
\hline Coenophlebia archidona & $?$ & $?$ & $?$ & $?$ & $?$ & $?$ & $?$ & $?$ & $?$ & $?$ & $?$ & $?$ & $?$ & $?$ & $?$ & $?$ & $?$ & $?$ & $?$ & $?$ & $?$ & $?$ & $?$ \\
\hline Consul electra & 0 & 2 & 1 & 0 & 1 & 1 & 0 & 0 & 1 & $0 / 1$ & 2 & 1 & 1 & 1 & 2 & 1 & 0 & 2 & 0 & 0 & 1 & 1 & 0 \\
\hline Consul fabius & 0 & 2 & 1 & 0 & 1 & 1 & 0 & 0 & 1 & $0 / 1$ & 2 & 1 & 1 & 1 & 2 & 1 & 0 & 2 & 0 & 0 & 1 & 1 & 0 \\
\hline Hypna clytemnestra & 0 & 1 & 1 & 0 & 1 & $?$ & 1 & 0 & 0 & 3 & 0 & 1 & 0 & 1 & 1 & 1 & 0 & 2 & 0 & 0 & 1 & 1 & 0 \\
\hline Polygrapha cyanea & $?$ & $?$ & $?$ & $?$ & $?$ & $?$ & $?$ & $?$ & $?$ & $?$ & $?$ & $?$ & $?$ & $?$ & $?$ & $?$ & $?$ & $?$ & $?$ & $?$ & $?$ & $?$ & $?$ \\
\hline Polygrapha suprema & 0 & 2 & $?$ & 0 & 1 & 1 & 0 & 0 & 0 & 0 & $?$ & $?$ & $?$ & $?$ & 2 & 0 & 0 & 2 & 2 & 0 & 1 & 1 & 0 \\
\hline Polygrapha tyrianthina & $?$ & $?$ & $?$ & $?$ & 1 & $?$ & $?$ & $?$ & $?$ & $?$ & $?$ & $?$ & $?$ & $?$ & $?$ & $?$ & $?$ & $?$ & $?$ & $?$ & $?$ & $?$ & ? \\
\hline Polygrapha xenocrates & 0 & $?$ & $?$ & $?$ & 1 & $?$ & $?$ & $?$ & $?$ & $?$ & $?$ & $?$ & $?$ & $?$ & $?$ & $?$ & $?$ & $?$ & $?$ & $?$ & $?$ & $?$ & $?$ \\
\hline Siderone galanthis & 1 & 1 & 1 & 1 & 1 & 0 & 1 & 0 & 2 & 0 & 0 & 1 & 1 & 1 & 2 & 0 & 0 & 3 & 1 & 0 & 1 & 1 & 0 \\
\hline Zaretis callydrias & 1 & 1 & 1 & 1 & 1 & 0 & 1 & 0 & 2 & 0 & 0 & 1 & 1 & 1 & 2 & 0 & 0 & 3 & 2 & 0 & 1 & 1 & 0 \\
\hline Zaretis isidora & 1 & 1 & 1 & 1 & 1 & 0 & 1 & 0 & 2 & $0 / 1$ & 0 & 1 & 1 & 1 & 2 & 0 & 0 & 3 & 2 & 0 & 1 & 1 & 0 \\
\hline Anaea troglodyta & 3 & 2 & 1 & 0 & 1 & 1 & 0 & 0 & 0 & $0 / 1$ & 0 & 1 & 1 & 1 & 2 & 0 & 0 & 2 & 2 & 0 & 1 & 1 & 0 \\
\hline Fountainea nessus & 3 & 2 & 1 & 0 & 1 & 1 & 0 & 0 & 0 & 0 & 2 & 1 & 1 & 1 & 2 & 0 & 0 & 2 & 2 & 0 & 1 & 1 & 0 \\
\hline Fountainea ryphea & 3 & 2 & 1 & 0 & 1 & 1 & 0 & 0 & 0 & $0 / 1$ & 2 & 1 & 1 & 1 & 2 & 0 & 0 & 2 & 2 & 0 & 1 & 1 & 0 \\
\hline Memphis appias & 0 & 2 & 1 & 0 & 1 & 1 & 0 & 0 & 0 & 1 & 2 & 1 & 1 & 1 & 2 & 0 & 0 & 2 & 2 & 0 & 0 & 1 & 0 \\
\hline Memphis glauce & 3 & 2 & 1 & 0 & 1 & 1 & 0 & 0 & 0 & $?$ & $?$ & $?$ & $?$ & $?$ & $?$ & 0 & $?$ & $?$ & $?$ & 0 & $?$ & ? & ? \\
\hline Memphis grandis & $?$ & $?$ & $?$ & 0 & 1 & 1 & 0 & 0 & $?$ & $?$ & $?$ & $?$ & $?$ & $?$ & $?$ & 0 & $?$ & $?$ & $?$ & 0 & $?$ & $?$ & $?$ \\
\hline Memphis hirta & 0 & $?$ & 1 & 0 & 1 & 1 & 0 & 0 & 0 & 0 & 2 & 1 & 1 & 1 & 2 & 0 & 0 & 2 & 1 & 0 & 0 & 1 & 0 \\
\hline Memphis leonida & 0 & 3 & 1 & 0 & 1 & 1 & 0 & 0 & 1 & 2 & $?$ & $?$ & $?$ & $?$ & 0 & 0 & 1 & 0 & 0 & 0 & 0 & 0 & 1 \\
\hline Memphis moruus & 0 & 3 & 1 & 0 & 1 & 1 & 0 & 0 & 4 & 2 & 2 & 1 & 1 & 1 & 0 & 0 & 1 & 0 & 0 & 0 & 0 & 0 & 1 \\
\hline Memphis philumena & 0 & 3 & 1 & 0 & 1 & 1 & 0 & 0 & 4 & 2 & 2 & 1 & 1 & 1 & 0 & 0 & 1 & 0 & 0 & 0 & 0 & 0 & 1 \\
\hline Memphis pithyusa & 3 & 2 & 1 & 0 & 1 & 1 & 0 & 0 & 0 & 1 & 2 & 1 & 1 & 1 & 0 & 0 & $?$ & 0 & 0 & 0 & 0 & 0 & 0 \\
\hline Memphis polycames & $?$ & $?$ & $?$ & 0 & 1 & 1 & 0 & 0 & $?$ & $?$ & $?$ & $?$ & $?$ & $?$ & $?$ & 0 & $?$ & $?$ & $?$ & 0 & $?$ & $?$ & $?$ \\
\hline Memphis polyxo & $?$ & $?$ & $?$ & 0 & 1 & 1 & 0 & 0 & 4 & $?$ & $?$ & $?$ & $?$ & $?$ & $?$ & 0 & $?$ & $?$ & $?$ & 0 & $?$ & $?$ & $?$ \\
\hline Memphis verticordia & 3 & 2 & 1 & 0 & 1 & 1 & 0 & 0 & 0 & 1 & 2 & 1 & 1 & 1 & 0 & 0 & $?$ & 2 & 2 & 0 & 0 & 0 & 0 \\
\hline Anaeomorpha splendida & $?$ & $?$ & $?$ & $?$ & 1 & $?$ & $?$ & $?$ & $?$ & $?$ & $?$ & $?$ & $?$ & $?$ & $?$ & $?$ & $?$ & $?$ & $?$ & 0 & $?$ & $?$ & $?$ \\
\hline Noreppa chromus & 2 & 1 & 1 & 1 & 1 & 0 & 1 & 1 & 4 & 3 & 1 & 0 & 0 & 0 & 1 & 1 & 0 & 1 & 0 & 0 & 1 & 0 & 0 \\
\hline Archaeoprepona amphimacus & 2 & 1 & 1 & 1 & 1 & 0 & 1 & 1 & 4 & 3 & 1 & 0 & 0 & 0 & 1 & 1 & 0 & 1 & 0 & 0 & 1 & 0 & 0 \\
\hline Archaeoprepona chalciope & 2 & 1 & 1 & 1 & 1 & 0 & 1 & 1 & 16 & 3 & 1 & 0 & 0 & 0 & $?$ & 1 & 0 & 1 & 0 & 0 & 1 & 0 & 0 \\
\hline Archaeoprepona demophon & 2 & 1 & 1 & 1 & 1 & 0 & 1 & 1 & $8 / 12 / 13$ & 3 & 1 & 0 & 0 & 0 & 1 & 1 & 0 & 1 & 0 & 0 & 1 & 0 & 0 \\
\hline Archaeoprepona demophoon & 2 & 1 & 1 & 1 & 1 & 0 & 1 & 1 & 4 & 3 & 1 & 0 & 0 & 0 & 1 & 1 & 0 & 1 & 0 & 0 & 1 & 0 & 0 \\
\hline Archaeoprepona licomedes & 2 & 1 & 1 & 1 & 1 & 0 & 1 & 1 & $?$ & $?$ & 1 & 0 & 0 & 0 & 1 & 1 & 0 & $?$ & $?$ & 0 & 1 & 0 & 0 \\
\hline Prepona praeneste & $?$ & 1 & 1 & 1 & 1 & 0 & 1 & 1 & $?$ & $?$ & 1 & 0 & 0 & 0 & 1 & 1 & 0 & $?$ & $?$ & 0 & 1 & 0 & 0 \\
\hline Prepona laertes & 2 & 1 & 1 & 1 & 1 & 0 & 1 & 1 & $6 / 7 / 8 / 11$ & 3 & 1 & 0 & 0 & 0 & 1 & 1 & 0 & 1 & 0 & 0 & 1 & 0 & 0 \\
\hline Prepona pheridamas & 2 & 1 & 1 & 1 & 1 & 0 & 1 & 1 & 6 & 3 & 1 & 0 & 0 & 0 & 1 & 1 & 0 & 1 & 0 & 0 & 1 & 0 & 0 \\
\hline Prepona pylene & 2 & 1 & 1 & 1 & 1 & 0 & 1 & 1 & 17 & 3 & 1 & 0 & 0 & 0 & 1 & 1 & 0 & 1 & 0 & 0 & 1 & 0 & 0 \\
\hline Agrias amydon & 2 & 1 & 1 & 1 & 1 & 0 & 1 & 1 & 3 & 3 & 1 & 0 & 0 & 0 & 1 & 1 & 0 & 1 & 0 & 0 & 1 & 0 & 0 \\
\hline Agrias claudina & 2 & 1 & 1 & 1 & 1 & 0 & 1 & 1 & $6 / 11$ & 3 & 1 & 0 & 0 & 0 & 1 & 1 & 0 & 1 & 0 & 0 & 1 & 0 & 0 \\
\hline Euxanthe eurinome & - & 2 & 1 & 0 & 0 & 0 & 0 & 0 & $5 / 7$ & 3 & 2 & 1 & 0 & 0 & 1 & 0 & 0 & 0 & 0 & 0 & 1 & 0 & 0 \\
\hline Euxanthe trajanus & - & 2 & 1 & 0 & 0 & 0 & 0 & 0 & 5 & 3 & 2 & 1 & 0 & 0 & 1 & 0 & 0 & 0 & 0 & 0 & 1 & 0 & 0 \\
\hline Palla decius & - & $?$ & 1 & 0 & $?$ & $?$ & 0 & 0 & $10 / 12$ & 0 & 0 & 0 & $?$ & 0 & 0 & 0 & 0 & $?$ & 0 & 0 & 0 & 0 & 0 \\
\hline Polyura athamas & - & 2 & 1 & 0 & 0 & 0 & 0 & 0 & 7 & 3 & 2 & 1 & 0 & 0 & 0 & 0 & 0 & 1 & $?$ & 0 & 0 & 0 & 0 \\
\hline Polyura delphis & - & 2 & 1 & 0 & 0 & 0 & 0 & 0 & 7 & 3 & 2 & 1 & 1 & 0 & 0 & 0 & 0 & 1 & 0 & 0 & 0 & 0 & 0 \\
\hline Polyura gamma & - & 2 & 1 & 0 & 0 & 0 & 0 & 0 & $?$ & $?$ & $?$ & $?$ & $?$ & $?$ & 0 & 0 & 0 & 0 & $?$ & 0 & 0 & 0 & 0 \\
\hline Poluyra pymhus & - & 2 & 1 & 0 & 0 & 0 & 0 & 0 & 7 & 3 & 2 & 1 & 1 & 0 & 0 & 0 & 0 & 1 & 0 & 0 & 0 & 0 & 0 \\
\hline Polyura jalysus & - & 2 & 1 & 0 & 0 & 0 & 0 & 0 & $?$ & $?$ & $?$ & $?$ & $?$ & $?$ & 0 & 0 & 0 & $?$ & $?$ & 0 & 0 & 0 & 0 \\
\hline Polyura schreiber & - & 2 & 1 & 0 & 0 & 0 & 0 & 0 & $5 / 7$ & 0 & 2 & 1 & 1 & 0 & 0 & 0 & 0 & 1 & 0 & 0 & 0 & 0 & 0 \\
\hline Charaxes varanes & - & 2 & 1 & 0 & 0 & 0 & 0 & 0 & $5 / 6$ & 0 & 2 & 1 & 0 & 0 & 0 & 1 & 0 & 0 & 0 & 0 & 0 & 0 & 0 \\
\hline Charaxes candiope & - & 2 & 1 & 0 & 0 & 0 & 0 & 0 & 0 & 0 & 2 & 1 & 0 & 0 & 0 & 1 & 0 & 1 & 0 & 0 & 0 & 0 & 0 \\
\hline Charaxes cynthia & - & 2 & 1 & 0 & 0 & 0 & 0 & 0 & 7 & 4 & 2 & 1 & 1 & 0 & 0 & 0 & 0 & 1 & $?$ & 0 & 0 & 0 & 0 \\
\hline Charaxes lucretius & - & 2 & 1 & 0 & 0 & 0 & 0 & 0 & 8 & 0 & 2 & 1 & 1 & $?$ & 0 & 0 & 0 & $?$ & $?$ & 0 & 0 & 0 & 0 \\
\hline Charaxes jasius & - & 2 & 1 & 0 & 0 & 0 & 0 & 0 & $7 / 9$ & 0 & 2 & 1 & 1 & 0 & 0 & 0 & 0 & 1 & 0 & 0 & 0 & 0 & 0 \\
\hline Charaxes tiridates & - & 2 & 1 & 0 & 0 & 0 & 0 & 0 & $2 / 5 / 7$ & $0 / 3$ & 2 & 1 & $?$ & 0 & 0 & 0 & 0 & 1 & 0 & 0 & 0 & 0 & 0 \\
\hline Charaxes hadrianus & - & 2 & 1 & 0 & 0 & 0 & 0 & 0 & 11 & 1 & 2 & 1 & 1 & 0 & $?$ & 1 & 0 & 1 & 0 & 0 & 0 & 0 & 0 \\
\hline Charaxes nobilis & - & 2 & 1 & 0 & 0 & 0 & 0 & 0 & $?$ & $?$ & $?$ & $?$ & $?$ & $?$ & 0 & $?$ & 0 & $?$ & $?$ & 0 & 0 & 0 & 0 \\
\hline Charaxes zoolina & - & 2 & 1 & 0 & 0 & 0 & 0 & 0 & 7 & 3 & 2 & 1 & 1 & 0 & 0 & 0 & 0 & 1 & 2 & 0 & 0 & 0 & 0 \\
\hline Charaxes eupale & - & 2 & 0 & 0 & 0 & 0 & 0 & 0 & 7 & 3 & 2 & 1 & 1 & 0 & 0 & 0 & 0 & 1 & 2 & 0 & 0 & 0 & 0 \\
\hline Charaxes jahlusa & - & 2 & 1 & 0 & 0 & 0 & 0 & 0 & $5 / 7$ & 0 & 2 & 1 & 1 & 0 & 0 & 0 & 0 & 1 & $?$ & 0 & 0 & 0 & 0 \\
\hline Charaxes pleione & - & 2 & 1 & 0 & 0 & 0 & 0 & 0 & 7 & 0 & 2 & 1 & 1 & 0 & 0 & 0 & 0 & 1 & 0 & 0 & 0 & 0 & 0 \\
\hline Charaxes zingha & - & 2 & 1 & 0 & 0 & 0 & 0 & 0 & $?$ & 3 & $?$ & $?$ & $?$ & $?$ & 0 & 0 & 0 & $?$ & $?$ & 0 & 0 & 0 & 0 \\
\hline Charaxes etesipe & - & 2 & 1 & 0 & 0 & 0 & 0 & 0 & $0 / 7$ & 0 & 2 & 1 & 1 & 0 & 0 & 0 & 0 & 1 & 2 & 0 & 0 & 0 & 0 \\
\hline Charaxes etheocles & - & 2 & 1 & 0 & 0 & 0 & 0 & 0 & 7 & 0 & 2 & 1 & 1 & 0 & 0 & 0 & 0 & 1 & 2 & 0 & 0 & 0 & 0 \\
\hline Charaxes nichetes & - & 2 & 0 & 0 & 0 & 0 & 0 & 0 & 0 & 3 & 2 & 1 & $?$ & 0 & 0 & 0 & 0 & $?$ & $?$ & 0 & 0 & 0 & 0 \\
\hline Charaxes laodice & - & 2 & 1 & 0 & 0 & 0 & 0 & 0 & 7 & $?$ & $?$ & $?$ & $?$ & $?$ & 0 & 0 & 0 & $?$ & $?$ & 0 & 0 & 0 & 0 \\
\hline Charaxes solon & - & 2 & 1 & 0 & 0 & 0 & 0 & 0 & 7 & 0 & $?$ & $?$ & $?$ & $?$ & 0 & 0 & 0 & 1 & 0 & 0 & 0 & 0 & 0 \\
\hline Charaxes latona & - & 2 & 1 & 0 & 0 & 0 & 0 & 0 & 4 & 3 & 2 & 1 & 1 & 0 & 0 & 0 & 0 & 1 & 0 & 0 & 0 & 0 & 0 \\
\hline Charaxes eurialus & - & 2 & 1 & 0 & 0 & 0 & 0 & 0 & $?$ & $?$ & $?$ & $?$ & $?$ & $?$ & 0 & $?$ & 0 & $?$ & $?$ & 0 & 0 & 0 & 0 \\
\hline Agatasa calydonia & - & 2 & 1 & 0 & 1 & 0 & $?$ & 0 & 8 & $?$ & 2 & $?$ & 1 & 1 & $?$ & 1 & 0 & 3 & 0 & 0 & 1 & 2 & 0 \\
\hline Prothoe australis & - & 2 & 1 & 0 & 1 & 0 & $?$ & 0 & 8 & 0 & $?$ & $?$ & 1 & 0 & $?$ & 1 & 0 & 0 & 0 & 1 & 1 & 1 & 0 \\
\hline Prothoe franck & - & 2 & 1 & 0 & 1 & 0 & $?$ & 0 & $?$ & $?$ & 2 & $?$ & $?$ & $?$ & $?$ & 0 & 0 & 0 & 0 & 1 & 1 & 2 & 0 \\
\hline
\end{tabular}

